Universidad de Lima

Facultad de Administración

Carrera de Negocios Internacionales

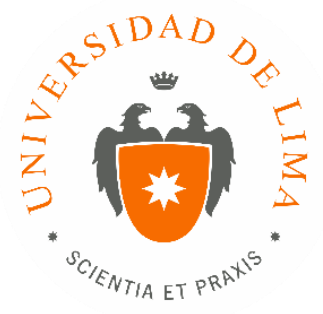

\title{
EXPORTACIÓN DE JOYAS DE PLATA CON INCRUSTACIONES DE PIEDRAS NATURALES A CHILE
}

Trabajo de investigación para optar el título profesional de Licenciado en Negocios Internacionales

\section{Giancarlo André Barreto Rimay}

Código 20090098

\author{
Asesor \\ Pedro Damian Ayala Chacaltana
}

Lima - Perú

Mayo de 2016 


\section{EXPORTACIÓN DE JOYAS DE PLATA CON INCRUSTACIONES DE PIEDRAS \\ NATURALES A CHILE}




\section{ÍNDICE}

INTRODUCCIÓN ........................................................................................ xvi

CAPÍTULO 1: PLANTEAMIENTO DEL PROBLEMA........................................ 19

1.1. Planteamiento del problema ....................................................... 19

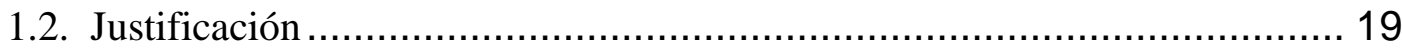

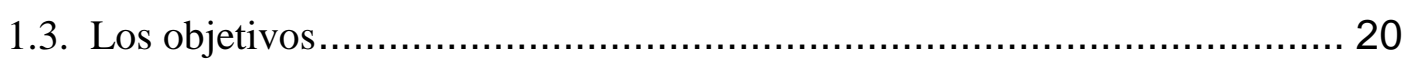

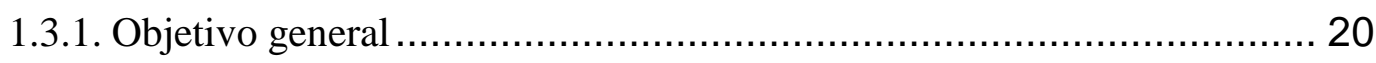

1.3.2. Objetivos específicos .................................................... 20

1.4. Descripción de la demanda en Chile ........................................... 21

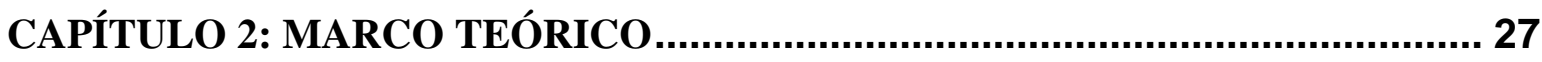

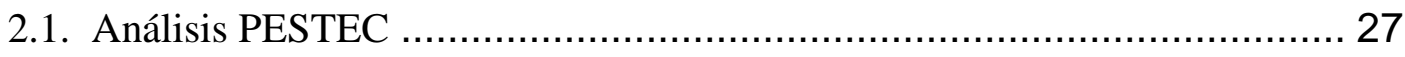

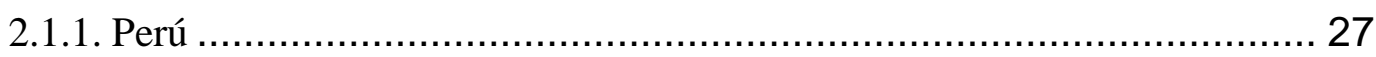

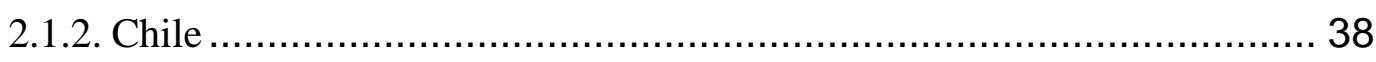

2.2. Diamante Competitivo de Porter: ............................................. 49

2.2.1. Condiciones de Factores:................................................... 50

2.2.2. Condiciones de la demanda: .................................................. 51

2.2.3. Industrias relacionadas y de apoyo: ......................................... 51

2.2.4. Estrategia, estructura y rivalidad de la empresa: ............................ 52

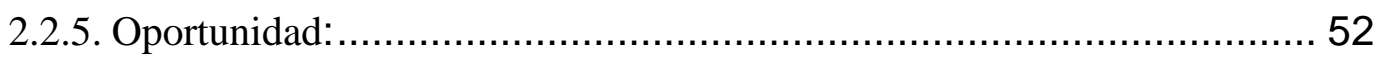

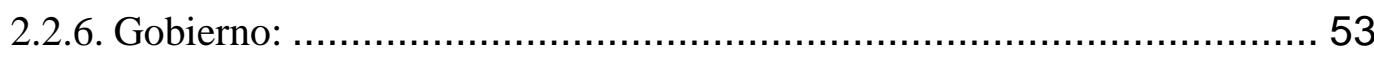

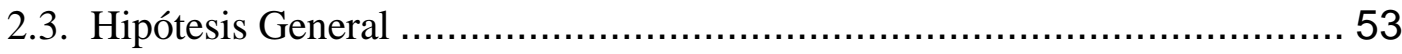

2.4. Hipótesis Específicas ........................................................ 53

CAPITULO 3: INFORMACIÓN GENERAL DEL PROYECTO.......................... 54

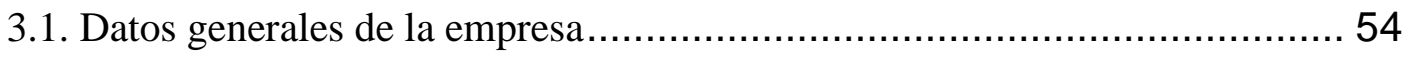

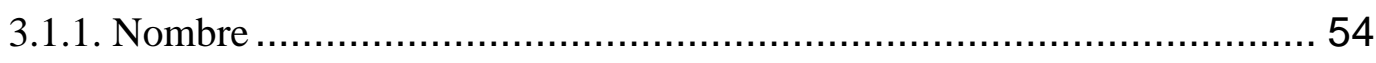

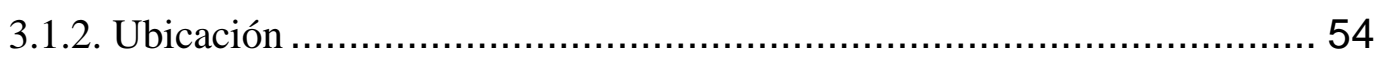

3.1.3. Unidad formuladora del proyecto ....................................... 55

3.1.4. Unidad ejecutora del proyecto.............................................. 55

3.2. Identificación de la oportunidad de negocio ................................... 55

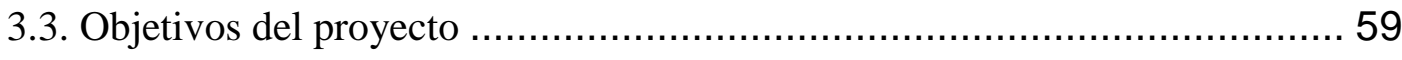

3.3.1. Objetivos de marketing ................................................... 59

3.3.2. Objetivos de operaciones................................................ 59 
3.3.3. Objetivos económicos y financieros ........................................... 60

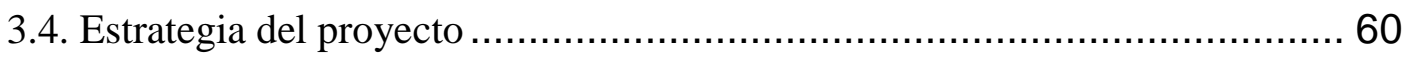

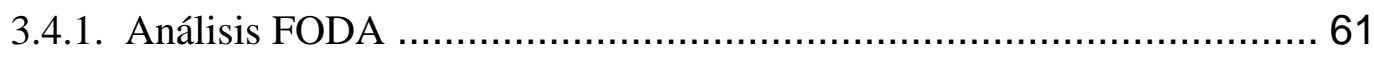

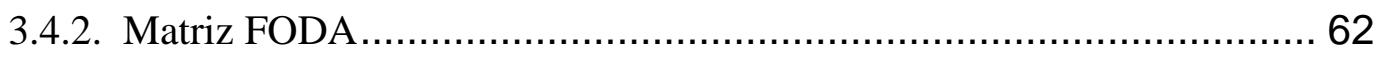

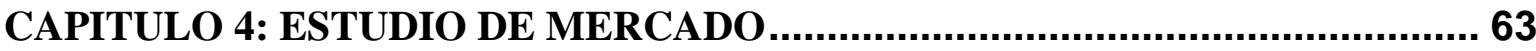

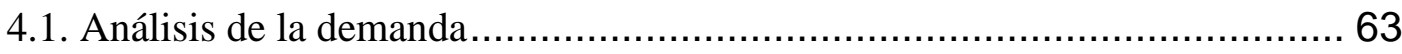

4.1.1. Definición del producto............................................................ 63

4.1.2. Principales características del producto ..................................... 66

4.1.3. Variables que afectan la demanda ........................................ 67

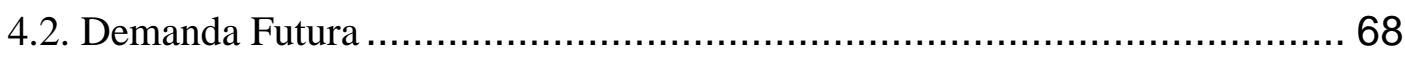

4.2.1 Demanda histórica............................................................... 68

4.2.2. Demanda Potencial ............................................................... 70

4.2.3. Demanda Objetivo................................................................. 73

4.3. Análisis de la competencia....................................................... 77

4.3.1 Análisis de la competencia local .............................................. 77

4.3.2. Análisis de proveedores ................................................ 79

4.3.3. Estrategia de la competencia ............................................... 81

4.3.4. Análisis de la competencia internacional ........................................ 82

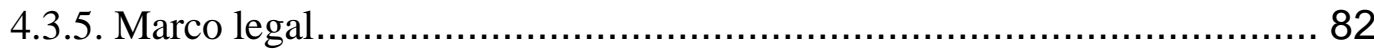

4.3.6. Mix comercial de la competencia ................................................. 83

4.4. Análisis FODA de la competencia .................................................. 84

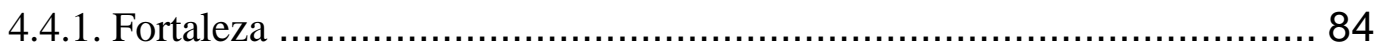

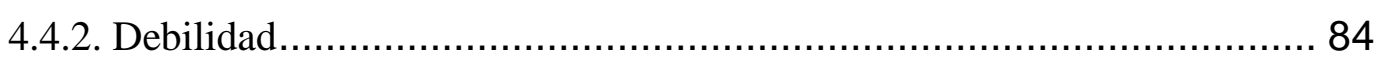

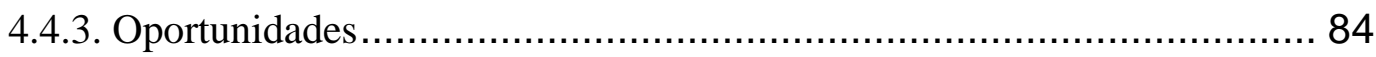

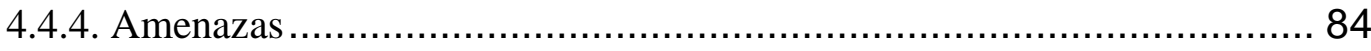

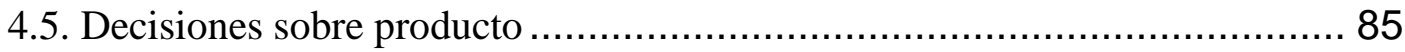

4.5.1 Características físicas del producto ............................................. 85

4.5.2. Empaque y embalaje ...................................................... 86

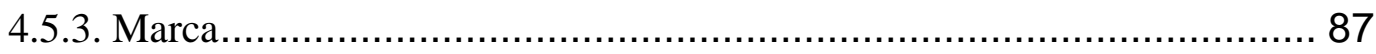

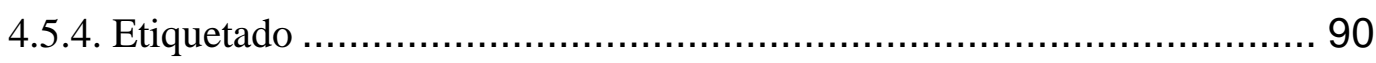

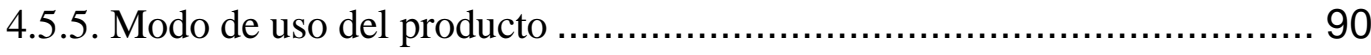

4.6. Decisiones sobre precio .......................................................... 90

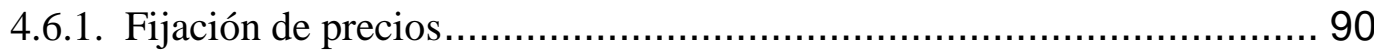


4.6.2. Política de pagos 91

4.6.3. Política de descuento ............................................................ 93

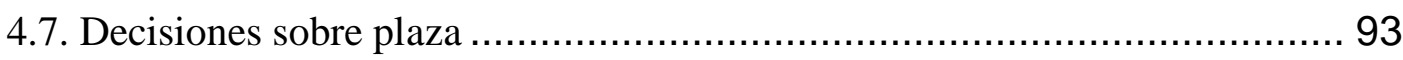

4.7.1. Cobertura de mercado ............................................................... 93

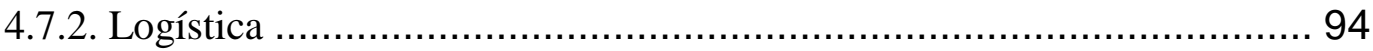

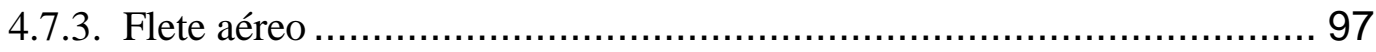

4.8. Decisiones sobre promoción .................................................... 98

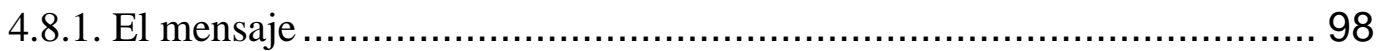

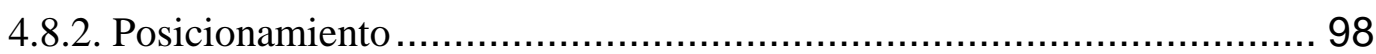

4.8.3. Penetración de Mercado ............................................................. 99

4.9. Análisis de ranking de factores................................................... 103

CAPITULO 5: ESTUDIO TÉCNICO........................................................... 105

5.1. Factores determinantes de tamaño .............................................. 105

5.1.1. Demanda objetivo proyectado............................................... 105

5.1.2. Participación de Mercado ........................................................ 105

5.1.3. Disponibilidad de insumos ........................................... 106

5.2. Proceso y tecnología …..................................................... 108

5.2.1. Diagrama de Flujo del Proceso de Producción .................................. 108

5.2.2. Descripción de los principales procesos del proyecto....................... 108

5.3. Localización ........................................................................ 111

5.3.1. Macro localización ............................................................ 111

5.3.2 Micro localización: .............................................................. 115

5.3.3. Especificación del local en la situación con proyecto....................... 116

5.4. Actividades Pre operativas .................................................. 117

5.4.1. Adquisiciones Intangibles................................................. 117

5.4.2. Adquisiciones Tangibles ........................................................ 118

5.5. Requerimiento de materia prima y servicios directos ......................... 119

5.6. Requerimiento de insumo ..................................................... 119

5.7. Mano de obra directa.................................................................... 119

5.8. Factores indirectos de operación.............................................. 119

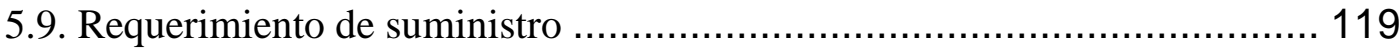

5.10. Requerimiento de servicios indirectos ......................................... 120 
6.1. Estructura Organizativa ................................................... 121

6.1.1. El Organigrama Funcional............................................. 121

6.1.2. Objetivo de personal, requerimientos y perfiles ........................... 122

6.2. Visión, Misión y Valores .......................................................... 124

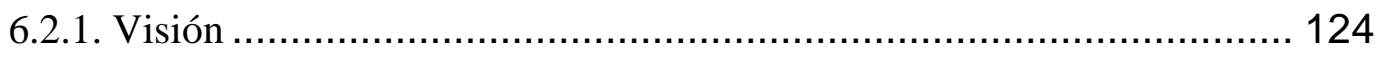

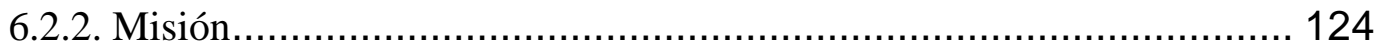

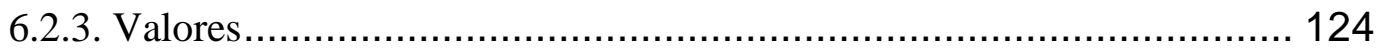

CAPITULO 7: ESTUDIO LEGAL ............................................................ 125

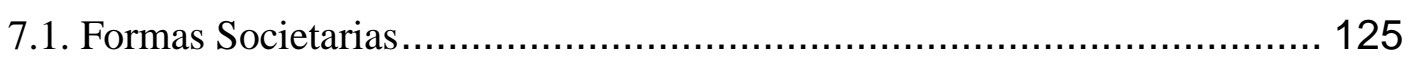

7.1.1. Justificación de la Forma Societaria........................................ 125

7.1.2. Flujo grama de Creación de la Empresa .................................. 126

7.1.3. Legislación arancelaria-tributaria. ....................................... 127

7.1.4. Legislación Ambiental ......................................................... 128

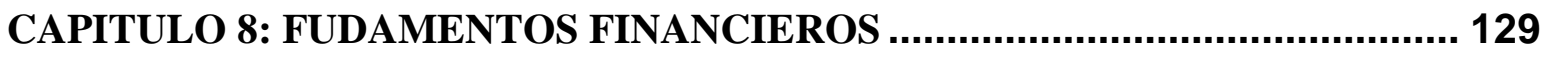

8.1. Estructura de costos fijos y variables ....................................... 129

8.1.1. Costos fijos ............................................................... 129

8.1.2. Costos variables .......................................................... 130

8.2. Estructura de Inversión............................................................... 131

8.4. Capital de Trabajo ................................................................... 133

8.5. Margen de venta: .................................................................... 133

8.3. Proyección de ventas........................................................... 134

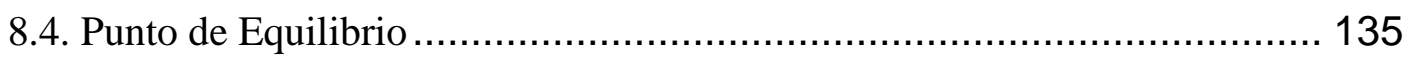

8.5. Financiamiento de la inversión: ............................................ 137

8.6. Flujo de caja económico (TIR y VAN)....................................... 138

8.7. Balance General .................................................................. 139

8.8. Estado de ganancias y pérdidas ................................................ 139

8.9. Análisis de sensibilidad: ................................................... 139

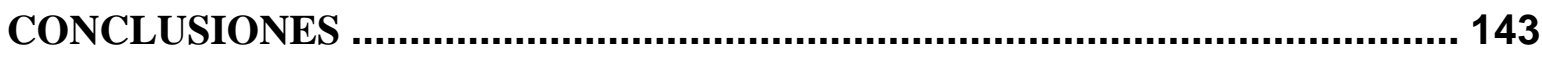

RECOMENDACIONES ......................................................................... 144

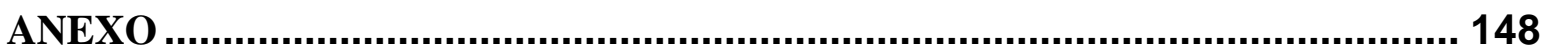




\section{LISTA DE GRÁFICOS}

Gráfico $N^{\circ}$ 1. 1: Intercambio comercial de Chile ........................................................... 22

Gráfico $\mathrm{N}^{\mathrm{o}}$ 1. 2: Intercambio comercial de joyas de plata en Chile............................... 23

Gráfico $\mathrm{N}^{\mathrm{o}}$ 1. 3: Importación de joyas de plata de Chile .............................................. 24

Gráfico $\mathrm{N}^{\mathrm{o}}$ 1. 4: Producción de plata en Chile ........................................................... 25

Gráfico No 2. 1: Evolución del PBI del Perú .....................................................................2 29

Gráfico № 2. 2: Tasa de Interés Activa de Perú, 2005 - 2014 …................................... 30

Gráfico No 2. 3: Tasa de Interés Pasiva de Perú, 2005 - 2014 ....................................... 30

Gráfico No 2. 4: Historial y proyección de Tasa de Inflación de Perú, 2010 - 2017 ...... 31

Gráfico No 2. 5: Exportación total de Perú (US\$ en Millones) ....................................... 32

Gráfico $\mathrm{N}^{\mathrm{o}}$ 2. 6: Población proyectada de Perú ............................................................. 33

Gráfico $N^{\circ}$ 2. 7: Porcentaje de Pobreza y pobreza extrema en el Perú ........................... 34

Gráfico No 2. 8: PBI Total y PBI Per Cápita de Chile …................................................ 41

Gráfico $\mathrm{N}^{\mathrm{o}}$ 2. 9: Variación Mensual de la Tasa de desempleo ...................................... 42

Gráfico No 2. 10: Tipo de Cambio del Peso Chileno a Dólar .......................................... 42

Gráfico $\mathrm{N}^{\mathrm{o}}$ 2. 11: Población total en Chile .................................................................. 43

Gráfico $\mathrm{N}^{\mathrm{o}}$ 2. 12: Ingreso mensual y número de personas ocupadas, según edad .......... 44

Gráfico $\mathrm{N}^{\mathrm{o}}$ 2. 13: Proyección de población en Chile por grupos de edad ...................... 45

Gráfico No 2. 14: Análisis del modelo de HOFSTEDE entre Perú y Chile, Año 2014 .. 47

Gráfico N ${ }^{\circ}$ 2. 15: Gasto en I+D y su relación con el PBI de Chile................................ 48

Gráfico $\mathrm{N}^{\mathrm{0}}$ 3. 1: Variación porcentual del PBI de los países de Sudamérica .................. 56

Gráfico No 4. 1: Exportación de joyas de plata de Perú a Chile, en US\$ (Dólares

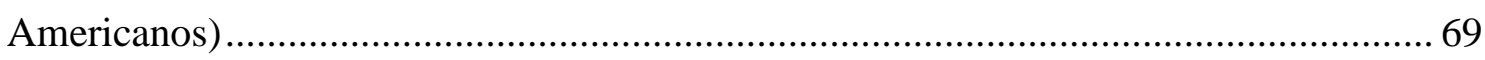

Gráfico No 4. 2: Exportación de joyas de Perú a Chile, en Kilogramos .......................... 69

Gráfico N 4. 3: Exportación de joyas de Perú a Chile, en US\$ por Kilogramo ............ 70

Gráfico No 4. 4: Proyección de exportación de joyas de Perú a Chile hasta el año 2020,

en Kilogramo

Gráfico No 4. 5: Proyección de importación de joyas de plata en Chile a nivel mundial,

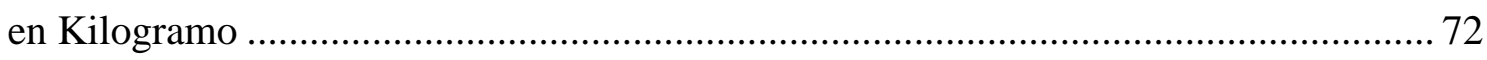


Gráfico $N^{\circ}$ 4. 6: Consumo de joyas en Chile.....

.73

Gráfico No 5. 1: Proyección de participación de mercado. 106

Gráfico No 8. 1: Punto de equilibrio de la colección "MYSTIC" 136

Gráfico No 8. 2: Punto de equilibrio de la colección "ULTRA" 136 


\section{LISTA DE CUADROS}

Cuadro $N^{\circ}$ 2. 1: Producción de joyas según tamaño de empresa

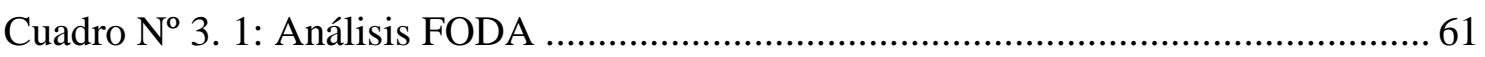

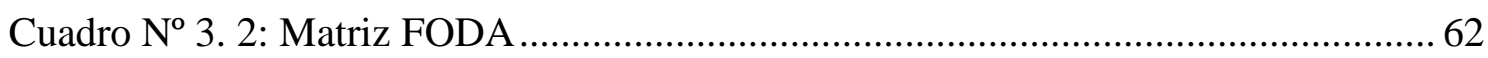

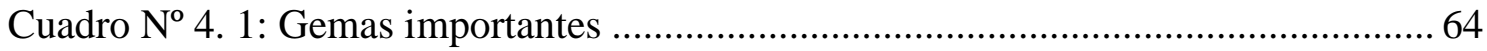

Cuadro $N^{o}$ 4. 2: Proyección de exportación de joyas de plata de Perú a Chile .............. 72

Cuadro $N^{\circ}$ 4. 3: Proyección de la demanda ................................................................... 77

Cuadro $N^{o}$ 4. 4: Principales empresas peruanas que exportan joyas de plata................. 78

Cuadro $N^{o}$ 4. 5: Empresas peruanas que exportan joyas de plata a Chile ...................... 79

Cuadro No 4. 6: Países que más exportan joyas de plata a Chile, año 2014 ................... 82

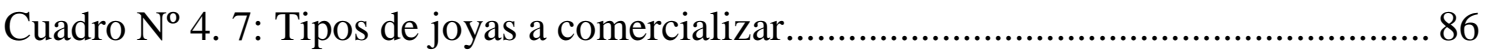

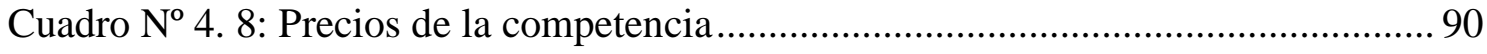

Cuadro № 4. 9: Exportación de joyas de plata de Perú, según Aduana ......................... 95

Cuadro $N^{\circ}$ 4. 10: Variables de la segmentación para la población de Chile ................... 99

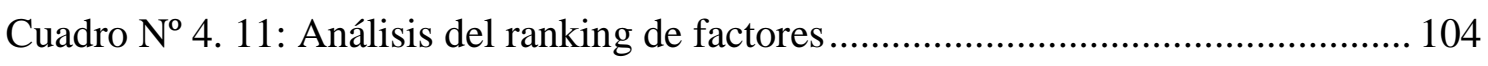

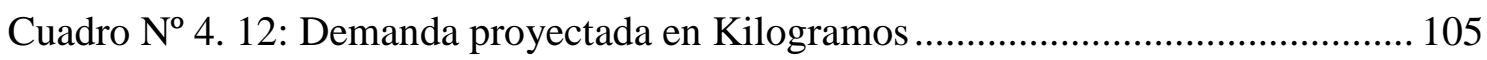

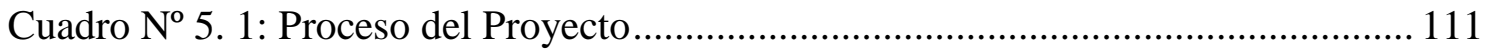

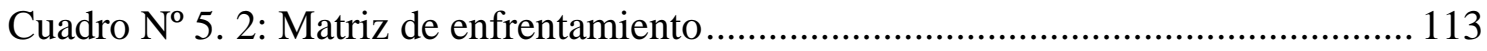

Cuadro $N^{\circ}$ 5. 3: Ranking de factores de Macro localización ........................................ 115

Cuadro No 5. 4: Ranking de factores de Micro localización......................................... 116

Cuadro $\mathrm{N}^{\mathrm{o}}$ 5. 5: Tiempo de adquisiciones de intangibles ......................................... 118

Cuadro $N^{o}$ 5. 6: Tiempo de adquisiciones de tangible ............................................. 118

Cuadro $N^{\circ}$ 6. 1: Descripción del personal en la empresa............................................. 123

Cuadro No 8. 1: Proyección de ventas de joyas en Kilogramos..................................... 129

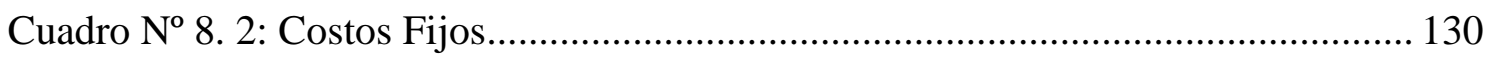

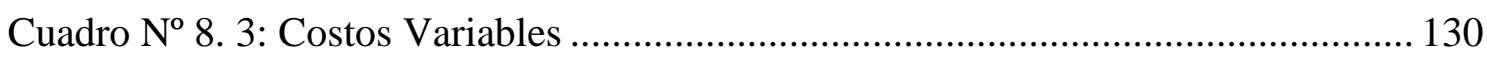

Cuadro $N^{o}$ 8. 4: Precio del producto anual en Incoterm FCA ..................................... 131 
Cuadro $\mathrm{N}^{\circ}$ 8. 5: Inversión Tangible del proyecto

Cuadro $\mathrm{N}^{\mathrm{o}}$ 8. 6: Inversión intangible del proyecto 132

Cuadro $N^{\circ}$ 8. 7: Gastos Fijos del proyecto.

Cuadro $N^{\circ}$ 8. 8: Capital de trabajo para los primeros tres meses...

Cuadro $\mathrm{N}^{\circ}$ 8. 9: Margen de venta. 134

Cuadro $N^{\circ}$ 8. 10: Proyección de Ventas de la colección MYSTIC 134

Cuadro $N^{\circ}$ 8. 11: Proyección de ventas de la colección ULTRA 135

Cuadro $N^{\circ}$ 8. 12 Punto de Equilibrio MYSTIC 135

Cuadro $N^{o}$ 8. 13: Punto de equilibrio ULTRA 136

Cuadro $N^{o}$ 8. 14: Financiamiento de la inversión (En US\$). 137

Cuadro No 8. 15: Flujo de Caja 138

Cuadro No 8. 16: Balance General..... 139

Cuadro $N^{\circ}$ 8. 17: Estado de Ganancias y Pérdidas 139

Cuadro $N^{\circ}$ 8. 18: Cuadros de Análisis de sensibilidad 140 


\section{LISTA DE IMÁGENES}

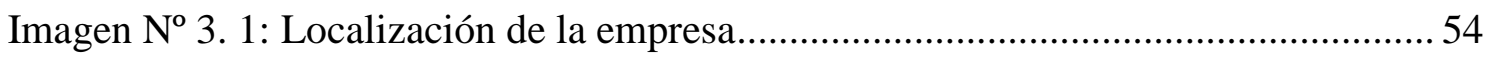

Imagen $\mathrm{N}^{\mathrm{o}}$ 3. 2: Crecimiento del consumo de joyería ................................................ 57

Imagen $N^{\circ}$ 4. 1: Concentración del Nivel Socioeconómico A, B, C1 entre los años 2002

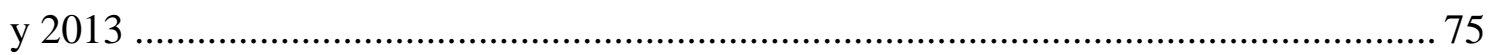

Imagen No 4. 2: Segmentación Socioeconómica en Chile, año 2015 ............................. 76

Imagen $N^{\circ}$ 4. 3: Página Web de la Procesadora Sudamericana ..................................... 80

Imagen $\mathrm{N}^{\mathrm{o}}$ 4. 4: Tarjeta de presentación del proveedor de piedras naturales ................. 80

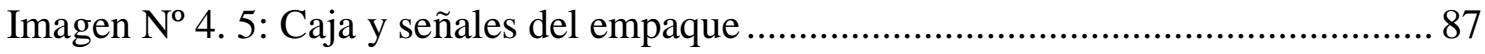

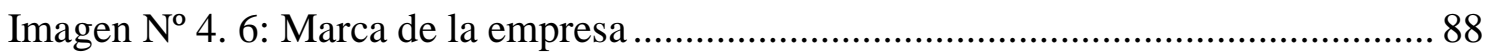

Imagen $\mathrm{N}^{\mathrm{o}}$ 4. 7: Marcas por sector mayor recordadas en Chile ..................................... 89

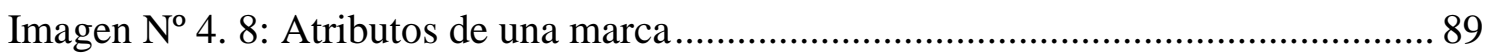

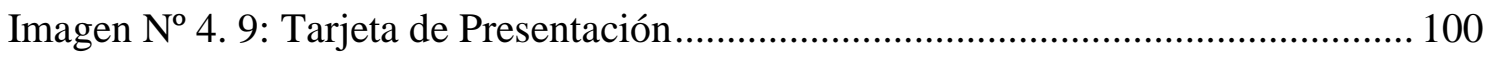

Imagen $\mathrm{N}^{\mathrm{o}}$ 4. 10: Ejemplo de correo en época navideña ........................................... 101

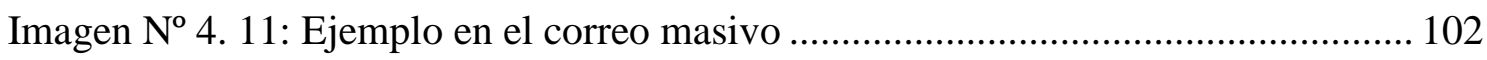

Imagen $N^{o}$ 4. 12: Página Web para los dos primeros años ....................................... 103

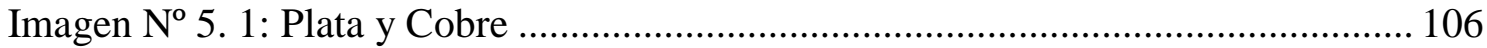

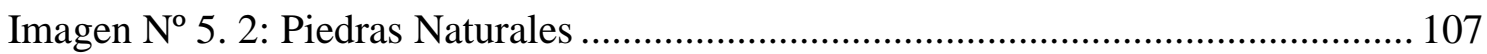




\section{LISTA DE ESQUEMAS}

Esquema $N^{o}$ 2. 1: Diamante de Porter sobre el sector de joyería en Perú

Esquema $\mathrm{N}^{\mathrm{o}}$ 4. 1: Flujo de pago a través de PayPal .................................................... 92

Esquema $N^{\circ}$ 4. 2: Proceso de envío y recepción de dinero a través de PayPal .............. 93

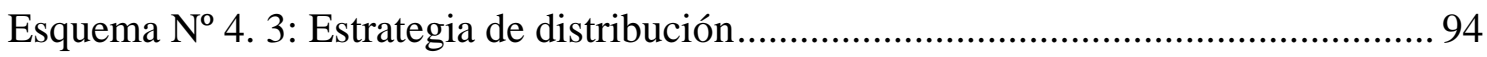

Esquema $N^{\circ}$ 4. 4: Participantes de la logística de entrada .............................................. 95

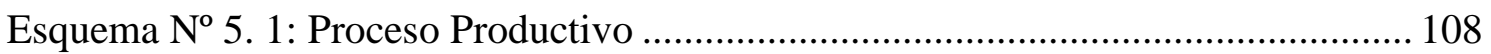

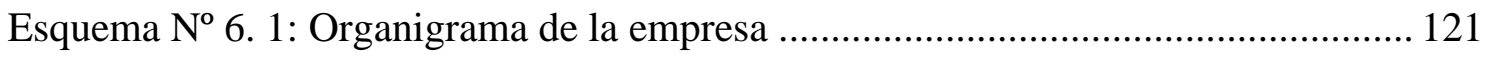




\section{LISTA DE ANEXOS}

ANEXO 1: Producción de Plata En Perú (En toneladas) 149

ANEXO 2: Principales proveedores de Chile de todos los productos (millones de dólares)

ANEXO 3: Participación de las exportaciones e importaciones de las Joyas de Plata en Chile 151

ANEXO 4: Exportación de joyas de Perú a Chile y Estados Unidos (Año 2014) 152

ANEXO 5: Participación de los principales países exportadores de joyas de plata hacia Chile, 2014 153

ANEXO 6: Producción minera de Chile 154

ANEXO 7: Principal problema que enfrenta el Estado peruano ................................ 155

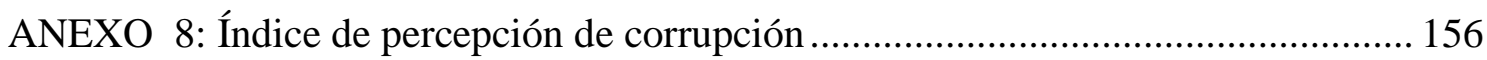

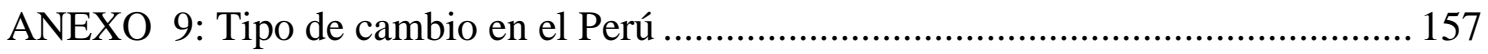

ANEXO 10: Medidas del BCRP contra la crisis internacional .................................. 158

ANEXO 11: Población en edad de trabajar en el Perú según condición de actividad (Año 2014) 160

ANEXO 12: Ranking de competitividad a nivel mundial ........................................ 161

ANEXO 13: Comparación de reporte de Competitividad entre Perú y Chile .............. 162

ANEXO 14: Proyección del PBI per cápita de Chile hasta el 2020 ............................ 163

ANEXO 15: Máquinas para joyería: Laminadora y Diamantadora …......................... 164

ANEXO 16: Participación de producción de plata a nivel mundial ............................. 165

ANEXO 17: Participación de producción de plata a nivel mundial ............................. 166

ANEXO 18: Índice Global del Comercio Electrónico ................................................. 167

ANEXO 19: Piedras Naturales de Perú ................................................................... 168

ANEXO 20: Precio Histórico de la Plata (Año 2000-2015)........................................... 170

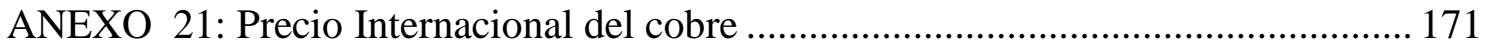

ANEXO 22: Exportación en US\$ de joyas de plata de Perú a Chile............................ 172

ANEXO 23: Exportación en Kilogramos de joyas de plata de Perú a Chile................ 173

ANEXO 24: Proyección de exportación de la empresa JOYERIA BARI EIRL (En

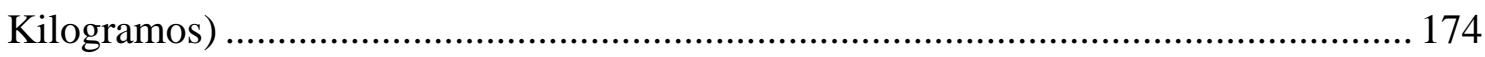

ANEXO 25: Importación mundial de joyas de plata en Chile (Kilogramos) ............... 175 
ANEXO 26: Máquinas de la joyería New Fashion Peru S.A. ..................................... 176

ANEXO 27: Canasta a la que pertenece la Partida NALADISA 7113110000 (Joyería de plata).

ANEXO 28: Cronograma de Desgravación de la canasta D-5 .................................... 178

ANEXO 29: Ley de Comercio exterior de objetos fabricados con metales preciosos 179

ANEXO 30: Ejemplos de joyas para la colección "Ultra” .......................................... 180

ANEXO 31: Ejemplos de joyas para la colección "Mystic" ....................................... 181

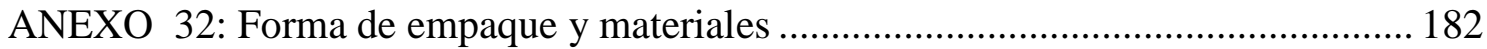

ANEXO 33: Búsqueda fonética para la marca Jolibari ............................................ 183

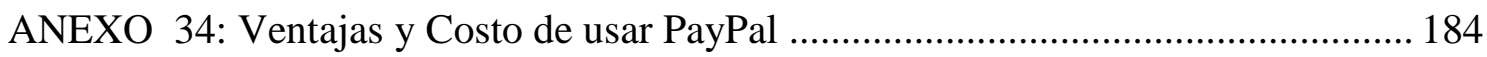

ANEXO 35: Plata Ley 999 del Proveedor Sudamericana ......................................... 185

ANEXO 36: Costos de Almacenaje en Talma.......................................................... 186

ANEXO 37: Presupuesto de pasaje Lima-Santiago de Chile ..................................... 187

ANEXO 38: Mapa de la sala del Hotel Marriott para las reuniones ........................... 188

ANEXO 39: Precio por habitación de un día en el Hotel Marriott en Chile ................ 189

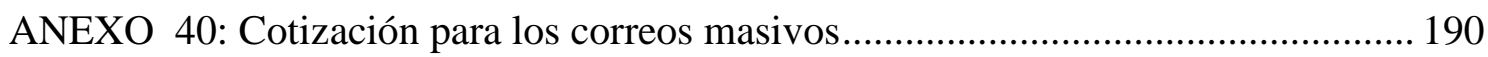

ANEXO 41: Principales máquinas para la producción de joyas .................................. 191

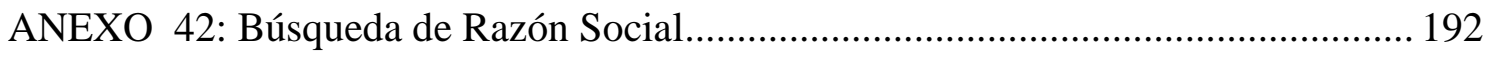

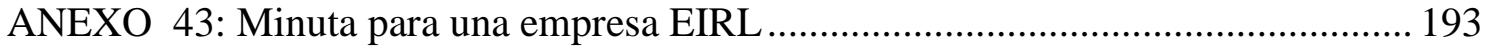

ANEXO 44: Costo del personal detallado (En US\$) ................................................ 195

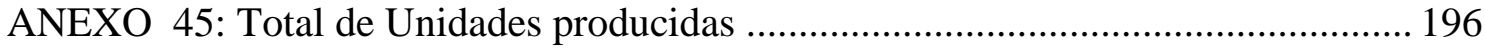

ANEXO 46: Obtención del Costo unitario para las joyas ley 950 y 925 .................... 197

ANEXO 47: Unidades Producidas según colección de joyas...................................... 198 


\section{INTRODUCCIÓN}

La joyería en el Perú es toda una tradición que ha tenido acogida a nivel internacional; en primer lugar gracias al gran trabajo artesanal para la elaboración de joyas; en segundo lugar a la alta calidad y abundancia de la plata, y en tercer lugar a la variedad de las piedras naturales peruanas que permite mayor innovación en los diseños.

La idea nace debido a la información obtenida sobre el sector de joyería como por ejemplo las tendencias en diseño, los costos de materia prima, las máquinas involucradas dentro de la operación de producción, el proceso productivo, el costo promedio de artesanos dedicados a la joyería y las herramientas de comercio exterior.

El principal cliente de Perú y del mundo es Estados Unidos de América que posee una participación del $30 \%$ de compras de joyas a nivel mundial. Actualmente se están diversificando los mercados de destino y esto ha permitido una mejora en la industria de las joyas de plata en el Perú; sin embargo, esto no le alcanza para lograr ser competitivo internacionalmente debido a la falta de elementos significativos en las joyerías.

La plata tiene innumerables aplicaciones que son significativos, de las cuales sobresalen sólo tres importantes categorías: La industria, la inversión y las joyas de plata. Estas juntas representan el 99\% de demanda anual de plata a nivel mundial.

A nivel internacional, se usa la plata ley 925; sin embargo en el Perú se pueden encontrar joyas de plata ley 950 el cual posee un mejor grado de pureza y calidad de la plata la cual está siendo reconocida a nivel internacional para intereses del presente proyecto.

El presente trabajo de investigación trata sobre la constitución de una empresa dedicado a producir y exportar joyas de plata Ley 950 y 925 con aplicaciones de piedras naturales con destino a Chile. El nombre de la empresa del proyecto es "JOYERIA BARI E.I.R.L.” que llevará el nombre de la marca JOLIBARI desde el inicio de las operaciones. Ambos se encuentran disponibles para el registro en las respectivas instituciones. 
El presente plan de negocio tiene como objetivo evaluar la rentabilidad del negocio a través de un análisis de estudio de mercado de los consumidores en Chile basándose en una estrategia de diferenciación del producto y en la implementación de una marca desde el inicio de las operaciones. Se ofrece una variedad de artículos de joyería de plata incluidos en dos colecciones, "ULTRA" y "MYSTIC", los cuales serán los nombres para la producción de joyería de plata 925 y 950, respectivamente.

El capital es de un solo socio quien a su vez será el gerente de la empresa. Las operaciones de producción serán realizadas por joyeros que trabajan en un taller independiente de la empresa del proyecto. El taller de joyería que realizará la producción será “TALLER MARTINEZ E.I.R.L.”. Tanto la empresa del proyecto como el taller se encuentran en el Centro de Lima y esta cercanía favorece en el tiempo por las visitas constantes que se realizarán a los talleres para la verificación de la producción.

Las joyas estarán dirigidas a toda persona entre 18 y 60 años que viven en Chile en un nivel socioeconómico medio y alto, pues en los últimos años ha estado consolidándose como un gran socio comercial de Perú debido a su crecimiento económico, estabilidad política, factores macro económicos, factores logísticos y el costo y tiempo de la operación, distancia geográfica, cultura, idioma y el acuerdo comercial entre ambos países.

Se exportará aplicando el INCOTERM FCA - Callao mediante la modalidad de transporte aéreo con destino a Santiago de Chile pues sale más rentable por el poco espacio que ocupa el producto ya con embalaje.

Asimismo, el Agente de Aduana "CASOR ADUANERO S.A.C." será el representante de la empresa ante la Aduana y se encargará de todo trámite documentario ante dicha institución. Esta elección se debe principalmente a la experiencia de la Agencia en trabajar con empresas del rubro de joyería y por presentar costos competitivos.

El proyecto se divide en ocho capítulos, el cual empieza con el planteamiento del problema del proyecto, luego el Marco Teórico, después la información del proyecto, seguido de la investigación de mercado, estudio técnico, forma de la organización, el aspecto legal y por último el capítulo de Fundamento Financiero. 
En el Estudio de mercado se ha realizado dos proyecciones. El primero es de la exportación de joyas de plata de Perú a Chile y el segundo es de la importación mundial de joyas de plata de Chile, en ambos casos de los últimos 6 años. Ambas proyecciones presentan una tendencia positiva, pero la segunda se proyecta con un mayor crecimiento que el primero, mostrando en un futuro un mejor aumento en la demanda de Chile en el que las empresas de joyería del Perú deben aprovechar.

Finalmente, se hizo un análisis financiero el cual se realiza en el octavo capítulo donde se demuestra que el proyecto es viable ya que el TIR financiero logra ser de $45 \%$ y el VAN financiero de US\$22'502.

Chile ha presentado un incremento en sus importaciones de joyas de plata la cual presenta una oportunidad para las empresas peruanas ya sea micro o gran empresa, pues la falta de materia prima y piedras naturales en Chile le crean una demanda no satisfecha en el sector de joyería. 


\section{CAPÍTULO 1: PLANTEAMIENTO DEL PROBLEMA}

\subsection{Planteamiento del problema}

La presente tesis parte del problema sobre implementar un negocio que produzca y exporte joyas de plata Ley 950 y 925 con incrustaciones de piedras naturales con destino de exportación a Chile.

\subsection{Justificación}

$\checkmark$ Se tiene acceso a los datos para el análisis de estudio de mercado.

$\checkmark$ El investigador está involucrado en el comercio de joyas de plata para lo cual desea tener un enfoque mucho más amplio y en un futuro hacer crecer el negocio con temas de exportación.

$\checkmark$ Tal cual lo declara en su web el Ministerio de Energía y Mina (2015): "Perú es un país minero el cual posee a la plata como uno de sus principales minerales". Hay abundancia de recursos minerales para la operación del presente proyecto. En el Anexo 1 se muestra la producción anual de Plata en el Perú de los últimos diez años.

$\checkmark$ La Sociedad Nacional de Minería Petróleo y Energía (2014) según su estudio sobre la producción de plata afirma: "Perú es el tercer productor mundial de la plata, con una producción anual de más de 3,600 TM. y el segundo país en el mundo con las mayores reservas de plata, concentrando el $16.7 \%$ de un total estimado en 520,000 TM".

$\checkmark$ Los costos logísticos e investigación de mercado de Chile se reducen en comparación con países europeos ya sea por la distancia y similares costumbres entre ambos países.

$\checkmark$ Según la web Acuerdos Comerciales Perú (2011) sobre el TLC PerúChile, indica: "Ha beneficiado el intercambio comercial entre ambos países con exportaciones no tradicionales que han venido creciendo a tasas anuales promedio de $15 \%$. Cabe notar que $70 \%$ de las empresas peruanas exportadoras a Chile son micro y pequeñas empresas". 
$\checkmark$ Existe varios talleres de joyería que cuentan con artesanos, herramientas y máquinas para realizar un trabajo con calidad para las joyas.

$\checkmark$ Chile no cuenta con suficiente producción de joyería de plata que pueda cubrir su demanda.

$\checkmark$ Existe una cultura similar entre Perú y Chile que facilita la negociación.

$\checkmark$ La economía de Chile se encuentra en alza en los últimos años. Según El Banco Central de Chile. (2016) afirma: "El país del sur creció 2\% para el año 2015 y para el año 2016 estará en un rango de 2\% a 3\%”. A pesar de que no es un crecimiento significativo, Chile está presentando consolidación económica para intereses del proyecto.

$\checkmark$ Hay apoyo por parte del estado peruano en cuanto asesoramiento de comercio exterior a las MYPES (PROMPERU).

$\checkmark$ Los bancos brindan herramientas de financiamiento tales como pre y post embarque para los exportadores que necesitan capital de trabajo a tasas competitivas y los swaps para reducir el riesgo de tasa de interés, así como también brinda seguro por el capital de trabajo invertido.

\subsection{Los objetivos}

\subsubsection{Objetivo general}

Cubrir la demanda del proyecto con un negocio de producción y exportación de joyas de plata Ley 950 y 925 con incrustaciones de piedras naturales.

\subsubsection{Objetivos específicos}

$\checkmark$ Trabajar con un taller de joyería que brinde garantía y seguridad en el trabajo y que cumpla con el tiempo de producción establecidos.

$\checkmark$ Generar una rentabilidad en el negocio cumpliendo los requisitos del inversionista.

$\checkmark$ Aceptación de las joyas en el mercado objetivo debido a que es un producto con características innovadoras. 
$\checkmark$ Identificar las dificultades que impiden generar sostenibilidad y rentabilidad para lograr estrategias que ayuden al éxito del proyecto.

$\checkmark$ Desarrollo de los nuevos productos dos veces al año (Marzo y Setiembre).

$\checkmark$ Tener conocimiento de las tendencias en uso de joyas de plata en Chile.

$\checkmark$ Concretar negocios en misiones comerciales en beneficio de la empresa.

$\checkmark$ Consolidarse en Chile como una empresa de joyería de calidad a precio competitivo.

\subsection{Descripción de la demanda en Chile}

$\checkmark$ Chile presenta al cobre como uno de sus principales productos mineros ${ }^{1}$; sin embargo, tiene una baja producción de plata para las joyas y no logra satisfacer la demanda.

$\checkmark$ Según se aprecia en el Gráfico N ${ }^{\circ} 1.1$, entre el año 2009 y 2011, Chile obtuvo un incremento en el total de exportaciones (sobre todo en los minerales) pasando desde US\$ 55 mil millones a US\$ 81 mil millones, mientras que en los años 2009 y 2012, las importaciones totales de Chile aumentaron de US\$ 42 mil millones a US\$ 80 mil millones. En el Anexo 2 se muestran a los cuatro principales socios comerciales de Chile entre el año 2009 y 2014.

$\checkmark$ Asimismo se aprecia que a partir del año 2012 hubo una ligera caída en el total de las exportaciones de las cuales está directamente vinculado con los minerales.

La caída en las exportaciones se explica por el descenso de precios del mineral. El precio del cobre registró un precio en el 2012 de US\$ 3.6 la libra, lo cual es 9.9\% menor al 2011. Asimismo, las exportaciones "no cobre" también se redujeron como por ejemplo las exportaciones de

Se presenta tanto en sus manufacturas y en sus concentrados. 
frutos, los alimentos que son procesados (excluyendo el salmón), los productos forestales, metálicos, maquinarias y equipos.

(Ministerio de Relaciones Exteriores de Chile, 2013).

$\checkmark$ Los TLC han sido beneficiosos y en esta ocasión la firma bilateral entre Perú y Chile han dado oportunidades a las empresas de ingresar con sus productos al país del sur.

Desde que el TLC Perú-Chile entró en vigencia, las exportaciones totales de Perú a Chile aumentaron en un $111 \%$ alcanzando los US\$ 1,541 millones en el año 2014 de los cuales el $56 \%$ pertenece a las exportaciones tradicionales que crecieron $115 \%$ y el $44 \%$ a las no tradicionales que crecieron un 106\% entre 2009 y 2014.

(Sociedad de Comercio Exterior de Perú-COMEXPERÚ, 2015)

\section{Gráfico $\mathbf{N}^{0}$ 1. 1: Intercambio comercial de Chile}

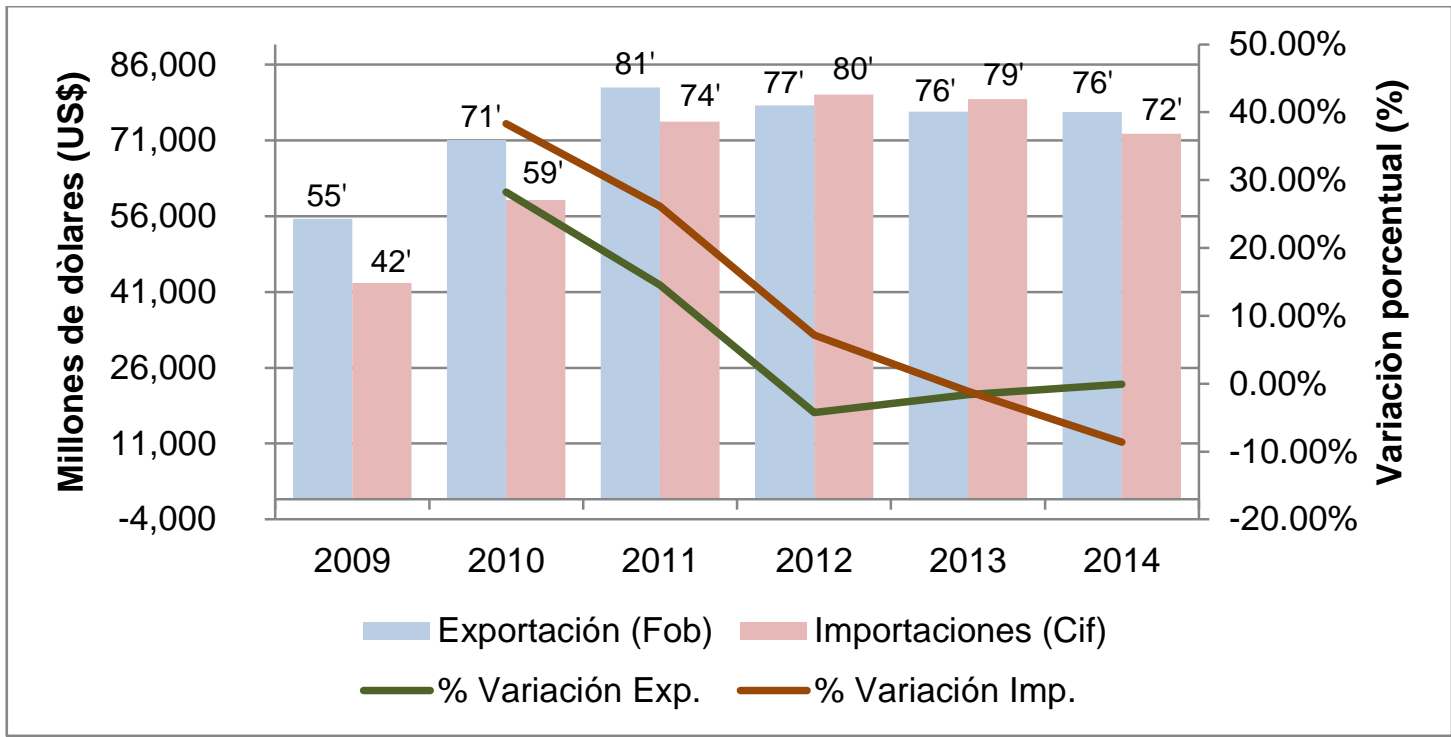

Nota: Incluye todos los productos tradicionales y no tradicionales

Fuente: TRADEMAP

$\checkmark$ El Gráfico N ${ }^{\circ} 1.2$ presenta las exportaciones e importaciones de joyas de plata entre el año 2009 y 2014 en Chile. Las importaciones presentan una tendencia creciente con un $28 \%$ en promedio anual. Por otro lado, las exportaciones presentan una tendencia irregular, presentando en el año 2013 una caída del $48 \%$. 
$\checkmark$ Las exportaciones e importaciones de joyas de plata de Chile no representan ni el $1 \%$ del total de cada uno, pero sí se presentan como un producto potencial con una oportunidad de crecimiento.

$\checkmark$ Para el año 2014, las importaciones de joyería de plata representaron el $0.03 \%$ siendo este el más alto en los últimos cinco años. Esta información se muestra más detallada en el Anexo 3 el cual se muestra de los últimos cinco años.

\section{Gráfico $N^{0}$ 1. 2: Intercambio comercial de joyas de plata en Chile}

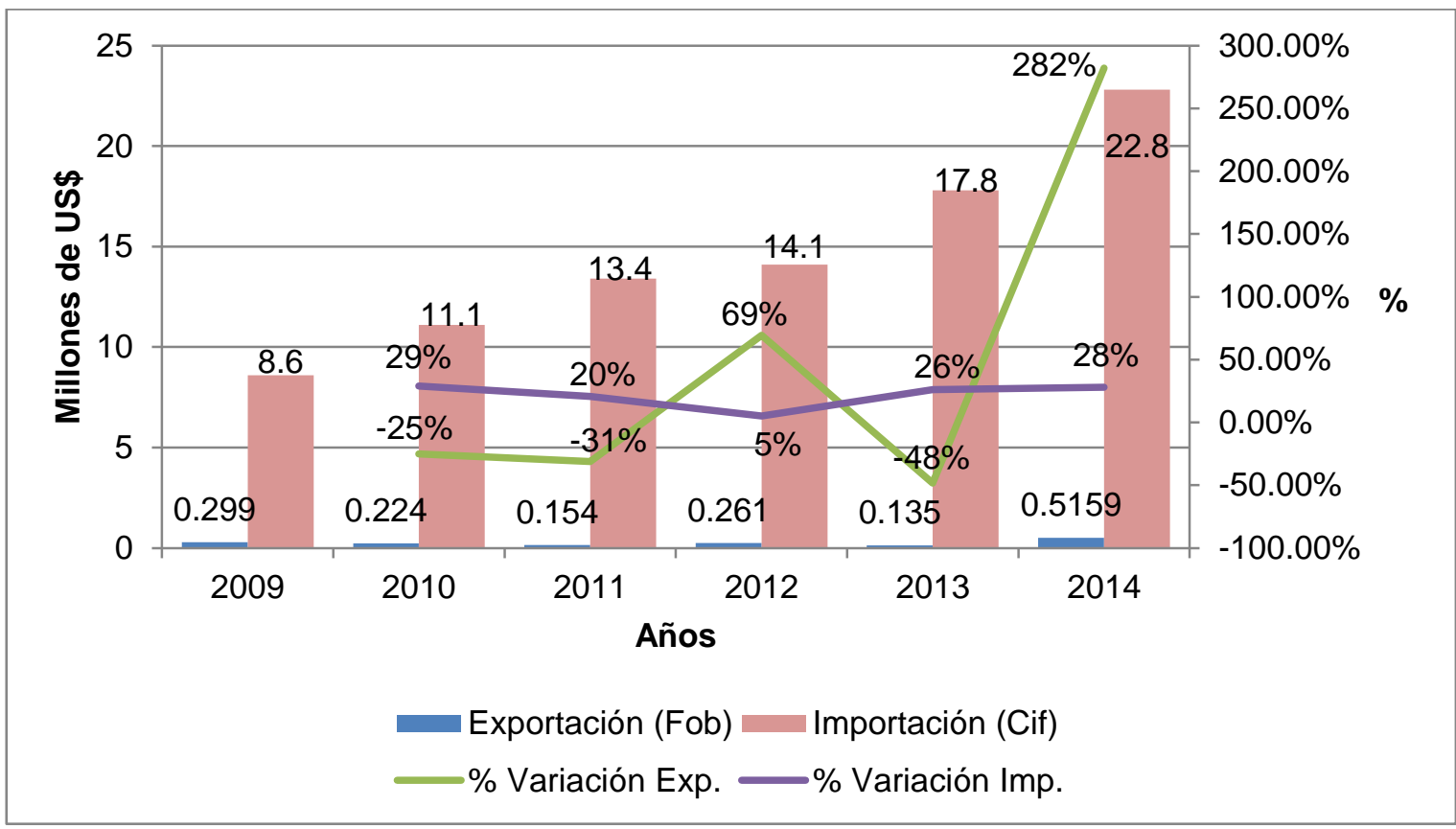

Nota: Los montos pertenecen a la partida nacional 7113110000

Fuente: TRADEMAP

$\checkmark$ De acuerdo al Gráfico $\mathrm{N}^{\circ} 1.3$, las cuales contienen datos extraídos de TRADEMAP, Italia pasó a ser el mayor proveedor de joyas de plata (23\%) a Chile seguido de Tailandia (17\%) desde el año 2013. Al cierre del año 2014, Perú (6\%) se encontró en el puesto siete por encima de Panamá y debajo de Colombia y México.

$\checkmark$ El monto total que Chile importó de joyas a nivel mundial en el año 2014 fue de US\$ 22.8 Millones, siendo la participación de Perú, US\$ 1.2 Millones el cual representa aproximadamente 6\%. Por otro lado, Perú 
exportó a Estados Unidos US\$ 5.2 Millones en joyas de plata lo cual representa el cuádruple de lo exportado a Chile tal cual se aprecia en el Anexo 4.

$\checkmark$ Los principales países productores de joyas de plata han incrementado sus exportaciones a Chile, por ejemplo Italia pasó de US\$ 1.2 Millones a US\$ 4.7 Millones entre los años 2007 y 2014; Colombia pasó de US\$ 30 Mil a US\$ 1.6 Millones en el mismo tiempo. Por otro lado, Perú ha tenido un menor crecimiento pasando de US\$ 113 Mil a US\$ 1.5 Millones, siendo superado por Colombia. En el Anexo 5, hay un cuadro comparativo de Perú con los tres principales exportadores de joyas de plata que exportan a Chile.

$\checkmark$ Según el Diario El Mundo (2013) afirma sobre la joyería y la bisutería que se produce en Tailandia: "Tailandia está imitando diseños de joyerías reconocidas a nivel internacional y a un bajo costo en la producción. Usan plata, oro e incluso diamantes para parecerse a los originales" Todo esto no es suficiente para poder lograr consolidarse como el principal proveedor de joyas de plata de Chile y debido a esto Italia pasó a ser el primer puesto.

\section{Gráfico № 1. 3: Importación de joyas de plata de Chile}

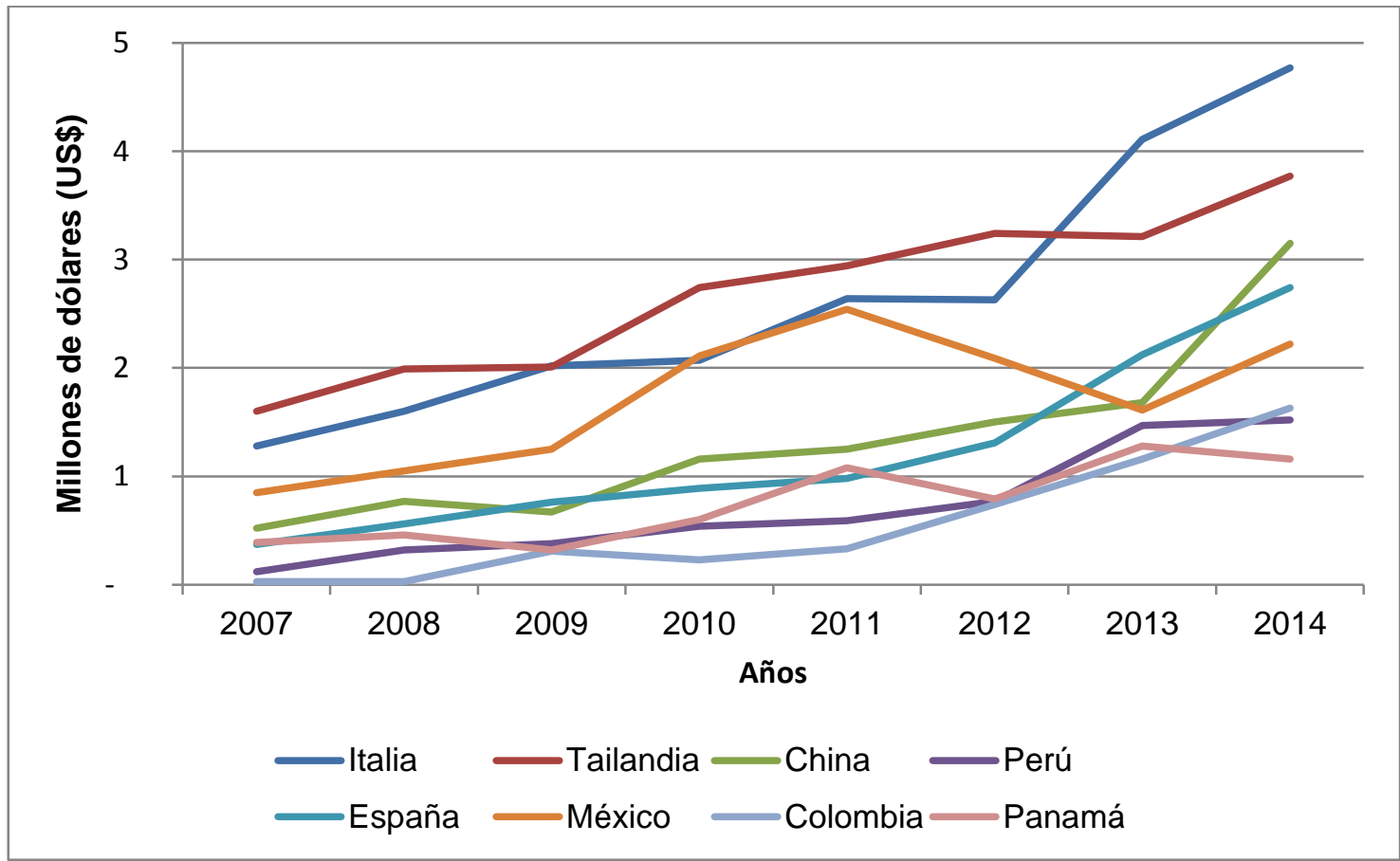

Fuente: TRADEMAP 
$\checkmark$ Dentro de los estudios del Ministerio de Minería en Chile (2015) se sostiene: "Chile ocupa el primer puesto de la producción a nivel mundial en cobre y el octavo puesto de producción de plata a nivel mundial. En el año 2014, Chile logró una producción de cobre de 2,700 miles de Toneladas Métricas que equivale al 12\% del total mundial" (Ver Anexo 6 para mayor información).

$\checkmark$ Según el Gráfico $\mathrm{N}^{\circ}$ 1.4, Chile obtuvo su más alta producción de plata en el año 2012 con 1.95 Toneladas y las de más baja producción fue en los años 2010 y 2011 con 1.29 Toneladas cada uno.

$\checkmark$ Chile no dispone de gran disponibilidad de materia prima (PLATA PURA - Ley 999); por lo tanto requiere de las importaciones de joyas de plata para satisfacer la creciente demanda.

\section{Gráfico № 1. 4: Producción de plata en Chile}

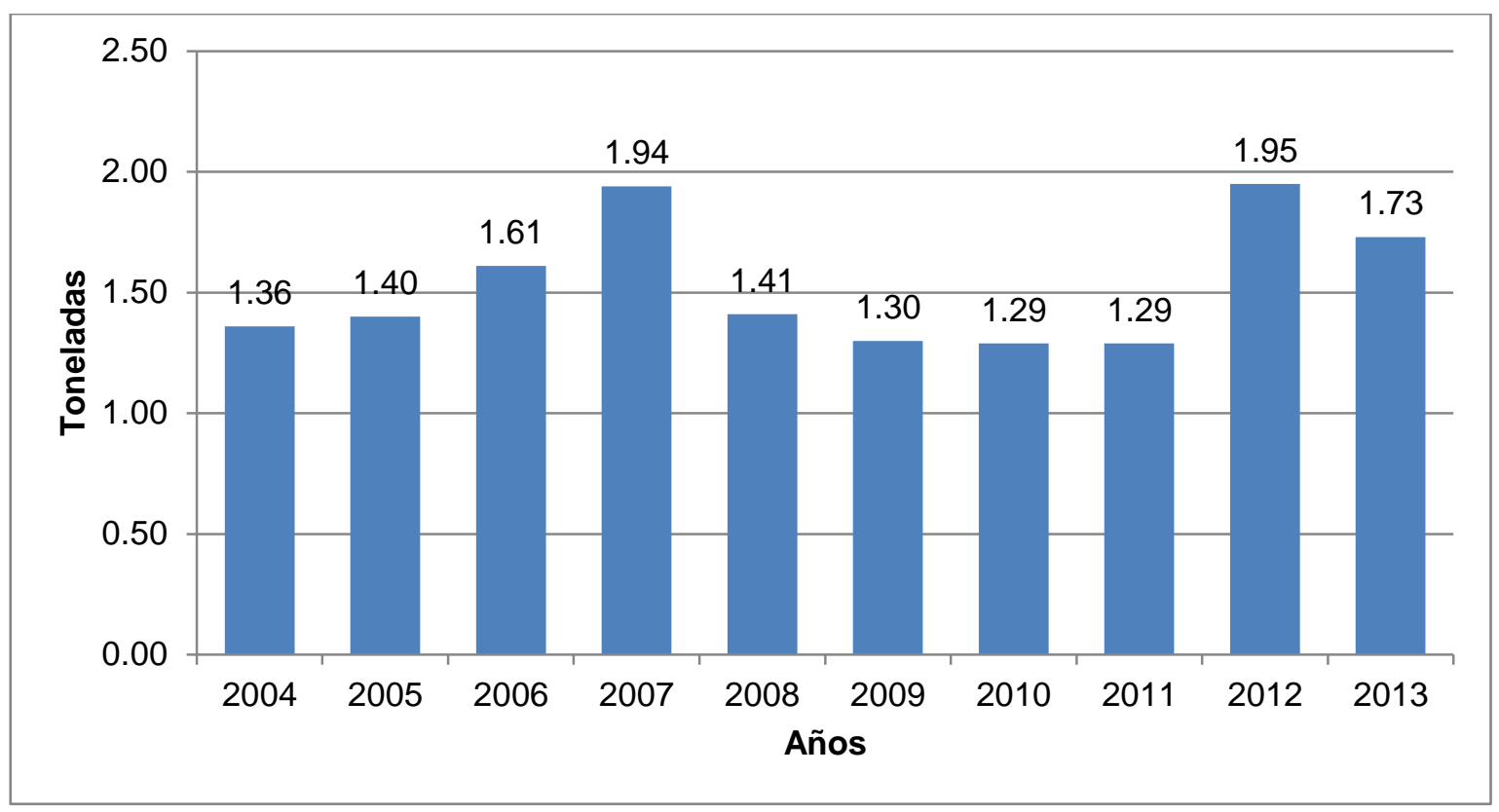

Fuente: SERNAGEOMIN - Estadística de Producción Minera

$\checkmark$ Los consumidores chilenos cada vez son más exigentes, sobretodo en el sector joyería en el cual desean productos con $100 \%$ en trabajo de calidad. Este objetivo se puede lograr brindando una buena información al artesano los cuales deben saber toda característica exacta para que el producto sea tal cual desean los clientes. 
$\checkmark$ A los consumidores chilenos les gusta reducir precios o conseguir productos con precios más bajos que los de la competencia. Puede ser una desventaja para el sector de joyas de plata ya que existen joyas elaboradas una materia prima más barata; sin embargo, el comercio de las joyas de plata tienen una presencia consolidada en el país del sur y eso se puede evidenciar en el incremento de sus importaciones. Asimismo, para una demanda que gusta de promociones y descuentos se puede realizar joyas de menor peso manteniendo la misma calidad de la plata tanto en Ley 950 y 925 y lo mismo se podría aplicar si el precio internacional de la Plata aumenta en altas cantidades. 


\section{CAPÍTULO 2: MARCO TEÓRICO}

\subsection{Análisis PESTEC}

Este análisis hace referencia al entorno que afecta directa o indirectamente a la empresa.

\subsubsection{Perú}

\section{a) Político}

$\checkmark$ Según la opinión del ex Ministro de Comercio Exterior y Turismo, Alfredo Ferrero (2015): “Actualmente Perú goza de una estabilidad política que se espera que continúe en los siguientes años. Sin embargo, la corrupción que muestra el país afecta la competitividad de las empresas debilitando el rol del estado en el cumplimiento del ordenamiento legal". Asimismo los peruanos piensan que uno de los principales problemas en el Estado es la corrupción tal cual se muestra a más detalle en el Anexo 7.

$\checkmark$ La República del Perú tiene sus leyes bajo la constitución política del Perú de 1993. Este país cuenta con 25 departamentos, 196 provincias y 1854 distritos los cuales están habitadas por 31 millones de personas.

$\checkmark$ En una entrevista brindada por el ex Ministro de Economía y Finanzas, Luis Miguel Castilla (2014) indicó lo siguiente: "Las políticas aplicadas por el Perú, así como exportaciones en crecimiento y mejores condiciones financieras internacionales, generó un ciclo favorable en ámbitos económicos y sociales para el Perú en los últimos años lo cual se espera continúe por los siguientes años”. Todo esto generaría un mayor crecimiento de la clase media y mayores oportunidades para el Perú.

$\checkmark$ Perú está siendo gobernado por Ollanta Humala mediante el Partido Nacionalista Peruano; sin embargo, el periodo de gobierno culmina en Julio del 2016. Se espera que continúe la estabilidad política en el Perú a pesar del cambio de gobierno. 
$\checkmark$ Según el estudio sobre el Índice de Percepción de Corrupción por parte del TRANSPARENCY INTERNATIONAL (2014) se sostiene: "Perú está ubicado en el puesto 85 de 174 países con un puntaje de 35 sobre 100 y quien encabeza la lista es Dinamarca en el primer puesto con un puntaje de 92”. La corrupción está presente en todos los países pero unas más graves en otras así que la falta de leyes en contra de la corrupción en el Perú hace que se salga de control. En el Anexo 8 se muestra los primeros lugares de la lista.

$\checkmark$ La acción gubernamental brinda fomento del comercio internacional. Entre los organismos de apoyo existen PROMPERU, MINCETUR, el Ministerio de Producción (PRODUCE), entre otros.

$\checkmark$ El riesgo país de Perú para el 27 de Enero del 2016 es de 2.73 puntos porcentuales, según el EMBI+ Perú, 2016. Este índice mide el riesgo político y el incumplimiento de un país con sus obligaciones de pago a los acreedores internacionales. Perú presenta los riesgos más bajos de Latinoamérica junto a México (2.60) y Colombia (3.72).

\section{b) Económico}

$\checkmark$ El tipo de cambio de Perú ha estado al alza constantemente en los últimos años (Ver Anexo 9 para observar datos históricos del tipo de cambio).

$\checkmark$ Del Gráfico $N^{\circ} 2.1$ se muestra que el PBI de Perú ha aumentado casi al triple pasando de US\$ 74 mil millones a US\$ 202.9 mil millones desde el 2005 al 2014. El crecimiento y la estabilidad económica en el Perú es notoria y se espera mejores perspectivas en los siguientes años.

$\checkmark$ De acuerdo a los informes del Banco Central de Reserva del Perú y el Instituto Nacional de Estadística e Informática (2015) se indica: "De los últimos diez años, la mayor variación positiva del PBI fue de $14.3 \%$ del año 2007-2008. Esto fue gracias a los sectores de construcción, manufactura, comercio, servicios, minería, electricidad y agua”. 
$\checkmark$ Para la crisis del año 2009, El BCRP realizó unas medidas las cuales se encuentran en el Anexo 10. Estas permitieron proveer liquidez y controlar el flujo de capitales a corto plazo.

$\checkmark$ En el Perú, los distintos sectores aportan a la economía pero una más que otras. Para esto se realizan investigaciones e informes como Santander Trade (2016) afirma:

La agricultura contribuye con el $6 \%$ del PBI y emplea menos del $3 \%$ de la población activa. Los principales productos son caña de azúcar, algodón, café, trigo arroz, maíz y cebada. El sector industrial genera el 34\% del PBI y emplea el 22\% de la población activa. Existe una gran industria minera siendo el mejor productor de plata, quinto en producción de oro, tercero en producción de cobre y un gran proveedor de Zinc y Plomo. Asimismo, posee grandes reservas de gas natural y aceite. El sector terciario contribuye con el $60 \%$ de PBI y emplea el $75 \%$ de mano de obra.

\section{Gráfico No 2. 1: Evolución del PBI del Perú}

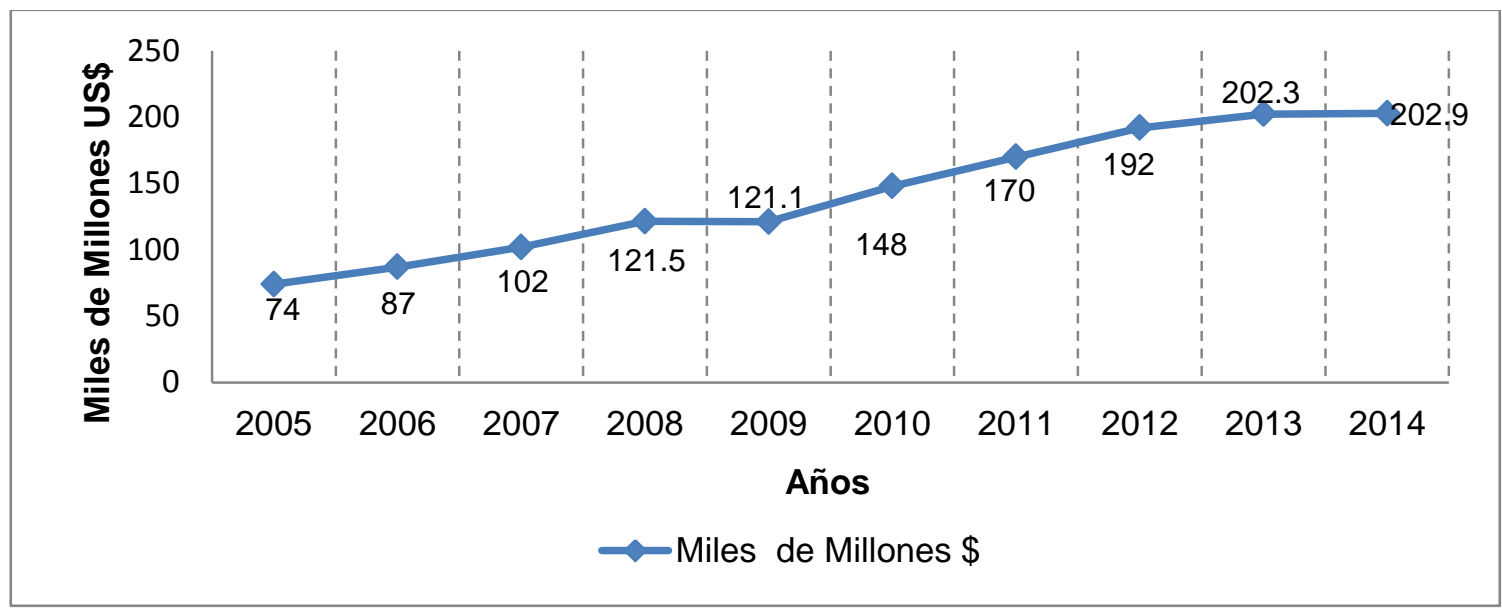

Fuente: Banco Mundial

$\checkmark$ De acuerdo al Gráfico $\mathrm{N}^{\circ} 2.2$, se muestra que la tasa de interés activa $^{2}$ en los últimos diez años ha presentado una tendencia decreciente.

Es la que cobran los bancos por los préstamos a clientes de primera línea. 
$\checkmark$ Esto beneficiaría a la inversión del proyecto debido a una tasa de interés más competitiva y menores gastos financieros.

Gráfico No 2. 2: Tasa de Interés Activa de Perú, 2005 - 2014

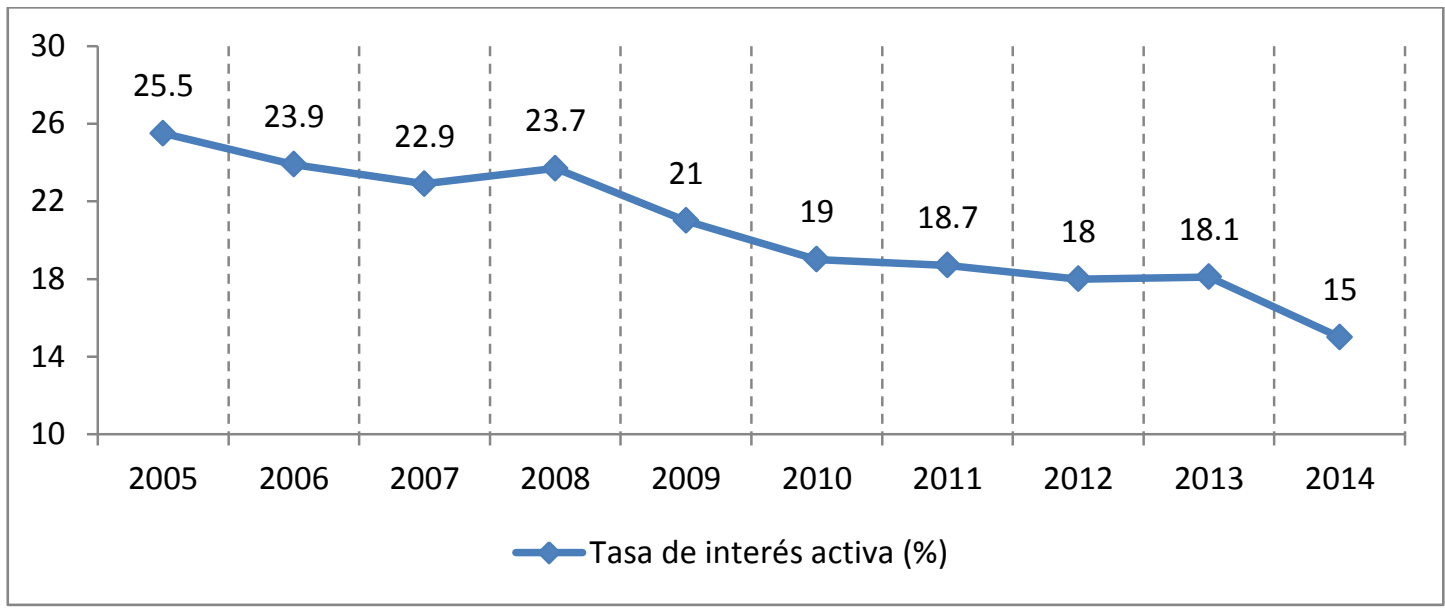

Fuente: Banco Mundial

$\checkmark$ Por otro lado, la tasa de interés pasiva ha mostrado altibajos según lo mostrado en el Gráfico № 2.3 .

$\checkmark$ En el año 2014, Perú mantuvo el $2.3 \%$ de Tasa de interés pasiva y las expectativas muestran una tendencia creciente por la competencia entre los bancos para captar clientes.

Gráfico N 2. 3: Tasa de Interés Pasiva de Perú, 2005 - 2014

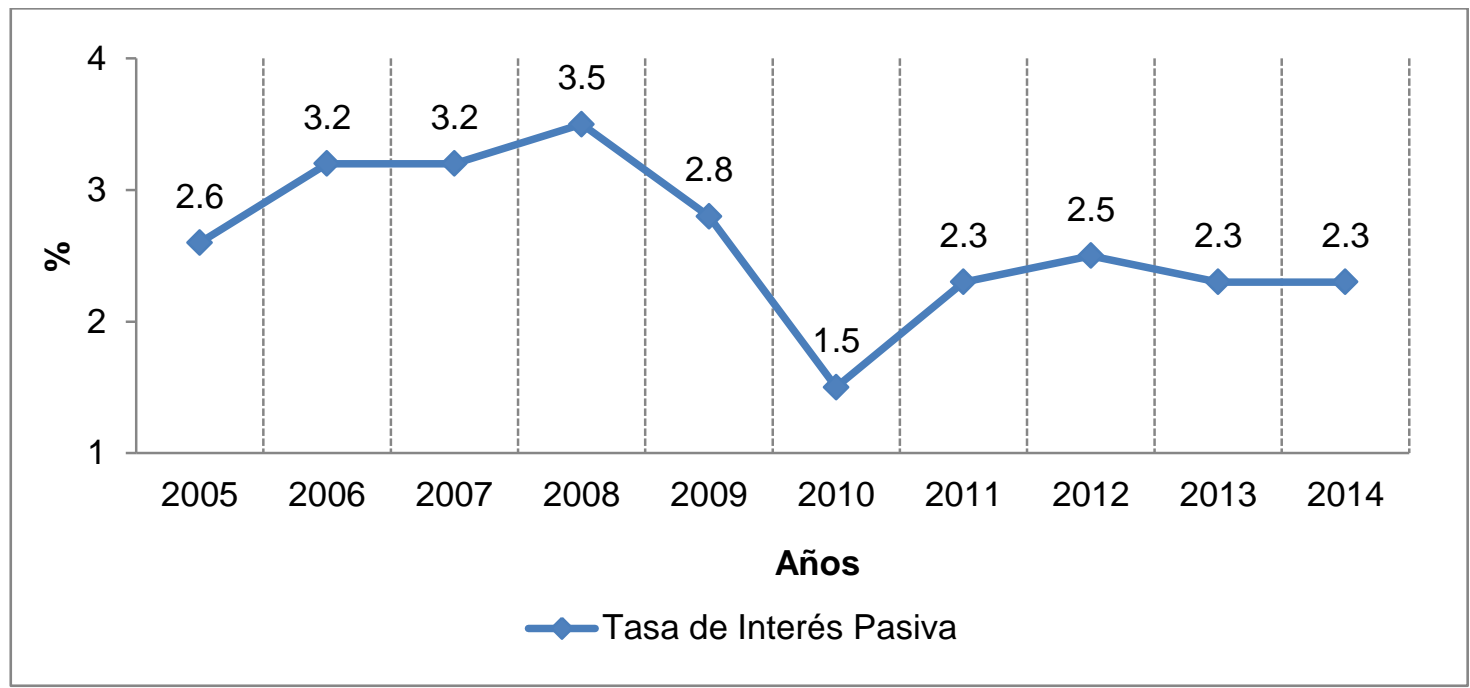

Fuente: Banco Mundial 
$\checkmark$ En el Gráfico $\mathrm{N}^{\circ} 2.4$ se muestra la tasa de inflación ${ }^{3}$ de los últimos seis años. Según un estudio sobre la inflación del BCRP (2011) se sostiene: "La mayor tasa se dio en el año 2011 con $4.74 \%$ causada por los precios de commodities y así como factores climatológicos internos que afectaron la oferta de algunos alimentos perecibles".

$\checkmark$ El alza de precios en los distintos sectores ha sido variable. Según INEI (2016) sobre su informe de la inflación se afirma:

La inflación anual del 2015 ha sido de $4.1 \%$ y fue resultado del alza en ocho grandes grupos de consumo tales como: Alquiler de vivienda, combustibles y electricidad (7.75\%); alimentos y bebidas (5.37\%); cuidados y conservación de la salud (4.58\%); esparcimiento, servicios culturales y enseñanza (4.30\%). Y en menor porcentaje, vestido y calzado (3.16\%); otros bienes y servicios (2.74\%); muebles y enseres (2.22\%) y transportes $\mathrm{y}$ comunicaciones $(1.83 \%)$.

$\checkmark$ El BCRP estimó que las tasas anuales de inflación de los años 2016 y 2017 serán de $3 \%$ y $2.5 \%$, respectivamente, tratando que no supere el rango meta.

Gráfico No 2. 4: Historial y proyección de Tasa de Inflación de Perú, 2010 - 2017

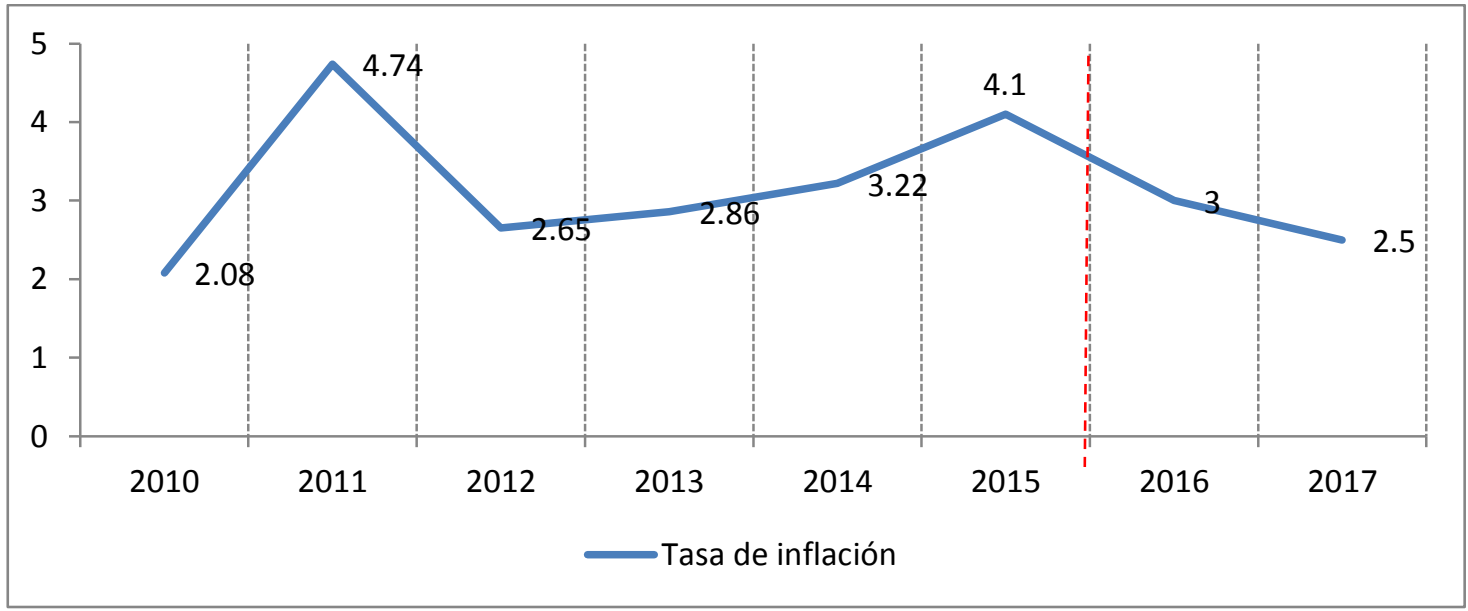

Fuente: BCRP

El BCRP tiene como uno de sus objetivos mantener la tasa de inflación entre 1\% - 3\%. 
$\checkmark$ A continuación se presenta el Gráfico $N^{o} 2.5$, la cual muestra las exportaciones mensuales de Perú en los últimos dos años. Las exportaciones totales del mes de marzo del 2015 han bajado con respecto al año 2014, las exportaciones de este mes alcanzaron los US\$ 2,543 millones, monto que representó una caída de $20 \%$ con respecto al mismo mes del 2014. Este resultado está asociado, principalmente, a una caída de las exportaciones tradicionales en un $24 \%$ (US\$ 1,676 millones) y de las exportaciones no tradicionales en un 12\% (US\$ 867 millones).

$\checkmark$ ADEX (2015) según su informe sobre las exportaciones de Perú afirma:

La caída de las exportaciones tradicionales fue a consecuencia de una caída en la pesca tradicional (-65.7\%), petróleo y gas natural ($55 \%$ ) y minería (-22\%). Asimismo, dentro de las exportaciones no tradicionales se encuentra el sector metalmecánico (-46.5\%), prendas de vestir (-34.4\%) y textil (-35.3\%) como los principales sectores que han tenido una baja en las exportaciones.

$\checkmark$ Se ha dado un incremento del valor de las exportaciones de joyas de plata desde el año 2007 a pesar de la crisis mundial debido a la reducción de la demanda de joyas de oro.

\section{Gráfico N 2. 5: Exportación total de Perú (US\$ en Millones)}

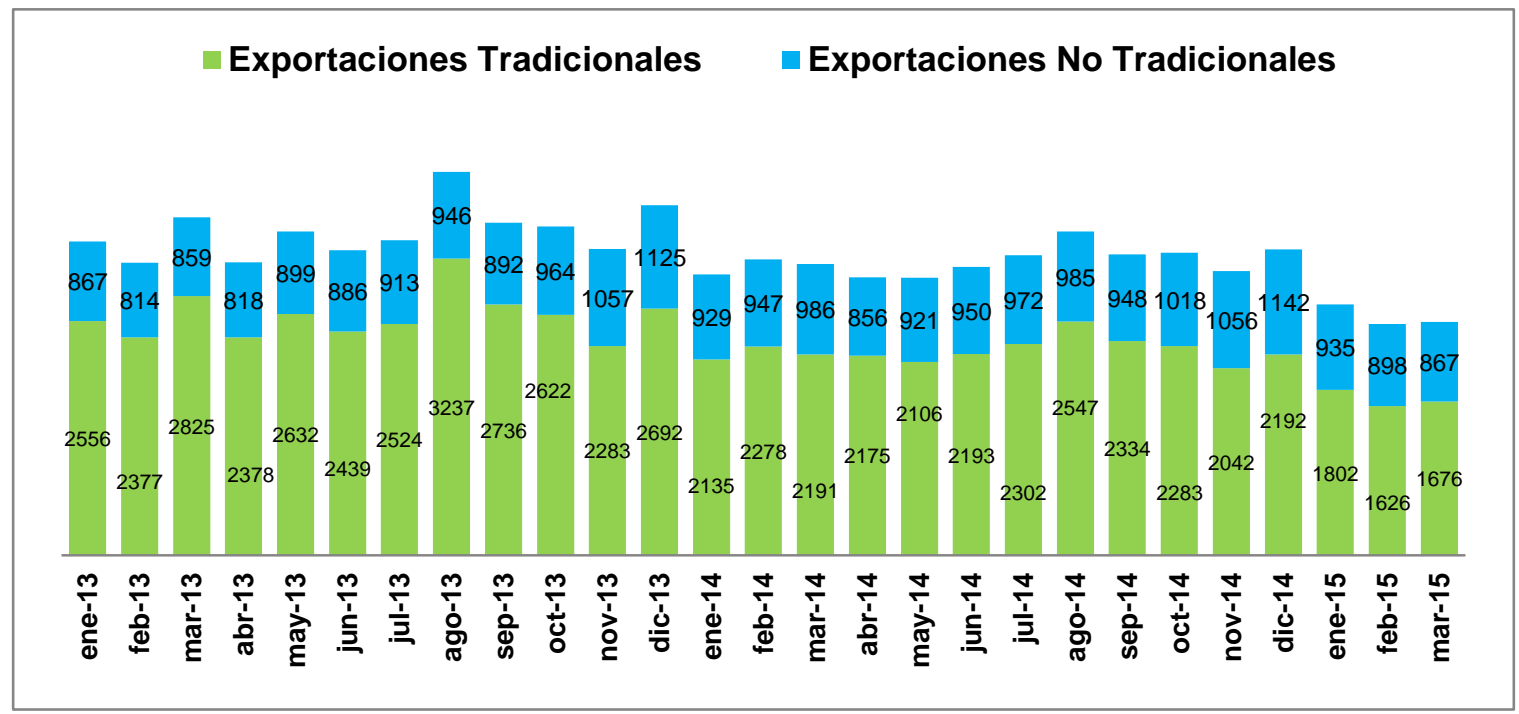

Fuente: SUNAT 
$\checkmark$ Perú cuenta con estabilidad macroeconómica al igual que varios países de Latinoamérica. La percepción se ha invertido ahora porque antes esta región era caracterizada por la crisis y hoy ya no lo es.

\section{c) Social}

$\checkmark$ Se extrajeron datos de la INEI sobre la población de Perú las cuales se pueden apreciar en el Gráfico № 2.6. En el año 2014, alcanzó la cifra de 30.8 millones de habitantes en todo el Perú y más adelante para el año 2030, a través de proyecciones de la INEI, el Perú llegará a un estimado de 35.9 millones de habitantes.

$\checkmark$ Cada año el crecimiento es cada vez menor ya sea por la imposición de nuevas culturas en el país, priorizando las satisfacciones personales en lugar de la formación de una familia o por mayores tratamientos anticonceptivos. Todo esto traerá como consecuencia un estancamiento en el crecimiento de la población en los siguientes años.

\section{Gráfico N 2. 6: Población proyectada de Perú}

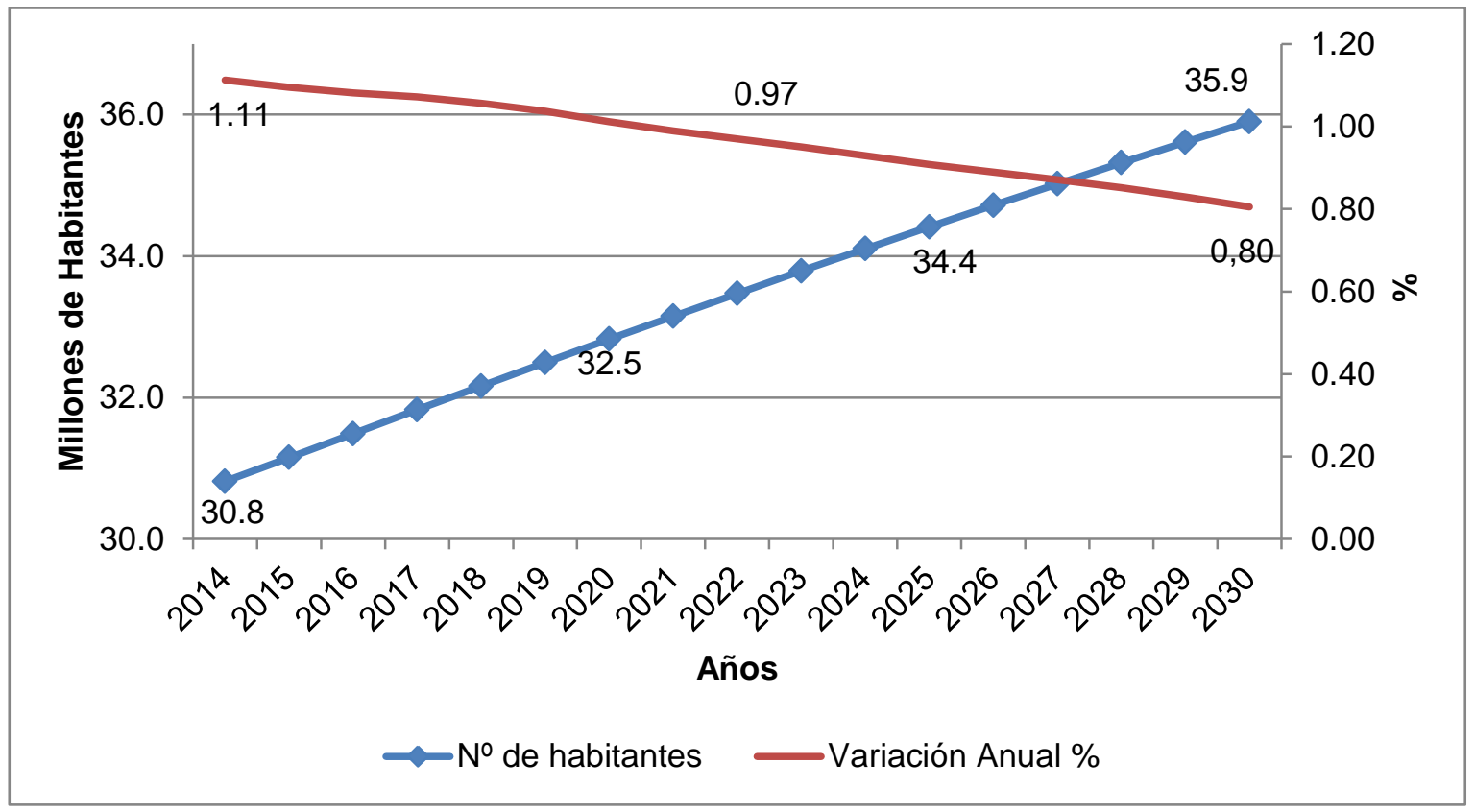

Fuente: INEI 
$\checkmark$ Según el Gráfico $N^{\circ}$ 2.7, en el Perú ha habido un alto porcentaje de pobreza y pobreza extrema ${ }^{4}$ en el año 2004; sin embargo, anualmente estos indicadores se han reducido gracias tanto a políticas nacionales como internacionales.

$\checkmark$ En un artículo del Diario Gestión, Rolando Arellano (2014) declara: “Como consecuencia del crecimiento económico, a nivel económicosocial, hubo un incremento de la clase media en el Perú que beneficia en el consumo nacional y mano de obra de las empresas".

$\checkmark$ Actualmente, según el estudio de la INEI (2014): "Hay un 4.3\% de pobreza extrema y un $22.7 \%$ en pobreza. Igualmente, se espera un descenso en los porcentajes de estos indicadores en los próximos años ya que se está fortaleciendo e incentivando políticas y estrategias en beneficio de los más necesitados".

\section{Gráfico $N^{\circ}$ 2. 7: Porcentaje de Pobreza y pobreza extrema en el Perú}

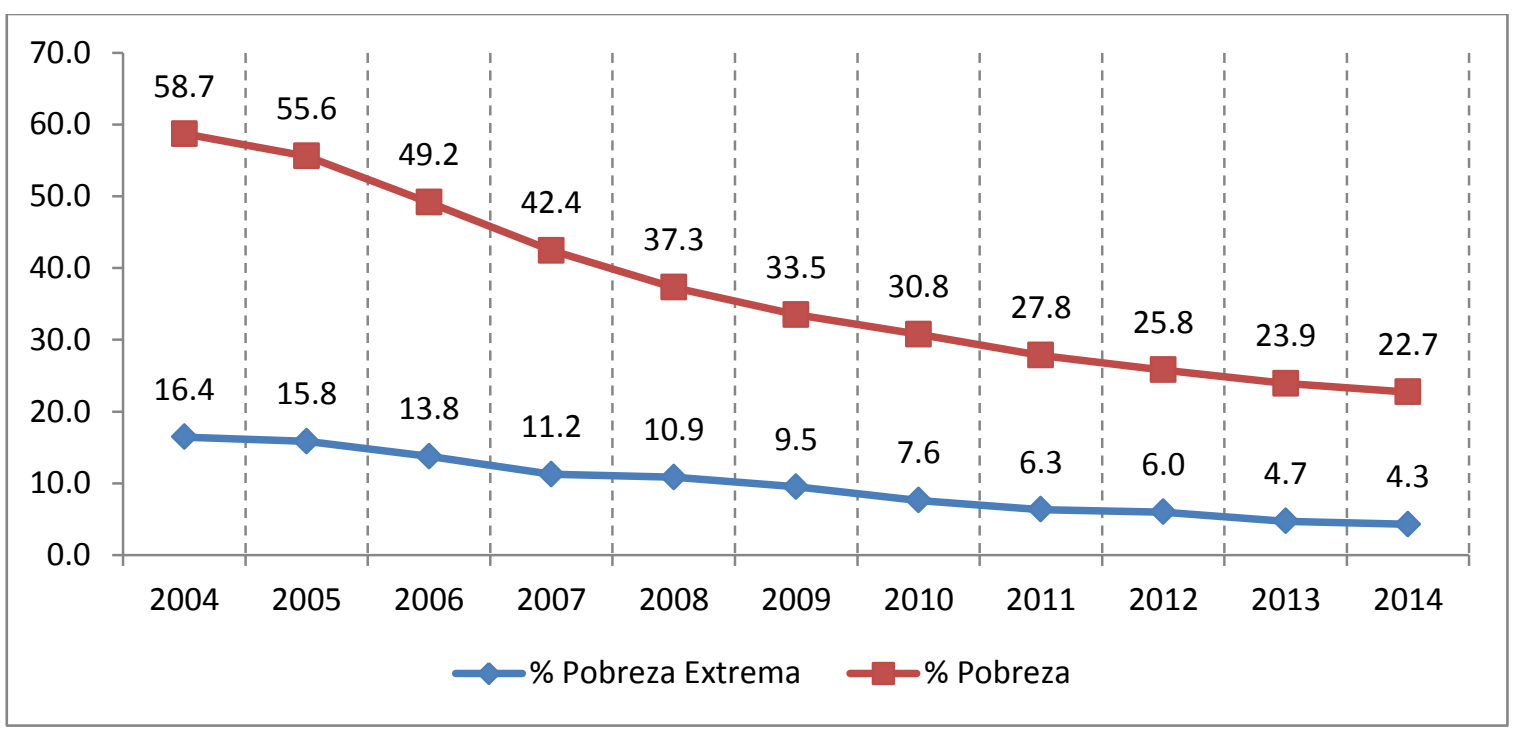

Fuente: INEI

$\checkmark$ Se registraron en la región de Lima Metropolitana un aproximado de 7 millones de personas con edad para desempeñar una actividad económica (Población en Edad de Trabajar - PET), que constituyen la población potencialmente demandante de empleo.

\footnotetext{
$4 \quad$ Pobreza extrema: No satisface las necesidades alimenticias y Pobreza: No satisface una de sus necesidades principales.
} 
$\checkmark$ La PET está compuesta por la Población Económicamente Activa (PEA), que representa el 68\% (4 millones 993 mil 800 personas) y por la Población Económicamente No activa (No PEA) con el 32\% (2 millones 353 mil 500 personas), que agrupa a las personas que no participan en la actividad económica como ocupados ni desocupados (Ver Anexo 11 para mayor detalle).

\section{d) Tecnológico}

$\checkmark$ El uso de la tecnología en el Perú no está desarrollado a comparación de otros países de Europa Occidental. Estos avances tecnológicos causarían un avance significativo en las industrias ya que crea la posibilidad de entrar en otros mercados, producir más productos, crear ventajas competitivas a través de mejores productos y precios.

$\checkmark$ Según "THE GLOBAL INFORMATION TECHNOLOGY REPORT 2015", la cual es un proyecto especial dentro del marco de "WORLD ECONOMIC FORUM (WEF)", indica:

Perú se ve limitado por barreras en el sistema educativo y la falta de eficiencia de los órganos legislativos para mejores resultados en la tecnología peruana. Perú está en el puesto 90 en el impacto de las TIC'S en el proceso de desarrollo y competitividad de 143 economías del mundo. El desarrollo de Perú se ve limitado por barreras tales como el sistema educativo de baja calidad (Puesto $133^{\circ}$ ), baja calidad de la educación en matemáticas y ciencias (Puesto $138^{\circ}$ ) que dificultan la preparación del país para hacer un buen uso de las Tecnologías de la información, así como la falta de eficacia de los órganos legislativos (Puesto $140^{\circ}$ ), que retrasan el entorno regulatorio para las TIC.

$\checkmark$ La tecnología es un elemento importante para el aumento de la productividad. En el sector joyero se anhela lograr la innovación requerida pero conservando las técnicas ancestrales. En tal sentido, sería positivo la implementación de técnicas modernas a fin de enriquecer y aumentar la oferta, mejorando la productividad y calidad 
de los productos. Sin embargo son escasos los esfuerzos orientados a lograr estos objetivos.

$\checkmark$ Dentro del sector joyería, se encuentra el CITE CATACAOS y KORIWASI el cual es un Centro de Innovación para la joyería. Tratan de promover la competitividad a través de buena gestión, innovación tecnológica, facilidad de oferta debido a que brinda a los artesanos el servicio con las máquinas existentes a fin de incrementar la productividad.

\section{e)Ecológico}

$\checkmark$ A nivel Internacional existen diversas certificaciones y entre ellas la certificación ISO 14001 que tiene como principal objetivo la aplicación del plan de manejo ambiental. Este tipo de certificación puede ayudar a las empresas mineras a tener efectos positivos en el medio ambiente dado que este sector ha tenido mucha repercusión negativa en el Perú por la constante contaminación.

$\checkmark$ En el Perú, la Dirección General de Salud Ambiental (DIGESA), que pertenece al Ministerio de Salud, es la encargada de realizar las habilitaciones y los registros sanitarios de los alimentos. Las empresas productoras de alimentos y material educativo, juguetes y otros bienes que estén en contacto directo con las personas tienen que obtener esa autorización para asegurar la calidad de las materias primas.

$\checkmark$ Asimismo, está el Organismo de Evaluación y Fiscalización Ambiental (OEFA) cuyo objetivo es garantizar que se cumpla la legislación ambiental como por ejemplo la LEY No 29325 que indica: "La creación del Sistema Nacional de Evaluación y Fiscalización Ambiental para asegurar el cumplimiento de la legislación ambiental por parte de todas las personas naturales o jurídicas".

$\checkmark$ Uno de los objetivos principales dentro del sector joyería es lograr una adecuada gestión ambiental por parte de las empresas naturales y jurídicas que desarrollan actividades mineras dentro del ámbito de sus 
competencias ya que la materia prima se obtiene de mineras y refinerías.

$\checkmark$ En el Perú, la empresa ARINSA es un claro ejemplo de una implementación del Programa de Gestión Ambiental tal cual lo informan en su página web sobre la implementación de programas sobre cómo usar eficientemente la energía eléctrica y el agua potable en sus operaciones.

\section{f)Competitivo}

$\checkmark$ El joyero peruano y gran porcentaje de las joyerías del Perú muestran una limitada predisposición a la innovación de diseños, técnicas de trabajo y uso de insumos. La mayor parte de sus diseños son copiar y, en el caso de las exportadoras, el diseño de los productos es dictado por el importador.

$\checkmark$ Para que un país llegue a ser competitivo, se considera que debe tener la habilidad de crear y mantener un ambiente en donde las empresas puedan competir.

$\checkmark$ Frecuentemente, la plata se obtiene de manera informal porque se puede obtener precios bajos por el mineral; sin embargo, formalmente se debe conseguir con factura a un precio internacional, la cual no es una desventaja pues te deja con IGV a favor.

$\checkmark$ Para otro lado, el Centro de Competitividad Mundial del IMD (Institute for Management Development), saca un reporte de los países más competitivos a nivel internacional entre los cuales el Perú se encuentra en el puesto 54 de 140 (Ver Anexo 12). Los temas que están involucrados para una mejor competitividad a nivel nacional según el IMD son el funcionamiento y rendimiento económico, la eficiencia del gobierno, la eficiencia en los negocios y la infraestructura.

$\checkmark$ En el sector joyería la competitividad u productividad varía según el tamaño de empresa pues las empresas más grandes tienen una 
estructura de la empresa mucho más completo que le brinda una mejor producción usando tecnología que las empresas artesanales.

$\checkmark$ Las escalas promedio de producción según el tamaño de las empresas de joyas de plata se puede observar en el cuadro $\mathrm{N}^{\circ} 2.1$ :

\section{Cuadro $\mathrm{N}^{\circ}$ 2. 1: Producción de joyas según tamaño de empresa}

\begin{tabular}{|c|c|}
\hline Tamaño de la empresa & Cantidad de Producción \\
\hline Microempresa & 300 piezas $x$ mes \\
\hline Pequeña & Hasta 2,500 piezas $\times$ mes \\
\hline Mediana & Hasta 5,500 piezas $\times$ mes \\
\hline Grande & Más de 5,500 piezas $\times$ mes \\
\hline
\end{tabular}

Fuente: Instituto nacional del emprendedor (México)

$\checkmark$ Las microempresas trabajan con un proceso tradicional, donde se efectúan muchas labores manualmente.

$\checkmark$ A partir de la pequeña empresa ya usan las innovaciones tecnológicas que agilizan el proceso de producción, promoviendo el aumento del volumen de fabricación.

$\checkmark$ Es amplio el número de empresas que fabrican joyería en el Perú. Hay nuevas empresas que aparecen y otras que desaparecen. Sin embargo, la joyería peruana no está siendo competitiva pues las empresas extranjeras están tomando gran porcentaje de la demanda internacional.

\subsubsection{Chile}

\section{a) Político}

$\checkmark$ A nivel nacional, Chile tiene varias leyes y normas que tratan de beneficiar a la producción y al comercio exterior para una economía sana sin presencia de monopolios y con regulaciones de protección ambiental, leyes fiscales y de promoción para las empresas.

$\checkmark$ En Chile existen instituciones dedicadas a fiscalizar e imponer regulaciones a los monopolios debido a que pueden aparecer acciones desleales por parte de las empresas con tal de tomar una gran 
participación de mercado. Por un lado está el Tribunal de Defensa de la Libre Competencia dedicado a todo lo relacionado con materias vinculadas a la libre competencia y por otro lado existe la Fiscalía Nacional Económica que promueve una competencia libre en todo Chile.

$\checkmark$ Las normas, leyes y promociones por parte del gobierno también influyen en el comercio exterior de Chile. En primer lugar existe la página web de PROCHILE que beneficia tanto a importadores $\mathrm{y}$ exportadores en la información de estudios de mercado para que tomen mejores decisiones en las estrategias de la empresa. En segundo lugar, por parte del ministerio de economía de Chile han implementado un programa llamado "Chile Atiende MYPES" la cual es un portal web que permite mejor accesibilidad para la información de todas las instituciones públicas que estén relacionadas con el emprendimiento.

$\checkmark$ Internacionalmente, según el ministerio de Relaciones Exteriores en Chile (2015):

El sistema político exterior de Chile ha realizado políticas y normas con interés en fortalecer la imagen de Chile en el exterior, promoviendo los intereses económicos, teniendo más socios comercialmente con otros países, contribuyendo al fortalecimiento de la integración regional y al fortalecimiento del multilateralismo, entre otros.

$\checkmark$ El sistema político de Chile se encuentra estable y democrático; por lo tanto brinda seguridad para hacer negocios. Políticamente está estructurado en Ejecutivo, Legislativo y Judicial. El presidente es elegido mediante votos y está a la cabeza del Poder Ejecutivo. El congreso tiene a su cargo el poder legislativo, mientras que el poder judicial es independiente y autónomo y tiene la responsabilidad de poner justicia.

$\checkmark$ Entre Perú y Chile se encuentra una similar estructura política; sin embargo, Chile ha tenido más eficiencia en cuanto a sus leyes y 
normas los cuales pueden ser demostrados mediante el Ranking de "Índice de Competitividad Global" elaborado por WORLD ECONOMIC FORUM. Dentro de los pilares del estudio, se encuentra uno relacionado al gobierno llamado "Eficiencia del Gobierno" en el cual existen cinco variables y Chile está dentro de los 33 primeros lugares de un total de 144 economías (Ver Anexo 13).

\section{b) Económico}

$\checkmark$ Chile presenta un modelo económico estable que favorece al comercio y la inversión ya sea local o internacional. Según el Gráfico $\mathrm{N}^{\mathrm{o}}$ 2.8, Chile tiene un PBI más alto que el de Perú (202 millones de US\$ en el 2014) principalmente debido a una alta actividad económica en los servicios empresariales y en la minería.

$\checkmark$ Según Diario La Tercera. (2010) se afirma sobre la clase media en América Latina: "La clase media pasó a ser del 65\% de la población total en América Latina y lo convierte en el protagonista de la región y Chile pasa a liderarlo con el $77 \%$ de su población como clase media".

$\checkmark$ El PBI de Chile para el año 2014 alcanzó los US\$ 258 mil millones con un PBI Per cápita Paridad de Poder Adquisitivo (PPA) de US\$ 22,971 el cual fue el más alto en los últimos cinco años.

$\checkmark$ En el Anexo 14, según fuente de CNN, se muestra la proyección del PPA de Chile hasta el 2020, en el cual se aprecia el crecimiento continuo logrando sobrepasar el PPA de México. 
Gráfico No 2. 8: PBI Total y PBI Per Cápita de Chile

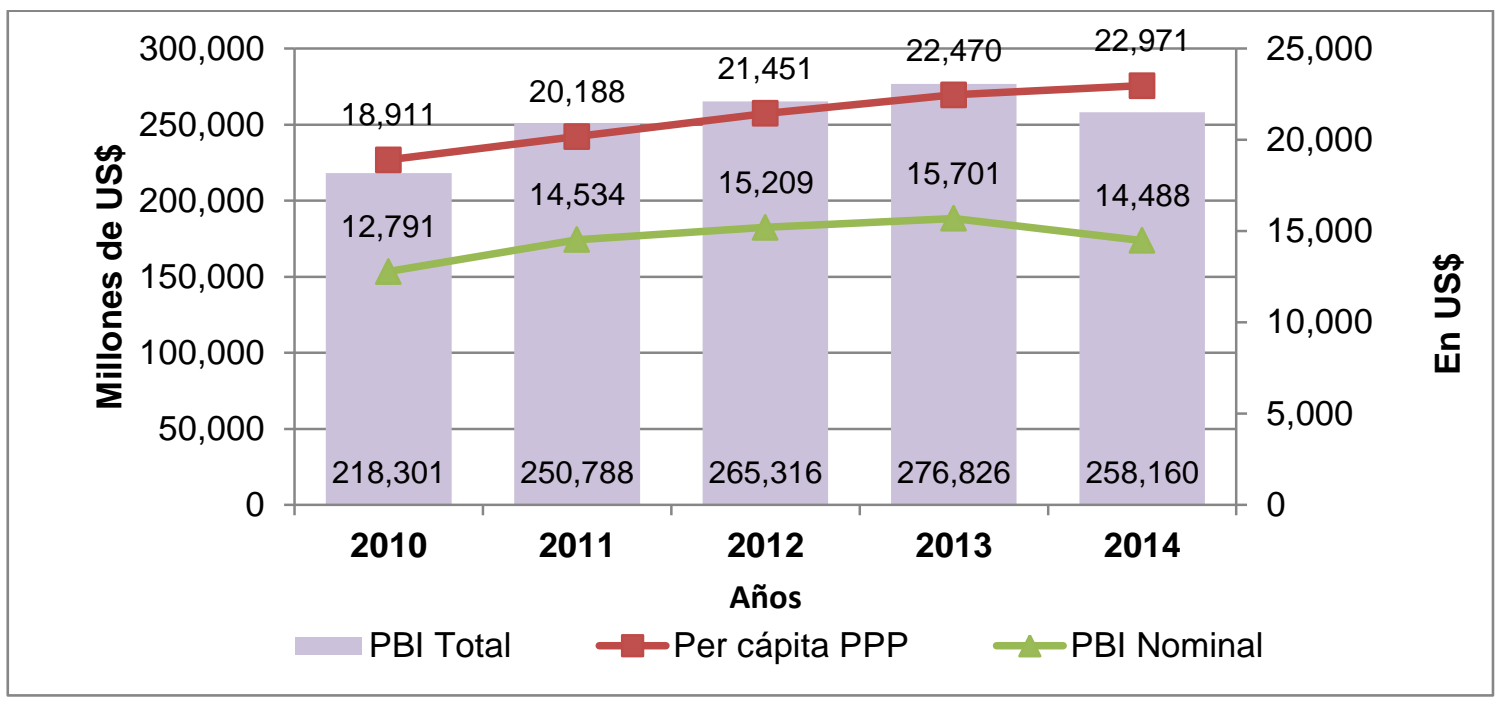

Fuente: Banco Central de Chile

$\checkmark$ La tasa de desempleo ${ }^{5}$ en Chile ha estado disminuyendo en estos últimos años. Como se muestra en el Gráfico $\mathrm{N}^{\circ}$ 2.9, presenta información de los últimos meses del sector empleo del país. En enero del 2014, Chile tuvo una tasa de desempleo de $6.1 \%$ la cual ha estado variando mensualmente debido a una inestabilidad laboral.

$\checkmark$ En agosto se registró la tasa más alta del 2014 logrando alcanzar $6.7 \%$ de desempleo. Se presenciaba una tendencia a la baja a partir de haber alcanzado el pico más alto; sin embargo, en mayo del 2015 hubo un incremento del desempleo lo cual llegó a 6.6\% del total de la fuerza laboral.

$\checkmark$ Según el INE de Chile (2015), los sectores más afectados han sido la Industria, Agricultura y la Inmobiliaria los cuales son los que más caída de empleo han tenido. 
Gráfico No 2. 9: Variación Mensual de la Tasa de desempleo

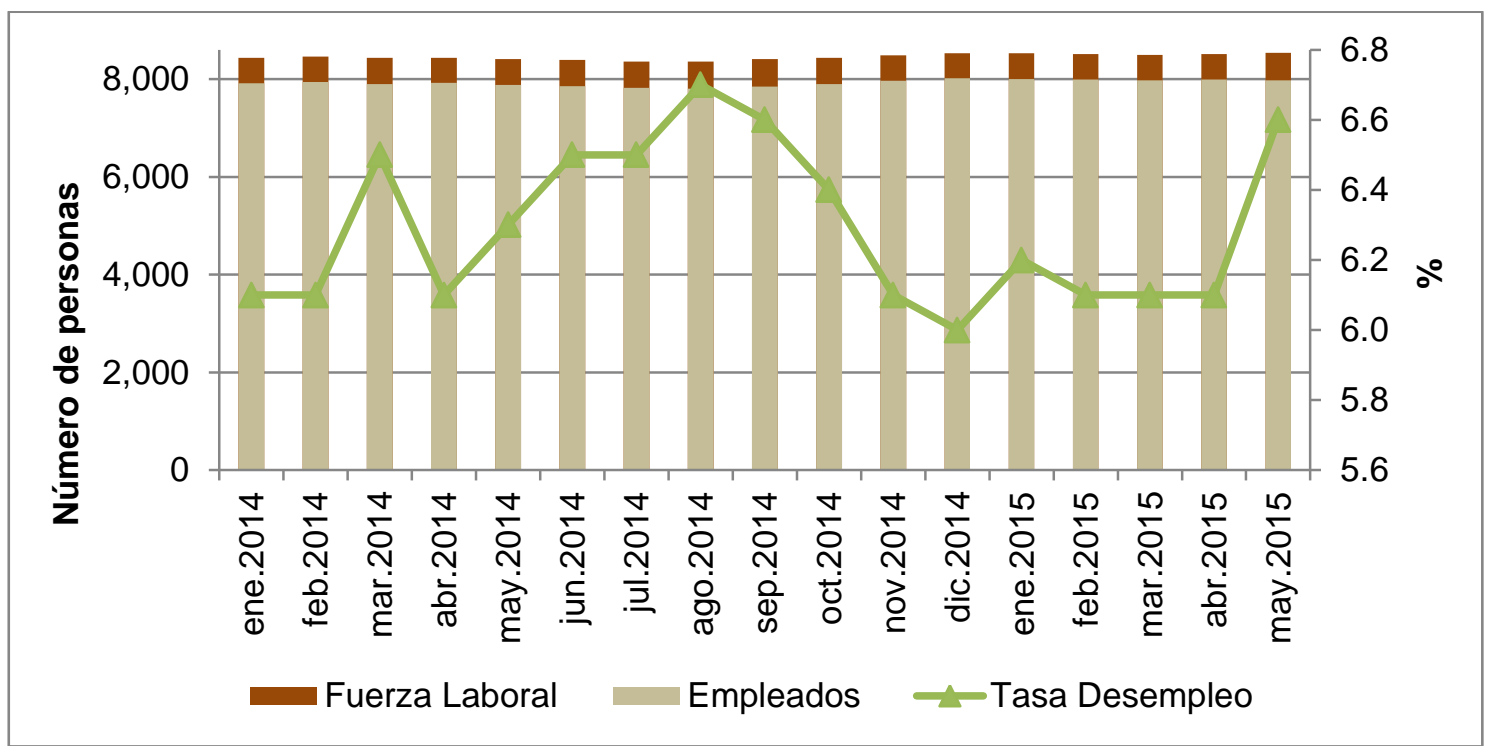

Fuente: INTERNATIONAL MONETARY FUND

$\checkmark$ Según la información del Gráfico $\mathrm{N}^{\circ} 2.10$, el dólar en Chile ha tenido un alza pasando desde \$427.67 en Enero del 2013 a \$629.99 en Junio del año 2015. Una de las causas de este aumento puede deberse a la variación del precio de los metales en Chile.

\section{Gráfico N². 10: Tipo de Cambio del Peso Chileno a Dólar}

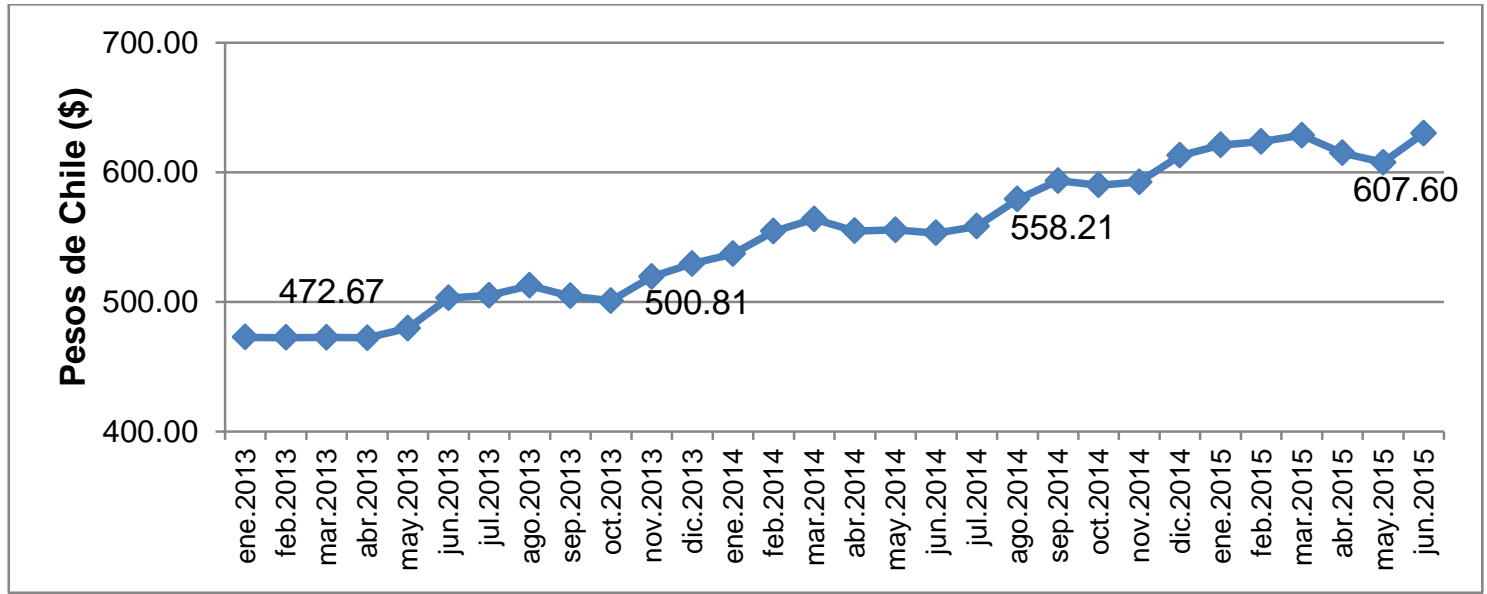

Fuente: Banco Central de Chile

\section{c) Social}

$\checkmark$ El Gráfico $\mathrm{N}^{\circ} 2.11$ se muestra una tendencia positiva de la población de Chile ya que para el año 2005 había aproximadamente 
más de 15 millones de personas pasando para el año 2015 a un promedio de 18 millones.

$\checkmark$ A pesar de que se presenta un incremento de la cantidad de personas, la variación anual aumenta en una proporción menor al año anterior. Según INE de Chile, una causa es la baja en la tasa de fecundidad al pasar de 2.1 a 1.9 hijos por mujer por lo que Chile viene a ser uno de los países con más baja fecundidad en América Latina.

\section{Gráfico No 2. 11: Población total en Chile}

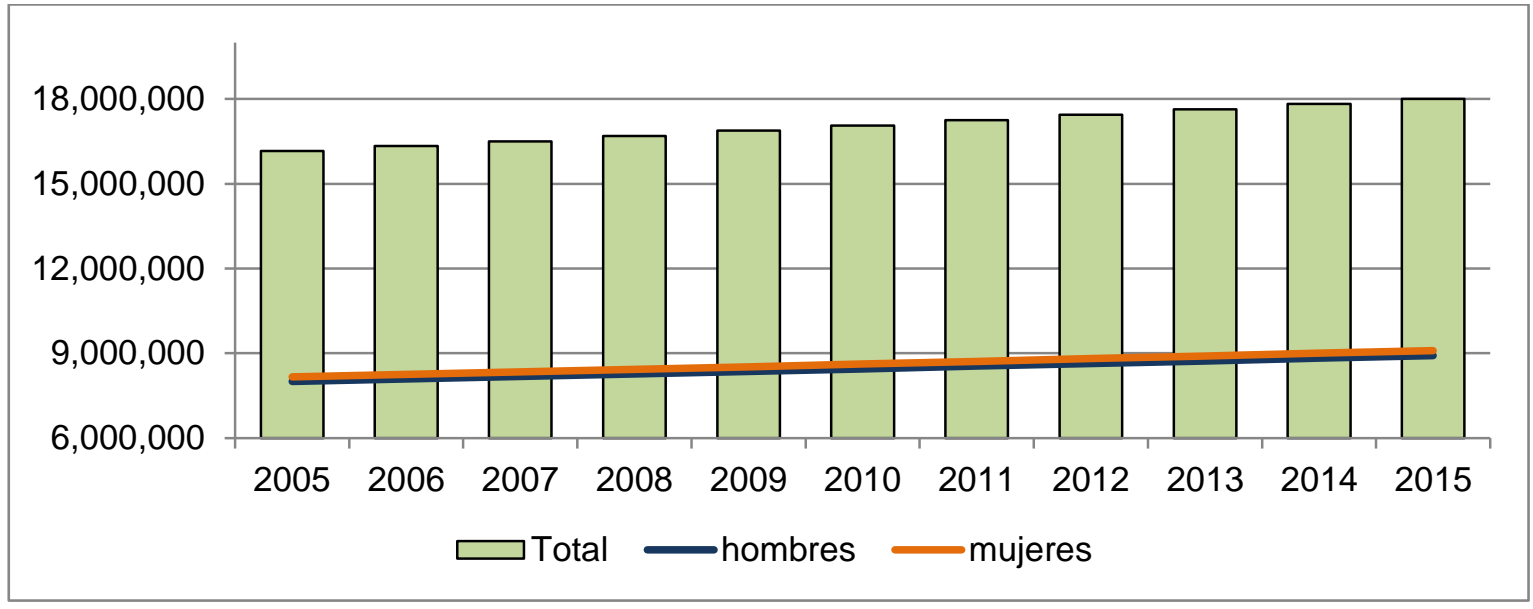

Fuente: INE Chile

$\checkmark$ Según se aprecia en el gráfico $\mathrm{N}^{\circ} 2.12$, la edad entre 45-54 años son los que mayor porcentaje de ocupados representa en Chile y en el último lugar están los de 65 años a más.

$\checkmark$ Asimismo, los que presentan mayor ingreso en los hombres son los de 35-44 años de edad y en las mujeres son las de 30-34 años de edad debido a que presentan estudios con maestrías o doctorados.

$\checkmark$ Según INE de Chile (2015), en promedio, los hombres ganan más en el salario que las mujeres en todos los ámbitos como edad, empleo, educación y tamaño de empresas. 
Gráfico $\mathbf{N}^{\circ}$ 2. 12: Ingreso mensual y número de personas ocupadas, según edad

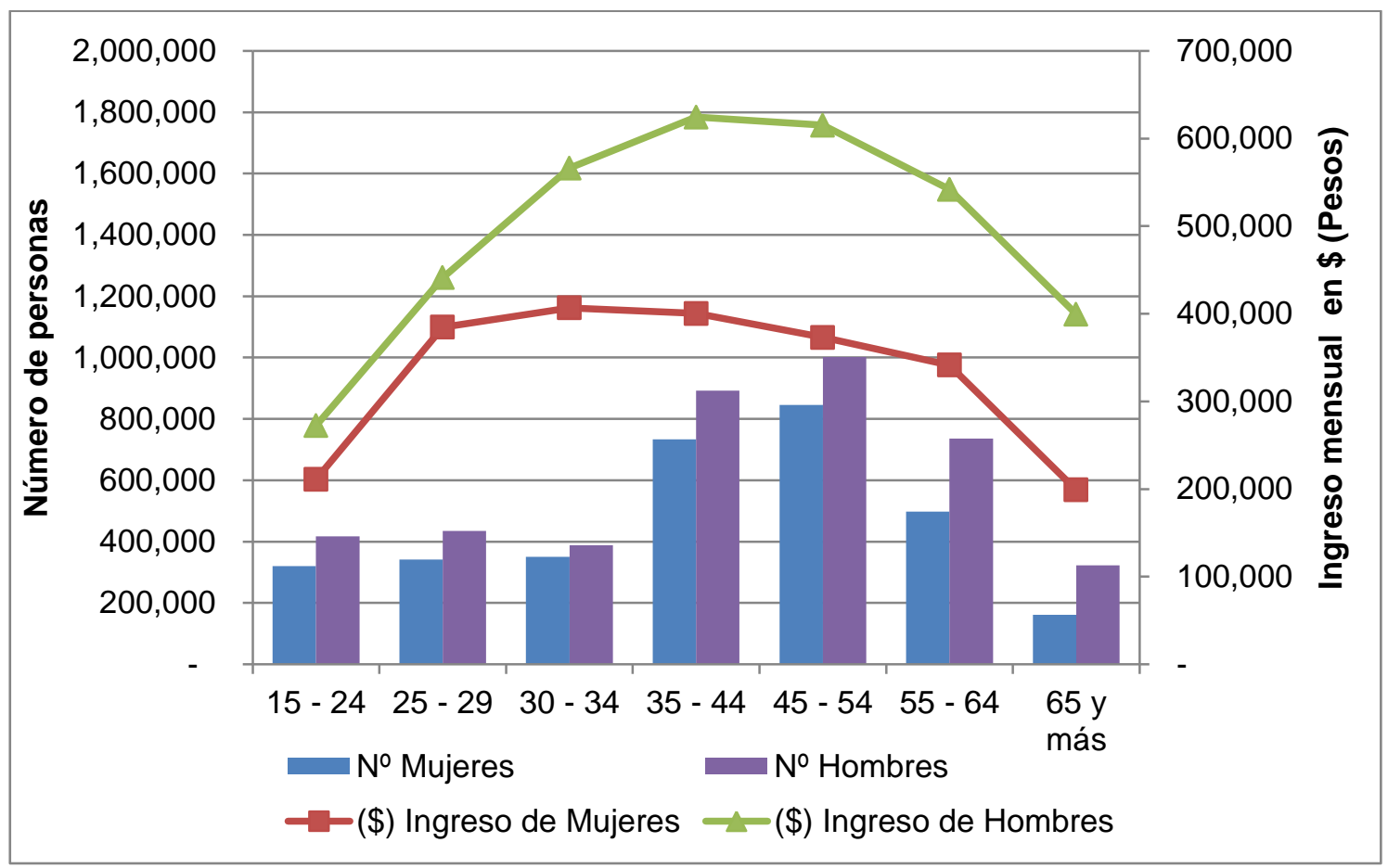

Fuente: INE, Año 2014

$\checkmark$ Según el cuadro $\mathrm{N}^{\circ} 2.13$, se tiene tres grupos de edades los cuales presentan tendencia diferente en la proyección hasta el año 2020 según el número de personas.

$\checkmark$ Existe una brecha muy grande entre las personas de edades de 0-14 años y 15-59 años la cual sigue en constante crecimiento debido principalmente a una baja tasa de Fecundidad lo que genera menos cantidad de niños.

$\checkmark$ Sobre un estudio del comportamiento organizacional de Jhon Hellriegel (2009), se rescata la siguiente cita: "Es importante conocer los cambios demográficos ya que desempeñan un papel muy importante para el marketing, la publicidad y la administración de recursos humanos". 
Gráfico $N^{\circ}$ 2. 13: Proyección de población en Chile por grupos de edad

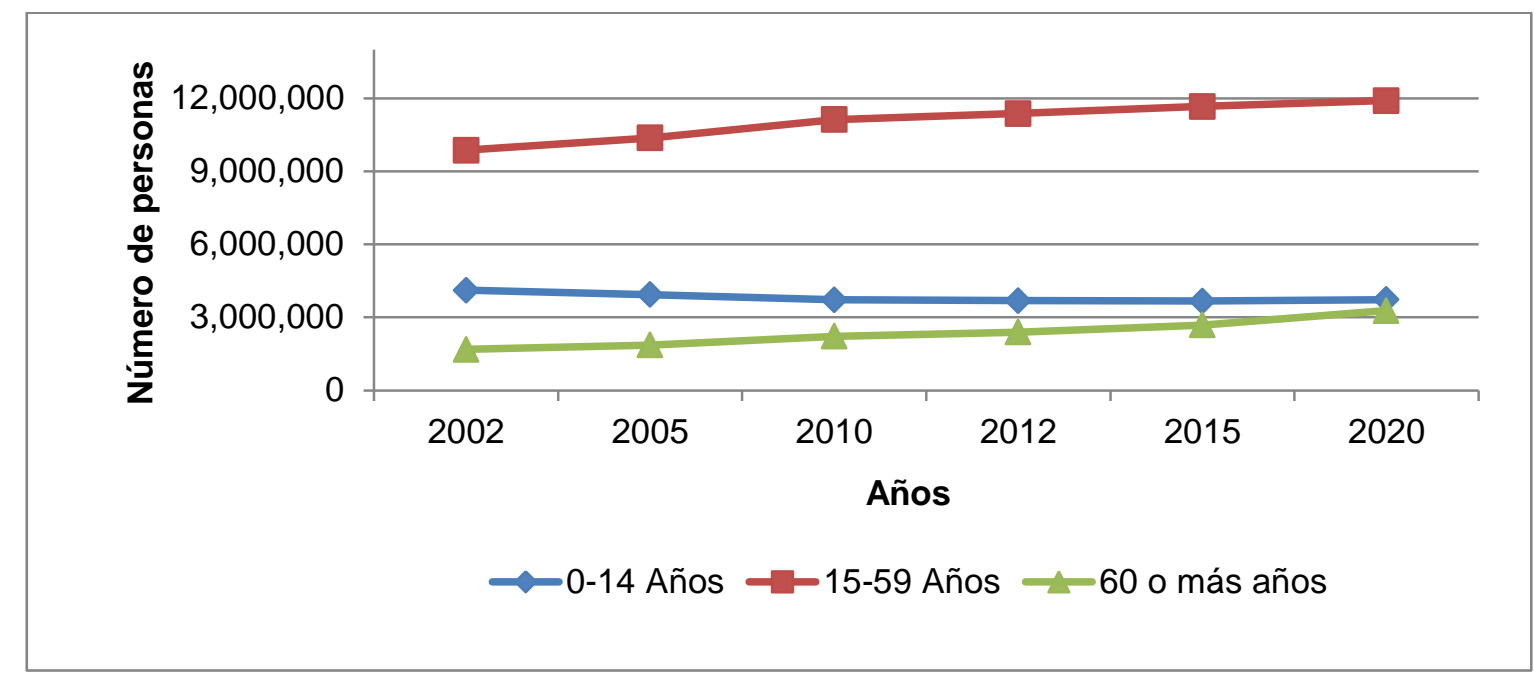

Fuente: INE Chile, Año 2015

$\checkmark$ Por otro lado, existe un "MODELO DE DIMENSIONES DE HOFSTEDE" la cual es explicado con variables a través del Gráfico $\mathrm{N}^{\mathrm{o}}$ 2.14. Estas variables pueden ser aplicable en las empresas de distintos países. Este modelo es interesante pues permite conocer la efectividad de las culturas en las organizaciones. A continuación las seis variables:

-Distancia Poder: Perú y Chile presentan un índice similar; por lo tanto en ambos países la mayoría presentan inconvenientes con una distribución desigual pero toleran diferencias de clases sociales y niveles ocupacionales.

-Individualismo: Se presenta individualismo entre ambos países y uno de las causas puede ser el incremento económico que fomenta el trabajo individual.

-Masculinidad: Es el grado en que la cultura enfatiza valores asociados con estereotipos masculinos (como agresivos y dominancia) o femeninos (Compasión, empatía, emocionalidad, entre otras). Chile presenta una puntuación de 28 y Perú de 42 pues a pesar de tener una diferencia alta en las puntuaciones, ambos países tienden a ser sociedades "femeninas". Tanto chilenos y peruanos presentan 
comportamientos y actitudes modestas, valoran la igualdad y calidad de su vida laboral.

-Aversión a la incertidumbre: Miembros de una cultura se sienten amenazados por situaciones desconocidas. Tanto Chile y Perú presentan una puntuación muy alta de 86 y 87 respectivamente. Por tal motivo, ambas sociedades prefieren reglas y situaciones predecibles, y evitan, por lo tanto, el riesgo y la ambigüedad.

-Orientación a Largo Plazo: Esta dimensión describe el horizonte temporal de una sociedad pues se encuentran sociedades en corto plazo que prefieren métodos tradicionales y las de largo plazo que miran al futuro más que al pasado y presente tratando de lograr objetivos. Ya sea en Perú y Chile (con puntuaciones bajas de 25 y 31 respectivamente), se considera que prefieren las cosas tradicionales y normas establecidas.

-Indulgencia: Trata sobre el grado en que las personas tratan de controlar sus deseos e impulsos. Perú presenta una puntuación de 46 por lo que presenta un poco de ambos ya sea indulgente y restrictivo; por otro lado, Chile presenta una puntuación de 68 por lo que resulta ser más indulgente así que se deja llevar por sus emociones, hace lo que más le gusta hacer y prevalece el optimismo. 
Gráfico No 2. 14: Análisis del modelo de HOFSTEDE entre Perú y Chile, Año 2014

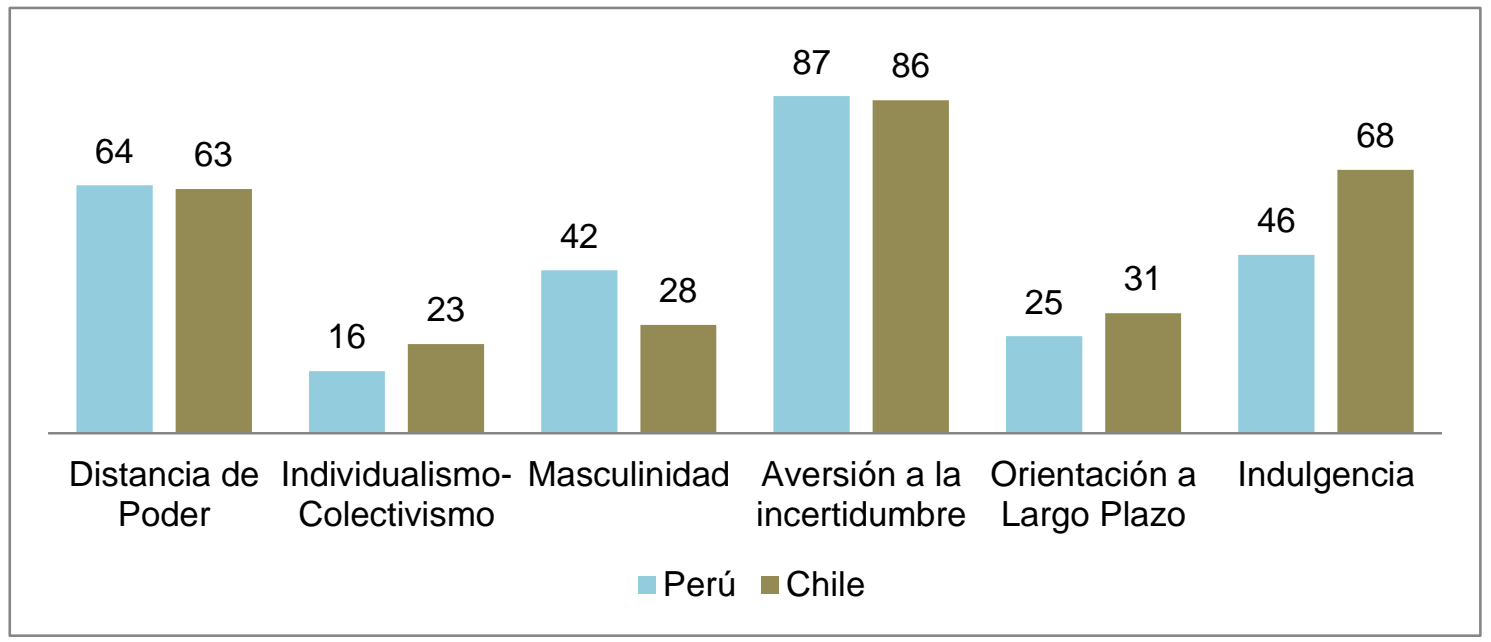

Fuente: GEERT-HOFSTEDE

\section{d) Tecnológico}

$\checkmark$ A continuación, según el Gráfico $\mathrm{N}^{\circ} 2.15$, se presentan los gastos en Investigación y Desarrollo en Chile. Estos gastos podrían permitir obtener cambios tecnológicos que modificarían la ventaja competitiva en un país.

$\checkmark$ Según estudios de la OCDE, El gasto en I+D del año 2013 en Chile fue de 530,292 millones de pesos, equivalente a un 0.39\% del PIB. Se presenta una tendencia creciente; por lo tanto el gobierno chileno está invirtiendo cada año más o brindando financiamiento para investigación.

$\checkmark$ Dentro de las regiones de Chile, las que presentan mayor inversión en I+D son La Región Metropolitana la cual presenta 56.2\% del total (258,769 Millones de pesos) y en segundo lugar está la región de Valparaíso con 11.8\% (54,251 Millones de pesos) en el año 2013; sin embargo las regiones que menos aportaron fueron la región Libertador Bernardo O’Higgins $(0.3 \%)$ y la región Aysén del General Carlos Ibáñez del Campo (0.3\%).

$\checkmark$ Asimismo, los sectores económico donde más se ha invertido fueron las Industrias Manufactureras (21.9\%) y Explotación de minas y canteras $(17.4 \%)$; por otro lado, los sectores de menos inversión 
fueron Los Alojamientos, Servicio de Comida (0.1\%) y Transporte y Almacenamiento (0.3\%).

\section{Gráfico No 2. 15: Gasto en I+D y su relación con el PBI de Chile}

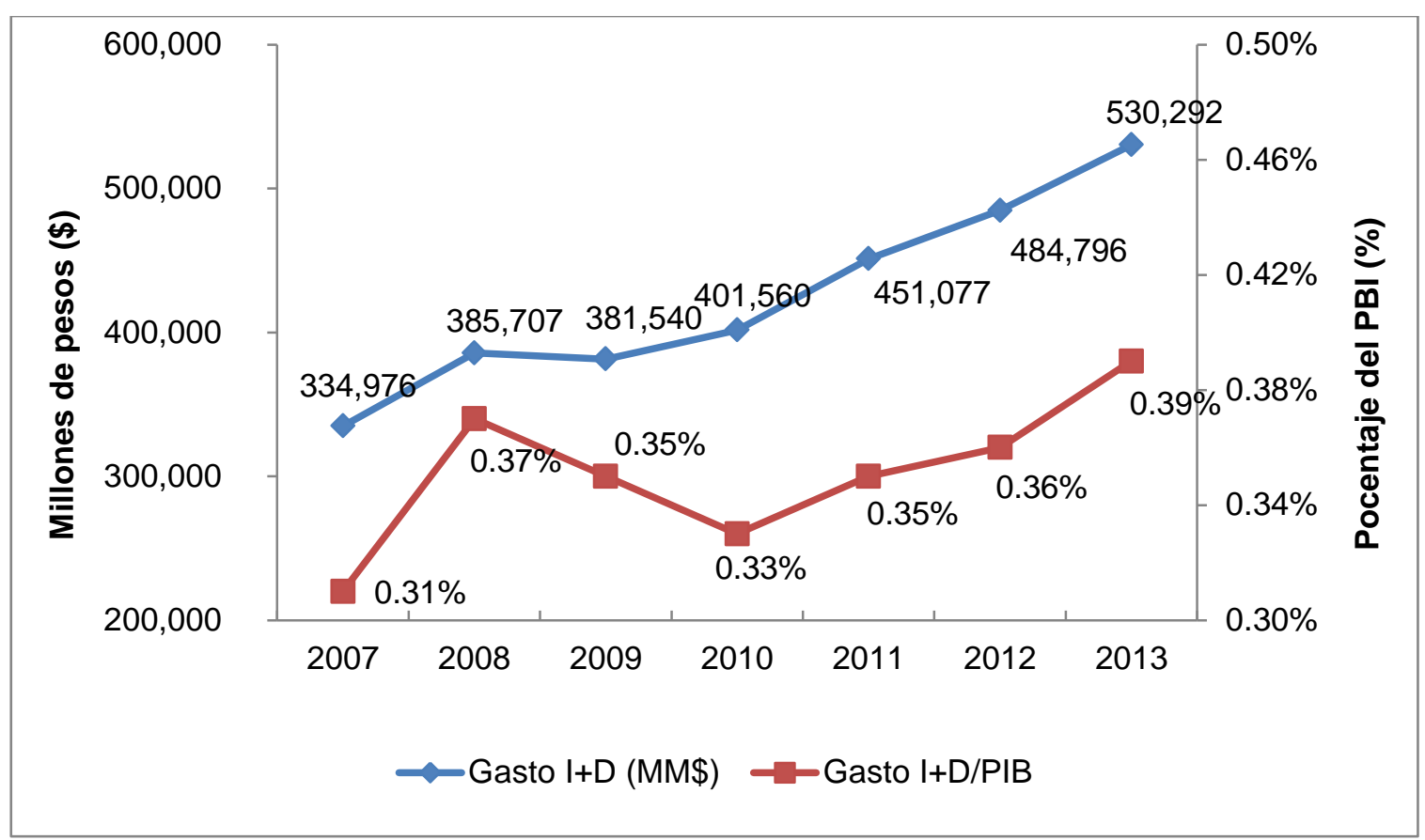

Fuente: OCDE

e) Ecológico

$\checkmark$ Todo Chile está muy involucrado en lo que se refiere al cuidado del medio ambiente pues no es solo prioridad del gobierno sino también de las entidades privadas. Internamente, la Región Metropolitana de Chile ha implementado estrategias de desarrollo económico con sustentabilidad ambiental y el cuidado de la biodiversidad.

$\checkmark$ Por otro lado, en el sector joyería se practican actividades como el reciclaje de la materia prima para poder usar menos plata refinada ${ }^{6}$ la cual de alguna manera impacta en el medio ambiente.

\section{f) Competitivo}

$\checkmark$ Según el $\operatorname{IMD}^{7}$ (2015), Chile se encuentra en el puesto 35 y lo convierte en el país más competitivo de Latinoamérica debido a los

$6 \quad$ Es la etapa final de purificación de productos metálicos y en donde las impurezas son removidas del metal fundido introduciendo aire y fundentes.

INSTITUTE FOR MANAGEMENT DEVELOPMENT. 
estudios realizados sobre la competitividad en los países para el año $2015^{8}$.

$\checkmark$ Gracias a mejores flujos de inversiones extranjeras, finanzas públicas y un mejor mercado laboral a comparación de otros países latinos, Chile se mantiene como una zona atractiva para actividades productivas y de servicio y encabeza la lista de América Latina según la eficiencia gubernamental y desempeño económico.

$\checkmark$ Los factores que abarca son rendimiento económico, eficiencia empresarial, calidad de la infraestructura e innovación. La lista está encabezada por Estados Unidos; mientras que Brasil, Argentina y Venezuela aparecen en los últimos lugares.

\subsection{Diamante Competitivo de Porter:}

El Esquema $\mathrm{N}^{\circ} 2.1$ presenta el "DIAMANTE DE PORTER" la cual es un conjunto de variables que intervienen en la operación de los negocios. Para esto Michael Porter. (1991) expresa lo siguiente:

Los países tienen mayor probabilidad de lograr el éxito en factores donde los determinantes sean más favorables. Sin embargo, esto no quiere decir que todas las empresas de una nación conseguirán ventaja competitiva pues dependerá mucho de cómo usen las técnicas y recursos (P. 225).

$8 \quad$ Para elaborar el listado, la IMD considera 300 criterios estadísticos y encuestas a 6.234 ejecutivos internacionales, además de aspectos como el rendimiento económico, eficiencia empresarial, calidad de la infraestructura e innovación. 
Esquema No 2. 1: Diamante de Porter sobre el sector de joyería en Perú

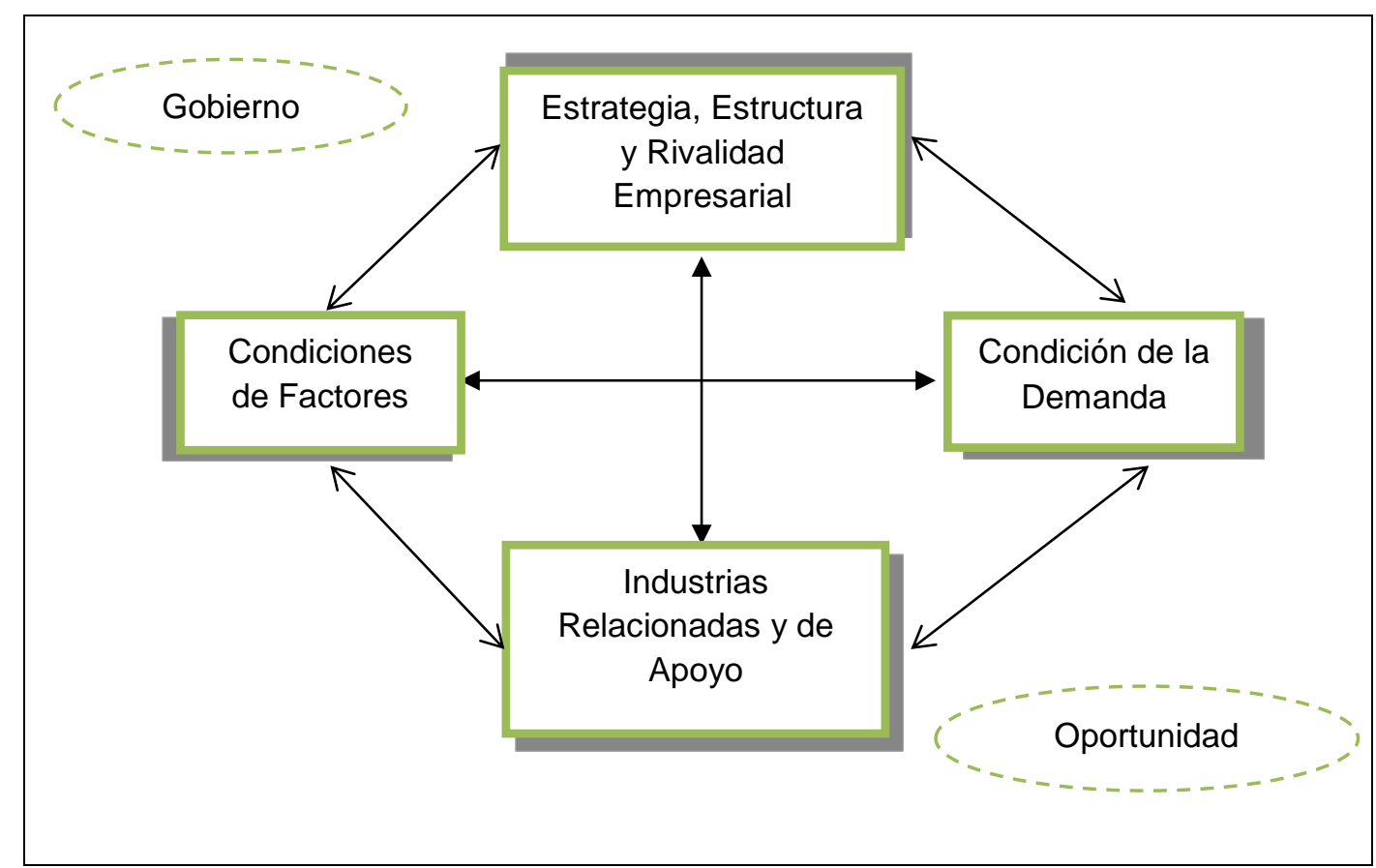

Fuente: La ventaja Competitiva de las Naciones

\subsubsection{Condiciones de Factores:}

$\checkmark$ Perú posee la materia prima necesaria para poder sobresalir en el sector de joyería de plata ya que es el principal productor de Plata la cual se puede obtener con alto grado de pureza - ley 999 después de una refinación. Todo esto crea una ventaja competitiva con respecto a otros países que importan el mineral.

$\checkmark$ Hay profesionales especializados dentro del sector tales como gemólogos que brindan garantía y certifican la calidad de las gemas y piedras preciosas (Por ejemplo, Diamante Perú), artesanos de joyería e ingenieros metalúrgicos.

$\checkmark$ Existen algunas máquinas peruanas que se usan para la producción de joyas; sin embargo, las máquinas extranjeras (Por ejemplo, LEONARDO CAVALLIN y DURSTON) son más eficientes, productivas y sofisticadas. Principalmente, se usan máquinas importadas dentro de las cuales pueden ser laminadora, estampadora, diamantadora, entre otros (Ver Anexo 15). 
$\checkmark$ Existe poca investigación y desarrollo por parte de empresas sobre conocimientos de tendencias de gustos de sus clientes. Principalmente esa información se obtiene de las ferias sobre joyería y misiones comerciales.

$\checkmark$ Asimismo, existe producción de piedras naturales dentro de las cuales en el Perú se produce la Rodocrosita, Pirita, Ónix, Crisocola, Cuarzo, Magnetita, Rodonita, entre otros.

\subsubsection{Condiciones de la demanda:}

$\checkmark$ En Chile, los consumidores de joyería de plata buscan productos de calidad para usarlo como accesorios en el día a día.

$\checkmark$ El mayor porcentaje de producción de joyería en Chile es de Cobre (Por ejemplo la joyería: JOYAS DE COBRE); sin embargo, la producción de joyería de plata no es suficiente para la demanda; por lo tanto, eso lo convierte en uno de los mayores importadores de joyería de plata en Latinoamérica.

\subsubsection{Industrias relacionadas y de apoyo:}

$\checkmark$ La "Procesadora Sudamericana" procesa varios minerales y dentro de estos está la plata la cual se puede obtener garantizando una ley no menor de $99.9 \%$ de pureza.

$\checkmark$ El sector textil complementa al sector joyería pues ambos están dentro de la moda más que todo en las mujeres.

$\checkmark$ Empresas talladoras de piedras naturales con un trabajo de calidad para dar el acabado final a las joyas.

$\checkmark$ Hay ferias y misiones comerciales sobre joyería a nivel internacional los cuales benefician en el conocimiento de las tendencias.

$\checkmark$ Empresas como ADEX (Asociación de Exportadores) y SNI (Sociedad Nacional de Industrias) brindan los servicios de participar en Ferias y Misiones comerciales los cuales son de libre registro previo pago. 


\subsubsection{Estrategia, estructura y rivalidad de la empresa:}

$\checkmark$ Trata de cómo se crean, organizan y gestionan las empresas, así como la rivalidad en el interior del país.

$\checkmark$ Las estrategias y formas de organizar de las empresas peruanas varían de otras empresas extranjeras pues presentan cultura y metas distintas.

$\checkmark$ La mayoría de las joyerías en el Perú son Pymes la cual está administrada por una persona, socios, amigos o por la misma familia. Estas empresas pueden estar operando tanto formal o informalmente, pero actualmente las leyes establecidas por el gobierno quieren reducir la cantidad de estas últimas.

$\checkmark$ Sobresalen algunas joyerías por la gran producción, diseño, colecciones de joyas, organización y exportación. En algunas situaciones el artesano joyero trabaja para la empresa siendo el sueldo por la producción o con un sueldo fijo la cual depende de cada empresa.

$\checkmark$ Asimismo, los modelos de joyas, en su mayoría, son copiados por los mismos artesanos joyeros para lograr vender a tiendas de joyerías, pues esto le genera más beneficios. Por otro lado, hay algunas empresas que tienen sus propios catálogos con diseños propios de la empresa lo cual brinda un diferenciador con la competencia.

$\checkmark$ Existe una rivalidad en el sector pues cada vez son más las joyerías que aumentan en el Perú pero que a veces no logran durar en el mercado por falta de un plan de negocio.

$\checkmark$ Las principales regiones en el Perú que producen altas cantidades de joyas de plata son Lima, Piura, Cajamarca, Junín, Cusco, Arequipa y Lambayeque.

\subsubsection{Oportunidad:}

$\checkmark$ Reducción de impuestos para importaciones de máquinas de joyería podría reducir los precios de estas máquinas en el Perú.

$\checkmark$ Asimismo el inicio de las negociaciones para un TLC bilateral entre Perú y la India podría ser beneficioso para poder ser importados y 
lograr venderlo ya sea por una tienda virtual o un punto de venta en Perú.

\subsubsection{Gobierno:}

$\checkmark$ La política económica ha presentado puntos positivos pues se está buscando cada vez obtener beneficios a través de tratados bilaterales que traten de colocar al Perú como un socio comercial importante.

$\checkmark$ El gobierno liberaliza la economía brindando asesorías y herramientas a las empresas en el comercio exterior.

$\checkmark$ Instituciones como MINCETUR y PROMPERU asesoran a empresas que deseen mejorar temas de negociación internacional.

$\checkmark$ Información para inteligencia de mercados y datos macroeconómicos como son en los casos de SUNAT, BANCO CENTRAL DE RESERVA DEL PERÚ, INEI, entre otros.

\subsection{Hipótesis General}

Dado los recursos nacionales en materia prima e insumos, es factible la creación, dirección y gestión de una empresa productora y comercializadora de joyas de plata 950 y 925 con incrustaciones de piedras naturales a Chile.

\subsection{Hipótesis Específicas}

$\checkmark$ La ciudad de Santiago de Chile es un destino rentable para las exportaciones de joyas debido a su alto poder adquisitivo y de compra.

$\checkmark$ Usar colecciones con nombres MYSTIC para la joyería de ley 950 y ULTRA para la joyería de ley 925 fortalecerá al producto desde el punto de vista de Marketing.

$\checkmark$ Pagar servicio por uso de maquinaria en el proceso de producción servirá para generar menos costos de inversión.

$\checkmark$ Existe una demanda potencial en Chile de joyería de plata con piedras naturales. 


\section{CAPITULO 3: INFORMACIÓN GENERAL DEL PROYECTO}

\subsection{Datos generales de la empresa}

\subsubsection{Nombre}

El nombre de la empresa será "JOYERIA BARI". La palabra BARI proviene de los apellidos del autor y se usa Joyería para que se identifiquen con el tipo de negocio.

\subsubsection{Ubicación}

$\checkmark$ El pago de alquiler más gastos de mantenimiento, luz y agua está US\$ 1,500 mensual.

$\checkmark$ La dirección estará en Jr. Huallaga 123 Of. 602, Cercado de Lima.

$\checkmark$ El local tiene un espacio de $160 \mathrm{~m}^{2}$ el cual permitirá los trabajos administrativos.

\section{Imagen $N^{0}$ 3. 1: Localización de la empresa}

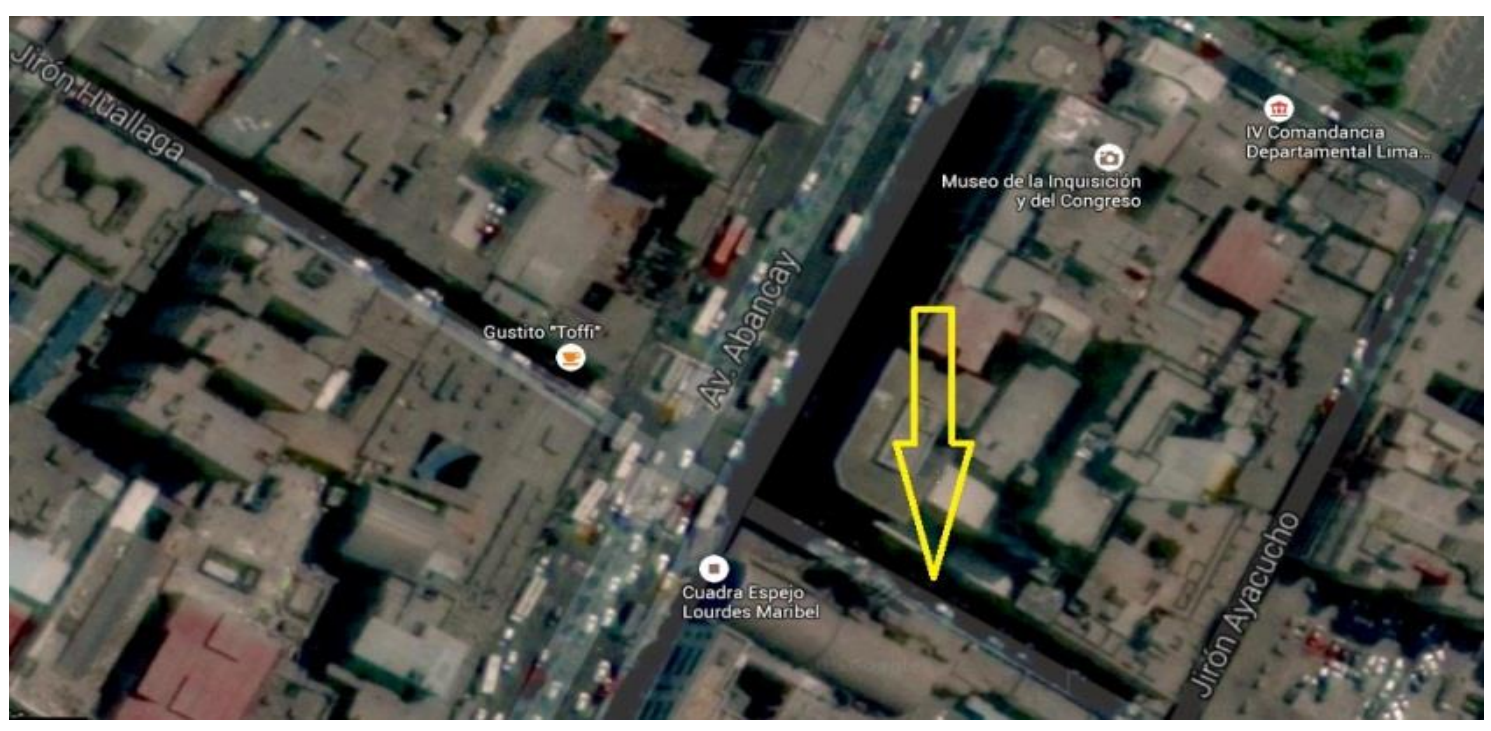

Fuente: GOOGLE MAP (Lugar: Cercado de Lima) 


\subsubsection{Unidad formuladora del proyecto}

El encargado de la formulación y elaboración del proyecto será el Bachiller en Negocios Internacionales Giancarlo Barreto Rimay.

\subsubsection{Unidad ejecutora del proyecto}

El proyecto será ejecutado por el Bachiller Giancarlo Barreto Rimay egresado de la carrera de Negocios Internacionales de la Universidad de Lima.

\subsection{Identificación de la oportunidad de negocio}

$\checkmark$ "La Plata a nivel mundial ha sido destinado para el sector industrial (45\%, 2010), fabricación de joyería y orfebrería $(16 \%, 2010)$ y el restante para inversión en plata $(39 \%, 2010)$; sin embargo, en Perú, menos del 1\% se destina a joyería”, según un informe sobre joyería de ADEX (2014).

$\checkmark$ La joyería se considera una tendencia emergente en Chile, según Silvia Seperack, Consejera Económico Comercial en Santiago de Chile (2012), señala: "Es un producto que ha seguido creciendo a pesar de la crisis internacional".

$\checkmark$ México y Perú comparten la mayor producción de plata a nivel mundial con una participación de $22 \%$ y $14 \%$ respectivamente como se muestra en el Anexo 16.

$\checkmark$ A nivel mundial, América es una región que se ha caracterizado por su consolidación económica y política ante crisis económicas. Un ejemplo es Chile pues presenta uno de los mayores ingresos en la región; por lo tanto, productos que no son básicos, como la joyería, presentan una demanda potencial.

$\checkmark$ En el Gráfico $\mathrm{N}^{\circ} 3.1$, se muestra las tendencias de las variaciones del PBI desde el año 2006 al 2014 de todos los países de Sudamérica.

$\checkmark$ Todos los países presentan una tendencia similar en la variación porcentual del PBI ya que todos han bajado en los años 2009 y 2014. En el 
año 2009 y 2014, al país que más le ha afectado la crisis fue a Paraguay ya que tuvo caídas porcentuales del PBI de $-3.97 \%$ y $-1.24 \%$, respectivamente.

\section{Gráfico N 3. 1: Variación porcentual del PBI de los países de Sudamérica}

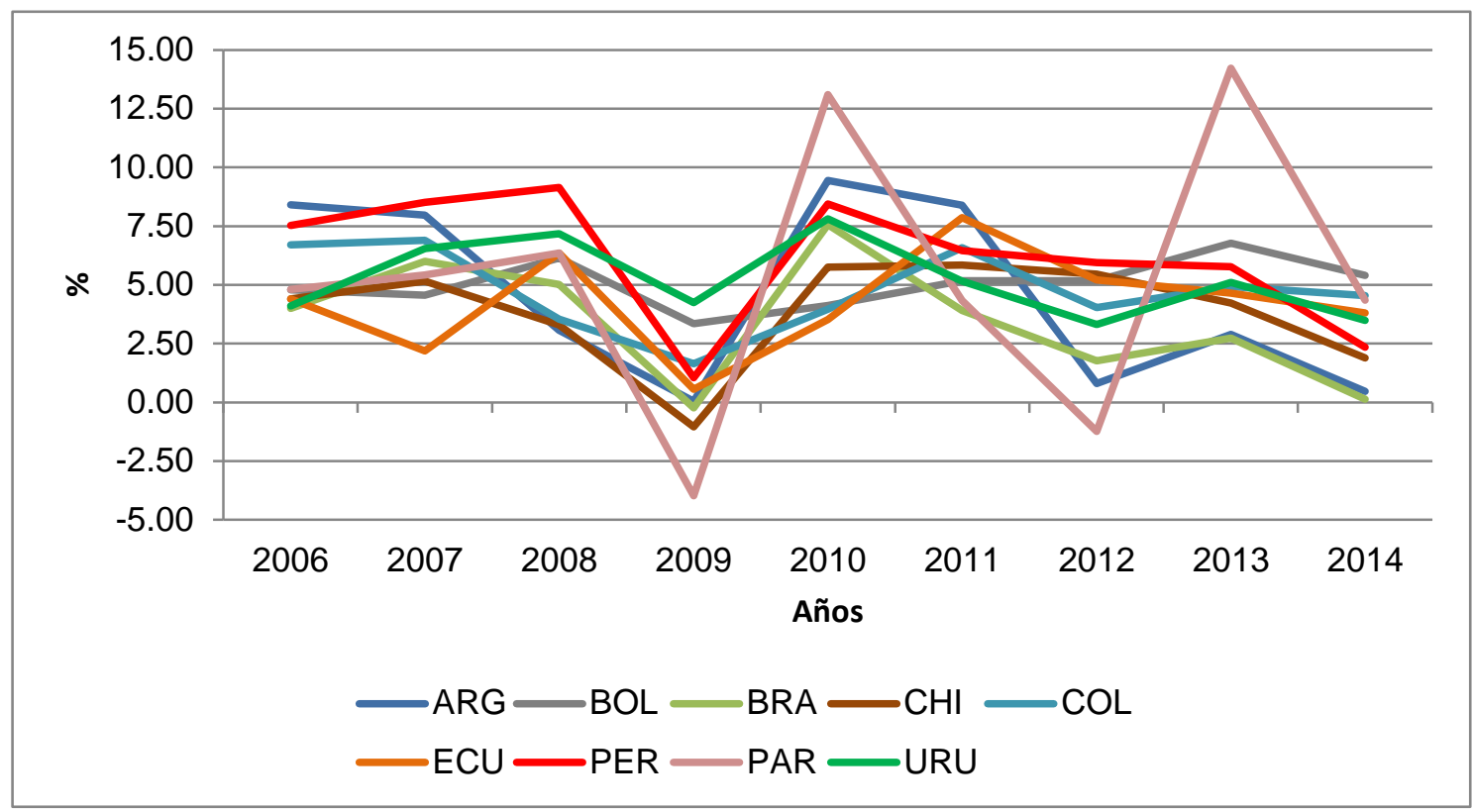

Nota: Las variaciones son anuales.

Fuente: Banco Mundial

$\checkmark$ Según la Imagen $\mathrm{N}^{\circ}$ 3.2, obtenida de EUROMONITOR, existe un crecimiento de consumo de joyería. Asia es el que más crecimiento ha presentado con más de 60\%, África y Oceanía están entre 40-60\%, América entre $20-40 \%$ y Europa entre 0-20\%.

$\checkmark$ América, África, Asia y Oceanía presentan las mejores opciones por su tendencia en el crecimiento de consumo. En Asia, los países de la India y Tailandia tiene una alta producción de joyería y ocupan la mayor parte del mercado pues ambos países tienen producción a gran escala usando tecnología y gran cantidad de mano de obra. En África los ingresos per cápita son bajos y no existen beneficios tributarios hacia dicho continente por lo que no sería rentable a largo plazo la exportación de joyas. En Oceanía tampoco existen beneficios arancelarios para las exportaciones de joyas de plata. Por lo tanto, América es la opción a elegir porque existen beneficios con tratados internacionales, desgravación de arancel, reducción de costos logísticos y culturas similares. 
$\checkmark$ Dentro del sector lujo, la joyería es la que mayor crecimiento tiene superando a los objetos tecnológicos, vinos y licores, viajes y ropa de diseñador. Este crecimiento se ha proyectado hasta el 2017, brindando seguridad y garantía en el proyecto.

\section{Imagen $\mathrm{N}^{0}$ 3. 2: Crecimiento del consumo de joyería}

\section{Luxury Jewellery and Timepieces to Make Up 20\% of Luxury Spend \\ Datagraphic 107 Nov 2012}

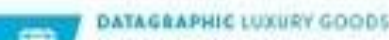

Luxury Jewellery and Timepieces to make up 20\% of Luxury Spend

Asia Pacifie Dietates Hard Laxury Crowth Luxury Jewellery and Timepieces Growth

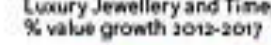

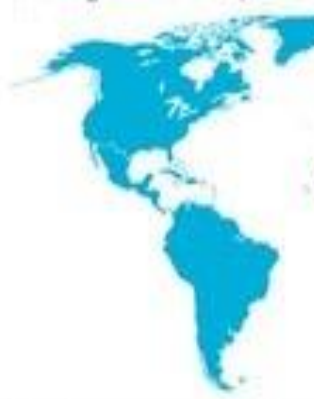

Future Outlook luxury Goods forecast Growth S value grewth jota-den

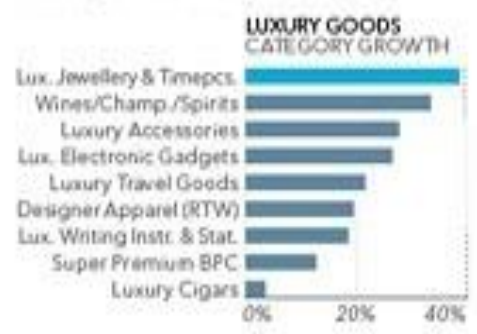

Fuente: EUROMONITOR

$\checkmark$ Chile es uno de los mayores importadores de joyería de plata en Sudamérica, también presenta un riesgo bajo de otorgamiento de créditos al consumidor con respecto a los demás países de la región.

$\checkmark$ Existe demanda insatisfecha debido a que la producción de joyería chilena es más preferida por los turistas, pero no es popular por los mismos consumidores chilenos. La joyería chilena se suele hacer a base de pelo de caballo, cuerno, cerámica, madera, cobre y lápiz lazuli.

$\checkmark$ En el año 2014, Perú recibió más de 3 millones de turistas en total, de los cuales 1.78 millones son chilenos (Ver Anexo 17 para información más detallada). Solo un pequeño porcentaje visita Perú por motivos de negocio, siendo esta una oportunidad de establecer contactos en la feria que se realiza en el Perú, llamada Perú-Moda. 
$\checkmark$ "Solo en el departamento de Lima y Callao se recibió 1.91 millones de turistas provenientes de diferentes partes del mundo, obteniendo un porcentaje del 60\% de los destinos internacionales", según MINCETUR (2015).

$\checkmark$ Según el Banco mundial (2015), en su reporte sobre la facilidad de crear negocios, Chile ocupa el puesto 41 de 189 países, bajando dos posiciones $\left(39^{\circ}\right)$ con respecto al año 2014.

$\checkmark$ Chile, institucionalmente, se encuentra muy consolidado con un gobierno que beneficia el clima de negocio del país pues eso lo ayudó a ser miembro de la OCDE a partir del año 2010. Por otro lado, la corrupción en Chile es percibida como baja gracias a las legislaciones que enfrentan estos temas.

$\checkmark$ Según el diario La Tercera, actualmente los consumidores chilenos están informados, son impulsivos materialistas e impacientes en sus compras logrando tener un promedio de compras muy alto en Latinoamérica. Asimismo, las compras personales por impulso por un reciente estudio de “CHILE 3D” mostró que en el 2013 el 42\% de mujeres y 40\% de hombres admitieron "tener las ganas de comprar algo y no ser capaz de resistir" lo cual favorece a los productos novedosos y llamativos. También declaró que el 14\% de chilenos son compradores impulsivos comparado con otros países que están entre el 5-10\%.

$\checkmark$ Hay festividades como el día del padre, madre, niño, San Valentín, aniversario de bodas, cumpleaños y navidad en los que es costumbre la entrega de regalos siendo una opción la joyería.

$\checkmark$ Según la Corporación Consultora A.T. KEARNEY se afirma:

Chile es como la "Gema oculta" en el crecimiento del E-COMMERCE pues el crecimiento entre los años 2008 al 2012 del valor por compra a través de Internet ha sido mayor al promedio. Este crecimiento tiende a que las empresas informen a los consumidores a través de páginas webs, blogs o redes sociales y será necesario el uso de estas herramientas para crear un efecto positivo en las ventas. En el año 2015, se ha hecho un ranking de los países que más emplean el comercio electrónico el cual es 
liderado por Estados Unidos. Dentro de esta lista se encuentra Chile en el puesto 19, subiendo de posición con respecto al año pasado. En el Anexo 18 se encuentra la lista de los 30 países con los puntajes evaluados.

\subsection{Objetivos del proyecto}

\subsubsection{Objetivos de marketing}

$\checkmark$ Hacer uso de las redes sociales y crear una Página Web ya que Chile tiene altos índices de compra por internet. En estas herramientas se harán publicaciones de las joyas de cada colección con sus precios correspondiente y se mantendrá comunicación ya sea el cliente o el consumidor final.

$\checkmark$ Enviar correos masivos a empresas y personas en Chile a través de la empresa Masivos.cl ya que cuentan con una base de datos que tiene la ciudad por segmentos.

$\checkmark$ Usar la marca de JOLIBARI en todas las joyas producidas por la empresa. Por otro lado, existirán dos colecciones en la producción de joyería, por un lado están las joyas de Ley 950 que llevarán el nombre de “Colección MYSTIC”, por otro lado están las joyas de Ley 925 que llevarán el nombre de "Colección ULTRA".

$\checkmark$ Contratar dos veces al año (Marzo y Octubre) a fotógrafos profesionales para obtener las mejores imágenes posibles de las joyas.

$\checkmark$ Participar en las ferias y misiones comerciales de Perú (PERUMODA, PERUGIFTSHOW) y Chile.

$\checkmark$ Hacer folletos y catálogos de joyería con la marca de JOLIBARI los cuales ayudarán como apoyo de ventas en las ferias y misiones comerciales.

\subsubsection{Objetivos de operaciones}

$\checkmark$ Revisar las joyas hechas por el mismo gerente.

$\checkmark$ Tener todas las joyas inventariadas para un mejor control. 
$\checkmark$ Realizar producciones de joyas de plata ley 950 y 925 los cuales tendrán el sello respectivo de su ley estampada en la parte posterior de la joya.

$\checkmark$ Lograr una diversificación en modelos y diseños de joyas usando piedras naturales producidas nacionalmente.

\subsubsection{Objetivos económicos y financieros}

$\checkmark$ Lograr una recuperación de inversión en el tercer año.

$\checkmark$ Usar eficientemente las herramientas de financiamiento.

$\checkmark$ Esperar un retorno de inversión mayor al $25 \%$.

$\checkmark$ Obtener financiamiento por parte del banco del $30 \%$ del total.

\subsection{Estrategia del proyecto}

$\checkmark$ La diferenciación se transmitirá con la calidad en la producción de acuerdo a las exigencias del cliente.

$\checkmark$ Se trabajará con la ley de pureza 950 y 925 la cual estará a elección del cliente. El uso de ambos permitirá tener una producción más diversificada en cuanto a la calidad del producto.

$\checkmark$ Con la estrategia de diferenciación el cliente percibirá una mejor calidad sumado a su vez de garantía, seguridad y modernidad en los procesos de producción.

$\checkmark$ La estrategia principal se mantendrá durante todo el proyecto, de los cuales se han establecido los siguientes:

-Utilizar materia prima certificada y lograr un producto final capaz de cumplir con requisitos de exportación de mercados exigentes.

- Presentar asesoría personalizada a los clientes y un cumplimiento en el tiempo de entrega de los productos.

- Crear Alianzas con proveedores de materia prima así como los centros de formación tecnológica y talleres de joyería en el Perú.

-Establecer dos colecciones de joyas los cuales representarán las de Ley 950 y 925. 


\subsubsection{Análisis FODA}

$\checkmark$ Esta herramienta permite saber la situación actual para realizar estrategias futuras.

$\checkmark$ En el Cuadro $\mathrm{N}^{\circ} 3.1$, se presenta el FODA de la empresa JOLIBARI y en el Cuadro $\mathrm{N}^{\circ} 3.2$ se proponen estrategias que se implementará en el proyecto.

\section{Cuadro No 3. 1: Análisis FODA}

\section{FORTALEZA}

(F1) Conocimiento sobre el negocio, exportaciones, e-commerce, gestión de negocios globales, ferias internacionales y tendencia en el mercado.

(F2) Estrecha relación y confianza con artesanos altamente calificados, capacitados y con amplia experiencia en el rubro.

(F3) Preferencia arancelaria de joyas de plata al mercado chileno.

(F4) Perú es segundo productor de plata a nivel mundial.

(F5) La depreciación del nuevo sol o apreciación del dólar afecta positivamente en las pequeñas empresas exportadoras.

\section{OPORTUNIDAD}

(O1) Crecimiento de la demanda de joyería y del número de empresas importadoras de Chile.

(O2) Software accesible utilizado para el diseño de joyas.

(O3) Aparecen nuevas máquinas y tecnología en el sector joyería.

\section{DEBILIDAD}

(D1) Altos costos de inversión en materia prima y maquinaria.

(D2) Existe una estacionalidad de ventas.

(D3) Perú no es reconocido por innovar en diseños.

(D4) Dificultad en generar confianza por ser una empresa nueva.

(D5) Falta de imagen y reputación en el mercado.

\section{(A1) Competidores (Italia, México,} India, España, Colombia).

(A2) Facilidad en el sector de joyería de plata en copiar diseño.

(A3) Volatilidad de precio del metal.

(A4) Los artesanos pueden usar chafa como reemplazo de la plata perjudicando al cliente y a la empresa.

(A5) Aumento de tributos e impuestos haciendo menos competitivo a las joyas.

Elaboración: Propia 


\subsubsection{Matriz FODA}

\section{Cuadro No 3. 2: Matriz FODA}

\begin{tabular}{|c|c|c|c|}
\hline & OPORTUNIDAD & AMENAZA \\
\hline & & $\begin{array}{l}\text { (O1) Crecimiento de la } \\
\text { demanda de joyería y del } \\
\text { número de empresas } \\
\text { importadoras de Chile. } \\
\text { (O2) Software accesible } \\
\text { utilizado para el diseño de joyas. } \\
\text { (O3) Aparecen nuevas } \\
\text { máquinas y tecnología en el } \\
\text { sector joyería. }\end{array}$ & $\begin{array}{l}\text { (A1) Competidores (Italia, México, } \\
\text { India, España, Colombia). } \\
\text { (A2) Facilidad en el sector de } \\
\text { joyería de plata en copiar diseño. } \\
\text { (A3) Volatilidad de precio del metal. } \\
\text { (A4) Los artesanos pueden usar } \\
\text { alpaca como reemplazo de la plata } \\
\text { perjudicando al cliente y a la } \\
\text { empresa. } \\
\text { (A5) Aumento de tributos e } \\
\text { impuestos haciendo menos } \\
\text { competitivo a las joyas. }\end{array}$ \\
\hline & $\begin{array}{l}\text { (F1) Conocimiento sobre el } \\
\text { negocio, exportaciones, } \\
\text { commerce, gestión de negocios } \\
\text { globales, ferias internacionales y } \\
\text { tendencia en el mercado. } \\
\text { (F2) Estrecha relación y confianza } \\
\text { con artesanos altamente } \\
\text { calificados, capacitados y con } \\
\text { amplia experiencia en el rubro. } \\
\text { (F3) Preferencia arancelaria de } \\
\text { joyas de plata al mercado chileno. } \\
\text { (F4) Perú es segundo productor de } \\
\text { plata a nivel mundial. } \\
\text { (F5) La depreciación del nuevo sol } \\
\text { o apreciación del dólar afecta } \\
\text { positivamente en las pequeñas } \\
\text { empresas exportadoras. }\end{array}$ & $\begin{array}{l}\text { (F2)(O1): Obtener productos de } \\
\text { calidad, incentivando al } \\
\text { artesano joyero en recibir } \\
\text { mejores pagos por trabajos } \\
\text { complicados de realizar. } \\
(\mathrm{F} 1)(\mathrm{O} 2) \text { : Capacitar al personal } \\
\text { en el proceso de exportación y } \\
\text { producción. } \\
\text { (F3)(O3): Usar máquinas y } \\
\text { tecnología para producir } \\
\text { mayores cantidades. } \\
\text { (F1)(O1): Para los primeros } \\
\text { años el diseño se obtendrá a } \\
\text { través de la información que se } \\
\text { obtiene de las ferias en Lima y } \\
\text { en Chile con empresarios } \\
\text { joyeros que conozcan el } \\
\text { mercado chileno. }\end{array}$ & $\begin{array}{l}\text { (F4)(A3): Realizar compras de más } \\
\text { plata cuando su precio esté bajo. } \\
(\mathrm{F} 2)(\mathrm{A} 4) \text { : Se trabajará con } \\
\text { artesanos garantizados y con alta } \\
\text { confianza en el negocio. } \\
(\mathrm{F} 1)(\mathrm{A} 1) \text { : Mejorar la calidad en } \\
\text { diseño y acabado en el producto } \\
\text { con respecto al de la competencia } \\
\text { en otros países. } \\
(\mathrm{F} 1)(\mathrm{F} 2)(\mathrm{A} 2) \text { : Mostrar los nuevos } \\
\text { modelos a través de catálogos } \\
\text { virtuales a clientes que } \\
\text { frecuentemente importan nuestras } \\
\text { joyas. }\end{array}$ \\
\hline 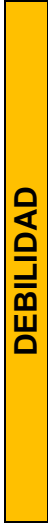 & $\begin{array}{l}\text { (D1) Altos costos de inversión en } \\
\text { materia prima y maquinaria. } \\
\text { (D2) Existe una estacionalidad de } \\
\text { ventas. } \\
\text { (D3) Perú no es reconocido por } \\
\text { innovar en diseños. } \\
\text { (D4) Dificultad en generar confianza } \\
\text { por ser una empresa nueva. } \\
\text { (D5) Falta de imagen y reputación } \\
\text { en el mercado. }\end{array}$ & $\begin{array}{l}\text { (D1)(O1): Uso de financiamiento } \\
\text { para compras de materia prima. } \\
\text { (D2)(D3)(O3)(O2): Elaborar y } \\
\text { sacar diseños todo el año con el } \\
\text { fin de mejorar las ventas en } \\
\text { momentos de poca demanda. } \\
\text { (D5)(O2): Tener una marca y un } \\
\text { logo de la empresa que sea fácil } \\
\text { de recordar para el cliente. } \\
\text { (D2)(O3)(O2): Comprar una } \\
\text { máquina o adquirir una licencia } \\
\text { de algún software sobre diseño } \\
\text { de joyas. }\end{array}$ & $\begin{array}{l}\text { (D4)(D5) }(\mathrm{A} 1)(\mathrm{A} 2) \text { : Posicionar la } \\
\text { marca como una alternativa nueva } \\
\text { con servicio y calidad superiores } \\
\text { con el fin de contrarrestar el precio } \\
\text { de la competencia. } \\
\text { (D1)(A4): Pagar por el uso de la } \\
\text { tecnología a empresas que cuentan } \\
\text { con maquinaria y tecnología acorde } \\
\text { al nivel internacional. }\end{array}$ \\
\hline
\end{tabular}

Elaboración: Propia de joyas.

$9 \quad$ Material con un parecido físico a la plata pura pero de menor valor. 


\section{CAPITULO 4: ESTUDIO DE MERCADO}

\subsection{Análisis de la demanda}

\subsubsection{Definición del producto}

$\checkmark$ Las joyas de plata en Ley ${ }^{10} 950^{11}$ y $925^{12}$ con incrustaciones de piedras naturales y según el tipo de accesorio se producen en:

-Set de joyas (Collar + Arete + Pulsera).

-Anillos - Sortijas

-Pulseras

-Aretes - Colgantes

-Collares

$\checkmark$ Se usará las siguientes piedras naturales mostradas en el Cuadro $\mathrm{N}^{\circ}$ 4.1 las cuales se producen en el Perú y las imágenes de estas se muestran en el Anexo 19.

\section{Cuadro $N^{\circ}$ 4. 1: Piedras Naturales que se usarán}

\begin{tabular}{|c|c|c|}
\hline CUARZO & RODONITA & FLUORITA \\
\hline MAGNETITA & DIOPTASA & HUBNERITA \\
\hline AUGELITA & MOSCOVITAS & FERBERITA \\
\hline RODOCROSITA & MALAQUITAS & AZURITA \\
\hline PIRITA & ENARGITA & GRATONITA \\
\hline ALABANDITA & BOURNONITA & PATRONITA \\
\hline TETRAEDRITA & ESFALERITA & PIRROTITA \\
\hline LEOPARDITA & BROCHANTITA & ATACAMITA \\
\hline TURQUESA & SERPENTINA & OROPIMENTE \\
\hline
\end{tabular}

Fuente: Museo de Minerales

$\checkmark$ Las piedras naturales se pueden describir como un mineral no metálico del cual resalta cuatro propiedades físicas importantes las

\footnotetext{
10 Proporción en peso en la que el metal precioso puro entra en una aleación y debe ser expresado en milésimas

$11 \quad$ Obtenido de $95 \%$ de plata y $5 \%$ de cobre.

12 Obtenido de $92.5 \%$ de plata y $7.5 \%$ de cobre.
} 
cuales son el lustre, dureza, color y densidad, según Edwin Simons (1990, Pg. 189).

$\checkmark$ Estas piedras naturales elegidas no tienen un valor alto en el mercado, más bien se puede conseguir a un buen precio a empresas distribuidoras o a mineras que producen su mismo mineral no metálico. A pesar de no ser de un alto valor, sus características físicas lo respaldan por lo que existe una durabilidad en el producto.

$\checkmark$ Ciertos minerales raros poseen belleza de tal magnitud que puede llegar a alcanzar un precio muy alto. Una gema tiene las características de belleza, durabilidad, rareza y, en cierto modo, estilo.

$\checkmark$ El uso de estos minerales como insumo para la producción de joyas elevaría los costos para la materia prima; sin embargo deja un margen de utilidad más alto por lo que se aplicaría esta estrategia más adelante pues es necesario tener a un proveedor de gemas de garantía y un gemólogo que acredite la originalidad de las piedras. Algunas de las gemas preciosas se listas en el cuadro $\mathrm{N}^{\circ} 4.2$.

\section{Cuadro $N^{0}$ 4. 2: Gemas importantes}

\begin{tabular}{|c|c|}
\hline GEMA & FUENTE MINERAL \\
\hline DIAMANTE & DIAMANTE NATIVO \\
\hline RUBÍ & CORINDON \\
\hline TOPACIO & CORINDON \\
\hline AMATISTA & CORINDON \\
\hline ESMERALDA & BERILO \\
\hline OPALO PRECIOSO & OPALO \\
\hline AGATA & CUARZO \\
\hline ONIX & CUARZO \\
\hline JADE & JADEITA \\
\hline PIEDRA LUNAR & FELDESPATO \\
\hline
\end{tabular}

Nota: El Museo cuenta con todo tipo de minerales pero estos son los más representativos.

Fuente: Museo Andrés del Castillo (Museo de Minerales)

$\checkmark$ Las colecciones de las joyas se llamarán MYSTIC y ULTRA hechas con Plata 950 y 925 respectivamente. 
$\checkmark$ La joyería de plata pertenece a la sub partida 711311 que según Aduanas tiene la siguiente descripción: "Artículos de joyería de plata, incluso revestida o chapada de otro metal precioso (plaqué)" y en relación a los beneficios del proyecto, no existe pagos arancelarios de este producto.

$\checkmark$ La materia prima a usarse será la Plata pura y el cobre electrolítico. Según la Ley de pureza en metales preciosos la composición es la siguiente:

-Plata Ley 950: 95\% de Plata Pura (Ley 999.99 ${ }^{13}$ ) + 5\% de Cobre electrolítico.

-Plata Ley 925: 92.5\% de Plata Pura (Ley 999.99) + 7.5\% de Cobre electrolítico.

$\checkmark$ El punto de fusión de la plata es de $961.8{ }^{\circ} \mathrm{C}$ y el del cobre es de $1085^{\circ} \mathrm{C}$ y en este grado de temperatura los metales pasan de sólido a líquido, pasando a formar un metal combinado.

$\checkmark$ En la joyería de plata, como mínimo, las leyes permitidas para exportación son:

•Primera Ley: 925 milésimas

-Segunda Ley: 800 milésimas

$\checkmark$ Las joyas de plata Ley 950 no está explicada en la "Ley sobre objetos fabricados con metales preciosos", así que se estampará el número de ley correspondiente en cada joya.

$\checkmark$ Las joyas de plata son un producto de lujo y cuyos principales atributos son su diseño y acabado y el $80 \%$ de estas joyas producidas están orientadas al mercado femenino.

\section{$>$ Producto básico}

El producto realza la personalidad y gustos de la persona en los momentos que los use. Se enfoca en la calidad en diseño del producto para complementar atuendos de ropa.

13 La plata se consigue en la Ley 999.99 debido a que es un mineral que ha estado acompañado de otros minerales; por lo tanto no existe la plata Ley 1000. 


\section{$>$ Producto real}

Joyería de plata con Ley 950 y 925 con aplicaciones de piedras naturales las cuales tendrá un certificado avalando la calidad de producción del producto, estando dentro de una bolsa ziploc con cierre hermético y a su vez estarán colocadas en una caja de cartón corrugado.

\section{$>$ Producto aumentado}

La venta de los productos tendrá servicio post venta tales como la información al importador sobre el mantenimiento, limpieza correcta de las joyas y asesoramiento para la importación de joyas de plata a los clientes y evitar las demoras. Asimismo una comunicación directa a través de redes sociales o vía Skype sobre cualquier consulta sobre las joyas.

\subsubsection{Principales características del producto}

a) Usos

$\checkmark$ La joyería principalmente se usa en el cuello, manos y orejas, logrando que sea visible.

$\checkmark$ Asimismo también se puede usar las joyas en la ropa, como por ejemplo los gemelos que se usan en las camisas pues se suele usar dependiendo del gusto del consumidor.

\section{b) Bienes sustitutos y complementarios}

$\checkmark$ Los bienes sustitutos son la joyería en oro o cualquier otro accesorio ya sea hecho a través de telas, cuero o caucho.

$\checkmark$ Existen joyas bañadas en plata y logran ser idénticas a las originales. Estas joyas pueden estar hecho de Alpaca, acero o cobre y presentan precios muy bajos.

$\checkmark$ Asimismo existen joyas de plata pero con una calidad muy baja ya que superan el $20 \%$ de cobre y menos del $80 \%$ de plata pura los cuales perjudican a las joyas de alta calidad. 
$\checkmark$ Dentro de los productos complementarios está la vestimenta que puedan usar las personas pues tanto como el diseño de ropa y de joyería realzan la elegancia de las personas.

\subsubsection{Variables que afectan la demanda}

\section{a) Precio de la materia prima}

$\checkmark$ El precio del producto afecta la demanda ya que es "elástica".

$\checkmark$ El precio internacional se puede obtener de la página de KITCO el cual brinda precios actuales tanto de la Plata como del Cobre.

$\checkmark$ En el Anexo 20 y Anexo 21 se muestran los precios históricos de la plata y del cobre respectivamente.

\section{b) Ingreso per cápita}

$\checkmark$ Esto es una variable que determina la demanda del producto de joyería porque una entrada a crisis reduciría su consumo por ser un producto con alto valor.

$\checkmark$ Para beneficios del proyecto Chile atraviesa una estabilidad económica creciente lo que conlleva a este proyecto elaborar productos de calidad.

\section{c) Gustos y Tendencias}

$\checkmark$ Según un estudio de EUROMONITOR (2014) se afirma: "Las chilenas gustan del accesorio personal y suelen usar perlas en sus aretes los cuales también pueden ser collares y brazaletes ya que son bien populares en los regalos de cumpleaños".

$\checkmark$ Si sucede un cambio en la tendencia y gustos y no se tiene un buen estudio del mercado puede afectar las ventas.

$\checkmark$ Las ferias comerciales es una gran fuente de conocimiento sobre las características del tipo de producto. Entre las ferias más conocidas están Perumoda, Colombiamoda, Feninjer, Inhorgenta, JCK Las Vegas, Iberjoya, entre otras. 
$\checkmark$ Las opiniones de los dueños de joyerías también son buenas referencias y en este caso la opinión de Valeria Laskowitz, dueña y socia de la empresa "Estefan Joyeros" afirma: "El chileno es muy sobrio y no acostumbra lucir y llevar joyas y accesorios demasiado caros, esto porque cree que no tienen mucha vida social y nocturna para salir a mostrar joyas de alta gama”.

\section{d) Infraestructura}

La infraestructura y la tecnología en la producción de joyería son piezas importantes para ser competitivos a nivel internacional. Tener una alta producción con diseños selectivos nos diferenciará de la competencia pues si no presentamos los requisitos como productor de joyería el cliente elegirá otro proveedor.

\section{e) Posicionamiento}

El uso de una marca ayudaría en el posicionamiento del producto en el extranjero. Esta marca se usará en diversas herramientas como páginas webs, redes sociales, folletos, correos promocionales, obsequios, etc.

\subsection{Demanda Futura}

\subsubsection{Demanda histórica}

$\checkmark$ En el Gráfico $\mathrm{N}^{\circ} 4.1$ se presenta las exportaciones de joyas de plata de Perú a Chile en dólares (En el Anexo 22 se encuentran todos los datos).

$\checkmark$ En los últimos seis años, ha existido una variedad en los montos exportados de dólares pues no existe una relación clara año tras año. La tendencia del mercado es muy irregular por lo que se debe tener en cuenta tener capacidad de producción a través de capital de trabajo para las materias primas.

$\checkmark$ Los meses de más baja exportación son Diciembre y Enero para lo cual servirá para poder proyectarse en el año y preparándose para las operaciones de exportación de los siguientes meses. 
Gráfico No 4. 1: Exportación de joyas de plata de Perú a Chile, en US\$ (Dólares Americanos)

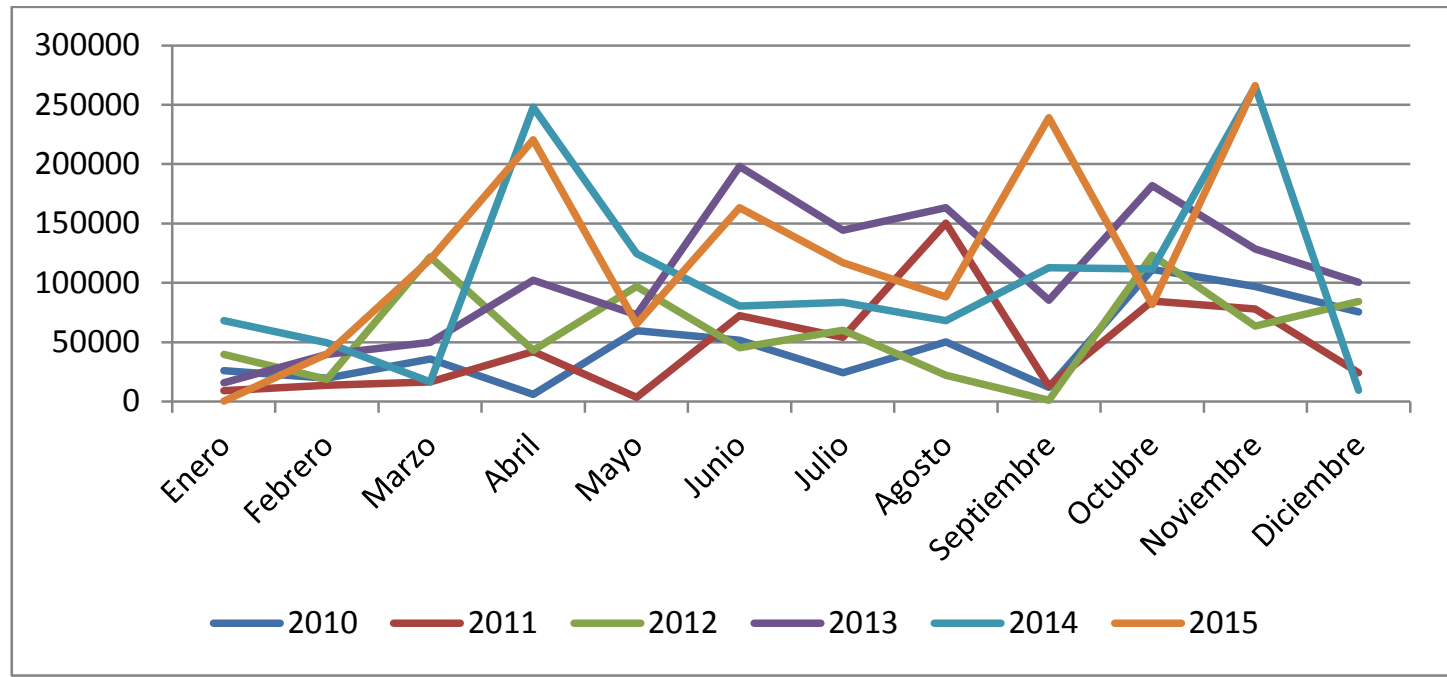

Fuente: PROMPERUSTAT

$\checkmark$ A continuación, en el Gráfico $\mathrm{N}^{\circ} 4.2$ se expresa la exportación de joyas de Perú a Chile en Kilogramos desde el año 2010 al 2015, teniendo el pico más alto en Abril del año 2014 con una cantidad exportada de $503 \mathrm{Kg}$. Los datos se pueden visualizar en el Anexo 23.

$\checkmark$ En la cantidad de joyas exportadas también se presenta una irregularidad, presentando los picos más altos en Abril y Noviembre y los picos más bajos en Enero y Diciembre.

\section{Gráfico $N^{\circ}$ 4. 2: Exportación de joyas de Perú a Chile, en Kilogramos}

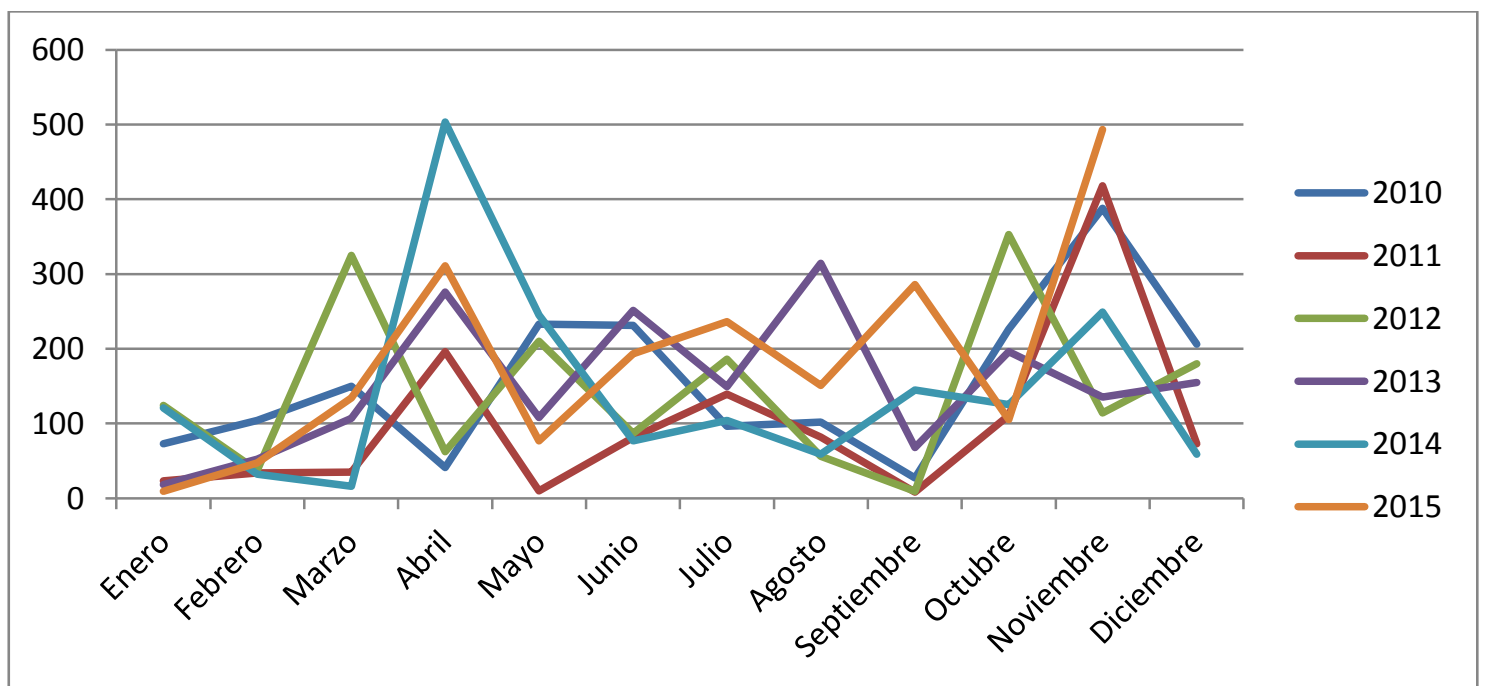

Fuente: PROMPERUSTAT 
$\checkmark$ En el Gráfico $\mathrm{N}^{\circ} 4.3$ se muestra el precio de venta de joyería de plata en dólares americanos por cada kilogramo que se exporta de Perú a Chile.

$\checkmark$ Los precios que paga Chile aumentan anualmente y eso alienta a las exportaciones hacia dicho país.

\section{Gráfico No 4. 3: Exportación de joyas de Perú a Chile, en US\$ por Kilogramo}

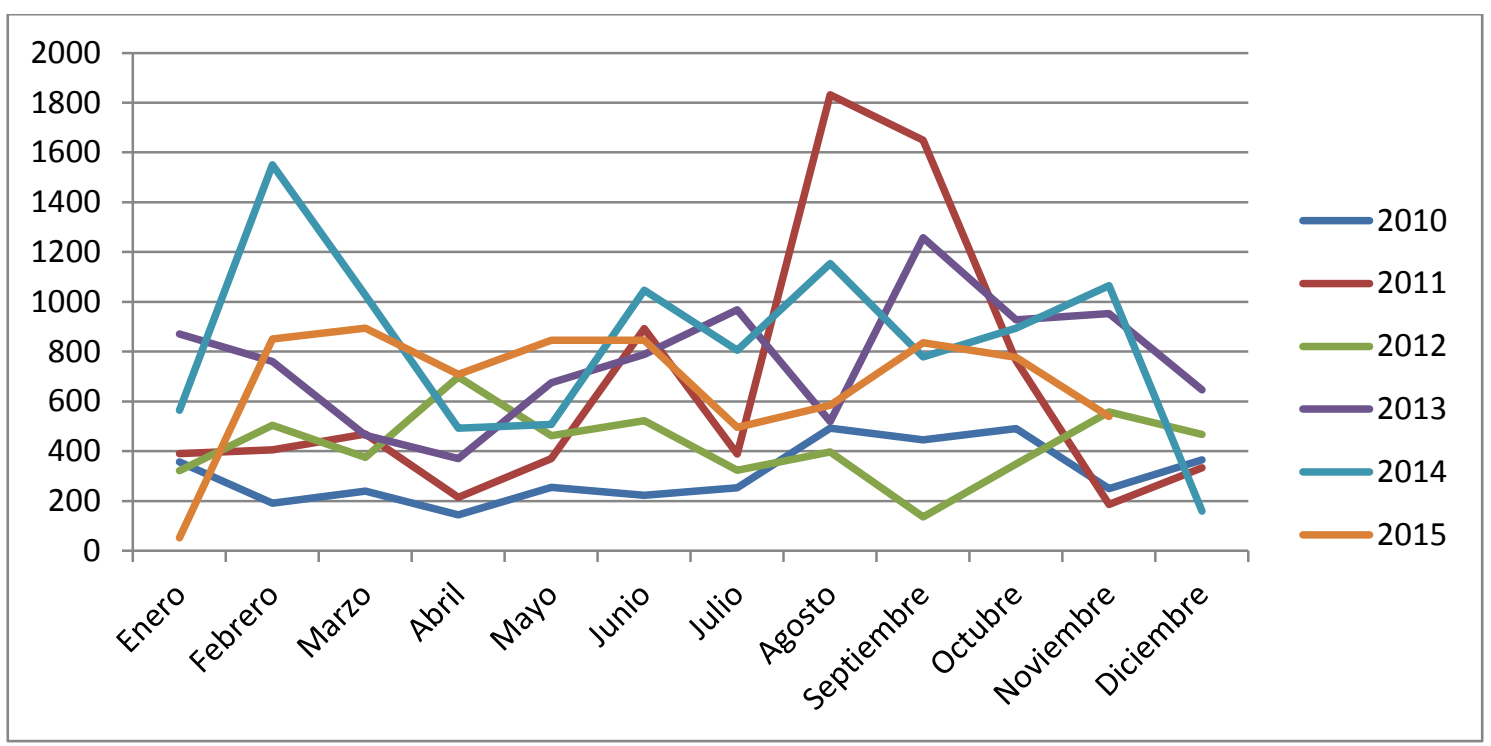

Fuente: TRADEMAP

\subsubsection{Demanda Potencial}

$\checkmark$ Se ha elaborado un gráfico a partir de un programa estadístico MINITAB en el cual se presenta la proyección de la demanda para los próximos cinco años.

$\checkmark$ Se presenta el Gráfico $N^{\circ} 4.4$ que tiene la proyección de las exportaciones mensuales de joyas de plata en Kilogramos para los próximos cinco años de Perú hacia Chile. Estos datos se encuentran en el Anexo 24. 
Gráfico $N^{\circ}$ 4. 4: Proyección de exportación de joyas de Perú a Chile hasta el año 2020, en Kilogramo

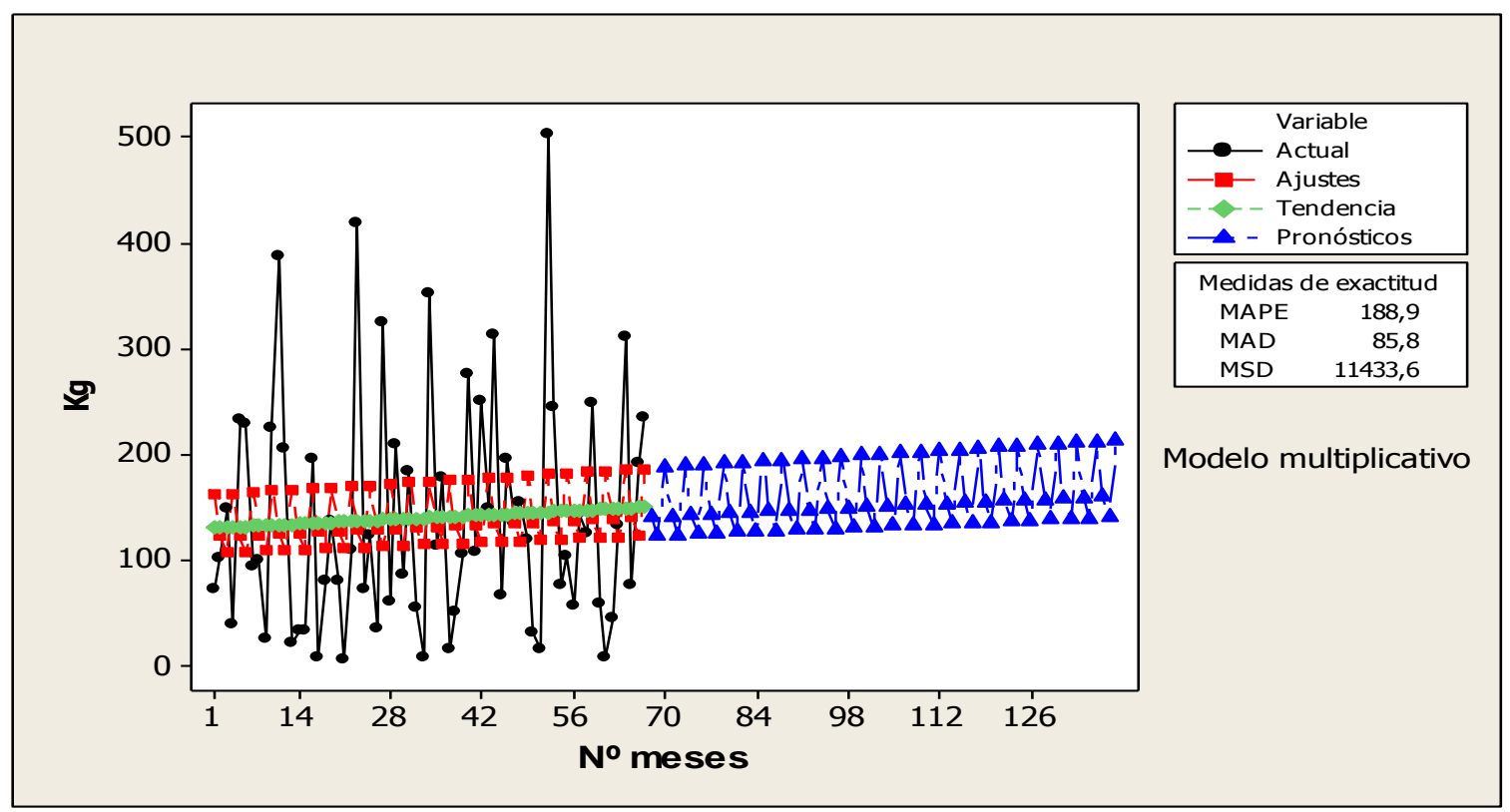

Fuente: PROMPERUSTAT

$\checkmark$ En el Gráfico $N^{o} 4.5$ se muestra la proyección de la importación mundial de joyería de plata de Chile cuyos datos analizados se encuentran en el Anexo 25.

$\checkmark$ La importación total de joyería de Chile tiene una proyección mucho más elevada que la importación desde Perú.

$\checkmark$ La diferencia de ambas tendencias se debe a que la joyería de plata en Perú no se produce en altas cantidades y también por la falta en diseño e innovación. 
Gráfico $\mathbf{N}^{\circ}$ 4. 5: Proyección de importación de joyas de plata en Chile a nivel mundial, en Kilogramo

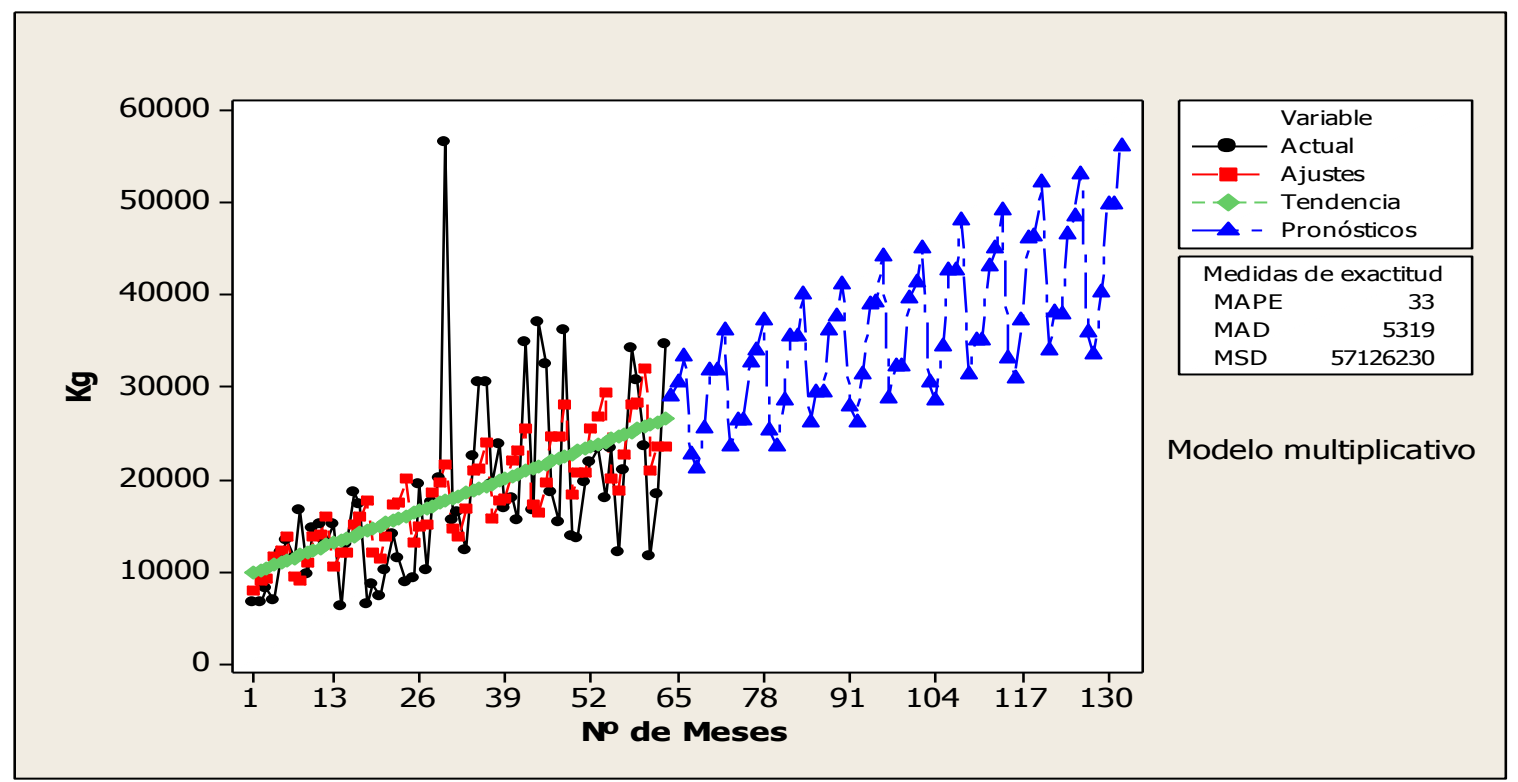

Fuente: TRADEMAP

$\checkmark$ En el Cuadro $\mathrm{N}^{\circ} 4.3$, están las proyecciones en kilogramos de lo que Chile importa en joyas de Perú y del Mundo para los próximos cinco años del proyecto.

$\checkmark$ Según las proyecciones presentadas, en el año 2016 Perú exportará a Chile $1,851 \mathrm{Kg}$ y para el año 2020 se proyecta $2,024 \mathrm{Kg}$.

$\checkmark$ Asimismo, la proyección de las importaciones totales de joyería de plata de Chile en el año 2016 es de 367,952 Kg y para el año 2020 es de $522,325 \mathrm{Kg}$.

Cuadro No 4. 3: Proyección de exportación de joyas de plata de Perú a Chile

\begin{tabular}{|c|c|c|c|}
\hline AÑO & Kg - Mundial & Kg - Perú & \% Part. \\
\hline $\mathbf{2 0 1 6}$ & 367,952 & 1,851 & $0.5 \%$ \\
\hline $\mathbf{2 0 1 7}$ & 406,546 & 1,893 & $0.5 \%$ \\
\hline $\mathbf{2 0 1 8}$ & 445,139 & 1,936 & $0.4 \%$ \\
\hline $\mathbf{2 0 1 9}$ & 483,732 & 1,979 & $0.4 \%$ \\
\hline $\mathbf{2 0 2 0}$ & 522,325 & 2,024 & $0.4 \%$ \\
\hline
\end{tabular}

Elaboración: Propia

$\checkmark$ La calidad y estilo de vida de los ciudadanos en Chile ha mejorado en la última década. Asimismo, este país se ubica cerca del promedio de satisfacción según The Organisation for Economic Co-operation and 
Development (OECD). Sin embargo, está por debajo del promedio en salud, empleo, remuneración, balance vida-trabajo, educación y calidad medioambiental.

$\checkmark$ La demanda potencial sería toda la Región Metropolitana de Santiago, Chile. Esta región cuenta con 7,3 millones de habitantes de los cuales se tomará en cuenta a personas entre las edades de 18 a 60 años de edad.

$\checkmark$ De acuerdo a un estudio de Euromonitor, el tamaño total de mercado de joyería en Chile ha ido aumentando tal cual se muestra en el Gráfico N4.6. Para el año 2014 hubo un consumo de 148.8 millones de dólares y se espera que aumente.

$\checkmark$ A consecuencia de ello, joyerías famosas conocidas internacionalmente como en el caso de la Joyería Americana Tiffany \& Co que ha inaugurado una tienda en Santiago de Chile en Setiembre del 2015. Este es el tercer país donde establece un local después de México y Brasil.

\section{Gráfico $N^{0}$ 4. 6: Consumo de joyas en Chile}

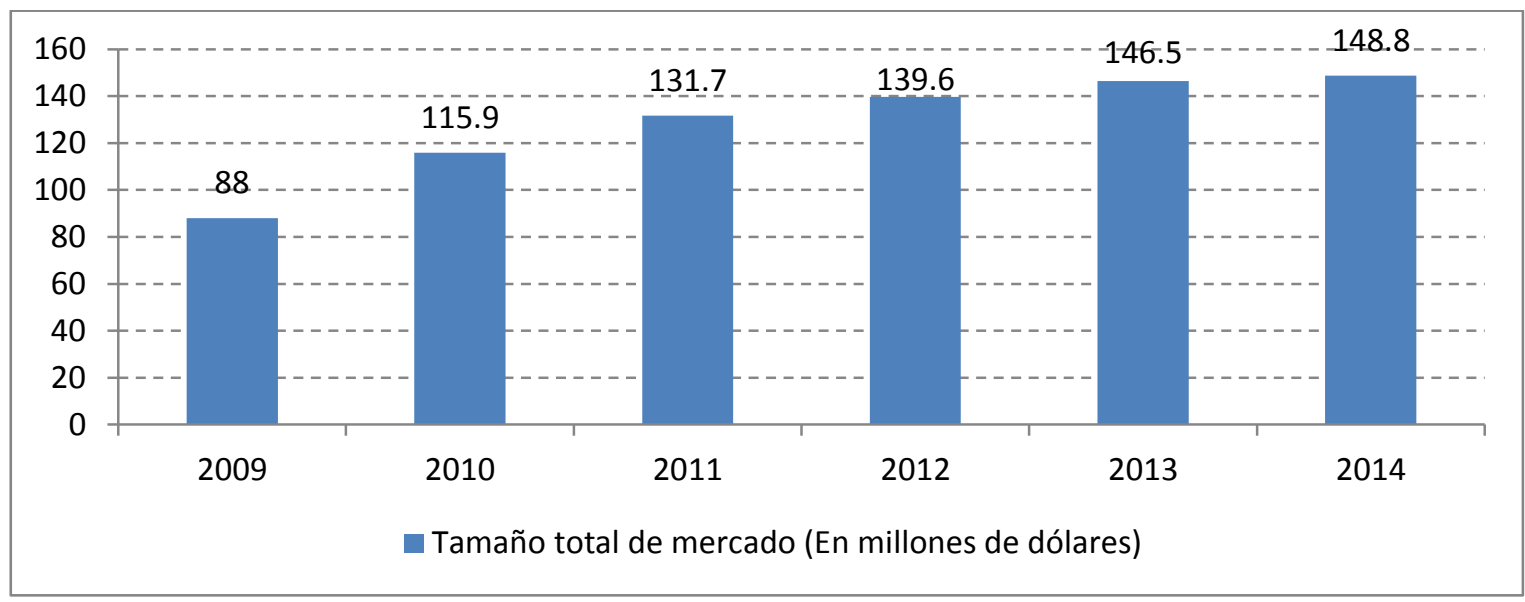

Fuente: EUROMONITOR

\subsubsection{Demanda Objetivo}

$\checkmark$ La demanda objetivo está constituido por personas de 18 a 60 años pertenecientes al nivel socio económico medio y alto, debido a que la joyería de plata es un producto que está al alcance de personas con 
poder adquisitivo medio con respecto a los compradores de joyería en oro.

$\checkmark$ La joyería estará hecha para la mujer y el hombre quienes pueden comprarse por ellos mismos o recibir como regalo de alguien más.

$\checkmark$ El producto se empezará a vender en la Región Metropolitana de Santiago que cuenta con una cantidad de más de 7 millones de personas según INE de Chile. (2015).

$\checkmark$ Dentro de la Región están las provincias:

-Santiago (5,287,875 habitantes)

-Cordillera $(718,667)$

-Chacabuco $(309,772)$

-Maipo $(545,746)$

-Melipilla $(265,789)$

-Talagante $(368,074)$

$\checkmark$ Como se puede apreciar en la previa lista, la provincia de Santiago es la indicada dado que cuenta con un número de habitantes más amplio y visitado por extranjeros.

$\checkmark$ Según Índice de Calidad de Vida Urbana (ICVU) las mejores comunas que tienen una mejor calidad de vida son los que a su vez presentan más personas de clase media y alta. Las principales comunas de la provincia de Santiago son:

-Ñuñoa (205,859 habitantes)

-Las Condes $(292,896)$

- Vitacura $(95,968)$

-Providencia $(130,985)$

-Lo Barnechea $(107,895)$

-La Reina $(101,347)$

$\checkmark$ Las comunas anteriormente mencionadas presentan un alto porcentaje de habitantes de clase media y alta quienes están dispuestos y en condiciones de adquirir joyas, ya sean de elevado valor o de precios más cómodos. 
$\checkmark$ En la imagen $\mathrm{N}^{\circ} 4.1$ se presenta las zonas de nivel socioeconómico A, B, C1 en la región metropolitana entre los años 2002 y 2013. Existe un aumento de estos grupos en la comuna de Lo Barnechea, Vitacura, Peñalolén y La Florida.

\section{Imagen $N^{\circ}$ 4. 1: Concentración del Nivel Socioeconómico A, B, C1 entre los años}

\section{2 y 2013}
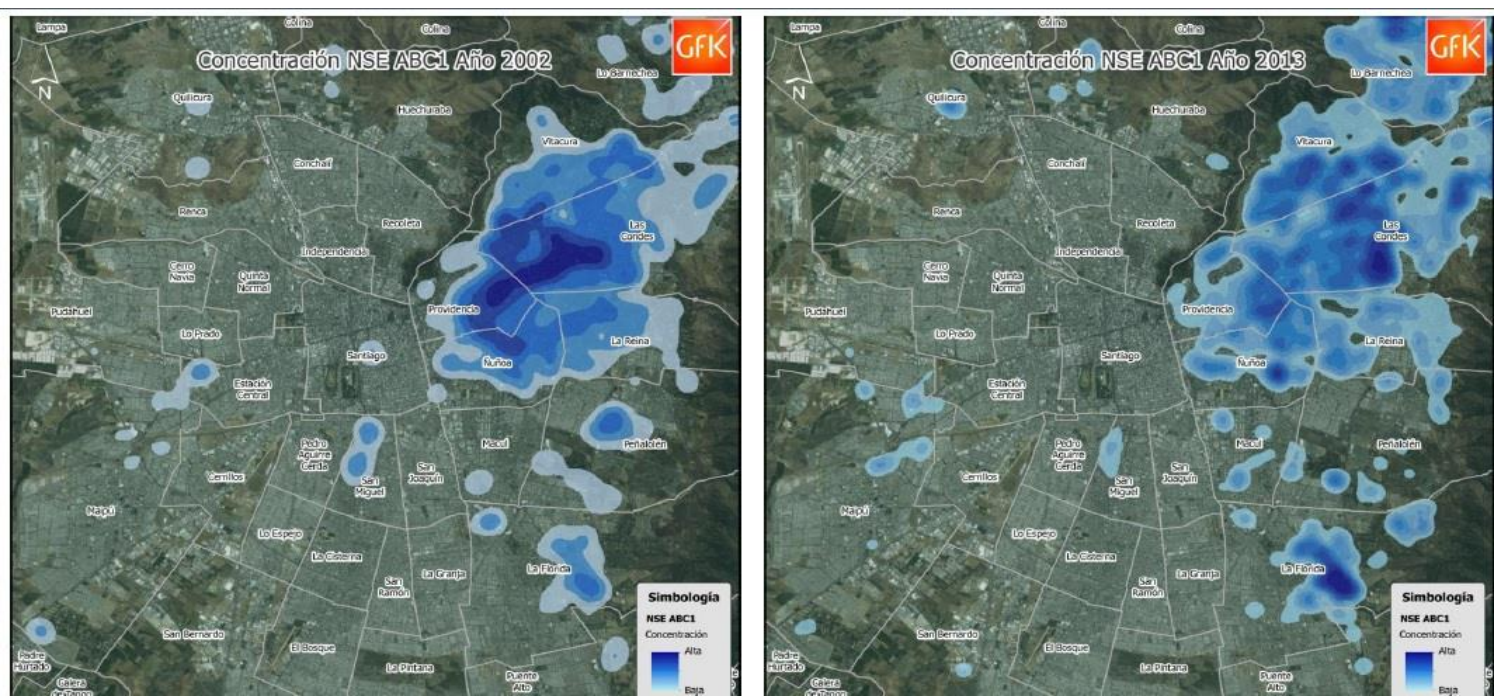

Fuente: CHILE 3D

$\checkmark$ En la Imagen $\mathrm{N}^{\circ} 4.2$ se aprecia que la clase alta y media representa el $16 \%$ de la población nacional en Chile de acuerdo al informe que realizó la asociación de Investigación de Mercados. En el ingreso del nivel socioeconómico A los ingresos superan los \$ 8,664,000.00 (Pesos Chilenos) por hogar, siendo el más alto del país con participación de $0.3 \%$ del total. La clase media ha aumentado con respecto a la de hace treinta años y eso alienta las inversiones extranjeras y las exportaciones a Chile. 
Imagen $N^{\circ}$ 4. 2: Segmentación Socioeconómica en Chile, año 2015

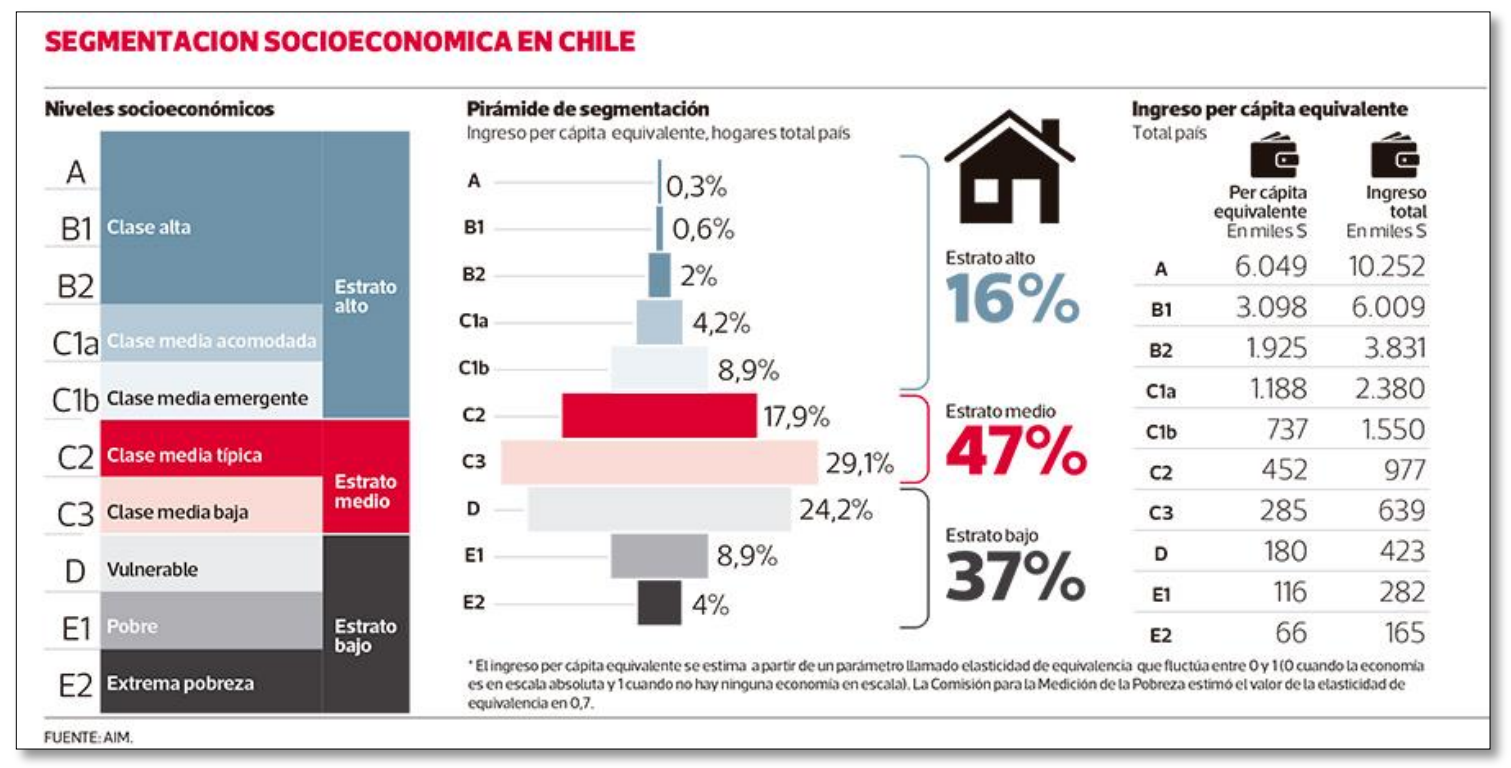

Fuente: AIM

$\checkmark$ El total de habitantes de las comunas seleccionadas es 935,498 personas de los cuales el 70\% (654,848 habitantes) de personas pertenecen a las edades entre 18 y 60 años de edad y de este grupo el $80 \%(523,878$ habitantes $)$ pertenece a la clase media y alta.

-Total de personas: 935,498

-Edades 18-60 Años: 654,848

-Clase media alta: 523,878

$\checkmark$ En el Cuadro $\mathrm{N}^{\circ} 4.4$, se presenta la proyección de exportación de joyería de plata de la empresa JOLIBARI en los cinco años del proyecto.

$\checkmark$ Para el presente proyecto se empezará con el $8 \%$ de participación y se justificará bajo las siguientes afirmaciones:

-El capital que se invertirá más el préstamo bancario permitirán cubrir el capital del trabajo para los tres primeros meses y las inversiones para el inicio del proyecto.

-Se enfocará en personas de 18 a 60 años.

-Se trabajará mediante un contrato tanto con el taller de joyería como con el cliente. Con el taller de joyería se busca el cumplimiento a 
tiempo de los trabajos y con el cliente se tomará importancia en que el precio del producto no disminuirá según lo pactado en la política de precios del proyecto.

-Se enfocará en el área comercial y marketing para lograr mejores resultados en las ventas.

\section{Cuadro $N^{\circ}$ 4. 4: Proyección de la demanda}

\begin{tabular}{|c|c|c|c|}
\hline Año & Peso Kg & \% Participación & Demanda Objetivo (Kg) \\
\hline 2016 & 1850,50 & $8 \%$ & 148 \\
\hline 2017 & 1893,20 & $10 \%$ & 190 \\
\hline 2018 & 1935,90 & $13 \%$ & 252 \\
\hline 2019 & 1978,60 & $15 \%$ & 297 \\
\hline 2020 & 2021,30 & $20 \%$ & 404 \\
\hline
\end{tabular}

Elaboración: propia

\subsection{Análisis de la competencia}

\subsubsection{Análisis de la competencia local}

$\checkmark$ Perú ha sido conocido en el sector de joyería debido a que plasmaba su historia a través de grandes diseños incaicos. Sin embargo, con el pasar de los años, el estilo ha variado y diversificado para distintos tipos de consumidores pues ingresaron varios competidores con productos cada vez más innovadores y modernos.

$\checkmark$ Las empresas peruanas no usan mucho el e-commerce pues no son amigables con el consumidor peruano; sin embargo, es algo que internacionalmente sí tiene mucha participación. Existen algunas empresas dentro del rubro de joyería que poseen una página bien diseñada por ejemplo "RIVIALLDI JOYERÍA", "JOYERÍA ALDO", “JOYERÍA ILARIA”, “ZOARA”, entre otros.

$\checkmark$ En el Cuadro $\mathrm{N}^{\circ} 4.5$ se muestra la participación de las empresas de Perú que exportan joyería de plata, dentro el cual, ARINSA es la empresa con mayor exportación de joyería de plata al mundo con una participación del 40\% del total en el año 2014. Por otro lado, la empresa GROUP V\&L SAC es la que mayor crecimiento ha tenido con $384 \%$ anual con respecto al año anterior logrando estar dentro de las diez principales empresas exportadoras en Perú. 
$\checkmark$ Tres empresas ocupan el $74 \%$ del total de exportaciones: ARINSA, DESIGN QUALITY EXPORT SAC y NEW FASHION PERU SA.

Cuadro $N^{\circ}$ 4. 5: Principales empresas peruanas que exportan joyas de plata

\begin{tabular}{|c|c|c|}
\hline Empresa & \% Variación 13-14 & $\%$ Part. \\
\hline DESIGN QUALITY & $-25 \%$ & 0.40 \\
\hline NEW FASHION & $46 \%$ & 0.24 \\
\hline IDEAS APLICADAS & $18 \%$ & 0.10 \\
\hline ALLPA & $13 \%$ & 0.06 \\
\hline NOVICA & $23 \%$ & 0.04 \\
\hline DEORO & $16 \%$ & 0.04 \\
\hline GROUPVYL & $59 \%$ & 0.03 \\
\hline NOVARA & $384 \%$ & 0.01 \\
\hline RESTO (34) & $-55 \%$ & 0.01 \\
\hline DESIGN QUALITY & -- & 0.04 \\
\hline
\end{tabular}

Fuente: SIICEX, Año 2014

$\checkmark$ En el cuadro $N^{\circ} 4.6$ se muestra las principales empresas peruanas que exportaron joyería de plata en el año 2014. NEW FASHION PERU SA ha sido la empresa que más ha exportado a Chile en los últimos años con una participación del $60 \%$ en el año 2014 con un valor de exportación de US\$717,560.

$\checkmark$ IDEAS APLICADAS SA exporta a Chile debido a que tiene otra empresa instalada en ese país; por lo tanto, la mayoría de las exportaciones van dirigidas a su misma empresa en Chile mientras que un porcentaje mínimo irá a otros clientes.

$\checkmark$ Sin embargo, ambas empresas trabajan con la Ley 925; por lo que el presente trabajo de investigación buscará una diversificación a través del uso de la plata 925 y 950 en sus productos. 
Cuadro $N^{\circ}$ 4. 6: Empresas peruanas que exportan joyas de plata a Chile

\begin{tabular}{|c|c|c|}
\hline Empresas & Suma de FOB US\$ & $\%$ Part. \\
\hline ALAGON GIRALDO PATRICIA VERONICA & 78,857 & $7 \%$ \\
\hline ALAGON GIRALDO SONIA AMPARO & 111,916 & $\mathbf{9} \%$ \\
\hline ART ATLAS SRL & 233 & $0.1 \%$ \\
\hline IDEAS APLICADAS SA & 280,446 & $23 \%$ \\
\hline NEW FASHION PERU SA & 717,560 & $60 \%$ \\
\hline YOBEL SCM COSTUME JEWELRY SA & 6,986 & $\mathbf{1} \%$ \\
\hline Total general & $\mathbf{1 , 1 9 5 , 9 9 8}$ & $\mathbf{1 0 0 \%}$ \\
\hline
\end{tabular}

Fuente: DATATRADE, Año 2014

\subsubsection{Análisis de proveedores}

$\checkmark$ En Lima existen varias personas que trabajan como artesanos de joyería los cuales trabajan para un taller. El pago que recibe el artesano es por cantidad en $\mathrm{Kg}$ de joyas trabajadas usando la Plata y la piedra natural.

$\checkmark$ La empresa abastecedora de Plata Pura será la "PROCESADORA SUDAMERICANA TRADING S.A." la cual trabaja con el precio cotizado internacionalmente. Para obtener la materia prima, es necesario estar asociado a dicha institución y la entrega es en la misma sede ubicada en Ate.

$\checkmark$ Por otro lado, se puede conseguir la Plata a través de joyerías o tiendas especializadas los cuales venden el material a precio internacional con un aumento o reducción en el precio; sin embargo la mayoría no cuenta con una alta oferta. 
Imagen No 4. 3: Página Web de la Procesadora Sudamericana



Fuente: PSA

$\checkmark$ Las piedras semipreciosas se comprará de "ARTURINSA" localizado en el distrito de San Juan de Lurigancho. Esta empresa tiene gran capacidad de inventario para poder abastecer a varias empresas lo cual beneficia al proyecto. El precio de las piedras naturales presentan una leve variación según el tipo y naturaleza.

Imagen $N^{\circ}$ 4. 4: Tarjeta de presentación del proveedor de piedras naturales

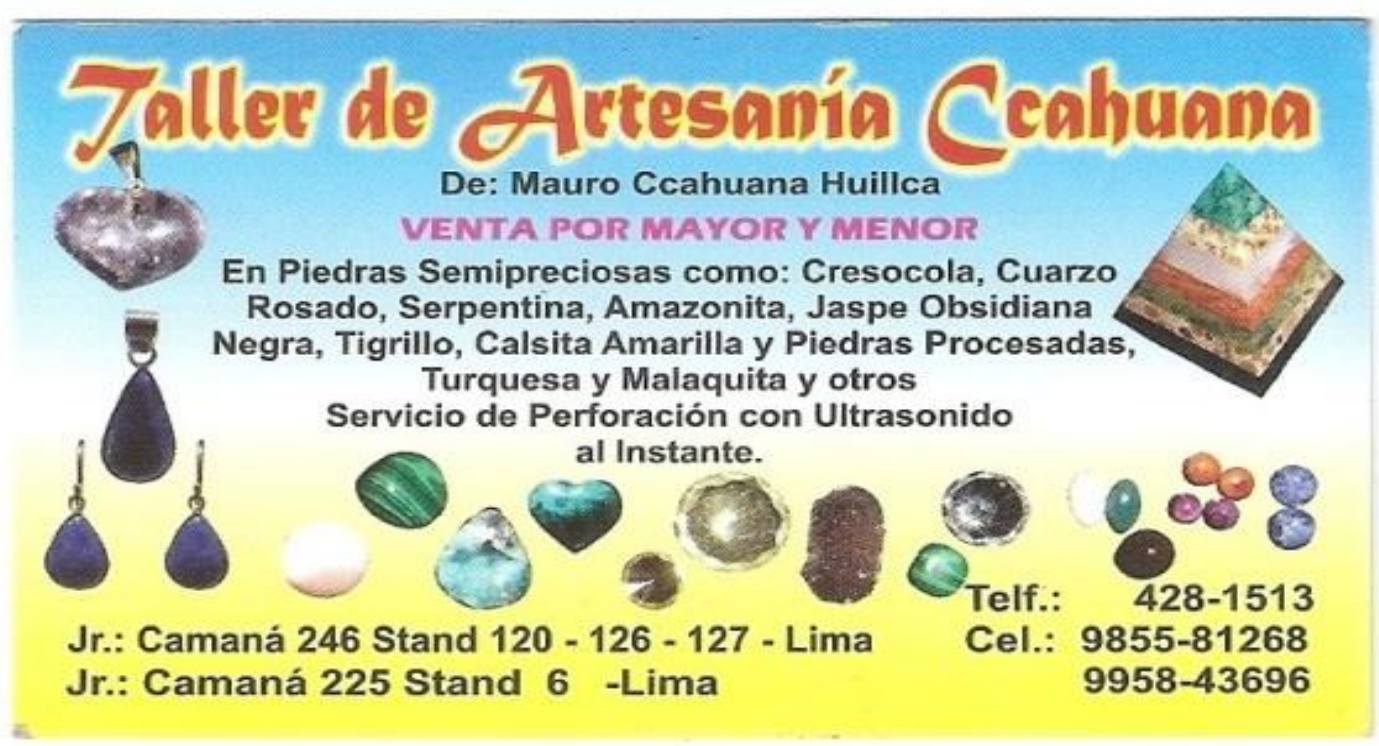

Fuente: Taller de Artesanía Ccahuana 


\subsubsection{Estrategia de la competencia}

Las principales empresas exportadoras de joyería de plata son:

\section{$\checkmark A R I N$ SA:}

Es uno de los más grandes exportadores de joyería en Perú pues usan la tecnología para mejorar la productividad tanto en plata y en oro.

Asimismo cuentan con una gran cantidad de personal altamente calificado que tiene mucha experiencia en el sector.

Por otro lado, cuentan con otros servicios como:

-Limpieza de joyería

-Refinado

•Baño galvánico

\section{$\checkmark$ NEW FASHION PERU SAC:}

La estrategia está basada en la creación de joyería a través del uso de maquinaria (Ver Anexo 26) específicamente para cadenas, pulseras y aretes.

El casting es el proceso seleccionado para la elaboración de joyas de plata y no usa las piedras naturales para su elaboración.

\section{$\checkmark$ DESIGNS QUALITY EXPORTS SAC:}

Se basa en el diseño y fabricación de joyas Ley 925 de plata o bañadas en oro. Ha invertido mucho en maquinaria y puede realizar producción en casting $\mathrm{t}$ baños galvánicos que le da un acabado diferente al producto. Tiene una serie de colecciones que brinda un abanico de opciones al cliente.

Las tres empresas han perdido participación de mercado (ARINSA 25\%; DQE -46\% y NFP -18\%) en las exportaciones de joyería de plata al mundo entre el año 2013 y 2014 la cual pueda ser un motivo del aumento de la competencia ya sea de Perú o internacionalmente. 


\subsubsection{Análisis de la competencia internacional}

$\checkmark$ A nivel internacional, los país de los que más importa Chile es Italia, Tailandia y China que suman un total de $51.3 \%$ de participación. La concentración en estos tres países es gracias a su infraestructura, calidad y variedad en la oferta lo cual no ofrece Perú que obtuvo en el año 2014 una participación de $6.7 \%$ del total de importaciones de joyería de plata de Chile en términos de US\$ dólares.

$\checkmark$ En el Cuadro $N^{\circ} 4.7$ se presenta a los principales países que exportan joyería de plata a Chile, de los cuales Perú se encuentra en el séptimo lugar.

\section{Cuadro $N^{\circ}$ 4. 7: Países que más exportan joyas de plata a Chile, año 2014}

\begin{tabular}{|c|c|c|}
\hline Exportadores & Miles de USD & Participación \% \\
\hline Mundo & $\mathbf{2 2 , 7 6 8}$ & $\mathbf{1 0 0}$ \\
\hline Italia & 4,767 & 20.9 \\
\hline Tailandia & 3,772 & 16.6 \\
\hline China & 3,141 & 13.8 \\
\hline España & 2,739 & 12 \\
\hline México & 2,216 & 9.7 \\
\hline Colombia & 1,632 & 7.2 \\
\hline Perú & 1,517 & 6.7 \\
\hline Panamá & 1,158 & 5.1 \\
\hline Estados Unidos de América & 880 & 3.9 \\
\hline Resto & $\mathbf{9 4 6}$ & $\mathbf{4 . 1}$ \\
\hline
\end{tabular}

Fuente: TRADEMAP

\subsubsection{Marco legal}

\section{A.Barreras arancelarias:}

Gracias al Tratado de Libre Comercio Perú-Chile, no hay pago de Ad Valorem. (La canasta de desgravación y el cronograma de desgravación a la que pertenece la partida arancelaria se encuentran en el Anexo 27 y Anexo 28, respectivamente).

\section{B.Barreras no Arancelarias:}

No existe presentación de certificación alguna para la exportación de joyería a Chile. Sin embargo, debe seguirse la reglamentación de la Ley Internacional de la producción de metales preciosos o joyería de acuerdo a lo que se ha establecido. Los productos de joyería deben ser 
exportados de acuerdo a su ley de venta ya sea en Oro o en Plata (Anexo 29).

\subsubsection{Mix comercial de la competencia}

\section{A) Producto}

$\checkmark$ Las principales empresas de joyería a nivel internacional tienen una marca con productos competitivos. La capacidad de producción es muy alta debido a la accesibilidad a una buena tecnología, diseños (Italia) y mano de obra barata con excelentes acabados (Tailandia, China) los cuales han beneficiado a la competencia internacional.

$\checkmark$ Otro aporte a este sector es la concentración de diseñadores en los últimos años, lo que ha creado la diversidad en los productos que son reconocidos internacionalmente por poseer diseños que van con la tendencia.

$\checkmark$ Las grandes empresas de joyería dan prestigio al país donde iniciaron y brindan motivación a las demás empresas a lograr alcanzar el éxito en la innovación de sus productos.

\section{B) Precio}

$\checkmark$ En Italia los precios son altos por la calidad en los diseños y en el trabajo de producción.

$\checkmark$ Por otro lado, China y Tailandia los precios son muy competitivos debido bajos costos de producción.

\section{C) Plaza}

$\checkmark$ Tienen una producción y distribución con los principios de just in time por la cual tienen varios clientes a nivel internacional. Sus productos son importados por distribuidores que luego venden a minoristas.

$\checkmark$ Las grandes marcas de joyería se benefician colocando una franquicia en los países objetivos pues sus altos precios les permite vender directamente al consumidor. 


\section{D) Promoción}

$\checkmark$ Principalmente se usa el internet para hacer promociones (Página Web, Redes Sociales) porque los consumidores usan mucho las Webs para observar las tendencias y lo último en novedad.

\subsection{Análisis FODA de la competencia}

\subsubsection{Fortaleza}

$\checkmark$ Reconocimiento de diseño e innovación a nivel internacional.

$\checkmark$ Artesanos bien calificados y capacitados para la producción.

$\checkmark$ Centros educativos que forman y capacitan a joyeros.

$\checkmark$ Producción a economía de escala.

$\checkmark$ Acceso a canales de internet.

$\checkmark$ Tradición en joyería.

$\checkmark$ Mano de obra barata

\subsubsection{Debilidad}

$\checkmark$ Insuficiente producción de plata.

$\checkmark$ Inestabilidad Económica.

$\checkmark$ Copia de sus productos.

\subsubsection{Oportunidades}

$\checkmark$ Aparición de mercados emergentes

$\checkmark$ Desarrollo de una nueva tecnología

$\checkmark$ Reducción del precio internacional de la Plata

$\checkmark$ Tendencia de la demanda

\subsubsection{Amenazas}

$\checkmark$ Aumento del desempleo.

$\checkmark$ Estancamiento en la crisis.

$\checkmark$ Competidores incrementan su innovación.

$\checkmark$ Volatilidad del precio del metal. 


\subsection{Decisiones sobre producto}

\subsubsection{Características físicas del producto}

$\checkmark$ Todos los productos de joyas de plata Ley 950 y 925 llevarán incrustado piedras naturales. Las joyas de Ley 950 pertenecerán a la colección MYSTIC y las de Ley 925, a ULTRA. Ambas colecciones se enfocará en la innovación, el diseño, el acabado final tomando en cuenta los pequeños detalles del producto. En el Anexo 30 se exponen ejemplos de joyas con piedras naturales que se producirán pata la colección ULTRA y en el Anexo 31 se muestran los de la colección MYSTIC.

Estas piezas a producir tendrán un balance entre el estilo y la delicadeza del detalle.

$\checkmark$ La forma de las piedras naturales será diversa en forma y colores, logrando el brillo necesario para que las joyas luzcan atractivas.

$\checkmark$ Cada joya tendrá estampado la Ley que le corresponda. Se usará un punzón para marcar la joya en la parte interior con el fin que no se note el sello cuando la persona use la joya.

$\checkmark$ Asimismo, las joyas producidas se caracterizan por:

-Insumos de calidad ya que no se producirán a través de la fundición de joyas, sino a través de plata pura que no haya sido producida antes. -Diseño e innovación, pues se tendrá en cuenta los colores de las piedras naturales para obtener joyas llamativas.

-Tendencia ya que se crearán joyas acorde a lo moda internacional.

$\checkmark$ Para el presente proyecto será importante el establecer pesos fijos; sin embargo en la práctica puede haber variaciones de más o menos 3 gramos a lo mucho ya que serán hechos artesanalmente y suele ocurrir pequeños cambios en el peso. El peso que se ha establecido será para todas las joyas hechas durante los cinco años de evaluación del presente estudio.

-Arete 12 gramos

-Anillo 19 gramos 
-Collares 58 gramos

-Pulseras 29 gramos

-Set de joyas 76 gramos

\section{Cuadro $N^{\circ}$ 4. 8: Tipos de joyas a comercializar}

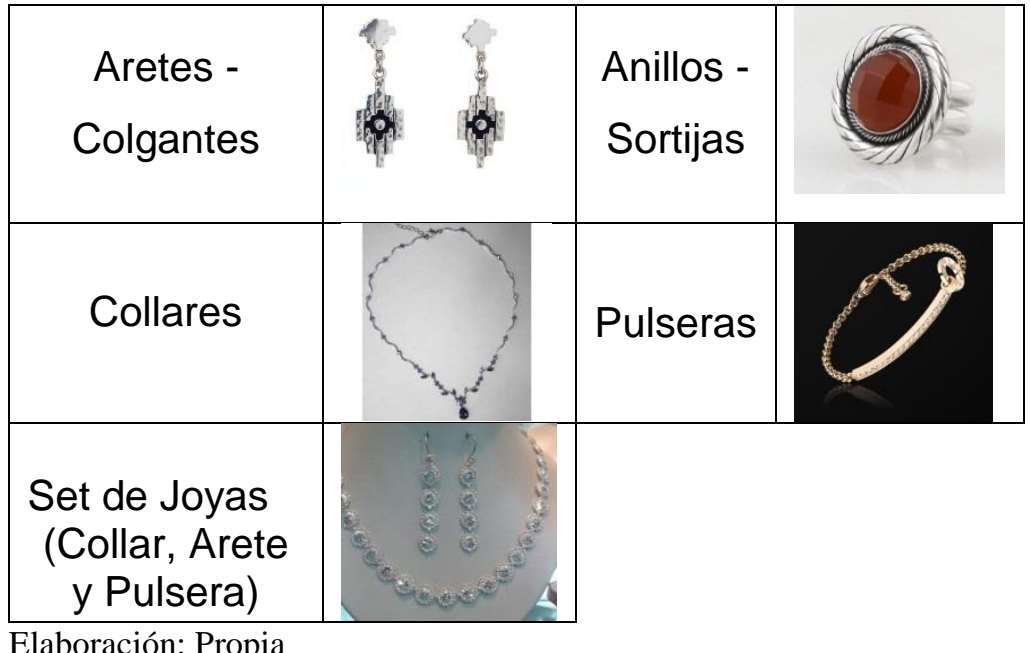

\subsubsection{Empaque y embalaje}

Esta parte es muy importante también porque se debe tener el más mínimo detalle en mantener bien sellado las joyas ya que se podría alterar el brillo. Lo necesario para tener las joyas bien selladas en su empaque son:

-Bolsas de burbuja de aire comprimido (Burbopack)

-Papel tissue

-Cajas de cartón corrugado y cinta de embalaje

-Bolsa de plástica ZIPLOC 


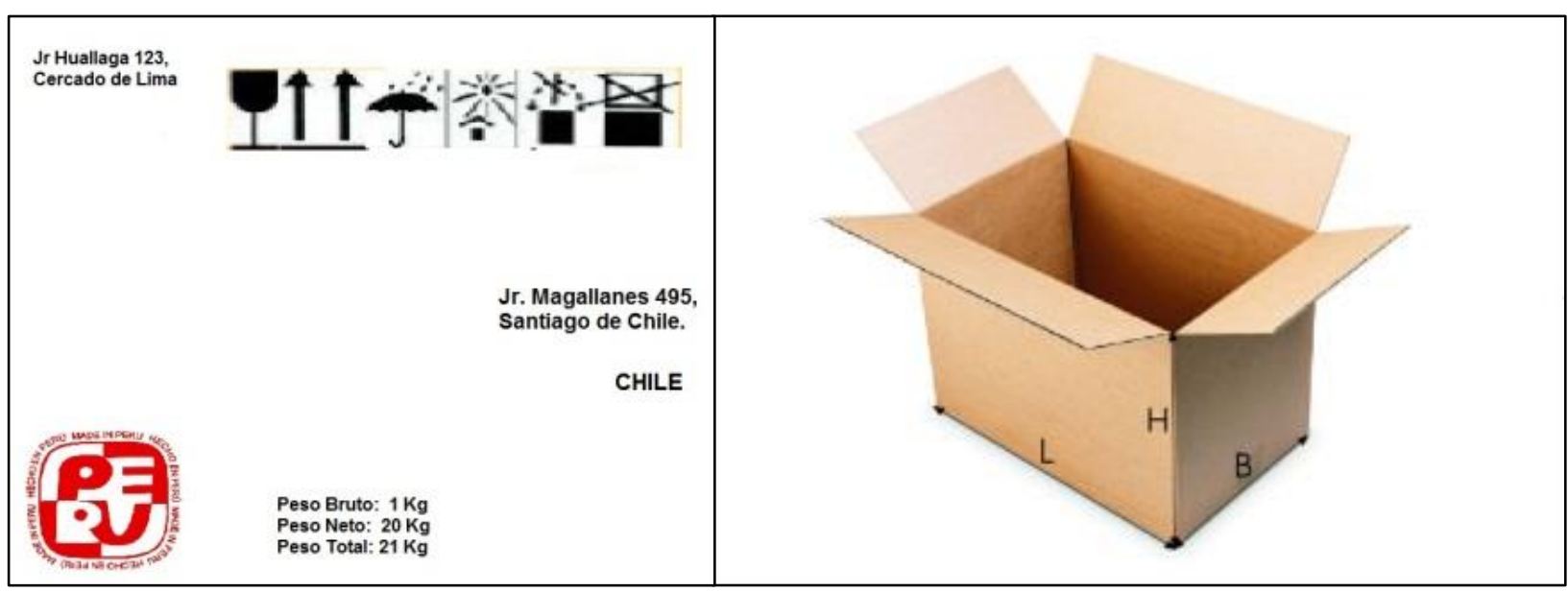

Elaboración: Propia

Una vez que se disponga de los materiales, el proceso de embalaje es el siguiente (En el Anexo 32 se muestra una imagen detallando el proceso):

-Limpiar los productos de polvo y de huellas dactilares.

-Revisar que los juegos estén completos.

-Las joyas son introducidas en bolsas de plástico ZIPLOC.

-Se coloca una lámina de burbuja al fondo de la caja de cartón.

-Se coloca la bolsa de ZIPLOC conteniendo las joyas; posteriormente, se cubre de otra lámina de burbuja de aire para luego colocar otra bolsa ZIPLOC con un artículo de joyería. Esto será sucesivamente hasta llenar la caja de cartón.

-Al final se colocarán todo dentro de un cartón corrugado y se sella. Las cajas de cartón corrugado serán de medida $33 \mathrm{~cm}$ de alto, $50 \mathrm{~cm}$ de lado y $33 \mathrm{~cm}$ de base y de color entero.

\subsubsection{Marca}

$\checkmark$ Para llegar al nombre de "JOLIBARI" se han evaluado varios nombres para la marca entre los cuales está "JOYERÍA COLOUR", “QUALITY JEWEL”, "FASHION SILVER”, "STONE \& SILVER”.

$\checkmark$ Si bien el método tradicional para la elección de una marca tendría que describir el producto y las ventajas, pues en esta oportunidad el nombre no representa estos, ya que en lugar de eso se escogieron las 
iniciales del apellido del autor ("BARI") complementado con "JOLI" que significa hermoso y belleza.

$\checkmark$ Para registrar la marca se debe hacer una búsqueda del nombre pues puede ya existir en la base de datos de la INDECOPI. EN el Anexo 33 se muestra el documento de búsqueda fonética obtenido en la INDECOPI.; por lo tanto se podría registrar la marca.

$\checkmark$ El logo de la marca trata de reflejar personalidad, estilo y elegancia la cual acompañará durante todo el proyecto.

\section{Imagen $N^{\circ}$ 4. 6: Marca de la empresa}

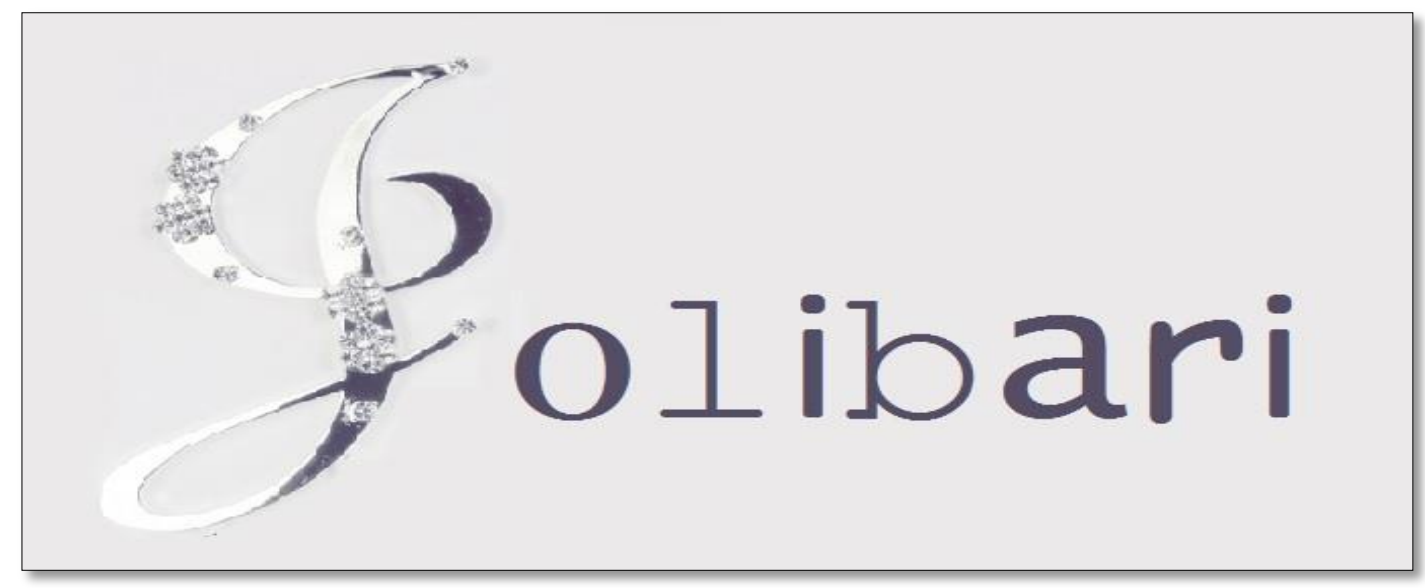

Elaboración: Propia

$\checkmark$ En la Imagen $\mathrm{N}^{\circ} 4.7$, se encuentra un estudio de mercado por parte de la empresa CHILE 3D en el cual expone que las marcas de Vestuario y Accesorios son el segundo más recordado representado con $17 \%$ el año 2014 y $22 \%$ en el año 2015. 


\section{Imagen $N^{\circ}$ 4. 7: Marcas por sector mayor recordadas en Chile}

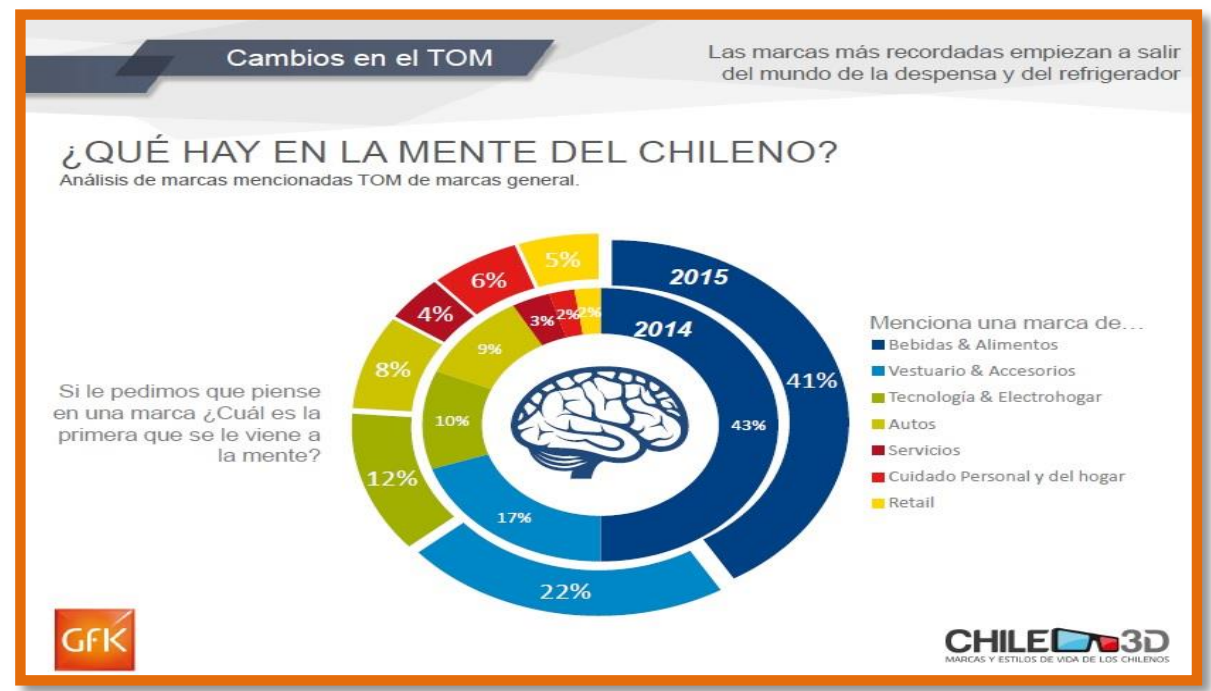

Fuente: CHILE 3D

$\checkmark$ En la Imagen $\mathrm{N}^{\circ} 4.8$ se encuentran los atributos de una marca dentro de los cuales sobresale la promesa, la identidad y la experiencia. Estos tres deben combinar perfectamente para que la marca tenga una excelente reputación.

\section{Imagen $N^{0}$ 4. 8: Atributos de una marca}

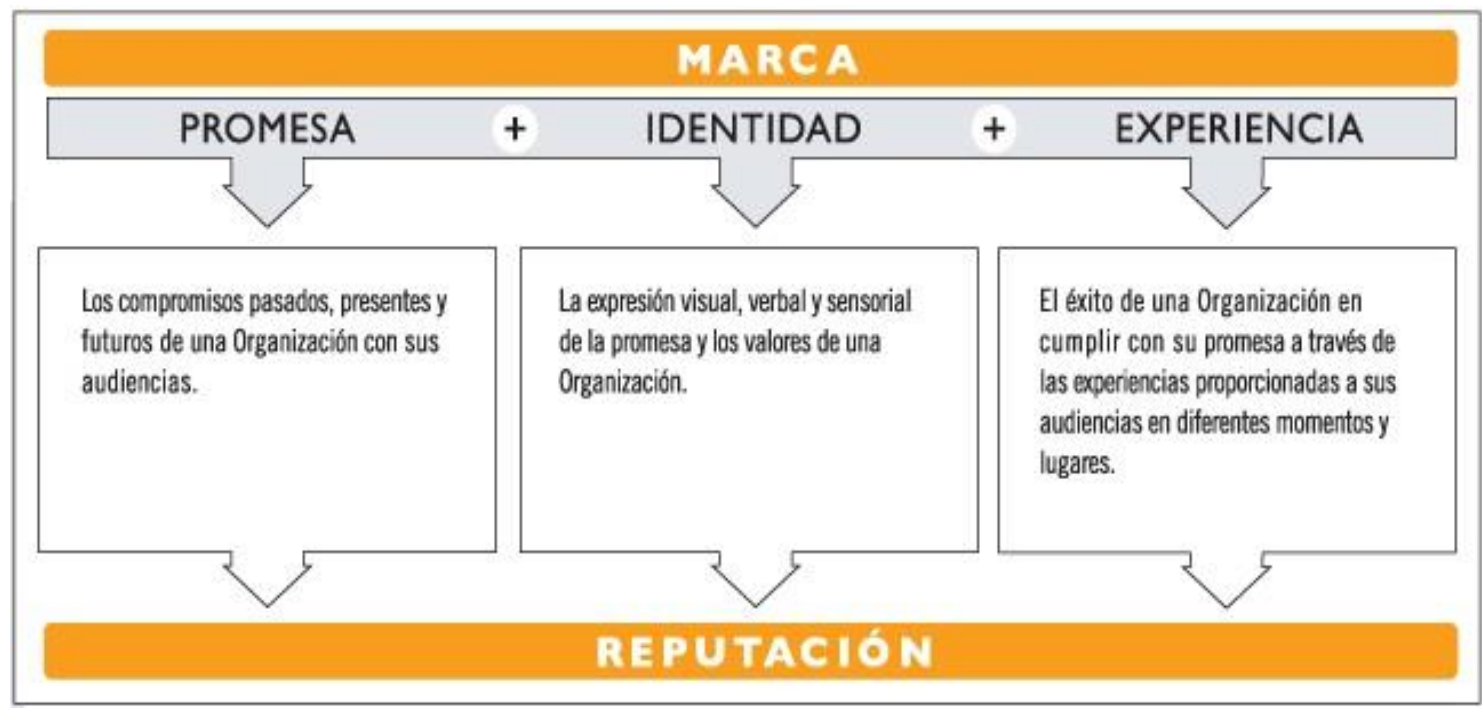

Elaboración: Propia 


\subsubsection{Etiquetado}

Se pondrá en las cajas de exportación la frase de "Hecho en Perú" la cual se debe presentar requisitos tales como información de la empresa, licencias y entre otros.

\subsubsection{Modo de uso del producto}

oEl uso de la joyería siempre debe estar al alcance de la vista y no escondido pues cualquier persona que lo usa lo exhibe en el cuello, mano o en la vestimenta.

oEvitar que le caiga algo de desinfectantes a las joyas y darle mensualmente una limpieza con franelas especiales.

\subsection{Decisiones sobre precio}

\subsubsection{Fijación de precios}

Los precios estarán por debajo de la competencia y para esto se presenta en el siguiente cuadro $\mathrm{N}^{\circ} 4.9$ los precios de joyas de empresas peruanas que exportan a Chile.

En el siguiente enlace se puede visualizar un archivo completo en Excel en el cual se encuentra la información de todas las exportaciones de joyas de Perú a Chile entre el año 2010 y 2015.

\section{Cuadro No 4. 9: Precios de la competencia}

\begin{tabular}{|c|c|c|c|c|c|}
\hline Exportador & Desc. Comercial & FOB US\$ & $\begin{array}{c}\text { Cant. Unidades } \\
\text { Aranc. } \\
\text { (Kilogramo) }\end{array}$ & $\begin{array}{c}\text { FOB US\$ x } \\
\text { Unidad }\end{array}$ & $\begin{array}{c}\text { Cant. } \\
\text { Unidades } \\
\text { Comerc. }\end{array}$ \\
\hline IDEAS APLICADAS SA & $\begin{array}{c}\text { PULSERA DE PLATA Y } \\
\text { PIEDRAS }\end{array}$ & 170 & 1.54 & 297.50 & 2 \\
\hline $\begin{array}{c}\text { PACKTOS EFECTIVAS } \\
\text { SAC }\end{array}$ & JOYERIA DE PLATA & 1,695 & 2.36 & 296.63 & 20 \\
\hline GABEL ZAMORA & $\begin{array}{c}\text { PULSERA DE PLATA Y } \\
\text { PIEDRAS, }\end{array}$ & 469 & 9.53 & 149.23 & 11 \\
\hline BALIQ JOYAS SAC & PULSERAS & 8,976 & 7.25 & 68.30 & 460 \\
\hline IDEAS APLICADAS SA & $\begin{array}{c}\text { ARTICULOS DE } \\
\text { HOMBRE Y MUJER }\end{array}$ & 136 & 0.25 & 158.67 & 3 \\
\hline IDEAS APLICADAS SA & $\begin{array}{c}\text { ARETES DE PLATA Y } \\
\text { PIEDRAS }\end{array}$ & 181 & 0.93 & 158.38 & 4 \\
\hline IMEXPORT ^ ELAZ EIRL & $\begin{array}{c}\text { PULSERA CRUZADA EN } \\
\text { PLATA 950 }\end{array}$ & 10,560 & 1.34 & 308.00 & 120 \\
\hline IDEAS APLICADAS SA & $\begin{array}{c}\text { ARETES DE PLATA Y } \\
\text { PIEDRAS }\end{array}$ & 357 & 0.68 & 312.38 & 4 \\
\hline IMEXPORT ^ ELAZ EIRL & $\begin{array}{c}\text { PULSERA OVALADA } \\
\text { DE PLATA 950 }\end{array}$ & 12,460 & 1.79 & 311.50 & 140 \\
\hline
\end{tabular}

Fuente: DATATRADE 
Asimismo, se muestra los precios de los mismos comercializadores en Santiago de Chile a través de Internet como mercado libre en la Imagen $\mathrm{N}^{\mathbf{o}}$ 4.9. El tipo de cambio en Chile es de $\$ 650$ por dólar y los precios están por encima que nuestros productos.

\section{Imagen $N^{\circ}$ 4. 9: Ejemplos de joyas que se venden en Chile en Mercado Libre}

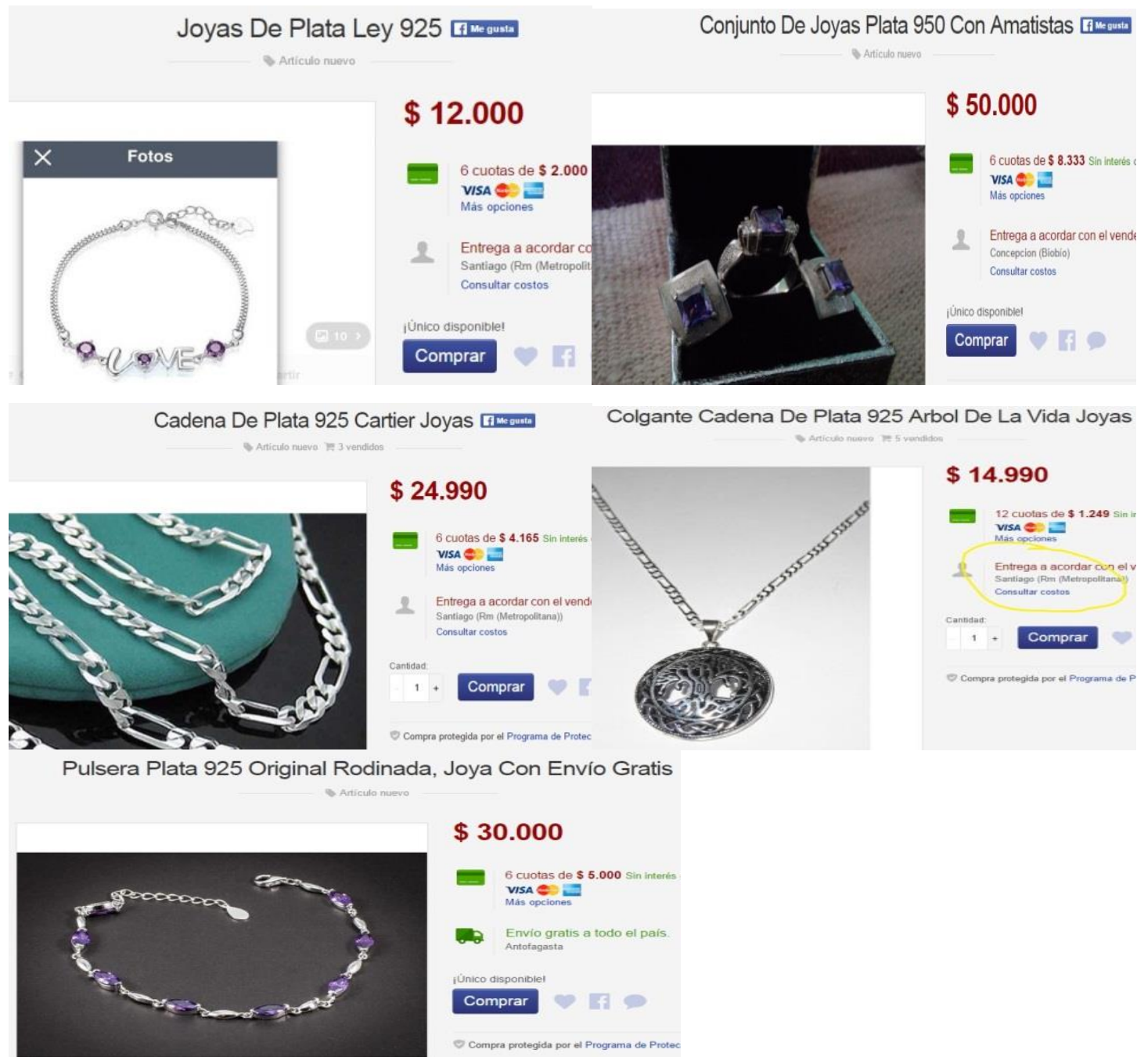

Fuente: Mercado Libre - Chile

\subsubsection{Política de pagos}

$\checkmark$ La política de cobro y pago se realizará mediante tres modalidades:

-Usando Carta de crédito irrevocable

-A través de PayPal

-Pago con tarjeta 
$\checkmark$ El uso de la carta de crédito será el tiempo de dos años debido a que brinda mayor seguridad para el exportador e importador; sin embargo, el uso de esta Carta influye en los costos finales.

$\checkmark$ Para el tercer año se empezará a cobrar a través de transacciones bancarias ya que existirá confianza entre el exportador y vendedor. El uso de la carta de crédito se realizará únicamente con el cliente principal ya que con este se vende las más altas cantidades.

$\checkmark$ El uso de PayPal (Anexo 34 se muestra las ventajas de su uso) y la tarjeta crédito o débito (VISA o MASTERCARD) se habilitarán principalmente para exportaciones minoristas los cuales compran ocasionalmente. Para ello se necesitará el abono del $100 \%$ del producto y la exportación se realizará vía DHL o FEDEX.

$\checkmark$ En el Esquema $\mathrm{N}^{\circ} 4.1$ y $\mathrm{N}^{\circ} 4.2$ se encuentra el flujo de pago y el proceso de envío de dinero de PayPal, respectivamente, el cual muestra los participantes y explica la transparencia de las transacciones para el comercio.

\section{Esquema $N^{0}$ 4. 1: Flujo de pago a través de PayPal}

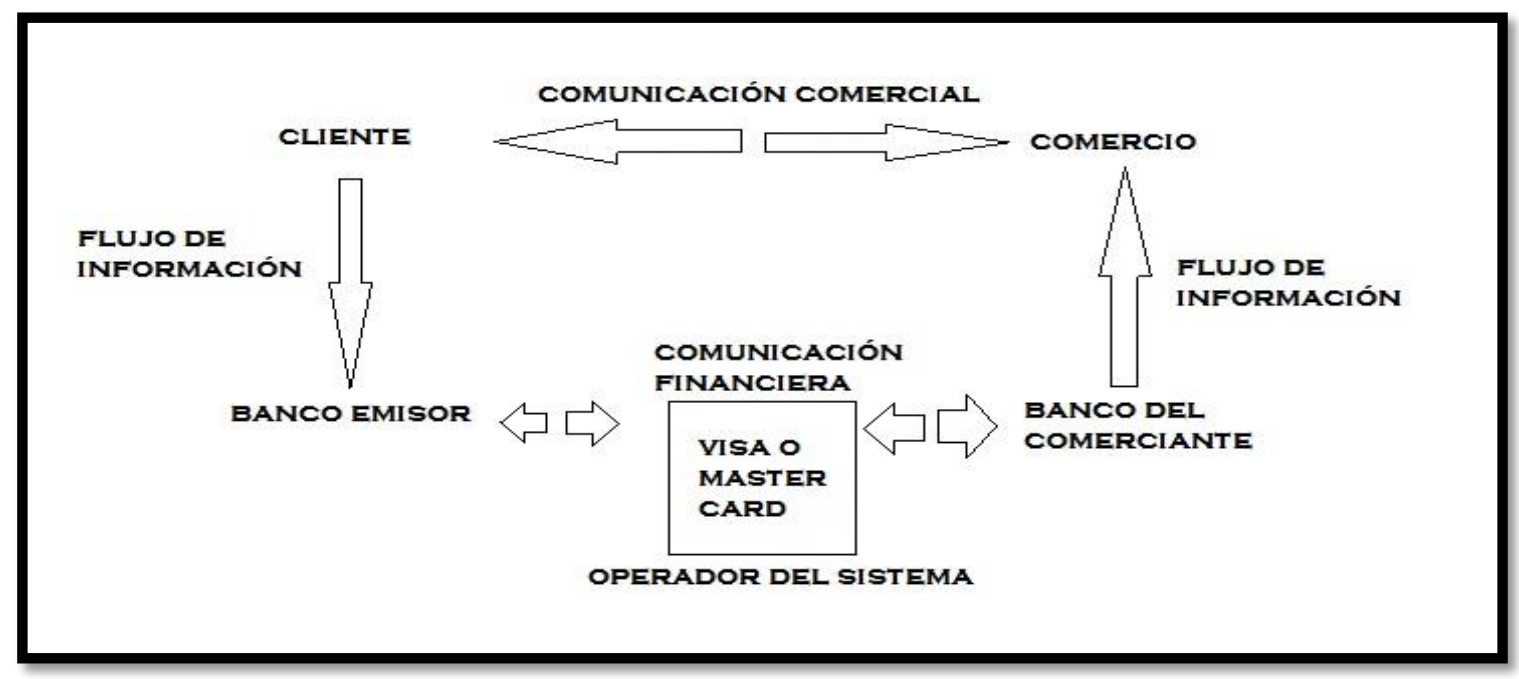

Fuente: PayPal 
Esquema $\mathrm{N}^{\circ}$ 4. 2: Proceso de envío y recepción de dinero a través de PayPal

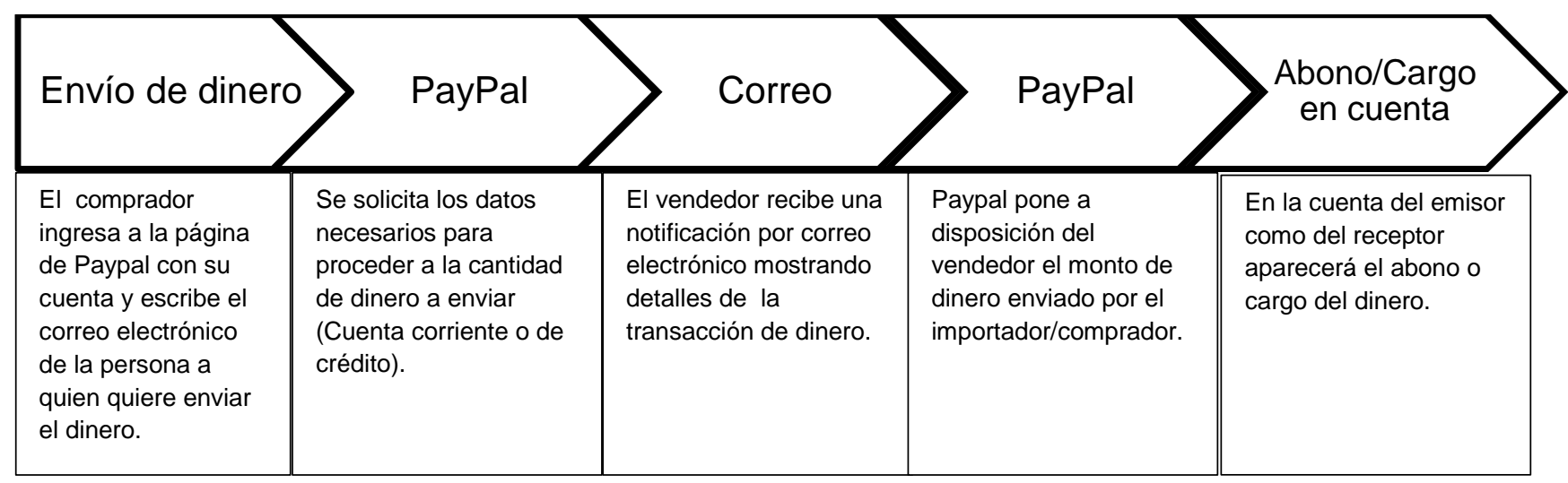

Fuente: PayPal

\subsubsection{Política de descuento}

Debido a que Chile posee una gran cantidad de consumidores que prefieren los descuentos, se realizará a partir de compras que sobrepasen los $\$ 20,000$ en compras.

\subsection{Decisiones sobre plaza}

\subsubsection{Cobertura de mercado}

$\checkmark$ Para empezar las operaciones de los primeros dos años, se trabajará con una empresa el cual cumpla con los siguientes requisitos:

-Solvencia económica

-Localizado en Santiago de Chile

-Lograr aumentar la cantidad de socios comerciales

-Tener una proyección de ventas creciente

$\checkmark$ Se debe encontrar un socio importante en Chile para las operaciones de exportación de joyería de plata para que cubran las producciones del año y alcanzar la participación proyectada y para esto se realizará viajes a Chile desde el primer año para visitar clientes y profundizar el mercado de joyas de plata en ese país.

$\checkmark$ Se planteará el plan de negocio al cliente sobre los precios y cantidad de exportación para poder trabajar durante varios años. 
$\checkmark$ La empresa seleccionada será "IMPORTADORA DE JOYAS DE CHILE" se encuentra localizado en Santiago de Chile, Avenida Ricardo Lyon 356.

$\checkmark$ Se ofrecerá los productos a través de la Página Web y se difundirá dicha web a través de revistas y diarios importantes que se comercializan en Santiago de Chile.

$\checkmark$ Desde el primer año se tendrá presencia en ferias y misiones comerciales las cuales se tendrá comunicación con ADEX y PROMPERU para inscribirse en dichos eventos los cuales permitirán conocer más el mercado internacional sobre todo el de Chile.

\section{Esquema $N^{\circ}$ 4. 3: Estrategia de distribución}

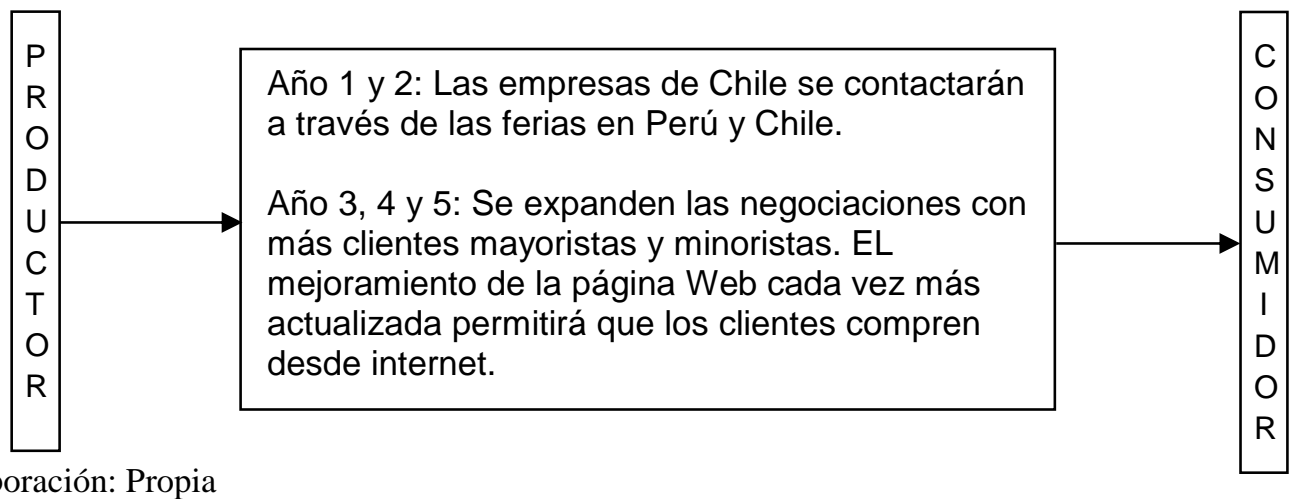

Elaboración: Propia

\subsubsection{Logística}

Los artículos y joyas de plata son distribuidos en tiendas especializadas y en las tiendas ubicados en los centros comerciales debido a que los chilenos les gustan encontrar sus productos en un lugar donde pueden encontrar variedad.

\section{A. Logística de entrada:}

Las empresas proveedoras serán PROCESADORA

SUDAMERICANA (En el Anexo 35 está la presentación del producto el cual viene un Kilogramo por bolsa) y ARTURINSA las cuales brindarán la Plata y las piedras naturales, respectivamente. Se debe ir hasta las instalaciones de los proveedores para poder adquirir los insumos necesarios para la exportación del mes para lo cual el 
transporte será a través del transporte privado. Una vez obtenido la materia prima, se enviará lo necesario para la producción al taller MARTINEZ E.I.R.L.

\section{Esquema $N^{\circ}$ 4. 4: Participantes de la logística de entrada}

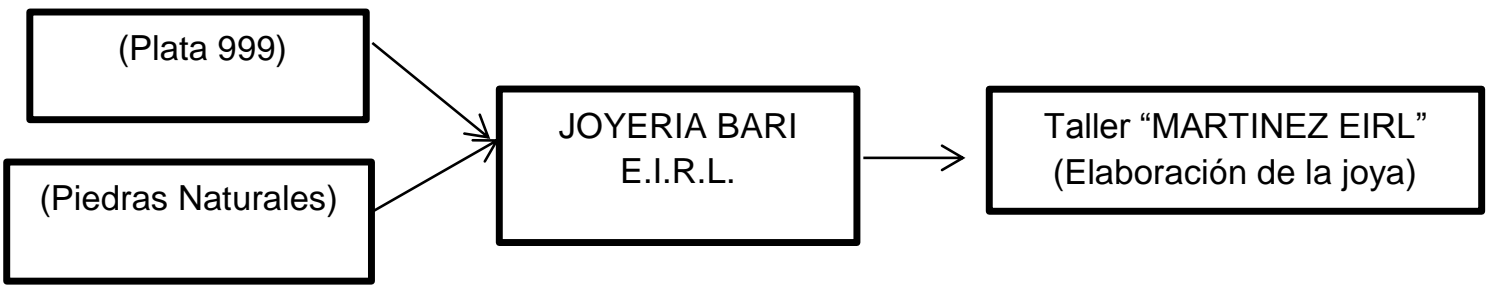

Elaboración: Propia

\section{B. Logística de salida:}

La aduana de salida será la Aérea del Callao debido a que es el envío común para la salida de la joyería de plata de Perú al extranjero. En el Cuadro $\mathrm{N}^{\circ} 4.10$ se observa que la Aduana Aérea del Callao representa el $99.1 \%$ del total de lo exportado al mundo en joyas de plata principalmente porque brinda seguridad, fluidez aduanera y costos.

Para las exportaciones a Bolivia principalmente pasa por Desaguadero y para los envíos a Colombia pasan por la aduana de Tumbes.

\section{Cuadro No 4. 10: Exportación de joyas de plata de Perú, según Aduana}

\begin{tabular}{|c|c|c|}
\hline Aduana & Suma de FOB US\$(*) & Porcentaje \\
\hline AEREA DEL CALLAO & 476,306 & $99,1 \%$ \\
\hline DESAGUADERO & 529 & $0,1 \%$ \\
\hline MARITIMA DEL CALLAO & 3,135 & $0,7 \%$ \\
\hline TUMBES & 507 & $0,1 \%$ \\
\hline Total general & $\mathbf{4 8 0 , 4 7 8}$ & $100,0 \%$ \\
\hline
\end{tabular}

Fuente: DATATRADE, SUNAT

(*) AÑO 2014

Debido a que las exportaciones sobrepasan los \$2,000 en valor FOB, será obligatorio contar con los servicios de un agente de aduanas el cual para esta oportunidad será "CASOR ADUANERO S.A.C.”. Este se encargará de operar las gestiones respectivas para lograr la 
exportación del producto. El costo del servicio es $1.6 \%$ sobre el total del Valor FOB exportado.

La empresa de transporte seleccionada para enviar alta cantidad de joyería será "LATAM AIRLINE GROUP S.A.” debido a la seguridad en el manejo y por otro lado FEDEX se seleccionará para el envío de productos de muestras o pequeñas cantidades que son directamente para los consumidores.

A continuación, se explica las operaciones de exportación aérea de joyería de plata a Chile:

* JOYERIA BARI E.I.R.L. (PRODUCTOR-EXPORTADOR):

-Emisión de documentos: Factura Comercial (a nombre del importador), PACKING LIST, certificación de origen, datos del importador, datos del exportador, certificado de calidad del producto y certificado de garantía.

-Solicitar reserva para el vuelo requerido.

-Entregar los documentos al Agente de Aduanas.

* CASOR ADUANERO S.A.C. (AGENTE DE ADUANAS)

-Recibe los documentos emitidos por el exportador.

-Presenta los documentos a Aduanas y numera la DAM seleccionando ser una exportación definitiva.

\section{* TALMA (ALMACÉN)}

-Recibe la notificación del exportador con información de las fechas de despacho del producto. (Anexo 36 se muestra el costo de almacenaje).

-Envía las joyas envasado en cajas de cartón al almacén portuario.

\section{* LATAM AIRLINE GROUP S.A (TRANSPORTISTA)}

-Revisar la mercancía y apuntar en la casilla 14 de la DAM información del embarque tales como el peso, cantidad, fecha y hora, terminando con colocar su sello y firma.

-Despachar la mercadería como máximo diez días después de haber numerado la DAM. 
* IMPORTADORA DE JOYAS DE CHILE (CLIENTE)

-Recibe vía correo la factura, certificado de origen, packing list.

-Retira las joyas de plata de la Aduanas en Santiago de Chile.

\section{Logística Inversa:}

Principalmente, trata sobre el reciclaje de las joyas que no se lograron vender por algunas fallas o por el tipo de diseño por lo que pasan a fundirse nuevamente para poder elaborar otro tipo de joyas. Este procedimiento se repetirá siempre y cuando las joyas no contengan soldadura pues hace bajar levemente la calidad del producto al fundirlo.

Para poder disminuir el porcentaje de productos cambiados o devueltos se exportará productos nuevos o aquellos que el cliente tenga dudas bajo el Régimen de exportación Temporal pues permite exportar el producto y volver a importarlo sin el pago de impuestos.

\subsubsection{Flete aéreo}

Se contará con dos empresas de transporte aéreo los cuales tienen experiencia en el envío al extranjero de joyería de plata las cuales con FEDEX y LAN.

$\checkmark$ FEDEX posee experiencia en el envío de mercadería valorada y deja el producto en la dirección del importador usando el código postal de 8320000 para Santiago de Chile. El precio que cobra varía según el Peso de la mercadería el cual como máximo puede ser de $5 \mathrm{Kg}$. Los precios son los siguientes:

-1 Kg a USD 128

•3 Kg a USD 199

$\bullet 5 \mathrm{Kg}$ a USD 270

$\checkmark$ Por otro lado, LAN Cargo cobra USD 35 por envío y se puede hacer el seguimiento de la carga desde Internet manteniendo el seguro del caso. Sin embargo, LAN lo reciben como carga general y la cantidad de envío pueden ser altas. 
$\checkmark$ Si algún cliente desea enviarlo mediante LAN para reducir costos, los riesgos pasarán al comprador y este envío se empleará para altas cantidades. Asimismo, FEDEX se empleará para pequeños envíos vendidos directamente a los consumidores a través de la página web.

\subsection{Decisiones sobre promoción}

\subsubsection{El mensaje}

$\checkmark$ Se hará énfasis en los diseños innovadores, el trabajo a tiempo, pasión por el trabajo y elaboración de los productos tratándose de diferenciar de la competencia.

$\checkmark$ El mensaje que se tendrá sobre la empresa será: "Los productos que realizamos no sólo es joyería; es un estilo de vida; es diseño; es un nuevo concepto que nos lleva a crear arte en plata a base de las nuevas tendencias".

$\checkmark$ Asimismo transmitir al cliente y consumidor que la empresa JOLIBARI ofrece la garantía de que los precios están acorde a la calidad de los productos.

\subsubsection{Posicionamiento}

La empresa estará posicionada en el mercado chileno como una de las mejores en diseños innovadores sin dejar de lado la calidad en el acabado. Asimismo, ser una empresa reconocida por el trabajo en calidad y variedad de productos de joyería de plata para mujeres.

Asimismo para tener un correcto posicionamiento se especificará la segmentación de mercado en el Cuadro $\mathrm{N}^{\circ} 4.11$ : 
Cuadro $N^{\circ}$ 4. 11: Variables de la segmentación para la población de Chile

\begin{tabular}{|c|c|c|}
\hline $\begin{array}{c}\text { Bases de la } \\
\text { Segmentación }\end{array}$ & $\begin{array}{c}\text { Variables de la } \\
\text { segmentación }\end{array}$ & Desglose \\
\hline Geográfica & región & Ciudad Santiago de Chile \\
& tamaño & $6,100,00$ habitantes \\
\hline \multirow{2}{*}{ Demográfica } & género & hombres y mujeres \\
& edad $18-60$ años \\
& ingresos & $\$ 800,000$ mensual (Peso Chileno) \\
\hline \multirow{2}{*}{ Psicográfica } & estilo de vida & Sofisticados \\
& necesidades & Calidad, servicio, precio/valor \\
\hline \multirow{2}{*}{ De conducta } & compra directa & Facebook, Correo, teléfono \\
& compra indirecta selectiva & Tiendas, establecimientos \\
frecuencia de uso & Uso frecuente \\
\hline
\end{tabular}

Fuente: Euromonitor

El nivel socioeconómico al que pertenece el público objetivo es del A, B, C1 entre los 18 a 60 años que se ubican en la provincia de Santiago de Chile.

\subsubsection{Penetración de Mercado}

Para obtener mayor participación de mercado en Chile se tendrá que realizar visitas al país de destino, folletos y catálogos de la empresa, tarjetas de presentación, obsequios a clientes potenciales en fechas importantes, reunión de empresas de joyería chilenas en hoteles, correos masivos a clientes, el uso de panales publicitarios y página web.

\section{a) Visitas al país de destino}

Las visitas serán para la feria de joyas, misiones comerciales y para las reuniones en el país de destino y las fechas serán los meses de Mayo y Setiembre respectivamente. La estadía será de cinco días para las ferias y misiones comerciales y de 3 días para las reuniones. Existe un límite de monto de \$5,000.00 en el valor del equipaje; sin embargo para el envío de muestras se exportará bajo el régimen de exportación temporal el cual no hay un límite de monto y se anula el pago de impuestos en el reingreso al Perú. El presupuesto del viaje más estadía es de $\$ 1,500.00$ para cinco días y de $\$ 1,200.00$ para un viaje de tres días. Los precios de pasaje se detallan en el Anexo 37. 


\section{b) Catálogos y folletos}

El costo promedio es de $\$ 1,300$ en el cual te producen 1000 folletos incluidos con la toma de fotografía. Los catálogos tendrán como portada la marca "JOLIBARI" y en el contenido se expondrá las joyas de las colecciones de ULTRA y MYSTIC.

\section{c)Tarjeta personal de presentación}

La tarjeta de presentación será para el gerente y el jefe comercial el cual brindará información personal y facilita para la obtención de más contactos. De esta forma, los clientes y los potenciales clientes consiguen contactar fácilmente con la empresa para adquirir sus productos y servicios. Estas tarjetas se usarán desde el primer año de operación.

\section{Imagen $N^{\circ}$ 4. 10: Tarjeta de Presentación}

\section{JOYERÍA Jolibari}

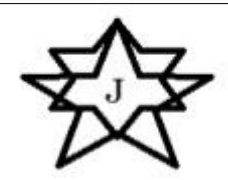

Gerente General: Giancarlo Barreto

Jr. Huallaga 123

Lima Centro

Correo: gerencia@jolibari.com.pe

Elaboración: Propia

\section{d)Obsequios}

Se dará obsequios a clientes potenciales para brindar una impresión favorable y también a algunos clientes que participen en alguna campaña o concurso que se comunicará a través de las redes sociales y página web. Los concursos se realizarán los meses de Abril y Setiembre, y los obsequios el mes de diciembre.

\section{e)Reunión con empresas en Chile}

Las reuniones se llevarán a cabo en el Hotel Marriott, ubicado en la comuna de Los Condes, una vez al año en Abril. Esta reunión será en día único en el cual se brindará coctel para los invitados mientras 
observan los nuevos diseños en joyería. Se realizará invitación previa para 200 personas que están en el negocio de importación de joyería y para los que desean ingresar. El presupuesto del alquiler para la reunión más los cocteles es de $\$ 4,000.00$. En el Anexo 38 está el mapa del hotel Marriott donde se llevará acabo las reuniones y en el Anexo 39 los precios por estadía por noche en el mismo Hotel.

\section{f)Correos masivos}

El servicio de correos masivos se realizará mediante la empresa "Santa Mail" en Chile ya que tiene base de datos de las personas que viven en Santiago de Chile. El precio es de \$ 52.00 el cual se puede observar en el Anexo 40 puesto en monedas de Peso Chileno según los distintos servicios. En las siguientes imágenes están ejemplos que los clientes recibirán por promociones o por saludo en navidad.

\section{Imagen $N^{\circ}$ 4. 11: Ejemplo de correo en época navideña}

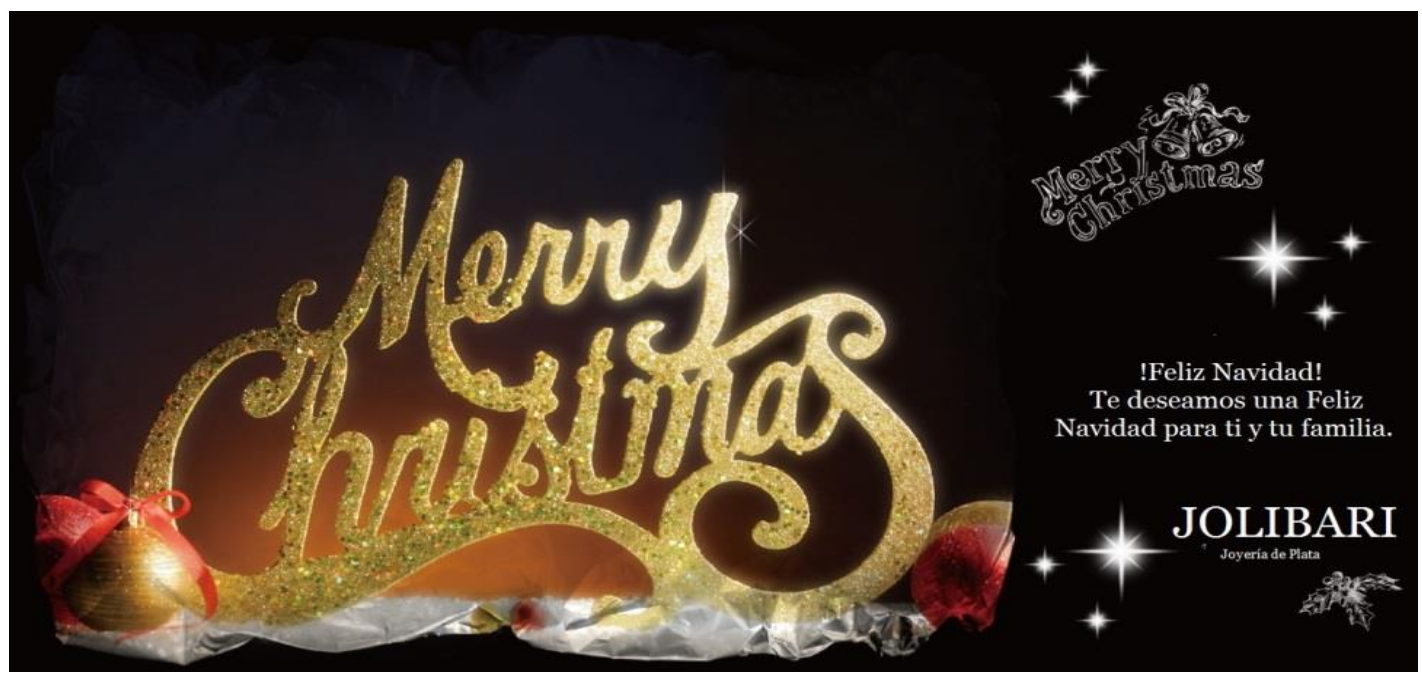

Fuente: Elaboración Propia 


\section{Imagen $N^{\circ}$ 4. 12: Ejemplo en el correo masivo}

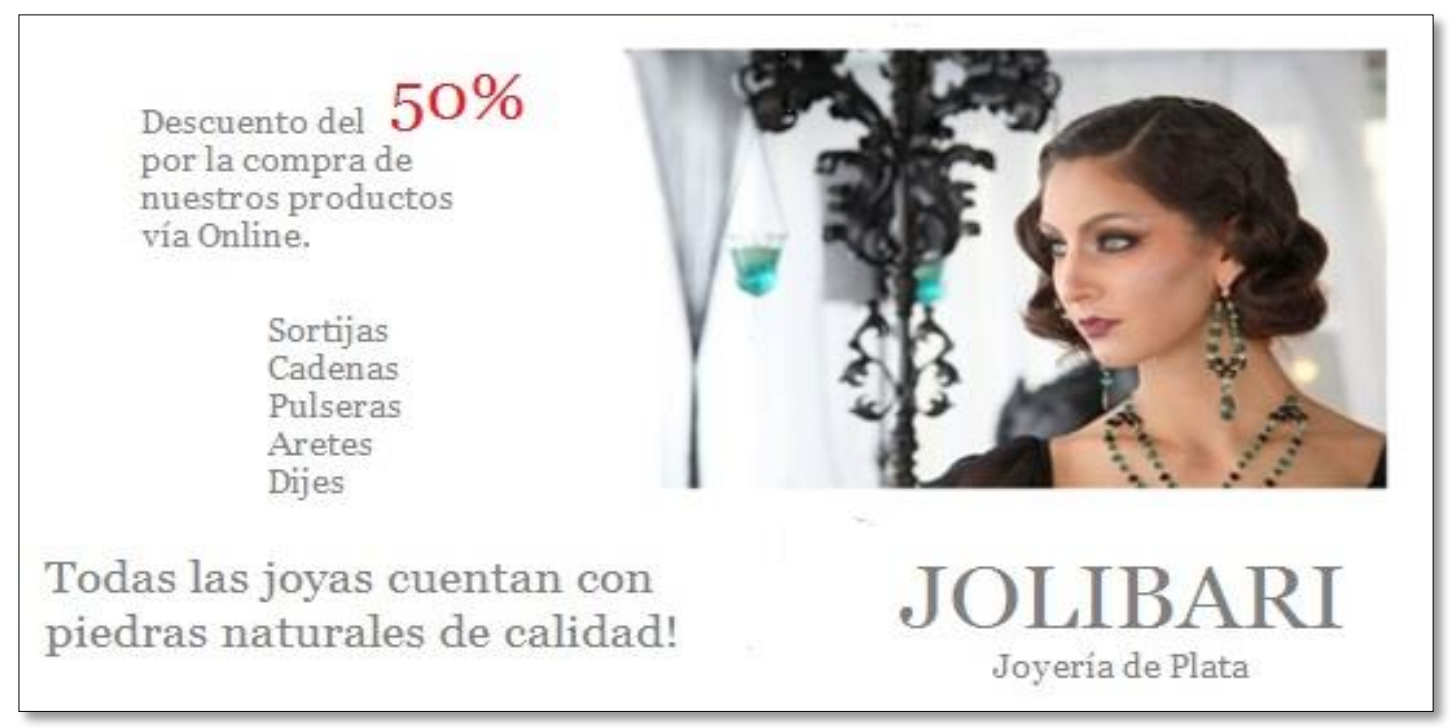

Fuente: Elaboración Propia

\section{g)Paneles publicitarios}

El panel publicitario estará en una avenida principal en Santiago de Chile y se llevará a cabo partir del quinto año para promocionar las joyas. El panel expondrá a una modelo usando joyas con piedras naturales incluyendo el nombre de la marca. Debido a que se usa en una avenida concurrida, el precio es de $\$ 2,000.00$ al mes; sin embargo brindará mayor promoción para la marca.

\section{h)Página web}

Se mandará a realizar una página web el cual brinde información de la empresa, de los productos y los precios para la comercialización. Las ventajas son:

- Transmitir una imagen más profesional

-Ser único dueño de la dirección web

- Tener uso exclusivo de la página web

-Más sencillo para recordar 


\section{Imagen $N^{0}$ 4. 13: Página Web para los dos primeros años}

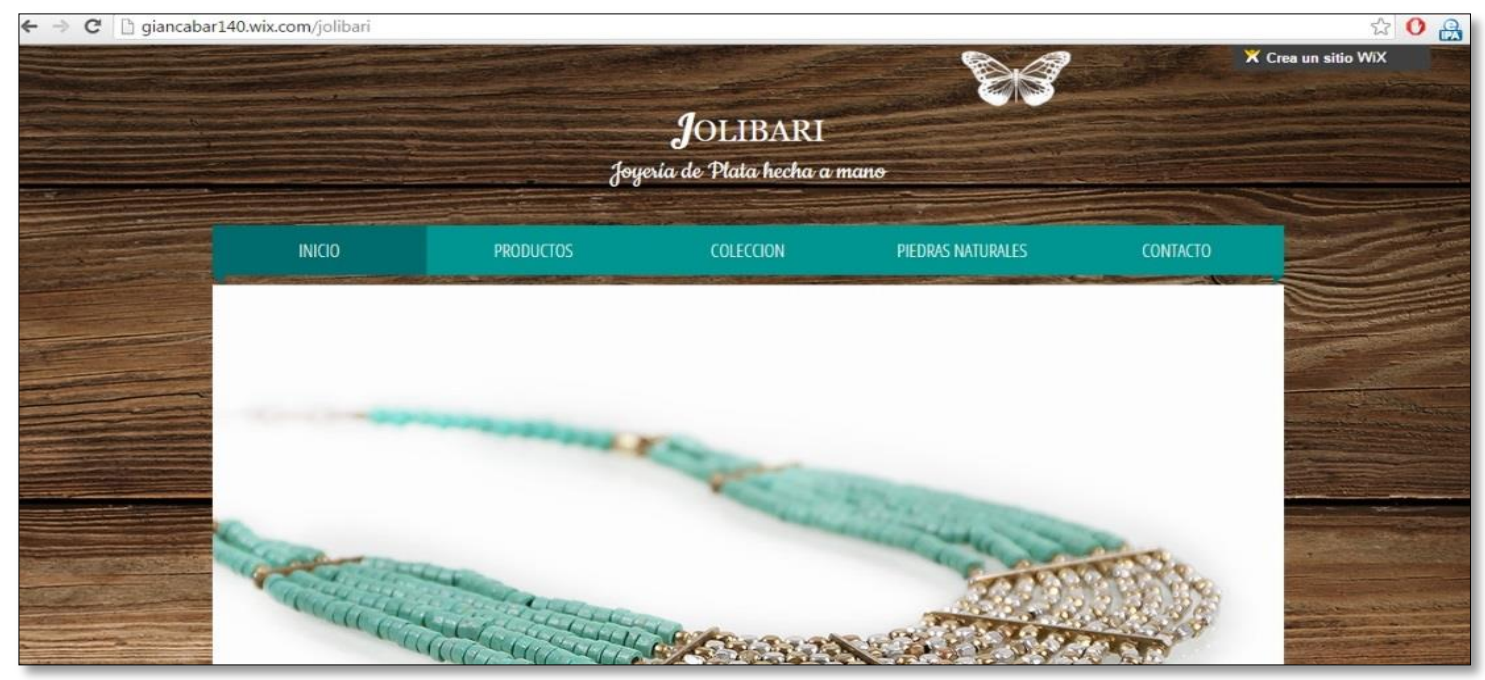

Fuente: WIX

\subsection{Análisis de ranking de factores}

Para esta sección se hará un análisis de países con respecto a temas macro y micro económico, logístico, costo y tiempo. Entre estos países se escogerá uno el cual es el que tiene el mejor promedio. Los países seleccionados para el análisis son Estados unidos, Chile, Alemania, México y Colombia.

Según información de Acuerdos Comerciales y TRADEMAP, se han escogido estos países principalmente porque:

○Existe beneficio tributario para la exportación de las joyas

oExiste alta demanda de joyería de plata

oLas joyas de Perú tienen presencia en ese país.

oSon altos importadores de joyería de plata.

El siguiente cuadro demuestra que Chile es el país correcto debido a un mejor promedio en los factores de logística, macro económico, costo y tiempo. 


\section{Cuadro $N^{\circ}$ 4. 12: Análisis del ranking de factores}

\begin{tabular}{|c|c|c|c|c|c|c|c|}
\hline FACTORES & VARIABLES & Estructura & USA & Ch. & Alem. & Méx. & Co. \\
\hline \multirow{8}{*}{$\begin{array}{l}\text { Factores } \\
\text { macro } \\
\text { económicos } \\
(30 \%)\end{array}$} & Crecimiento del PIB (\% anual) & $3.75 \%$ & 4 & 3 & 1 & 2 & 5 \\
\hline & Índice de facilidad para hacer negocios & $3.75 \%$ & 5 & 1 & 4 & 2 & 3 \\
\hline & İndice de valor de exportación & $3.75 \%$ & 1 & 4 & 3 & 2 & 5 \\
\hline & Índice del volumen de exportaciones & $3.75 \%$ & 1 & 2 & 4 & 3 & 5 \\
\hline & Exportaciones de bienes y servicios & $3.75 \%$ & 1 & 4 & 5 & 3 & 2 \\
\hline & Índice del valor de las importaciones & $3.75 \%$ & 1 & 4 & 3 & 2 & 5 \\
\hline & Índice del volumen de las importaciones & $3.75 \%$ & 2 & 4 & 1 & 3 & 5 \\
\hline & Importaciones de bienes y servicios & $3.75 \%$ & 4 & 5 & 1 & 2 & 3 \\
\hline \multirow{7}{*}{$\begin{array}{l}\text { Factores } \\
\text { Logísticos } \\
(30 \%)\end{array}$} & $\begin{array}{l}\text { calidad de la infraestructura relacionada con } \\
\text { el comercio y el transporte }\end{array}$ & $4.29 \%$ & 4 & 3 & 5 & 2 & 1 \\
\hline & $\begin{array}{l}\text { competitividad y calidad de los servicios } \\
\text { logísticos ( } 1=\text { baja a } 5=\text { alta) }\end{array}$ & $4.29 \%$ & 4 & 3 & 5 & 2 & 1 \\
\hline & eficiencia del despacho aduanero & $4.29 \%$ & 4 & 3 & 5 & 2 & 1 \\
\hline & $\begin{array}{l}\text { facilidad para coordinar embarques a precios } \\
\text { competitivo }\end{array}$ & $4.29 \%$ & 4 & 3 & 5 & 2 & 1 \\
\hline & $\begin{array}{l}\text { facilidad para localizar y hacer seguimiento a } \\
\text { los envíos }\end{array}$ & $4.29 \%$ & 4 & 3 & 5 & 2 & 1 \\
\hline & $\begin{array}{l}\text { frecuencia de arribo de embarques al } \\
\text { destinatario dentro del plazo previsto }\end{array}$ & $4.29 \%$ & 4 & 3 & 5 & 2 & 1 \\
\hline & Total & $4.29 \%$ & 4 & 3 & 5 & 2 & 1 \\
\hline \multirow{5}{*}{$\begin{array}{l}\text { Costos y } \\
\text { Tiempos } \\
(40 \%)\end{array}$} & Costo de exportaciones (US\$ por contenedor) & $10 \%$ & 3 & 5 & 4 & 2 & 1 \\
\hline & Costo de importaciones (US\$ por contenedor) & $10 \%$ & 3 & 5 & 4 & 2 & 1 \\
\hline & Tiempo para exportar (días) & $10 \%$ & 3 & 5 & 2 & 1 & 4 \\
\hline & Tiempo para importar (días) & $10 \%$ & 3 & 5 & 2 & 1 & 3 \\
\hline & & PROMEDIO & 3.11 & 3.91 & 3.53 & 1.91 & 2.44 \\
\hline
\end{tabular}

Elaboración: Propia 


\section{CAPITULO 5: ESTUDIO TÉCNICO}

\subsection{Factores determinantes de tamaño}

\subsubsection{Demanda objetivo proyectado}

La demanda objetivo que se obtuvo del análisis en el capítulo anterior se espera iniciar con una participación del $8 \%$ para el primer año. El Cuadro $\mathrm{N}^{\circ} 5.1$ resume las cantidades proyectadas de exportación para los siguientes cinco años del proyecto:

\section{Cuadro No 5.1: Demanda proyectada en Kilogramos}

\begin{tabular}{|c|c|c|c|c|c|}
\hline AÑOS & $\mathbf{2 0 1 6}$ & $\mathbf{2 0 1 7}$ & $\mathbf{2 0 1 8}$ & $\mathbf{2 0 1 9}$ & $\mathbf{2 0 2 0}$ \\
\hline Demanda Objetivo (Kg) & 148 & 190 & 252 & 297 & 404 \\
\hline
\end{tabular}

Elaboración: propia

\subsubsection{Participación de Mercado}

$\checkmark$ En el Gráfico $\mathrm{N}^{\circ} 5.1$ se muestra los porcentajes de participación y se ha planteado empezar con $8 \%$ del total de las exportaciones peruanas de joyas de plata a Chile. Se empezará con esta cifra debido a que aparte de que se cuenta con mano de obra cualificada se tendrá contacto con clientes de Chile en las ferias comerciales.

$\checkmark$ Para el segundo año se plantea una participación del $10 \%$ como resultado de lograr mejores negociaciones y por la proyección de un incremento en la demanda.

$\checkmark$ En el tercer año se espera una participación aproximada del 13\% debido a que se adquirirá máquinas como la de fundición que permitirá un mejor control para el mezclado de los metales. Asimismo las estrategias de marketing y ventas beneficiarán para que la empresa aumente sus ventas.

$\checkmark$ En el cuarto año se espera un $15 \%$ de la participación porque la marca se va a ir consolidando en Chile gracias a la calidad y diversidad en los productos. 
$\checkmark$ Para el quinto año la participación será de 20\%, logrando un reconocimiento en Chile, se tratará de competir con empresas y marcas de otros países.

\section{Gráfico $\mathbf{N}^{0}$ 5. 1: Proyección de participación de mercado}

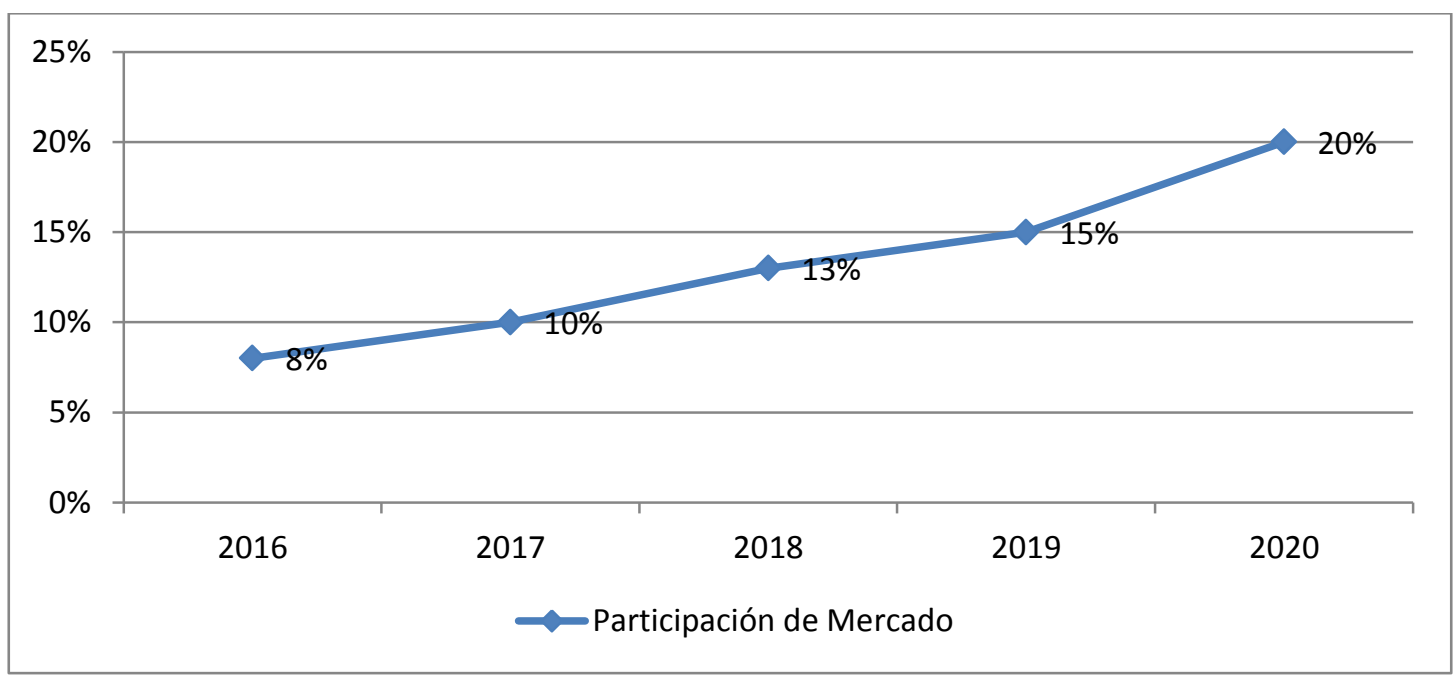

Elaboración propia

\subsubsection{Disponibilidad de insumos}

$\checkmark$ La disponibilidad de la plata para la joyería es alta lo cual beneficia al proyecto ya que es la principal materia prima, mientras que la producción de cobre no es una de las más altas en producción; sin embargo, no es el principal insumo.

\section{Imagen $N^{\circ}$ 5. 1: Plata y Cobre}
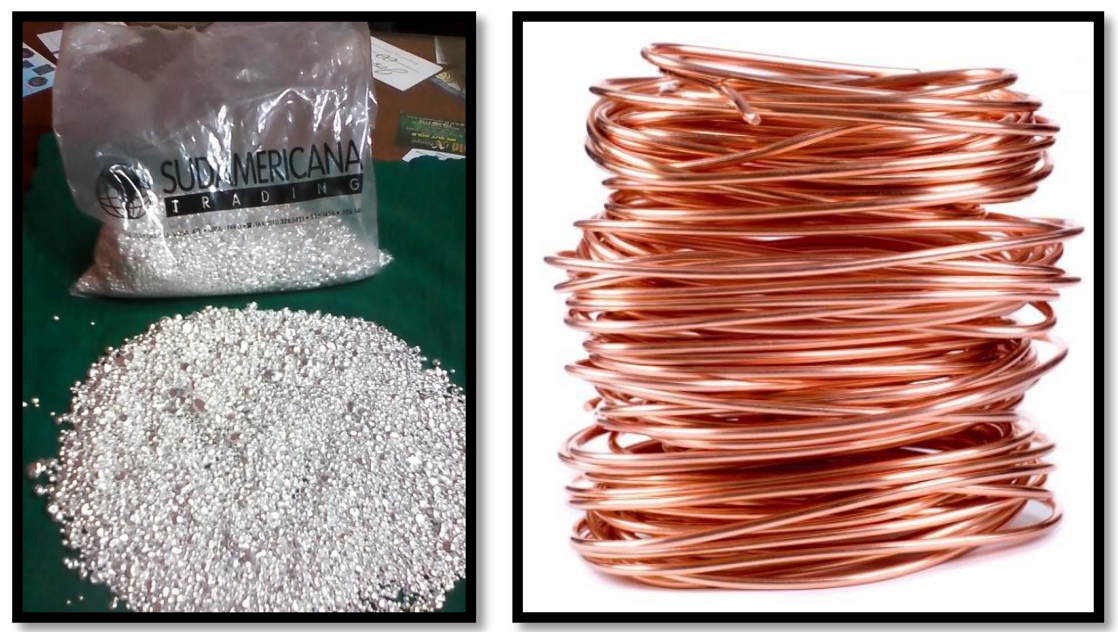

Fuente: Propia 
Las piedras naturales que usará la empresa se producen en Perú. Estas se obtienen de las minas y se puede encontrar en diversas partes de Lima de las cuales el proveedor elegido es ARTURINSA y ARTESANIA CCAHUANCA.

\section{Imagen $N^{0}$ 5. 2: Piedras Naturales}

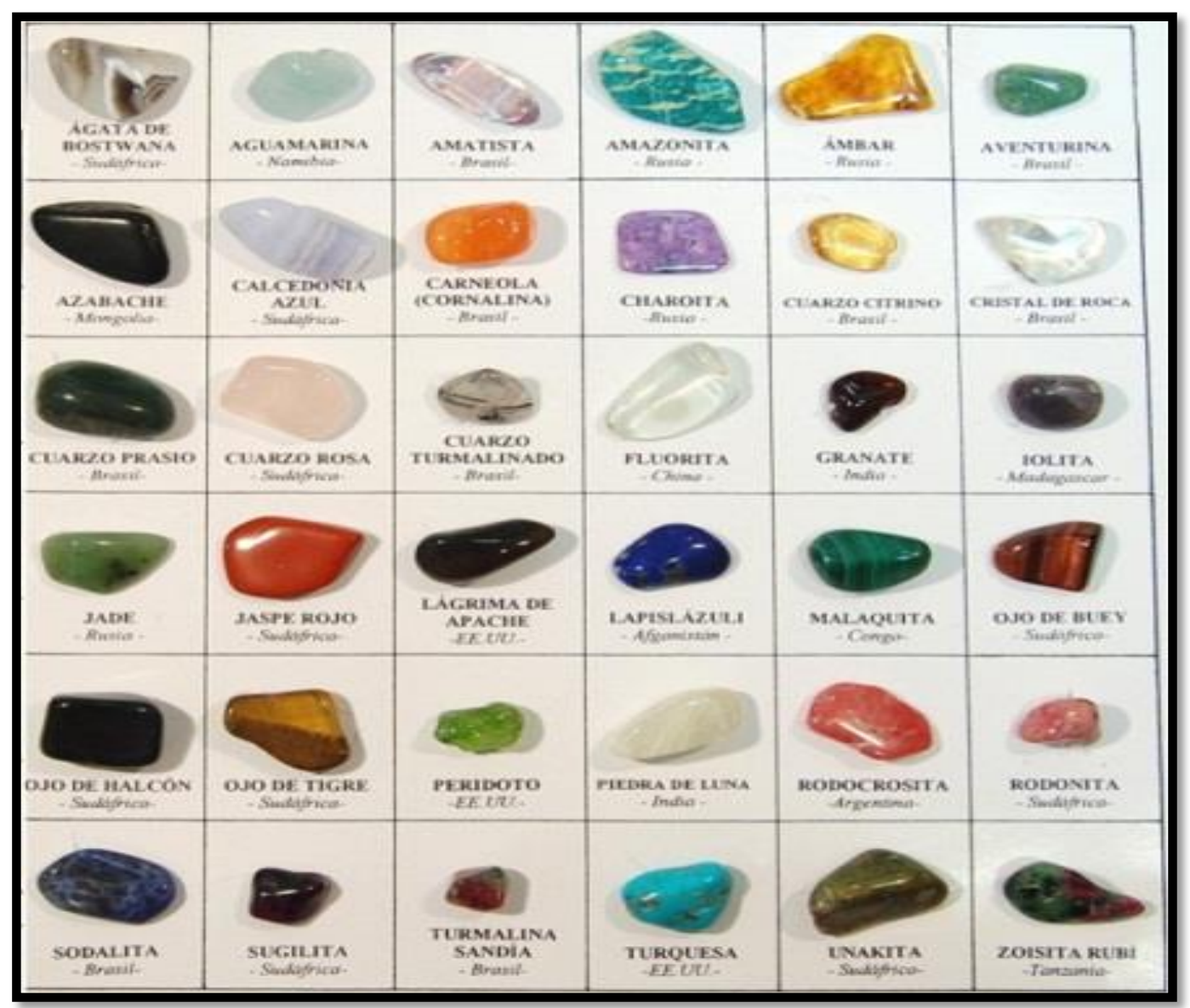

Fuente: PERU GEMS 


\subsection{Proceso y tecnología}

\subsubsection{Diagrama de Flujo del Proceso de Producción}

\section{Esquema $N^{\circ}$ 5. 1: Proceso Productivo}

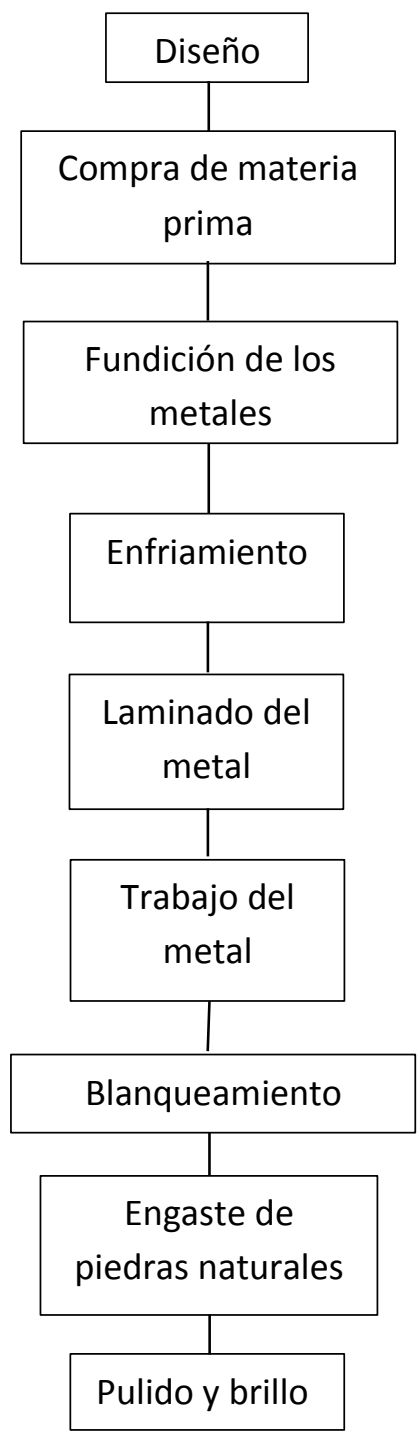

Elaboración: Propia

\subsubsection{Descripción de los principales procesos del proyecto}

\section{A. Diseño}

$\checkmark$ A través de las tendencias de la demanda en el país de destino se comienza a elaborar diseños. Los diseños se realizarán mediante un software adquirido por licencia desde el inicio de las operaciones de la empresa. 


\section{B. Compra de Materia Prima}

$\checkmark$ La plata se comprará de la PROCESADORA SUDAMERICANA

TRADING SA la cual será la principal proveedora. Antes de comprar, se debe inscribir en su base de datos. Asimismo, el cobre se comprará pero de minoristas garantizados.

$\checkmark$ Por otro lado, las piedras naturales se conseguirán de los proveedores ya mencionados y proporcionarán las piedras naturales en grandes tamaños.

\section{Fundición de los metales}

$\checkmark$ Se pesa tanto la plata y el cobre para tener una distribución específica para obtener las leyes correspondientes.

$\checkmark$ La plata y el cobre se colocan en un crisol de cera o granito para pasar a altas temperaturas en el área de fundición de metales.

\section{Enfriado}

$\checkmark$ Una vez que haya cambiado a su estado líquido, se vaciará a una lingotera previamente calentada para evitar accidentes.

$\checkmark$ Inmediatamente después se pasará a agua helada y se obtiene un lingote de plata 950 y otro de 925 .

\section{E. Laminado del Material}

$\checkmark$ Colocar el lingote de plata en la máquina laminadora ya sea eléctrica o manual.

$\checkmark$ Se debe colocar aproximadamente unas diez veces hasta obtener una lámina muy delgada para que se pueda trabajar la plata.

\section{F. Trabajo del metal}

$\checkmark$ Existen tres formas:

$>$ En primer lugar es a través de una máquina "estampadora" del cual se obtienen piezas de joyas. Este parte del proceso consiste en colocar una lámina del metal encima de la máquina la cual cortará la pieza según el molde solicitado. 
$>$ En segundo lugar está el proceso de la "cera perdida", que a diferencia de la estampadora, este brinda copias del producto final tales como anillos, dijes, gemelos y aretes. Se inicia con la preparación de los moldes hechos con cera para luego colocarlo en la inyectadora de cera. Se coloca todos los moldes de cera a la base de la inyectadora y después se recubre con yeso el cilindro y se espera a que seque. Finalmente se coloca la plata y el cobre según la Ley de joyería en el cilindro a altas temperaturas y así los metales se combinan y reemplazan a los moldes de cera, dejando varios modelos de joyas.

$>$ El tercer método es la producción manual en el cual el artesano usa de sus utensilios para poder producir joyas. Debido a que se producen una por una este método puede no ser beneficioso para la producción de altas cantidades a menos que se cuente con varios artesanos los cuales trabajen en un taller.

\section{G. Blanqueamiento}

$\checkmark$ Una vez terminado la joya se le coloca en un recipiente que contiene ácido sulfúrico para quitar las impurezas.

\section{H. Pulido y Brillo}

$\checkmark$ Las piezas pasas a pulirse en la máquina pulidora el cual consiste en un motor que permite girar a alta velocidad un pulidor. Se colocan sujetados con las manos las joyas en el pulidor giratorio hasta que alcance el pulido y brillo necesario.

\section{Engaste de las piedras naturales}

$\checkmark$ Hay que fijarlas en la pieza metálica de manera que luzca toda su belleza.

$\checkmark$ Finalmente se vuelve a pulir la joya con la piedra incrustada probando que esté firmemente engastada en el metal. 


\section{Cuadro $N^{\circ}$ 5. 2: Proceso del Proyecto}

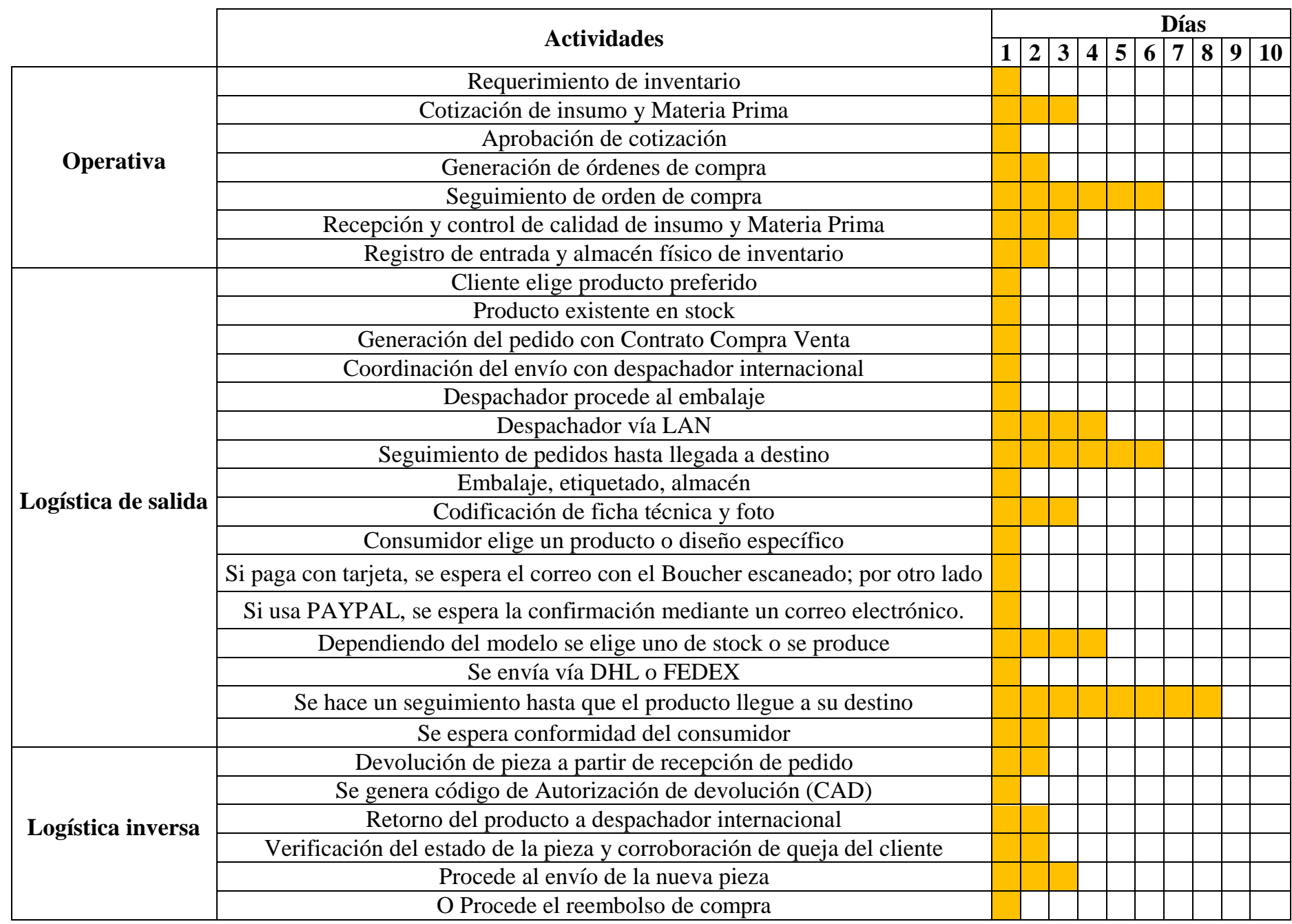

Elaboración: Propia

\subsection{Localización}

\subsubsection{Macro localización}

Para poder elegir la zona de trabajo se basa en las siguientes determinantes:

\section{A. Proximidad de las materias primas:}

En el territorio peruano existen refinadoras que operan con excelentes resultados. Está la refinería Southern Perú, que cuenta con la fundición y refinería de ILO, Oroya en Junín, Siderperú en Chimbote, Votorantim Metais con la refinería en Cajamarquilla y la refinería Procesadora Latinoamericana localizada en Ate. Las refinerías exportan la mayor parte de producción y el resto lo venden a los comercializadores locales. Por otro lado, no solo se puede adquirir de 
las refinadoras, sino también de comercializadores formales si la compra no requiere de gran cantidad.

\section{B. Disponibilidad de mano de obra}

Este factor es el más importante porque influye directamente en la joyería a producirse. Es una clave de éxito debido a que se necesitan artesanos capaces para la producción y el manejo de las máquinas y equipos.

\section{Cercanía a los medios de transporte}

La única manera para poder exportar de forma aérea debe ser a través del aeropuerto Jorge Chávez localizado en el callao. Otro medio como el terrestre suele usarse, pero depende de la rapidez con la que desea el cliente el producto.

\section{Disponibilidad de terrenos o alquileres}

Se requiere un espacio no muy grande ya que la mayoría del trabajo es artesanal e involucra solo unas cuantas máquinas pequeñas.

\section{E. Abastecimiento de servicios}

Es necesario contar con abastecimiento de electricidad ya que se necesitará para la iluminación en el trabajo de los artesanos y además para el correcto funcionamiento de las máquinas. Asimismo, el servicio de agua debe ser adecuado, constante y confiable principalmente para mantener la higiene del personal y para asegurar el correcto procedimiento de los procesos de producción.

A continuación, en el Cuadro $\mathrm{N}^{\circ} 5.3$ se analizará la importancia relativa de los principales factores de localización. Se necesitó codificar los nombres de los factores para poder presentarlo con mayor comodidad.
A: Proximidad de las materias primas
B: Disponibilidad de Mano de Obra
C: Cercanía de los medios de transporte
D: Disponibilidad de terrenos o alquileres
$\mathrm{E}$ : Abastecimiento de servicios 
Cuadro $N^{\circ}$ 5. 3: Matriz de enfrentamiento

\begin{tabular}{|c|c|c|c|c|c|c|c|}
\hline & A & B & C & D & E & Puntaje & Ponderación \\
\hline A & & 1 & 1 & 1 & 1 & 4 & $33 \%$ \\
\hline B & 1 & & 1 & 1 & 1 & 4 & $33 \%$ \\
\hline C & 0 & 0 & & 1 & 1 & 2 & $17 \%$ \\
\hline D & 0 & 0 & 0 & & 1 & 1 & $8 \%$ \\
\hline E & 0 & 0 & 0 & 1 & & 1 & $8 \%$ \\
\cline { 5 - 7 }
\end{tabular}

Elaboración: Propia

A continuación están los posibles Departamentos del Perú tomando en cuenta las ventajas de las mismas donde se puede establecer la empresa

\section{Lima}

-Se encuentra la refinería Cajamarquilla y Procesadora Latinoamericana.

-Hay gran cantidad de mano de obra disponible. Hay centros técnicos como SENATI donde actualmente brindan educación sobre joyería y orfebrería.

-El puerto Jorge Chávez se encuentra localizado en el Callao y es el único puerto del país que está permitido la exportación y la importación.

-El boom inmobiliario está permitiendo la construcción de varios centros con el fin de alquilarlos aunque la densidad poblacional en el departamento es muy alto.

-Los locales en Lima tienen buen suministro de agua y luz.

\section{Moquegua}

-Se encuentra localizada la refinería Southern Perú

-La cantidad de artesanos para el trabajo es limitada y hay pocos centros de capacitación para la joyería.

-Se encuentra en el sur del país; por lo tanto, el envío de la joyería por el medio de transporte terrestre sería beneficioso en costos. 
-Hay locales para alquilar debido a la baja densidad poblacional y los precios por metro cuadrado son baratos.

-El suministro de electricidad y agua es suficiente para las operaciones de producción.

\section{$\underline{\text { Junín }}$}

-Cuenta con la refinería de la Oroya

-El número de artesanos es alto debido a que existen gran cantidad de minoristas comerciales a la joyería.

-Localizado cerca a Lima para poder ser enviado vía aérea.

-Adecuado suministro de electricidad y agua.

-Disponibilidad de locales para alquiler más alta que en Lima e incluso a precios más bajos.

A continuación se evaluará y seleccionará la localización de la empresa. En el cuadro $\mathrm{N}^{\circ} 15$ hay una escala que asigna puntajes a los diferentes factores según en medida de cumplimiento. Este sistema se usará para las evaluaciones macro y micro localizaciones.

-1 - Malo

-2 - Regular

$-3-$ Bueno

-4 - Muy Bueno

-5 - Excelente

En el Cuadro $\mathrm{N}^{\circ} 5.4$ se ha establecido el puntaje a base de la calificación de cada factor el cual dio como resultado el departamento de Lima. 
Cuadro $N^{\circ}$ 5. 4: Ranking de factores de Macro localización

\begin{tabular}{|c|c|c|c|c|c|c|c|}
\hline \multirow{2}{*}{ Factores } & \multirow{2}{*}{ Ponderación } & \multicolumn{9}{|c|}{ Calificación } \\
\cline { 3 - 9 } & & \multicolumn{2}{|c|}{ Lima } & \multicolumn{2}{c|}{ Junín } & \multicolumn{2}{c|}{ Moquegua } \\
\cline { 3 - 9 } & & Calif & Ptje & Calif & Ptje & Calif & Ptje \\
\hline Proximidad a MP & $33.3 \%$ & 5 & 1.6 & 5 & 1.6 & 5 & 1.6 \\
\hline Disponibilidad de MO & $33.3 \%$ & 5 & 1.6 & 5 & 1.6 & 4 & 1.3 \\
\hline Cercanía de Medio Transporte & $16.8 \%$ & 4 & 0.6 & 3 & 0.5 & 2 & 0.3 \\
\hline Disponibilidad de alquiler & $8.3 \%$ & 2 & 0.1 & 5 & 0.4 & 5 & 0.4 \\
\hline Abastecimiento de servicios & $8.3 \%$ & 5 & 0.4 & 3 & 0.2 & 2 & 0.1 \\
\hline
\end{tabular}

Elaboración: Propia

\subsubsection{Micro localización:}

Ahora se tomará en cuenta la micro localización, la cual se empleará para saber en qué distrito de Lima operará la empresa. Se tomará en cuenta los distritos del Centro de Lima, Ate y Los olivos.

\section{Centro de Lima}

-Hay una distancia media de la refinería.

-Hay un alto número de artesanos para la elaboración de joyería. La mayoría cuenta con estudios técnicos mientras el resto solamente a través de la práctica.

-Localizado distante del aeropuerto Jorge Chávez por lo que se debe hacer sus precauciones para el envío de material de alto valor.

-Hay un adecuado suministro de agua y electricidad.

-Debido a la densidad poblacional, no hay una cantidad alta de locales que aseguren las operaciones.

$\underline{\text { Ate }}$

-Cerca de la refinadora Procesadora Latinoamericana de Ate

-El número de artesanos es muy similar a la del centro de Lima.

-Se encuentra lejos del aeropuerto. 
-El suministro de luz y agua es igual en toda la ciudad de Lima y con un costo fijo.

-Existen espacios para la producción industrial.

\section{$\underline{\text { Los Olivos }}$}

-Está alejado de las principales fuentes de materia prima

-Existe un número de artesanos muy similar al centro de Lima y Ate.

-Se encuentra alejado del aeropuerto Jorge Chávez

-El suministro de luz y agua es igual en toda la ciudad de Lima

-Hay disponibilidad moderada de locales industriales.

En el Cuadro $\mathrm{N}^{\mathrm{a}} 5.5$ se ha obtenido el puntaje para la micro localización el cual dio como resultado el centro de lima para tener las operaciones del proyecto.

\section{Cuadro $N^{0}$ 5. 5: Ranking de factores de Micro localización}

\begin{tabular}{|c|c|c|c|c|c|c|c|}
\hline \multirow{3}{*}{ Factores } & \multirow{3}{*}{ Ponderación } & \multicolumn{6}{|c|}{ Calificación } \\
\hline & & \multicolumn{2}{|c|}{$\begin{array}{l}\text { Centro de } \\
\text { Lima }\end{array}$} & \multicolumn{2}{|c|}{ Ate } & \multicolumn{2}{|c|}{ Los Olivos } \\
\hline & & Calif & Ptje & Calif & Ptje & Calif & Ptje \\
\hline Proximidad a MP & $33.3 \%$ & 5 & 1.6 & 5 & 1.6 & 3 & 0.9 \\
\hline Disponibilidad de MO & $33.3 \%$ & 5 & 1.6 & 5 & 1.6 & 5 & 1.6 \\
\hline Cercanía de Medio Transporte & $16.8 \%$ & 4 & 0.6 & 3 & 0.5 & 2 & 0.3 \\
\hline Disponibilidad de alquiler & $8.3 \%$ & 3 & 0.2 & 4 & 0.3 & 4 & 0.3 \\
\hline Abastecimiento de servicios & $8.3 \%$ & 5 & 0.4 & 5 & 0.4 & 5 & 0.4 \\
\hline & & & 4.6 & & 4.5 & & 3.7 \\
\hline
\end{tabular}

Elaboración: Propia

\subsubsection{Especificación del local en la situación con proyecto}

$\checkmark$ El local se localizará en Jr. Huallaga 123 debido a que en el centro de Lima se encuentran talleres para la joyería los cuales brindan servicio y facilita los costos al no tener acceso a los altos precios de maquinaria. 
$\checkmark$ El área del terreno es de $120 \mathrm{~m}^{2}$, el total del aforo es de 20 personas.

$\checkmark$ El local es de un piso con los siguientes ambientes:

-3 Oficinas administrativas

-1 sala de reuniones

-1 Área de Control de calidad

-2 baños

-Mesa de recepción

-Sala de espera

-Área de evacuación en caso de situaciones de desastres naturales.

\subsection{Actividades Pre operativas}

Antes de iniciar las operaciones, se adquirirán productos tangibles e intangibles para la empresa. A continuación se presenta el tiempo estimado para contar con todos los productos para dar el inicio de las operaciones.

\subsubsection{Adquisiciones Intangibles}

El plan de negocio también necesita de productos intangibles como en el caso de la tecnología para tener mejoras en los procesos administrativos y de producción como son los casos de una página web, licencias de software para diseño de joyas. El tiempo aproximado para la adquisición de estos bienes será de 5 meses por el tiempo de elaboración que demanda.

A continuación, en el cuadro $\mathrm{N}^{\mathrm{o}} 5.6$ se muestra el tiempo para la implementación de los productos intangibles en el proyecto. 
Cuadro $N^{0}$ 5. 6: Tiempo de adquisiciones de intangibles

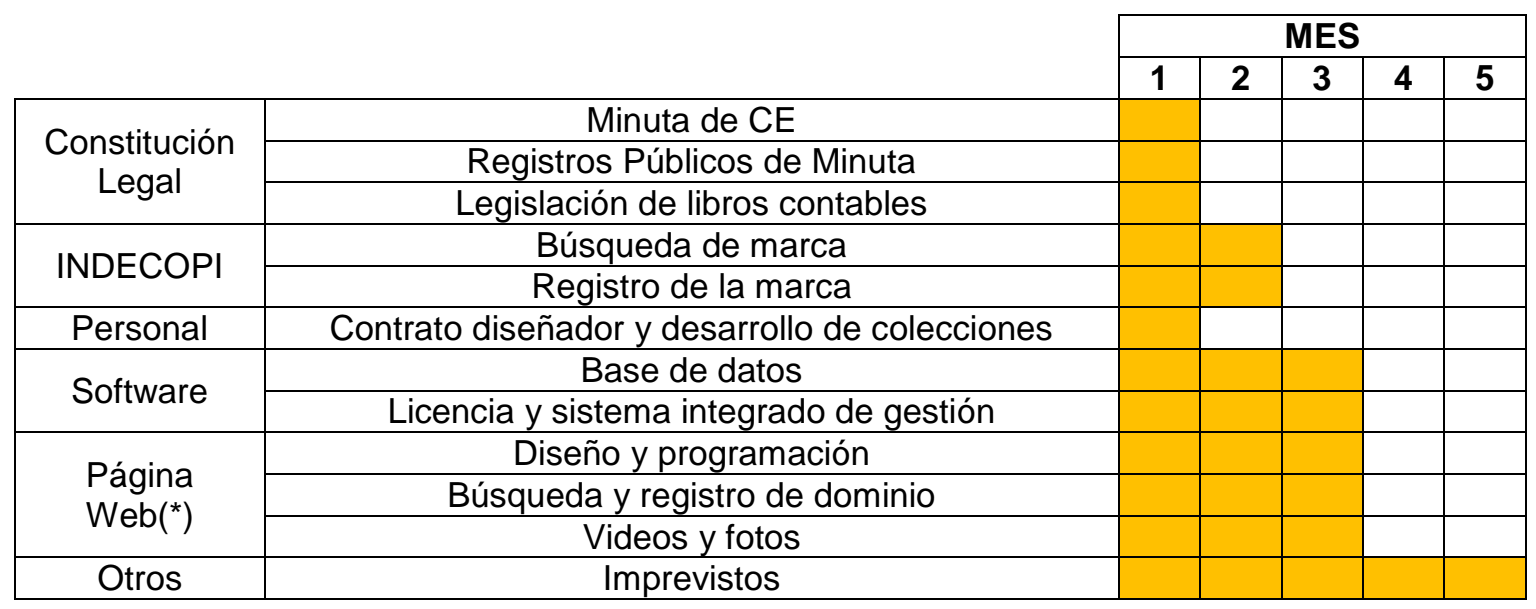

(*)A partir del tercer año

Elaboración: Propia

\subsubsection{Adquisiciones Tangibles}

Por otro lado, dentro de las adquisiciones tangibles están el equipo de cómputo, la materia prima, muebles, materiales para el control de calidad, suministro y la remodelación y equipamiento del inmueble. El tiempo para adquirir estos bienes será de dos meses aproximadamente tal cual se muestra en el Cuadro $\mathrm{N}^{\circ}$ 5.7.

\section{Cuadro $\mathrm{N}^{\circ}$ 5. 7: Tiempo de adquisiciones de tangible}

\begin{tabular}{|c|c|c|c|c|}
\hline & & \multicolumn{3}{|c|}{ MES } \\
\hline & & 1 & 2 & 3 \\
\hline \multirow{4}{*}{$\begin{array}{l}\text { Procesamiento de datos y } \\
\text { cómputo }\end{array}$} & Computo - Laptop & & & \\
\hline & Impresora - Fax & & & \\
\hline & Internet & & & \\
\hline & Teléfono - Celulares & & & \\
\hline \multirow{3}{*}{ Materia Prima } & Plata & & & \\
\hline & Cobre & & & \\
\hline & Piedra Natural & & & \\
\hline \multirow{4}{*}{ Muebles y enseres } & Escritorio & & & \\
\hline & Silla & & & \\
\hline & Útiles de oficina & & & \\
\hline & Tarjeta de presentación & & & \\
\hline \multirow{3}{*}{$\begin{array}{l}\text { Departamento de control de } \\
\text { calidad }\end{array}$} & Material para limpieza de joya & & & \\
\hline & Lupa pequeña & & & \\
\hline & Líquidos pulidores & & & \\
\hline Suministro & Extintor, botiquín & & & \\
\hline Inmueble & Remodelación & & & \\
\hline
\end{tabular}

Elaboración: Propia 


\subsection{Requerimiento de materia prima y servicios directos}

$\checkmark$ La materia prima para el proyecto será la plata en ley 950, 925 y las piedras semipreciosas:

-Obsidiana,

-Serpentina,

-Turquesa,

-Amatista,

-Leopardita

-Onix

$\checkmark$ Los servicios del artesano será:

-Elaboración de las joyas

-Incrustaciones de las piedras naturales en las joyas.

\subsection{Requerimiento de insumo}

-Bencina

-Plata

-Cobre

\subsection{Mano de obra directa}

$\checkmark$ El “TALLER MARTINEZ E.I.R.L." cuenta con 8 artesanos de joyas y 3 artesanos de piedras naturales.

$\checkmark$ Se hacen las negociaciones para que el taller tome como prioridad a la producción del proyecto puesto que también pueden producir de otras joyerías.

$\checkmark$ Se hará un contrato entre el taller y la empresa el cual se tomará más precisión en los puntos de producción, precio, tiempo para que la empresa no se perjudique por las demoras en la producción del taller.

\subsection{Factores indirectos de operación}

$\checkmark$ El gerente general

$\checkmark$ Jefe comercial

$\checkmark$ Asistente de operación.

\subsection{Requerimiento de suministro}

$\checkmark$ Servicio de luz

$\checkmark$ Agua 
$\checkmark$ Internet

$\checkmark$ Comunicación por teléfono y celular

5.10. Requerimiento de servicios indirectos

Todo requerimiento para servicios indirectos los dispondrá los mismos talleres de joyería debido a su maquinaria tal cual se muestra en el Anexo 41. 


\section{CAPITULO 6: EL ESTUDIO DE LA ORGANIZACIÓN}

\subsection{Estructura Organizativa}

La empresa con nombre "JOYERIA BARI E.I.R.L." se basará en producir y exportar joyería a base de plata peruana con piedras naturales.

\subsubsection{El Organigrama Funcional}

Esquema $N^{\circ}$ 6. 1: Organigrama de la empresa

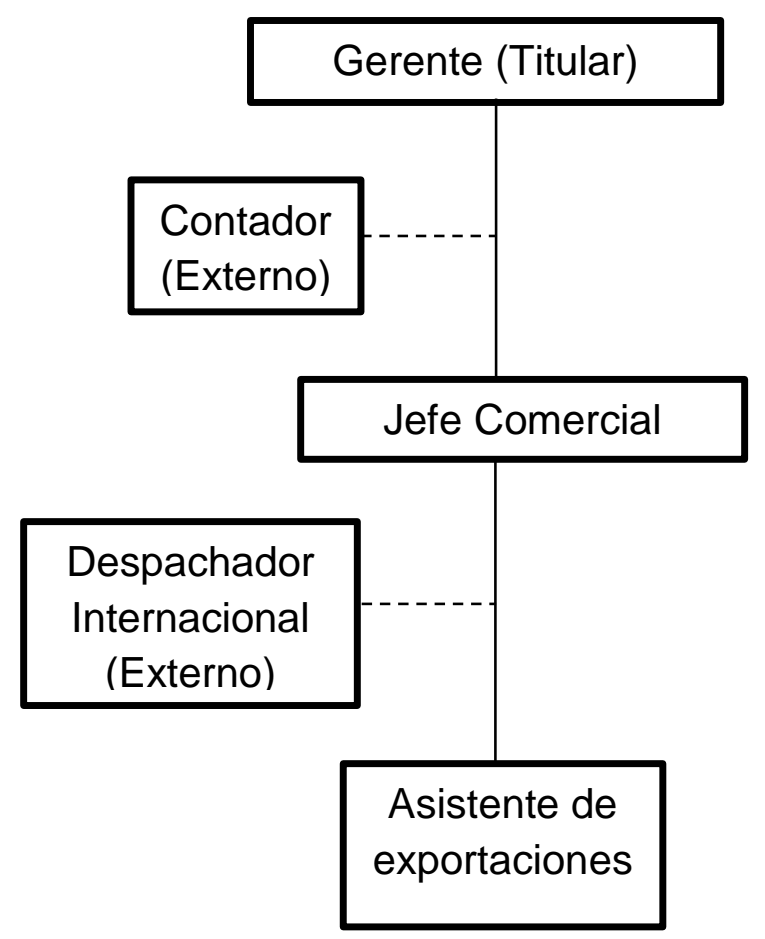

Elaboración: Propia 


\subsubsection{Objetivo de personal, requerimientos y perfiles}

\section{A. Objetivo de personal}

-El mantener y reclutar empleados identificados con la filosofía de la empresa, el respeto por la diversidad laboral y de empleados y el respaldo para lograr la igualdad en la motivación de los empleados.

-Lograr la satisfacción de los colaboradores en su puesto de trabajo, valorando sus propuestas y conocimientos en el rubro.

-Lograr un clima laboral estable y motivado, permitiéndoles desarrollar su máximo potencial.

-Lograr que el personal esté satisfecho con su salario.

-Obtener personal identificada con la cultura y valor de la empresa.

\section{B. Requerimientos:}

-Contratación de personal se realizará según referencias y recomendaciones de expertos del rubro para los cargos administrativos. Con respecto al personal externo, la selección se hará a través de anuncios vía internet.

-Proceso de selección comprende la evaluación del perfil profesional evaluación de competencias en el rubro, conocimiento del idioma a inglés, examen psicológico y entrevista personal.

-En el proceso de reclutamiento se tomará en consideración la aptitud y el profesionalismo del colaborador.

\section{Política de la empresa - Recursos Humanos}

-El personal seleccionado inicia un periodo de inducción de 3 días. Aprende la política, valores y exigencias de la empresa.

-Una vez seleccionado el personal a cargo, tendrá una prueba de 3 meses en el cual se evaluará el rendimiento de la persona. En caso logre superar o dar con las expectativas se hará contrato; sin embargo si no cumple se volverá a realizar otra selección. 
-Personal administrativo y gerencia tienen un horario de lunes a viernes de 8:00 a 6:00 P.M. y sábados de 8:00 a 1:00 PM con un refrigerio entre la 1:00 y 2:00 PM.

-Pago en cuenta sueldo BBVA último día útil del mes.

-La vestimenta será casual para la presencia en la oficina.

-El sueldo comprenderá de 12 sueldos mensuales trabajados, 2 gratificaciones (Julio y Diciembre), 9\% de ESSALUD, AFP Prima 13\%, CTS (1/2 sueldo), 15 días de vacaciones, según el Régimen Laboral Especial para Pequeña Empresa.

-Las vacaciones son previa aprobación del gerente y no serán cuando haya mucha carga laboral.

-Contador se presenta durante horario de oficina para hacer cálculos de impuestos a la renta e IGV a quien se le pagará US\$71 o S/.250 mensual.

\section{Cuadro $N^{\circ}$ 6. 1: Descripción del personal en la empresa}

\begin{tabular}{|c|c|c|c|c|}
\hline Cargo & Funciones & Perfil & $\begin{array}{l}\text { Tipo de } \\
\text { Contrato }\end{array}$ & Beneficio \\
\hline $\begin{array}{l}\text { Gerente } \\
\text { General }\end{array}$ & $\begin{array}{c}\text { Representante legal de la empresa. } \\
\text { Selección, contratación, evaluación } \\
\text { de personal. } \\
\text { Supervisión del proceso de pago } \\
\text { Velar por el cumplimiento de política } \\
\text { y norma. } \\
\text { Integrar equipos de acción. } \\
\text { Revisar cada joya producida. } \\
\text { Estrategias para un mejor } \\
\text { posicionamiento de la empresa. }\end{array}$ & $\begin{array}{c}\text { Estudios superiores en } \\
\text { Economía, } \\
\text { Administración o } \\
\text { Negocios } \\
\text { Internacionales. } \\
\text { Licenciado en Negocios } \\
\text { Internacionales } \\
\text { Nivel avanzado de inglés } \\
5 \text { años de experiencia } \\
\text { en el rubro. }\end{array}$ & $\begin{array}{c}\text { En planilla } \\
\text { Contrato } \\
\text { indeterminad } \\
0\end{array}$ & $\begin{array}{c}\text { Fijo } \\
\text { US } \$ 573 \text { o } \\
\text { S/.2,000 }\end{array}$ \\
\hline $\begin{array}{c}\text { Jefe } \\
\text { Comercial }\end{array}$ & $\begin{array}{c}\text { Control de calidad en toda la } \\
\text { cadena de valor. } \\
\text { Realizar investigación de nuevos } \\
\text { mercados. }\end{array}$ & $\begin{array}{c}\text { Egresado en Economía, } \\
\text { Administración o } \\
\text { Negocios } \\
\text { Internacionales. } \\
2 \text { años de experiencia en } \\
\text { el rubro }\end{array}$ & $\begin{array}{c}\text { En planilla } \\
\text { Contrato } \\
\text { indeterminad } \\
0\end{array}$ & $\begin{array}{l}\text { Fijo } \\
\text { US } \$ 487 \text { o } \\
\text { S/1,700 }\end{array}$ \\
\hline $\begin{array}{l}\text { Asistente de } \\
\text { exportación }\end{array}$ & $\begin{array}{l}\text { Coordinación de despachos de } \\
\text { pedidos. } \\
\text { Seguimiento de los despachos } \\
\text { hasta ser recepcionado por el } \\
\text { cliente. } \\
\text { Solicitud de cotización. } \\
\text { Llevar control de inventarios. }\end{array}$ & $\begin{array}{l}\text { Estudiante de últimos } \\
\text { ciclos o egresado de la } \\
\text { carrera de Negocios } \\
\text { Internacionales. } \\
1 \text { año de experiencia }\end{array}$ & $\begin{array}{l}\text { En planilla } \\
\text { Contrato } \\
\text { renovable }\end{array}$ & $\begin{array}{l}\text { Fijo } \\
\text { US } \$ 257.9 \\
\text { o } S / 900\end{array}$ \\
\hline
\end{tabular}

Elaboración: Propia 


\subsection{Visión, Misión y Valores}

\subsubsection{Visión}

Lograr la consolidación y posicionamiento de nuestra empresa como líder en la comercialización de joyas de plata.

\subsubsection{Misión}

Somos una empresa que comercializa joyas de plata con incrustaciones de piedras naturales, logrando la plena satisfacción de nuestros clientes a través de diseños innovadores.

\subsubsection{Valores}

$\checkmark$ Respeto: Condición indispensable para buena relación profesional.

$\checkmark$ Comunicación: Tenemos la obligación de comunicar. Creemos que la información implica mover y que la información mueva a las personas.

$\checkmark$ Confianza: Establecer relaciones a largo plazo en el cual se crea en los negocios entre ambos y sea ganar - ganar.

$\checkmark$ Responsabilidad: Componente motivador de empleado.

$\checkmark$ Profesionalismo: En el desempeño de las obligaciones.

$\checkmark$ Orientación hacia el servicio e innovación: Diferenciarnos de los competidores con un mejor producto y servicio al cliente.

$\checkmark$ Honestidad y transparencia: En las negociaciones y en las toda actividad y proceso de la empresa. 


\section{CAPITULO 7: ESTUDIO LEGAL}

\subsection{Formas Societarias}

Dentro de los regímenes de formas societarias, se elegirá ser una persona jurídica debido al uso de un capital social independiente del capital personal.

Asimismo, existen varios tipos de empresas jurídicas dentro de las cuales se elegirá EIRL, logrando tener el nombre de “JOYERIA BARI E.I.R.L.”. En el Anexo 42 se muestra la disponibilidad del nombre.

A continuación se señalan las premisas de constitución de la empresa:

-Tipo de Sociedad: E.I.R.L.

-Razón Social: JOYERIA BARI E.I.R.L.

-Nombre Comercial: JOLIBARI

-Rubro: Otros tipos de venta al por menor

-Giro del negocio: Comercialización de joyas de plata

-Accionariado: El propietario es Giancarlo Barreto Rimay a un 100\% al ser el único representante

-Domicilio Legal: Jr. Huallaga 123

\subsubsection{Justificación de la Forma Societaria}

$\checkmark$ La EIRL se forma por la voluntad de una persona a fin de desarrollar actividades económicas así que no se necesita conseguir otro socio para el inicio de la empresa. En el Anexo 43 está la minuta para la constitución de una EIRL.

$\checkmark$ Al tratarse de un negocio en el cual prevalece el diferenciador para un público objetivo, no es necesario tener una compleja estructura como las sociedades con acciones.

$\checkmark$ La formación de una asociación podría ser recomendable en el caso de tener uno o más socios que aporten capital; sin embargo, todo el capital será aportado por una persona que en este caso sería el titular responsable.

$\checkmark$ El titular asume la responsabilidad de titular - gerente. 


\subsubsection{Flujo grama de Creación de la Empresa}

\section{Esquema N$^{0}$ 7. 1: Proceso de creación de una empresa en Perú}

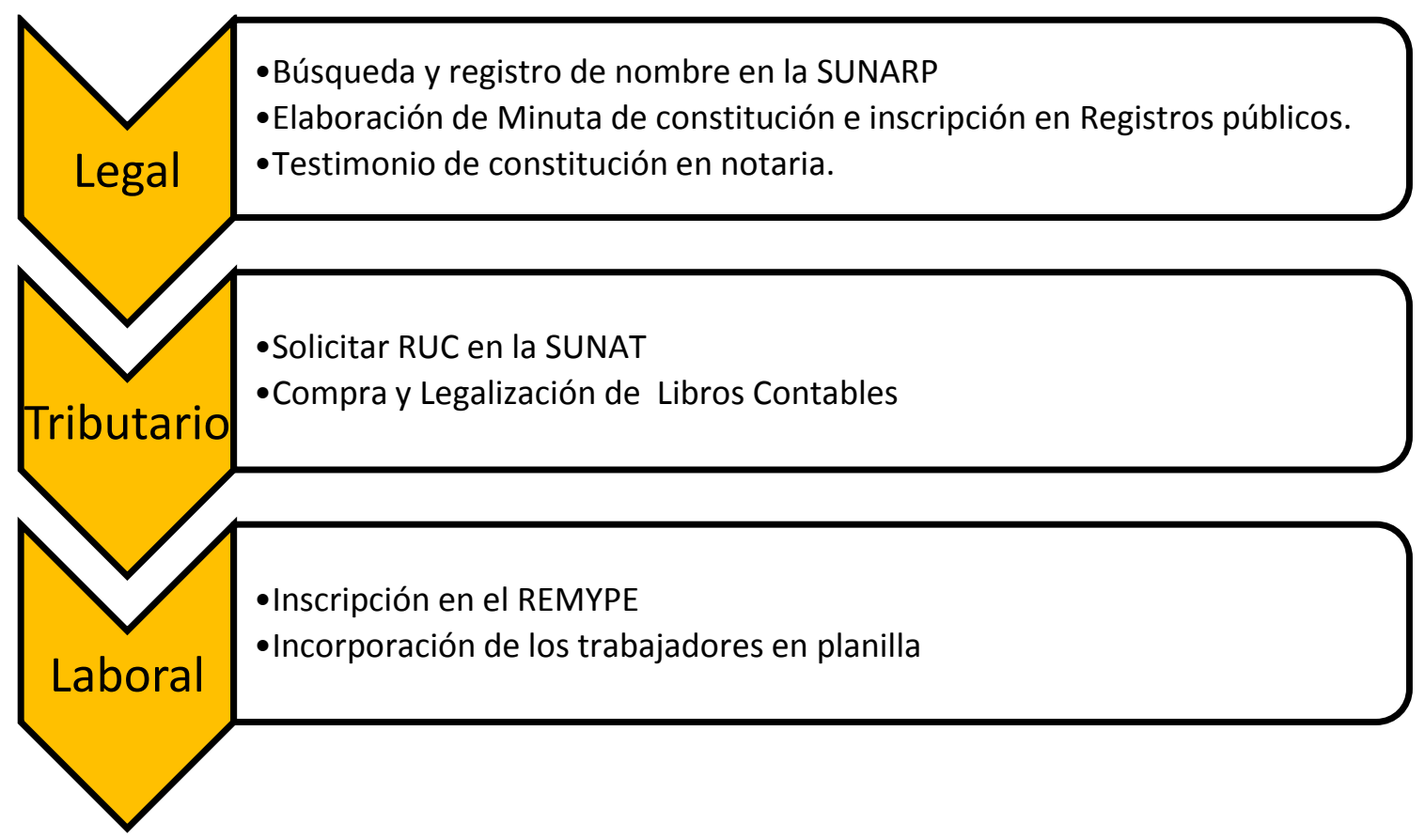

Elaboración: Propia

El presente plan de negocio se considera como pequeña empresa porque durante los años de proyección se tendrá las siguientes características:

-De 1 hasta 100 trabajadores

-Ingresos anuales mayores a 150 UIT (S/ 592,500 o US\$169,770) y no mayores a 1,700 UIT (S/.6,715,000 o US\$1,924,068). El UIT equivale a S/. 3,950 en el año 2016.

Remuneración Mínima de S/. 750 para los trabajadores

-Jornada-Horario de 8 horas diarias o 48 horas semanales

-Personal en Planilla

Asimismo se debe considerar los gastos para el personal que incurren mensualmente:

-ESSALUD representa 9\% del sueldo

-AFP Prima de $13 \%$

-Despido laboral: 20 Remuneraciones diarias por cada año

-CTS: $1 / 2$ sueldo por año de trabajo 
-Gratificaciones: $1 / 2$ Sueldo en Julio y Diciembre

-Derecho a 15 días de vacaciones por cada año de trabajo.

\subsubsection{Legislación arancelaria-tributaria.}

\section{A. Legislación Arancelaria}

Los productos que se producen y comercializan a Chile son joyas de plata la cual tiene la siguiente Sub partida Nacional: 7113110000

Según el Decreto Legislativo Nº 1053 (Perú), se aprueba la nueva Ley General de Aduanas la cual explica dentro de la Nota 9 del Capítulo 71 lo siguiente sobre artículo de joyería:

"Los pequeños objetos utilizados como adorno personal (por ejemplo: sortijas, pulseras, collares, broches, pendientes, cadenas de reloj, dijes, colgantes, alfileres y botones de corbata, gemelos, medallas o insignias, religiosas u otras)"

"Estos artículos pueden combinarse o incluir, por ejemplo: perlas finas (naturales) o cultivadas, piedras preciosas o semipreciosas (naturales, sintéticas o reconstituidas), concha, nácar, marfil, ámbar natural o reconstituido, azabache o coral."

En un futuro se plantea importar piedras naturales o preciosas desde la India ya que presenta precios muy competitivos manteniendo estándares altos de calidad, con esto se podría obtener beneficios del régimen del DRAWBACK. De este régimen tenemos la siguiente definición:

"Régimen aduanero que permite, como consecuencia de la exportación de mercancías, obtener la restitución total o parcial de los derechos arancelarios, que hayan gravado la importación para el consumo de las mercancías contenidas en los bienes exportados o consumidos durante su producción."

Por otro lado está la Tabla de Sanciones previstas en la Ley General de Aduanas las cuales son aplicables a los operadores de comercio 
exterior, despachadores de aduana, consignatarios, consignantes, dueños, transportistas, agentes de carga internacional, almacenes aduaneros, empresas de servicios postales, servicios de entrega rápida y concesionarios de almacenes libres. Las infracciones pueden inhabilitar, comisar o sancionar lo cual perjudica económicamente a las empresas.

Los impuestos vigentes para la exportación de joyas de plata de Perú a Chile se han liberalizado en su totalidad $(100 \%$ a consecuencia del TLC Perú-Chile), mientras que el pago del seguro está en un 3\% del valor FOB.

\section{B. Legislación Tributaria}

La empresa "JOYERIA BARI E.I.R.L." estará bajo el régimen general lo cual significa que estará afecto al impuesto a la renta (tercera categoría) e IGV. Las características de los impuestos se describen a continuación:

-Impuesto a la renta (3ra categoría) es de 27\% anual (Año 2016).

-Impuesto General a las Ventas es $18 \%$ sobre las ventas.

-El pago se efectúa dentro de los tres primeros meses del año siguiente.

\subsubsection{Legislación Ambiental}

$\checkmark$ Actualmente el Ministerio de Ambiente está incentivando una gestión de residuos sólidos y químicos dentro de las empresas la cual favorece la calidad de vida de los trabajadores.

$\checkmark$ Asimismo, se está destruyendo toda maquinaria y motores que usan aquellas personas dedicadas a la minería ilegal. Hoy, la minería ilegal se presenta como una de las principales amenazas a los bosques amazónicos por ejemplo. 


\section{CAPITULO 8: FUDAMENTOS FINANCIEROS}

En este último capítulo se hizo un análisis en el cual se demuestra la viabilidad del proyecto teniendo en cuenta estos datos:

- Tipo de cambio: S/ 3.49 (Enero 2016)

- Préstamo bancario: 30\% de la inversión inicial más capital de trabajo. El monto de préstamo será de US\$12,248 en dos años con una tasa de $25 \%$ anual.

- Todos los montos de dinero están expresados en Dólares Americanos (US\$)

- Constituido bajo el Régimen General, Pequeña Empresa (Venta mínima 150 UIT $=$ US\$169,285 y venta máxima de 1,700 UIT= US\$1,918,571)

- UIT(2016): 3,950 e IR(Enero2016): 27\%

- El Capital Trabajo inicial es para los tres primeros meses de operación

- INCOTERMS 2010

Cuadro $\mathrm{N}^{\circ}$ 8. 1: Proyección de ventas de joyas de plata en Kilogramos

\begin{tabular}{|c|c|}
\hline \multicolumn{2}{|c|}{ Proyección } \\
\hline Año & Kg \\
\hline 2016 & 148.23 \\
\hline 2017 & 189.59 \\
\hline 2018 & 251.81 \\
\hline 2019 & 296.83 \\
\hline 2020 & 404.43 \\
\hline
\end{tabular}

Elaboración: Propia

\subsection{Estructura de costos fijos y variables}

\subsubsection{Costos fijos}

Dentro de los costos se considera los pagos por servicio de telefonía fija, internet y Línea de Celular, el alquiler del local para las operaciones administrativas, el pago al personal y los costos para la estrategia de penetración de mercado. En el Anexo 44 se presenta detalladamente los gastos para el personal. 


\section{Cuadro N 8. 2: Costos Fijos}

\begin{tabular}{|c|c|c|c|c|c|c|}
\hline \multicolumn{7}{|c|}{ COSTOS FIJOS } \\
\hline CONCEPTO & $\begin{array}{c}\text { MENSUAL } \\
\text { TOTAL }\end{array}$ & 2016 & 2017 & 2018 & 2019 & 2020 \\
\hline $\begin{array}{c}\text { Internet - } \\
\text { servicio }\end{array}$ & 37.2 & 447.0 & 447.0 & 447.0 & 447.0 & 447.0 \\
\hline $\begin{array}{c}\text { Teléfono - } \\
\text { servicio }\end{array}$ & 43.0 & 515.8 & 515.8 & 515.8 & 515.8 & 515.8 \\
\hline $\begin{array}{c}2 \text { Planes de } \\
\text { celular }\end{array}$ & 80.2 & 962.8 & 962.8 & 962.8 & 962.8 & 962.8 \\
\hline $\begin{array}{c}\text { Alquiler y } \\
\text { Mantenimiento } \\
\text { de local }(*) \\
\end{array}$ & 859.6 & $10,315.2$ & $10,315.2$ & $10,515.2$ & $10,515.2$ & $10,515.2$ \\
\hline \multirow[t]{2}{*}{ Pago a personal } & $1,418.4$ & $17,021.1$ & $17,021.1$ & $17,021.1$ & $17,021.1$ & $17,021.1$ \\
\hline & TOTAL & $29,261.8$ & $29,261.8$ & $29,461.8$ & $29,461.8$ & $29,461.8$ \\
\hline
\end{tabular}

(*) Desde el año 2018 habrá un incremento en los gastos de electricidad por las nuevas máquinas.

Elaboración: Propia

\subsubsection{Costos variables}

Dentro de los costos variables está el costo de la materia prima, del servicio de producción, costos de exportación y de agente de aduanas. Este costo varía según la cantidad de producción durante los cinco años del proyecto. En el Anexo 45 se explica detalladamente el total de unidades producidas.

\section{Cuadro N 8. 3: Costos Variables}

\begin{tabular}{|c|c|c|c|c|c|c|c|c|c|c|c|}
\hline $\begin{array}{l}\text { COSTO VARIABLE } \\
\text { O DIRECTOS }\end{array}$ & \multirow{2}{*}{$\begin{array}{c}\text { Costo } \\
\text { unitario } \\
\text { variable }\end{array}$} & \multicolumn{2}{|c|}{2016} & \multicolumn{2}{|c|}{2017} & \multicolumn{2}{|c|}{2018} & \multicolumn{2}{|c|}{2019} & \multicolumn{2}{|c|}{2020} \\
\hline CONCEPTO & & Cantidad & $\begin{array}{l}\text { Costo } \\
\text { Total } \\
\end{array}$ & Cantidad & $\begin{array}{l}\text { Costo } \\
\text { Total } \\
\end{array}$ & Cantidad & $\begin{array}{l}\text { Costo } \\
\text { Total } \\
\end{array}$ & Cantidad & $\begin{array}{l}\text { Costo } \\
\text { Total } \\
\end{array}$ & Cantidad & $\begin{array}{l}\text { Costo } \\
\text { Total } \\
\end{array}$ \\
\hline $\begin{array}{c}\text { MP - Piedra } \\
\text { Naturales } \\
\end{array}$ & 0.050 & 56,744 & 2,837 & 72,570 & 3,629 & 96,432 & 4,822 & 113,652 & 5,683 & 154,898 & 7,745 \\
\hline MP - Plata Pura & 0.559 & 85,635 & 47,887 & 109,519 & 61,243 & 145,530 & 81,381 & 171,518 & 95,913 & 233,764 & 130,722 \\
\hline MP - Cobre & 0.009 & 5,709 & 50 & 7,301 & 64 & 9,702 & 85 & 11,435 & 100 & 15,584 & 136 \\
\hline $\begin{array}{c}\text { Servicio de Fundición } \\
(950-925)\end{array}$ & 0.014 & 91,344 & 1,309 & 116,820 & 1,674 & 155,232 & 2,224 & 182,952 & 2,621 & 249,348 & 3,572 \\
\hline $\begin{array}{c}\text { Servicio de } \\
\text { Producción de la } \\
\text { Plata }(950 \text { - 925) }\end{array}$ & 0.573 & 91,344 & 52,346 & 116,820 & 66,946 & 155,232 & 88,958 & 182,952 & 104,844 & 249,348 & 142,893 \\
\hline $\begin{array}{c}\text { Servicio de Tallado e } \\
\text { incrustación de } \\
\text { piedras } \\
\end{array}$ & 0.573 & 56,744 & 32,518 & 72,570 & 41,587 & 96,432 & 55,262 & 113,652 & 65,130 & 154,898 & 88,767 \\
\hline Embalaje & 0.040 & 6,927 & 278 & 8,859 & 355 & 11,767 & 472 & 13,870 & 556 & 18,899 & 758 \\
\hline $\begin{array}{c}\text { Gastos de Transporte } \\
\text { Interno + Seguro } \\
\end{array}$ & 0.003 & 148,088 & 424 & 189,390 & 543 & 251,664 & 721 & 296,604 & 850 & 404,246 & 1,158 \\
\hline Gasto de Estiba & 0.080 & 148,088 & 11,847 & 189,390 & 15,151 & 251,664 & 20,133 & 296,604 & 23,728 & 404,246 & 32,340 \\
\hline $\begin{array}{c}\text { Serv. Agente Aduana } \\
\text { FCA }(1.5 \%)\end{array}$ & 0.015 & 148,088 & 2,221 & 189,390 & 2,841 & 251,664 & 3,775 & 296,604 & 4,449 & 404,246 & 6,064 \\
\hline
\end{tabular}

Elaboración: Propia 
Asimismo se presenta el valor de las joyas FCA-Callao (Franco Transportista) para cada año. El INCOTERM 2010 - FCA indica que el comprador es quien se hace cargo de los costos del transporte principal y el seguro, por lo que no será tomado en cuenta en el costeo. En el Anexo 46 están los factores involucrados para el costo de la joya de ley 950 y 925

Cuadro $N^{\circ}$ 8. 4: Precio del producto anual en INCOTERM - FCA

\begin{tabular}{|c|c|c|c|c|c|c|}
\hline INCOTERM & Concepto & $\mathbf{2 0 1 6}$ & $\mathbf{2 0 1 7}$ & $\mathbf{2 0 1 8}$ & $\mathbf{2 0 1 9}$ & $\mathbf{2 0 2 0}$ \\
\hline \multirow{4}{*}{ EXW } & Costo de Producción & 136,947 & 175,142 & 232,731 & 274,290 & 373,834 \\
\cline { 2 - 7 } & Embalaje & 278 & 355 & 472 & 556 & 758 \\
\cline { 2 - 7 } & Costo total & 137,225 & 175,498 & 233,203 & 274,847 & 374,593 \\
\cline { 2 - 7 } & Utilidad & 45,368 & 58,042 & 76,980 & 90,791 & 123,594 \\
\cline { 2 - 7 } & Venta & 182,593 & 233,539 & 310,183 & 365,637 & 498,187 \\
\hline \multirow{4}{*}{ FCA } & Transporte + Seguro & 424 & 543 & 721 & 850 & 1,158 \\
\cline { 2 - 7 } & Agente Aduana (Doc.) & 2,221 & 2,841 & 3,775 & 4,449 & 6,064 \\
\cline { 2 - 7 } & Gastos Estiba & 11,847 & 15,151 & 20,133 & 23,728 & 32,340 \\
\cline { 2 - 7 } & TOTAL & $\mathbf{1 9 7 , 0 8 6}$ & $\mathbf{2 5 2 , 0 7 4}$ & $\mathbf{3 3 4 , 8 1 2}$ & $\mathbf{3 9 4 , 6 6 5}$ & $\mathbf{5 3 7 , 7 4 8}$ \\
\hline
\end{tabular}

Elaboración: Propia

\subsection{Estructura de Inversión}

La mayoría de estos costos representan todos los gastos que se han realizado antes del inicio del proyecto, mientras que hay algunos que se invertirá en el tercer año. En primer lugar se presenta la inversión intangible para la realización del proyecto y luego la inversión tangible.

\section{Cuadro $N^{0}$ 8. 5: Inversión intangible del proyecto}

\begin{tabular}{|c|c|c|c|c|c|c|}
\hline \multicolumn{7}{|c|}{ INVERSION INTANGIBLE } \\
\hline CONCEPTO & $($ Año 0) & $\mathbf{2 0 1 6}$ & $\mathbf{2 0 1 7}$ & $\mathbf{2 0 1 8}$ & $\mathbf{2 0 1 9}$ & $\mathbf{2 0 2 0}$ \\
\hline Registro de Marca & 286.5 & - & - & - & - & - \\
\hline Diseño de Página Web & 859.6 & - & - & - & - & - \\
\hline Software de Diseño de joyas & 687.7 & - & - & - & - & - \\
\hline Estudio del Proyecto & 286.5 & - & - & - & - & - \\
\hline TOTAL & $2,120.3$ & - & - & - & - & - \\
\hline
\end{tabular}

Elaboración: Propia 


\section{Cuadro $N^{0}$ 8. 6: Inversión tangible del proyecto}

\begin{tabular}{|c|c|c|c|c|c|c|c|c|}
\hline \multicolumn{9}{|c|}{ INVERSION TANGIBLE } \\
\hline CONCEPTO & UNIDADES & PRECIO UNIT. & 2015 (Año 0) & 2016 & 2017 & 2018 & 2019 & 2020 \\
\hline Computadora & 2 & 372.5 & 745.0 & - & - & - & - & - \\
\hline Laptop & 1 & 401.1 & 401.1 & - & - & - & - & - \\
\hline Impresora & 1 & 86.0 & 86.0 & - & - & - & - & - \\
\hline Fax & 1 & 100.3 & 100.3 & - & - & - & - & - \\
\hline Celulares & 2 & 114.6 & 229.2 & - & - & - & - & - \\
\hline Teléfono & 1 & 57.3 & 57.3 & - & - & - & - & - \\
\hline Escritorio & 3 & 257.9 & 773.6 & - & - & - & - & - \\
\hline Silla & 3 & 14.3 & 43.0 & - & - & - & - & - \\
\hline Útiles de oficina & 1 & 143.3 & 143.3 & - & - & - & - & - \\
\hline Tarjeta de presentación & 1 & 57.3 & 57.3 & - & - & - & - & - \\
\hline Extintor & 1 & 43.0 & 43.0 & - & - & - & - & - \\
\hline Botiquín & 1 & 14.3 & 14.3 & - & - & - & - & - \\
\hline Remodelación de oficina & 1 & $2,292.3$ & $2,292.3$ & - & - & - & - & - \\
\hline Mostrador & 2 & 573.1 & $1,146.1$ & - & - & - & - & - \\
\hline Archivador & 1 & 57.3 & 57.3 & - & - & - & - & - \\
\hline $\begin{array}{l}\text { Material para limpieza de } \\
\text { joya }\end{array}$ & 1 & 143.3 & 143.3 & - & - & - & - & - \\
\hline Lupa pequeña & 2 & 8.6 & 17.2 & - & - & - & - & - \\
\hline Pañuelos Pulidores & 50 & 0.6 & 28.7 & - & - & - & - & - \\
\hline Balanza & 1 & 257.9 & 257.9 & - & - & - & - & - \\
\hline Horno de Fundición & 1 & 830.9 & - & - & - & 830.9 & - & - \\
\hline Alicate para Crisol o Grafito & 1 & 22.9 & - & - & - & 22.9 & - & - \\
\hline Laminador Eléctrico & 1 & $2,292.3$ & - & - & - & $2,292.3$ & - & - \\
\hline & & TOTAL & $6,636.1$ & - & - & $3,146.1$ & - & - \\
\hline
\end{tabular}

Elaboración: Propia

\subsection{Gastos Fijos}

\section{Cuadro No 8. 7: Gastos Fijos del proyecto}

\begin{tabular}{|c|c|c|c|c|c|c|c|}
\hline \multicolumn{7}{|c|}{ GASTOS FIJOS } \\
\hline CONCEPTO & CANTIDAD & PRECIO UNIT. & $\mathbf{2 0 1 6}$ & $\mathbf{2 0 1 7}$ & $\mathbf{2 0 1 8}$ & $\mathbf{2 0 1 9}$ & $\mathbf{2 0 2 0}$ \\
\hline Mantenimiento de Sistema & 1 & 57 & 57 & 57 & 57 & 57 & 57 \\
\hline Cuota Interés & 12 & 663 & 7,954 & 7,954 & - & - & - \\
\hline Pago Anual de Página Web & 1 & 14 & 14 & 14 & 14 & 14 & 14 \\
\hline Depreciación & - & - & 1,327 & 1,327 & 1,642 & 1,642 & 1,642 \\
\hline Amortización & - & - & 212 & 212 & 212 & 212 & 212 \\
\hline Folletos y Revistas & 2 & 287 & 573 & 573 & 573 & 573 & 573 \\
\hline Pasajes a Chile (Ida y Vuelta) & 1 & 259 & 259 & 259 & 259 & 259 & 259 \\
\hline Alojamiento en Hotel & 1 & 219 & 219 & 219 & 219 & 219 & 219 \\
\hline Ferias Comerciales & 1 & 573 & 573 & 573 & 573 & 573 & 573 \\
\hline Panel Publicitario & 12 & 2,000 & - & - & - & - & 24,000 \\
\hline Misión Comercial & 1 & 143 & 143 & 143 & 143 & 143 & 143 \\
\hline Correos Masivos & 2 & 52 & - & - & 104 & 104 & 104 \\
\hline Alquiler Hotel para reunión & 1 & 4,000 & - & - & - & 4,000 & 4,000 \\
\hline Fotografía & 2 & 43 & 86 & 86 & 86 & 86 & 86 \\
\hline Certificado de Origen & 2 & 29 & 57 & 57 & 57 & 57 & 57 \\
\hline Imprevistos (Otros) & 1 & 287 & 287 & 287 & 287 & 287 & 287 \\
\hline & & TOTAL & $\mathbf{1 1 , 7 6 2}$ & $\mathbf{1 1 , 7 6 2}$ & $\mathbf{4 , 2 2 7}$ & $\mathbf{8 , 2 2 7}$ & $\mathbf{3 2 , 2 2 7}$ \\
\hline & & & & & \\
\hline & & & & & & & \\
\hline
\end{tabular}

Elaboración: Propia 


\subsection{Capital de Trabajo}

Para el capital de trabajo se toma en cuenta los tres primeros meses del proyecto. La producción en los tres meses iniciales será de $36.7 \mathrm{Kg}$ de joyas y para poder alcanzar esta producción de joyas en ese lapso de tiempo se necesitará de $\$ 20^{\prime} 126.33$ (dólares) la cual se explica en el Cuadro $\mathrm{N}^{\circ}$ 8.8.

\section{Cuadro $N^{\circ}$ 8. 8: Capital de trabajo para los primeros tres meses}

\begin{tabular}{|c|c|}
\hline Año 2016 & Producción Kg \\
\hline Enero & 15 \\
\hline Febrero & 11 \\
\hline Marzo & 10 \\
\hline Total & 37 \\
\hline
\end{tabular}

\begin{tabular}{|c|c|c|c|}
\hline Materia Prima & (\$) Mano de obra x Gr. & Materia Prima & (\$) Gramo \\
\hline PLATA & 0.57 & Plata 950 & 0.53 \\
\hline PIEDRA NATURAL & 0.57 & Plata 925 & 0.52 \\
\hline \multicolumn{2}{|r|}{} & Piedra Natural & 0.05 \\
\cline { 2 - 4 }
\end{tabular}

\begin{tabular}{|c|c|c|c|}
\hline Materia Prima & $\begin{array}{c}\text { Cantidad (Gr) - } \\
\text { Colección Mystic }\end{array}$ & $\begin{array}{c}\text { Cantidad (Gr) - } \\
\text { Colección Ultra }\end{array}$ & Cantidad total (Gr.) \\
\hline PLATA & $11,315.53$ & 11,316 & $22,631.07$ \\
\hline PIEDRA NATURAL & 7,029 & 7,029 & 14,059 \\
\hline TOTAL & 18,345 & 18,345 & 36,690 \\
\hline
\end{tabular}

\begin{tabular}{|c|c|c|c|}
\hline Materia Prima & $\begin{array}{c}\text { \$ Materia Prima - } \\
\text { Colección Mystic }\end{array}$ & $\begin{array}{c}\text { \$ Materia Prima - } \\
\text { Colección Ultra }\end{array}$ & \$ Mano de Obra total \\
\hline PLATA & 6,016 & $5,860.52$ & 12,969 \\
\hline PIEDRA NATURAL & 351 & 351 & 8,057 \\
\hline TOTAL & 6,368 & 6,212 & 21,026 \\
\hline \multicolumn{2}{|r}{} & TOTAL & $\mathbf{3 3 , 6 0 5 . 3 5}$ \\
\cline { 2 - 4 }
\end{tabular}

Elaboración: Propia

\subsection{Margen de venta:}

Se muestra en el Cuadro $\mathrm{N}^{\circ} 8.9$ la utilidad y el margen de venta de cada artículo de joya de cada colección.

Todos los artículos presentan diferente tipo de margen ya que es conveniente tener un extra por si algún cliente desea algún tipo de 
descuento. Los productos como la pulsera y los aretes son los que más margen presenta ya que son los más demandados; por otro lado, el set de joyas son los más bajos porque en este tipo de productos no habrá descuentos. Los costos unitarios de cada artículo de joya se muestran detalladamente en el Anexo 47 y esta información lo puede complementar con las ventas para hallar el margen de utilidad por artículo.

\section{Cuadro No 8. 9: Margen de venta}

\begin{tabular}{|c|c|c|c|}
\hline Colección & Artículo & Utilidad & Margen \\
\hline \multirow{4}{*}{ MYSTIC } & Arete - Colgante & 3.5 & $35 \%$ \\
\cline { 2 - 4 } & Anillo - Sortija & 3.2 & $22 \%$ \\
\cline { 2 - 4 } & Collares & 5.5 & $19 \%$ \\
\cline { 2 - 4 } & Pulseras & 9.4 & $44 \%$ \\
\cline { 2 - 4 } & Set de joyas (Collar+Arete+Pulsera) & 10.9 & $19 \%$ \\
\cline { 2 - 4 } & Arete - Colgante & 3.6 & $36 \%$ \\
\cline { 2 - 4 } & Anillo - Sortija & 3.3 & $23 \%$ \\
\cline { 2 - 4 } & Collares & 5.7 & $20 \%$ \\
\cline { 2 - 4 } & Pulseras & 9.5 & $24 \%$ \\
\hline
\end{tabular}

Elaboración: Propia

\subsection{Proyección de ventas}

\section{Cuadro Nº 8. 10: Proyección de Ventas de la colección MYSTIC}

\begin{tabular}{|c|c|c|c|c|c|c|}
\hline \multicolumn{7}{|c|}{ MYSTIC } \\
\hline \multirow{7}{*}{ PRECIO } & Pieza de Joya & 2016 & 2017 & 2018 & 2019 & 2020 \\
\hline & Arete - Colgante & 10 & 10 & 10 & 10 & 10 \\
\hline & Anillo - Sortija & 14 & 14 & 14 & 14 & 14 \\
\hline & Collares & 29 & 29 & 29 & 29 & 29 \\
\hline & $\begin{array}{l}\text { Pulseras } \\
\end{array}$ & 21 & 21 & 21 & 21 & 21 \\
\hline & Set de joyas (Collar+Arete+Pulsera) & 57 & 57 & 57 & 57 & 57 \\
\hline & PRECIO TOTAL DE JOYA & 132 & 132 & 132 & 132 & 132 \\
\hline \multirow{6}{*}{ CANTIDAD } & Arete - Colgante & 692 & 885 & 1,176 & 1,386 & 1,889 \\
\hline & Anillo - Sortija & 692 & 885 & 1,176 & 1,386 & 1,889 \\
\hline & Collares & 692 & 885 & 1,176 & 1,386 & 1,889 \\
\hline & Pulseras & 692 & 885 & 1,176 & 1,386 & 1,889 \\
\hline & Set de joyas (Collar+Arete+Pulsera) & 692 & 885 & 1,176 & 1,386 & 1,889 \\
\hline & $\mathbf{N}^{\circ}$ TOTAL DE JOYAS & 3,460 & 4,425 & 5,880 & 6,930 & 9,445 \\
\hline \multirow{6}{*}{$\begin{array}{c}\text { PRECIO } \\
\text { TOTAL }\end{array}$} & Arete - Colgante & 6,940 & 8,875 & 11,794 & 13,900 & 18,944 \\
\hline & Anillo - Sortija & 9,914 & 12,679 & 16,848 & 19,857 & 27,063 \\
\hline & Collares & 19,828 & 25,358 & 33,696 & 39,713 & 54,126 \\
\hline & Pulseras & 14,871 & 19,019 & 25,272 & 29,785 & 40,595 \\
\hline & Set de joyas (Collar+Arete+Pulsera) & 39,656 & 50,716 & 67,393 & 79,427 & 108,252 \\
\hline & PRECIO TOTAL & 91,209 & 116,648 & 155,003 & 182,682 & 248,980 \\
\hline
\end{tabular}

Elaboración: Propia 
Cuadro $N^{\circ}$ 8. 11: Proyección de ventas de la colección ULTRA

\begin{tabular}{|c|c|c|c|c|c|c|}
\hline & \multicolumn{6}{|c|}{ ULTRA } \\
\hline \multirow{7}{*}{ PRECIO } & Pieza de Joya & 2016 & 2017 & 2018 & 2019 & 2020 \\
\hline & Arete - Colgante & 10 & 10 & 10 & 10 & 10 \\
\hline & Anillo - Sortija & 14 & 14 & 14 & 14 & 14 \\
\hline & Collares & 29 & 29 & 29 & 29 & 29 \\
\hline & Pulseras & 21 & 21 & 21 & 21 & 21 \\
\hline & Set de joyas (Collar+Arete+Pulsera) & 57 & 57 & 57 & 57 & 57 \\
\hline & PRECIO TOTAL DE JOYA & 132 & 132 & 132 & 132 & 132 \\
\hline \multirow{6}{*}{ CANTIDAD } & Arete - Colgante & 692 & 885 & 1,176 & 1,386 & 1,889 \\
\hline & Anillo - Sortija & 692 & 885 & 1,176 & 1,386 & 1,889 \\
\hline & Collares & 692 & 885 & 1,176 & 1,386 & 1,889 \\
\hline & Pulseras & 692 & 885 & 1,176 & 1,386 & 1,889 \\
\hline & Set de joyas (Collar+Arete+Pulsera) & 692 & 885 & 1,176 & 1,386 & 1,889 \\
\hline & $\mathbf{N}^{0}$ TOTAL DE JOYAS & 3,460 & 4,425 & 5,880 & 6,930 & 9,445 \\
\hline \multirow{6}{*}{$\begin{array}{c}\text { PRECIO } \\
\text { TOTAL }\end{array}$} & Arete - Colgante & 6,940 & 8,875 & 11,794 & 13,900 & 18,944 \\
\hline & Anillo - Sortija & 9,914 & 12,679 & 16,848 & 19,857 & 27,063 \\
\hline & Collares & 19,828 & 25,358 & 33,696 & 39,713 & 54,126 \\
\hline & Pulseras & 14,871 & 19,019 & 25,272 & 29,785 & 40,595 \\
\hline & Set de joyas (Collar+Arete+Pulsera) & 39,656 & 50,716 & 67,393 & 79,427 & 108,252 \\
\hline & PRECIO TOTAL & 91,209 & 116,648 & 155,003 & 182,682 & 248,980 \\
\hline
\end{tabular}

Elaboración: Propia

\subsection{Punto de Equilibrio}

Debido a que el costo fijo es compartido por ambas colecciones de joyas el costo fijo se dividirá en dos (Para cada colección). El costo fijo total es de US\$ 22'975 y dividiéndolo entre dos se obtiene US\$ 11'487.5 el cual será la base para hallar el punto de equilibrio.

\section{Cuadro No 8. 12 Punto de Equilibrio MYSTIC}

\begin{tabular}{|c|c|c|c|c|c|}
\hline COLECCIÓN & \multicolumn{5}{|c|}{ MYSTIC } \\
\hline Ã̃NO & $\mathbf{2 0 1 6}$ & $\mathbf{2 0 1 7}$ & $\mathbf{2 0 1 8}$ & $\mathbf{2 0 1 9}$ & $\mathbf{2 0 2 0}$ \\
\hline Costo Fijo & 14,631 & 14,631 & 14,631 & 14,631 & 14,631 \\
\hline Precio Unitario & 132 & 132 & 132 & 132 & 132 \\
\hline Costo Variable Unitario & 99 & 99 & 99 & 99 & 99 \\
\hline PE (*) & 452 & 452 & 452 & 452 & 452 \\
\hline $\mathrm{N}^{\mathbf{o}}$ UNIDADES DE VENTA & 692 & 885 & 1,176 & 1,386 & 1,889 \\
\hline
\end{tabular}

Elaboración: Propia 
Gráfico No 8. 1: Punto de equilibrio de la colección "MYSTIC"

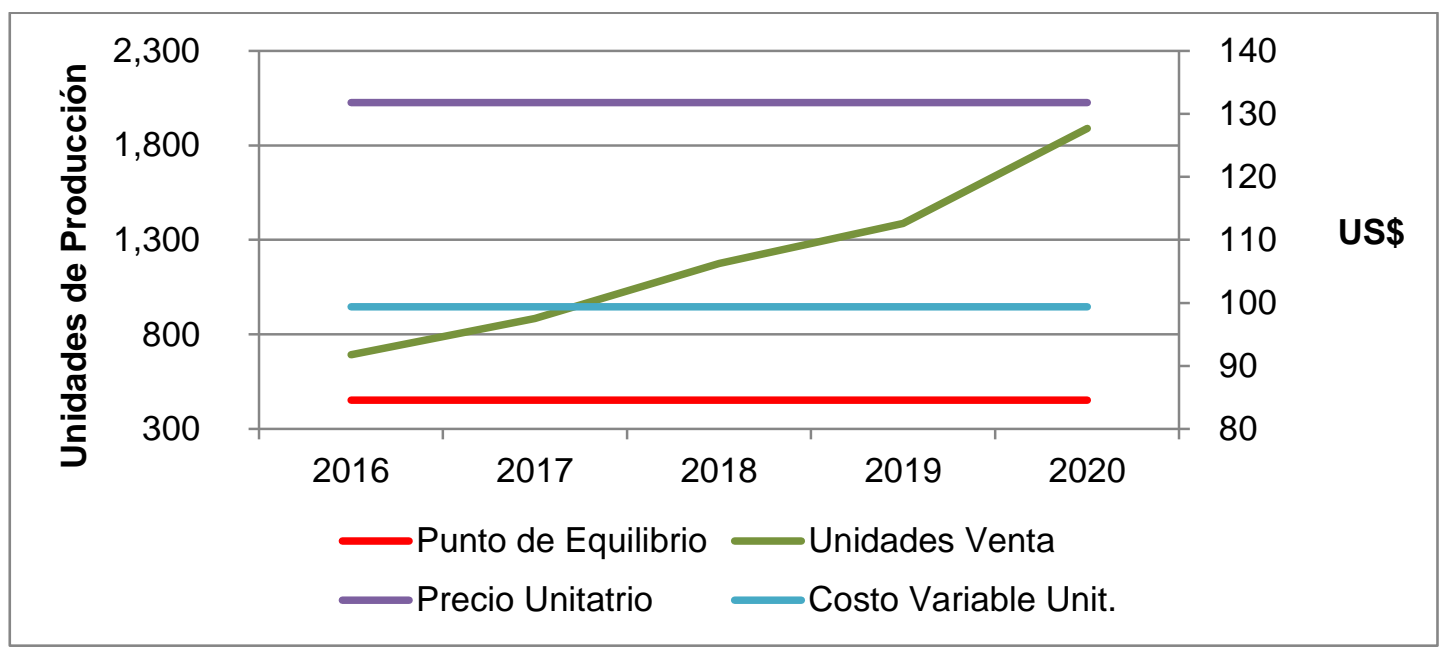

Elaboración: Propia

Cuadro $N^{\circ}$ 8. 13: Punto de equilibrio ULTRA

\begin{tabular}{|c|c|c|c|c|c|}
\hline COLECCIÓN & \multicolumn{5}{|c|}{ ULTRA } \\
\hline AÑNO & $\mathbf{2 0 1 6}$ & $\mathbf{2 0 1 7}$ & $\mathbf{2 0 1 8}$ & $\mathbf{2 0 1 9}$ & $\mathbf{2 0 2 0}$ \\
\hline Costo Fijo & 14,631 & 14,631 & 14,631 & 14,631 & 14,631 \\
\hline Precio Unitario & 132 & 132 & 132 & 132 & 132 \\
\hline Costo Variable Unitario & 98 & 98 & 98 & 98 & 98 \\
\hline PE (*) & 439 & 439 & 439 & 439 & 439 \\
\hline $\mathrm{N}^{\mathbf{o}}$ UNIDADES DE VENTA & 692 & 885 & 1,176 & 1,386 & 1,889 \\
\hline
\end{tabular}

Elaboración: Propia

\section{Gráfico $N^{\circ}$ 8. 2: Punto de equilibrio de la colección "ULTRA"}

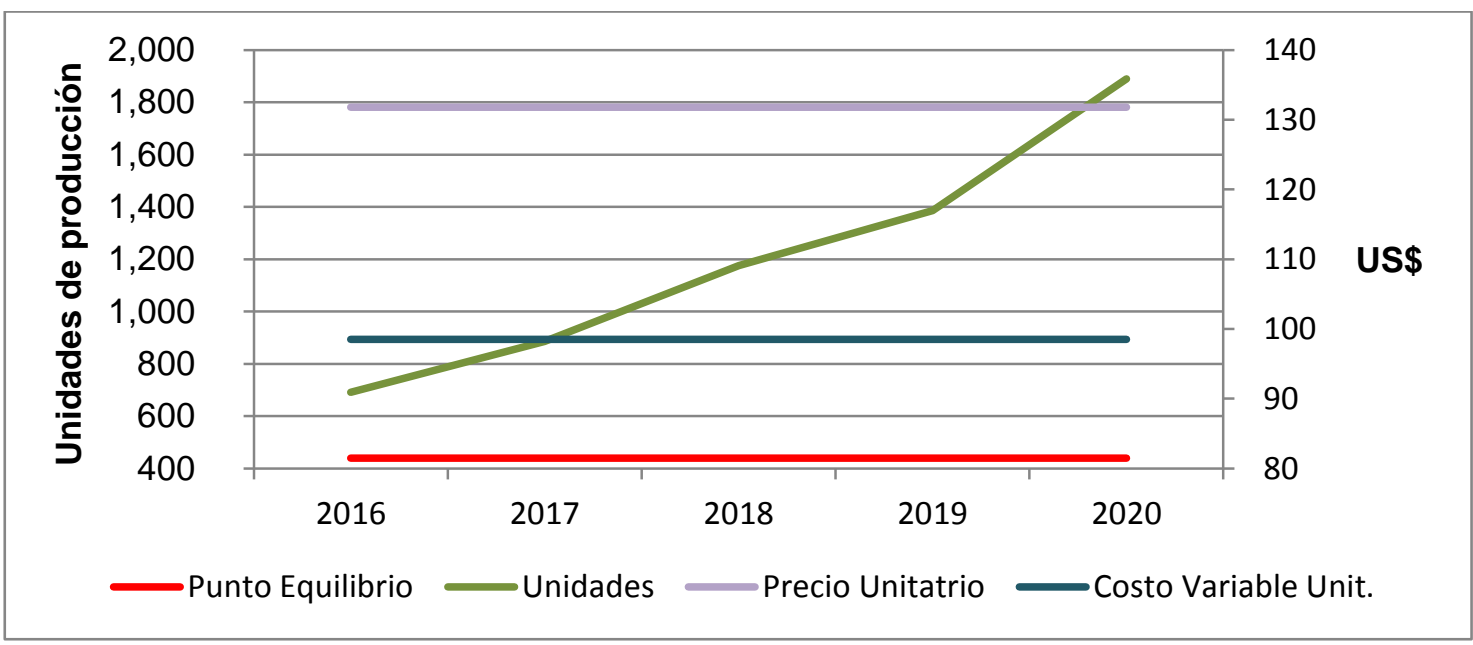

Elaboración: Propia 
8.5. Financiamiento de la inversión:

Cuadro $N^{\circ}$ 8. 14: Financiamiento de la inversión (En US\$)

\begin{tabular}{|c|c|c|c|c|c|c|c|}
\hline \multicolumn{8}{|c|}{ INTERES } \\
\hline MES & SALDO INICIAL & INTERES & $\mathbf{A M}$ & CION & & & SALDO FINAL \\
\hline 0 & & & & & & & 12,709 \\
\hline 1 & 12,709 & 239 & - & 424 & - & 663 & 12,284 \\
\hline 2 & 12,284 & 231 & - & 432 & - & 663 & 11,852 \\
\hline 3 & 11,852 & 222 & - & 440 & - & 663 & 11,412 \\
\hline 4 & 11,412 & 214 & - & 448 & - & 663 & 10,964 \\
\hline 5 & 10,964 & 206 & - & 457 & - & 663 & 10,507 \\
\hline 6 & 10,507 & 197 & - & 465 & - & 663 & 10,042 \\
\hline 7 & 10,042 & 188 & - & 474 & - & 663 & 9,568 \\
\hline 8 & 9,568 & 180 & - & 483 & - & 663 & 9,085 \\
\hline 9 & 9,085 & 171 & - & 492 & - & 663 & 8,593 \\
\hline 10 & 8,593 & 161 & - & 501 & - & 663 & 8,091 \\
\hline 11 & 8,091 & 152 & - & 511 & - & 663 & 7,581 \\
\hline 12 & 7,581 & 142 & - & 520 & - & 663 & 7,060 \\
\hline 13 & 7,060 & 133 & - & 530 & - & 663 & 6,530 \\
\hline 14 & 6,530 & 123 & - & 540 & - & 663 & 5,990 \\
\hline 15 & 5,990 & 112 & - & 550 & - & 663 & 5,440 \\
\hline 16 & 5,440 & 102 & - & 560 & - & 663 & 4,880 \\
\hline 17 & 4,880 & 92 & - & 571 & - & 663 & 4,309 \\
\hline 18 & 4,309 & 81 & - & 582 & - & 663 & 3,727 \\
\hline 19 & 3,727 & 70 & - & 593 & - & 663 & 3,134 \\
\hline 20 & 3,134 & 59 & - & 604 & - & 663 & 2,530 \\
\hline 21 & 2,530 & 47 & - & 615 & - & 663 & 1,915 \\
\hline 22 & 1,915 & 36 & - & 627 & - & 663 & 1,289 \\
\hline 23 & 1,289 & 24 & - & 638 & - & 663 & 650 \\
\hline 24 & 650 & 12 & - & 650 & - & 663 & 0 \\
\hline
\end{tabular}

\begin{tabular}{|c|c|}
\hline MONTO (US\$) & 12,709 \\
\hline MONTO (S/.) & 44,353 \\
\hline MESES & 24 \\
\hline TEA & $25 \%$ \\
\hline TEM & $2 \%$ \\
\hline
\end{tabular}

Elaboración: Propia 
8.6. Flujo de caja económico (TIR y VAN)

\section{Cuadro No 8. 15: Flujo de Caja}

\begin{tabular}{|c|c|c|c|c|c|c|}
\hline \multicolumn{7}{|c|}{ FLUJO DE CAJA } \\
\hline CONCEPTO & 2015 & 2016 & 2017 & 2018 & 2019 & 2020 \\
\hline INGRESOS & & 182,418 & 233,295 & 310,006 & 365,364 & 497,960 \\
\hline COSTOS & & 166,487 & 204,759 & 261,330 & 302,735 & 401,911 \\
\hline U BRUTA & & 15,932 & 28,536 & 48,675 & 62,628 & 96,049 \\
\hline GASTOS & & 11,759 & 11,759 & 4,227 & 8,227 & 32,227 \\
\hline DEPRECIACION - AMORTIZACION & & 1,539 & 1,539 & 1,854 & 1,854 & 1,854 \\
\hline UAII & & 2,633 & 15,238 & 42,595 & 52,548 & 61,969 \\
\hline IMPUESTOS (27\%) & & 711 & 4,114 & 11,501 & 14,188 & 16,732 \\
\hline UT NETA & & 1,922 & 11,124 & 31,094 & 38,360 & 45,237 \\
\hline DEPRECIACION & & 1,327 & 1,327 & 1,642 & 1,642 & 1,642 \\
\hline INVERSION & 8,756 & & & & & \\
\hline CAPITAL DE TRABAJO & 33,605 & & & & & \\
\hline FC ECONOMICO & $-42,362$ & 3,250 & 12,451 & 32,736 & 40,002 & 46,879 \\
\hline INTERESES & & 1,612 & 623 & - & - & - \\
\hline AMORTIZACION DE DEUDA & & $-\quad 5,648$ & $-7,060$ & & & \\
\hline PRESTAMO & 12,709 & & & & & \\
\hline FC FINANCIERO & - 29,653 & 787 & 6,014 & 32,736 & 40,002 & 46,879 \\
\hline
\end{tabular}

\begin{tabular}{|c|c|c|c|c|c|}
\hline Ke & Cok & VAN E & VAN F & TIR E & TIR F \\
\hline $25 \%$ & $25 \%$ & 17,167 & 22,502 & $37 \%$ & $45 \%$ \\
\hline
\end{tabular}

Con el modelo de Valoración de Activos Financieros se determinó el costo de oportunidad de capital.

\begin{tabular}{|c|c|}
\hline CAPM & $24.7 \%$ \\
\hline $\mathrm{Rf}$ & $45 \%$ \\
\hline $\mathrm{B}$ & $85.0 \%$ \\
\hline $\mathrm{Rm}$ & $24.8 \%$ \\
\hline $\mathrm{Rp}$ & $3.0 \%$ \\
\hline
\end{tabular}

Elaboración: Propia

\begin{tabular}{|c|c|c|}
\hline Damodaran & Beta & $85.0 \%$ \\
\hline BCR & Riesgo país & $3.0 \%$ \\
\hline Bloomberg & RF & $4.5 \%$ \\
\hline Bloomberg & RM & $24.8 \%$ \\
\hline
\end{tabular}




\subsection{Balance General}

\section{Cuadro No 8. 16: Balance General}

\begin{tabular}{|c|c|c|c|c|c|c|c|}
\hline & \multicolumn{7}{|c|}{ BALANCE GENERAL } \\
\hline & CONCEPTO & Pre-proyecto & 2016 & 2017 & 2018 & 2019 & 2020 \\
\hline \multirow{5}{*}{ ACTIVO } & Caja y Bancos & 42,362 & 5,146 & 23,422 & 63,404 & 77,836 & 91,496 \\
\hline & Activo fijo & & 6,636 & 6,636 & 9,782 & 9,782 & 9,782 \\
\hline & Depreciación Acumulada & & 1,539 & 1,539 & 1,854 & 1,854 & 1,854 \\
\hline & Inversión Fija Intangible & & 2,120 & 2,120 & 2,120 & 2,120 & 2,120 \\
\hline & Total Activo & 42,362 & 12,363 & 30,639 & 73,453 & 87,885 & 101,545 \\
\hline \multirow{2}{*}{ PASIVO } & Pasivo No Corriente (Préstamo bancario) & 44,353 & 7,951 & 7,951 & - & - & - \\
\hline & Total Pasivo & 44,353 & 7,951 & 7,951 & - & - & - \\
\hline \multirow{3}{*}{ PATRIMONIO } & Capital Social & $-\quad 1,991$ & 2,489 & 11,565 & 42,359 & 49,525 & 56,308 \\
\hline & Utilidades & & 1,922 & 11,124 & 31,094 & 38,360 & 45,237 \\
\hline & Total Patrimonio & - $\quad 1,991$ & 4,412 & 22,688 & 73,453 & 87,885 & 101,545 \\
\hline
\end{tabular}

Elaboración: Propia

\subsection{Estado de ganancias y pérdidas}

\section{Cuadro No 8. 17: Estado de Ganancias y Pérdidas}

\begin{tabular}{|c|c|c|c|c|c|}
\hline \multicolumn{7}{|c|}{ ESTADO DE GANANCIAS Y PERDIDAS } \\
\hline CONCEPTO & $\mathbf{2 0 1 6}$ & $\mathbf{2 0 1 7}$ & $\mathbf{2 0 1 8}$ & $\mathbf{2 0 1 9}$ & $\mathbf{2 0 2 0}$ \\
\hline Ventas & 182,418 & 233,295 & 310,006 & 365,364 & 497,960 \\
\hline (-) Costo de Producción & 166,487 & 204,759 & 261,330 & 302,735 & 401,911 \\
\hline Utilidad Bruta & $\mathbf{1 5 , 9 3 2}$ & $\mathbf{2 8 , 5 3 6}$ & $\mathbf{4 8 , 6 7 5}$ & $\mathbf{6 2 , 6 2 8}$ & $\mathbf{9 6 , 0 4 9}$ \\
\hline (-) Gastos Administrativos y Ventas & 11,759 & 11,759 & 4,227 & 8,227 & 32,227 \\
\hline EBIDTA & $\mathbf{4 , 1 7 3}$ & $\mathbf{1 6 , 7 7 7}$ & $\mathbf{4 4 , 4 4 9}$ & $\mathbf{5 4 , 4 0 2}$ & $\mathbf{6 3 , 8 2 3}$ \\
\hline (-) Depreciación / Amortización & 1,539 & 1,539 & 1,854 & 1,854 & 1,854 \\
\hline EBIT & $\mathbf{2 , 6 3 3}$ & $\mathbf{1 5 , 2 3 8}$ & $\mathbf{4 2 , 5 9 5}$ & $\mathbf{5 2 , 5 4 8}$ & $\mathbf{6 1 , 9 6 9}$ \\
\hline (-) Impuesto a la Renta (28\%) & 737 & 4,267 & 11,927 & 14,713 & 17,351 \\
\hline Resultado del Ejercicio & $\mathbf{1 , 8 9 6}$ & $\mathbf{1 0 , 9 7 1}$ & $\mathbf{3 0 , 6 6 8}$ & $\mathbf{3 7 , 8 3 4}$ & $\mathbf{4 4 , 6 1 7}$ \\
\hline Resultado Acumulado & $\mathbf{1 , 8 9 6}$ & $\mathbf{1 2 , 8 6 7}$ & $\mathbf{4 3 , 5 3 5}$ & $\mathbf{8 1 , 3 7 0}$ & $\mathbf{1 2 5 , 9 8 7}$ \\
\hline
\end{tabular}

Elaboración: Propia

\subsection{Análisis de sensibilidad:}

En este última parte del análisis financiero, se presenta el análisis de sensibilidad el cual demuestra que tan sensible son los resultados del VAN y la TIR si se presentan variaciones en algunas variables. En el Cuadro N ${ }^{\circ}$ 8.18 se presentan los datos de sensibilidad y las variables a tomar son: 
a)El costo de la plata ya que es la principal materia prima

b)El precio final de la joya

c)La cantidad exportada. Para esta variable se ha tomado solo el primer año.

\section{Cuadro Nº 8. 18: Cuadros de Análisis de sensibilidad}

\begin{tabular}{|c|c|c|c|c|c|}
\hline Variación & Costo de la Plata & VAN E & VAN F & TIR E & TIR F \\
\hline$-30 \%$ & 0,33 & $69,185.14$ & $73,879.06$ & $77 \%$ & $93 \%$ \\
\hline$-20 \%$ & 0,38 & $52,973.40$ & $57,816.75$ & $64 \%$ & $78 \%$ \\
\hline$-15 \%$ & 0,40 & $44,867.53$ & $49,785.59$ & $58 \%$ & $70 \%$ \\
\hline$-10 \%$ & 0,43 & $36,761.66$ & $41,754.44$ & $52 \%$ & $63 \%$ \\
\hline$-5 \%$ & 0,45 & $28,655.79$ & $33,723.28$ & $46 \%$ & $55 \%$ \\
\hline $0 \%$ & 0,47 & $20,549.36$ & $25,691.57$ & $40 \%$ & $48 \%$ \\
\hline$+5 \%$ & 0,50 & $12,444.05$ & $17,660.97$ & $34 \%$ & $41 \%$ \\
\hline$+10 \%$ & 0,52 & $4,338.18$ & $9,629.82$ & $28 \%$ & $34 \%$ \\
\hline$+15 \%$ & 0,54 & $3,767.69$ & $1,598.66$ & $22 \%$ & $26 \%$ \\
\hline$+20 \%$ & 0,57 & $11,873.56$ & $6,432.49$ & $15 \%$ & $19 \%$ \\
\hline$+30 \%$ & 0,62 & $28,085.30$ & $22,494.80$ & $1 \%$ & $2 \%$ \\
\hline
\end{tabular}

\begin{tabular}{|c|c|c|c|c|c|}
\hline Variación & $\mathbf{N}^{0} \mathbf{K g}$ & VAN E & VAN F & TIR E & TIR F \\
\hline$-30 \%$ & 904 & 147,925 & 142,783 & $-45 \%$ & $-55 \%$ \\
\hline$-20 \%$ & 1033 & 91,627 & 86,485 & $-28 \%$ & $-34 \%$ \\
\hline$-15 \%$ & 1097 & 63,478 & 58,335 & $-16 \%$ & $-18 \%$ \\
\hline$-10 \%$ & 1162 & 35,329 & 30,186 & $-10 \%$ & $-10 \%$ \\
\hline$-5 \%$ & 1226 & 7,180 & 2,037 & $19 \%$ & $23 \%$ \\
\hline $0 \%$ & 1291 & 20,549 & 25,692 & $40 \%$ & $48 \%$ \\
\hline$+5 \%$ & 1355 & 49,119 & 54,261 & $60 \%$ & $72 \%$ \\
\hline$+10 \%$ & 1420 & 77,268 & 82,410 & $78 \%$ & $95 \%$ \\
\hline$+15 \%$ & 1485 & 105,417 & 110,559 & $95 \%$ & $117 \%$ \\
\hline$+20 \%$ & 1549 & 133,566 & 138,708 & $112 \%$ & $139 \%$ \\
\hline$+30 \%$ & 1678 & 189,864 & 195,006 & $145 \%$ & $184 \%$ \\
\hline
\end{tabular}

\begin{tabular}{|c|c|c|c|c|c|}
\hline Variación & Precio & VAN E & VAN F & TIR E & TIR F \\
\hline$-30 \%$ & 92 & $-\quad 148,476$ & $-\quad 143,334$ & $-39 \%$ & $-45 \%$ \\
\hline$-20 \%$ & 105 & 92,134 & 86,992 & $-25 \%$ & $-30 \%$ \\
\hline$-15 \%$ & 112 & 63,963 & 58,821 & $-15 \%$ & $-19 \%$ \\
\hline$-10 \%$ & 119 & 35,792 & 30,650 & $-11 \%$ & $-10 \%$ \\
\hline$-5 \%$ & 125 & 7,621 & 2,479 & $18 \%$ & $22 \%$ \\
\hline $0 \%$ & 132 & 20,549 & 25,692 & $40 \%$ & $48 \%$ \\
\hline$+5 \%$ & 138 & 48,720 & 53,863 & $60 \%$ & $72 \%$ \\
\hline$+10 \%$ & 145 & 76,891 & 82,034 & $78 \%$ & $95 \%$ \\
\hline$+15 \%$ & 152 & 105,062 & 110,205 & $95 \%$ & $117 \%$ \\
\hline$+20 \%$ & 158 & 133,233 & 138,375 & $112 \%$ & $139 \%$ \\
\hline$+30 \%$ & 171 & 189,575 & 194,717 & $145 \%$ & $183 \%$ \\
\hline
\end{tabular}

Elaboración: Propia 
-Si el costo de la Plata aumenta un $20 \%$ como resultado sería un VAN financiero negativo (- US\$6,432) y un TIR negativo (-19\%). Si reduce un $20 \%$ el VAN aumenta hasta US $\$ 57,816$ y una TIR de $78 \%$.

-Si la cantidad de joyas vendidas se incrementa en un $30 \%$, el VAN aumenta a US\$195,006 y la TIR a $184 \%$. Si se reduce en un $30 \%$ de la cantidad exportada según lo proyectado, el VAN es negativo con US\$142,783 y una TIR negativa de 55\%.

-Si el precio de la joya aumenta un $20 \%$, se daría como resultado un VAN de US\$138,375 y una TIR $139 \%$. Si se reduce un $20 \%$ el precio, el VAN es negativo con US\$86,992 y una TIR negativa de $30 \%$

Asimismo se ha elaborado las tendencias de la información obtenida del análisis de sensibilidad. En el Gráfico $\mathrm{N}^{\circ} 8.3$ se muestra las tendencias del VAN financiero y TIR financiero según las variaciones del costo de la plata, cantidad exportada y del precio final del producto. Se concluye que el precio y la cantidad presentan una sensibilidad muy alta con respecto al costo de la plata ya que sus variaciones son bien pronunciadas en ambos extremos tal cual se muestra en el gráfico.

\section{Gráfico $\mathbf{N}^{\mathrm{o}}$ 8. 3: Tendencia de la sensibilidad del Van}

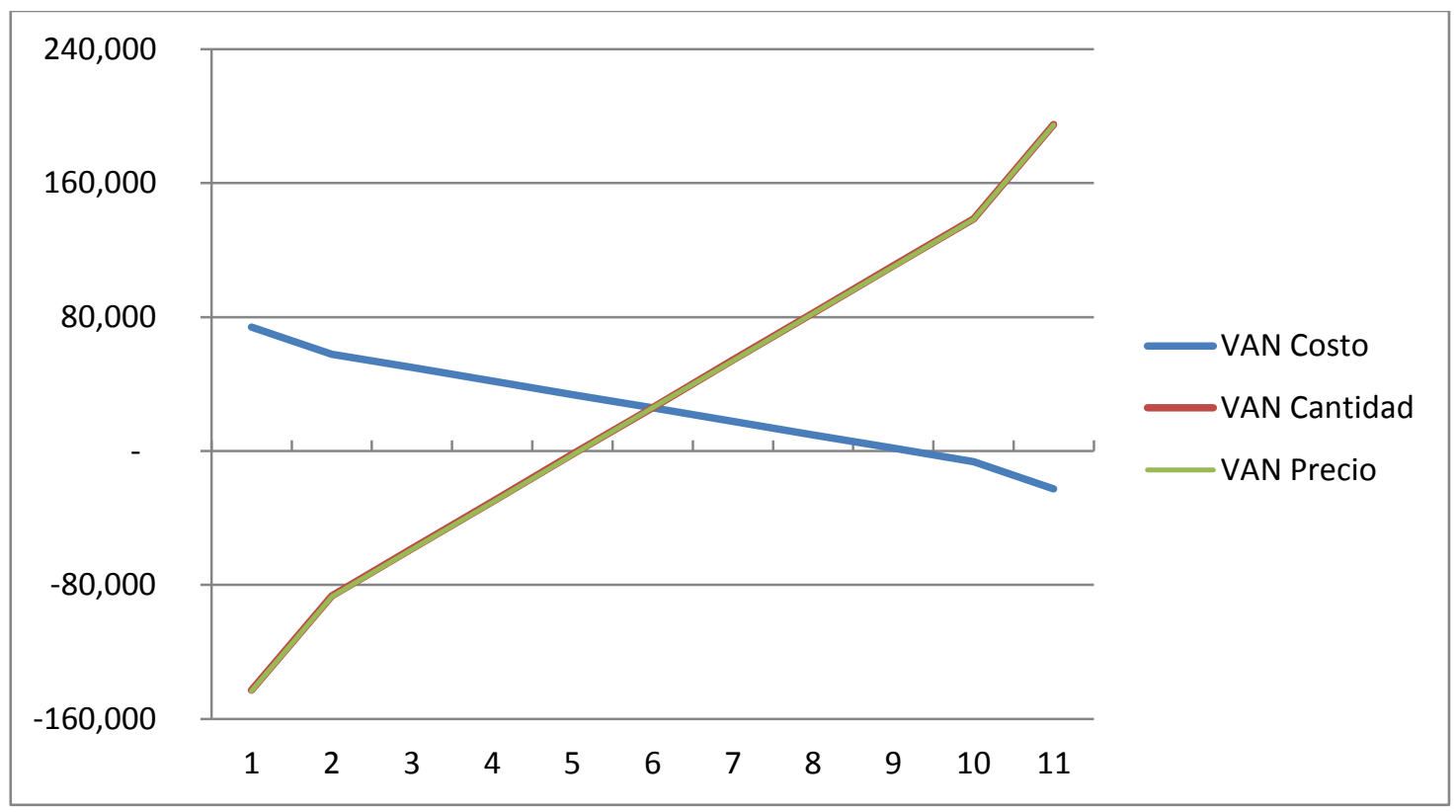

Elaboración: Propia 
Gráfico $N^{0}$ 8. 4: Tendencia de la sensibilidad de la TIR

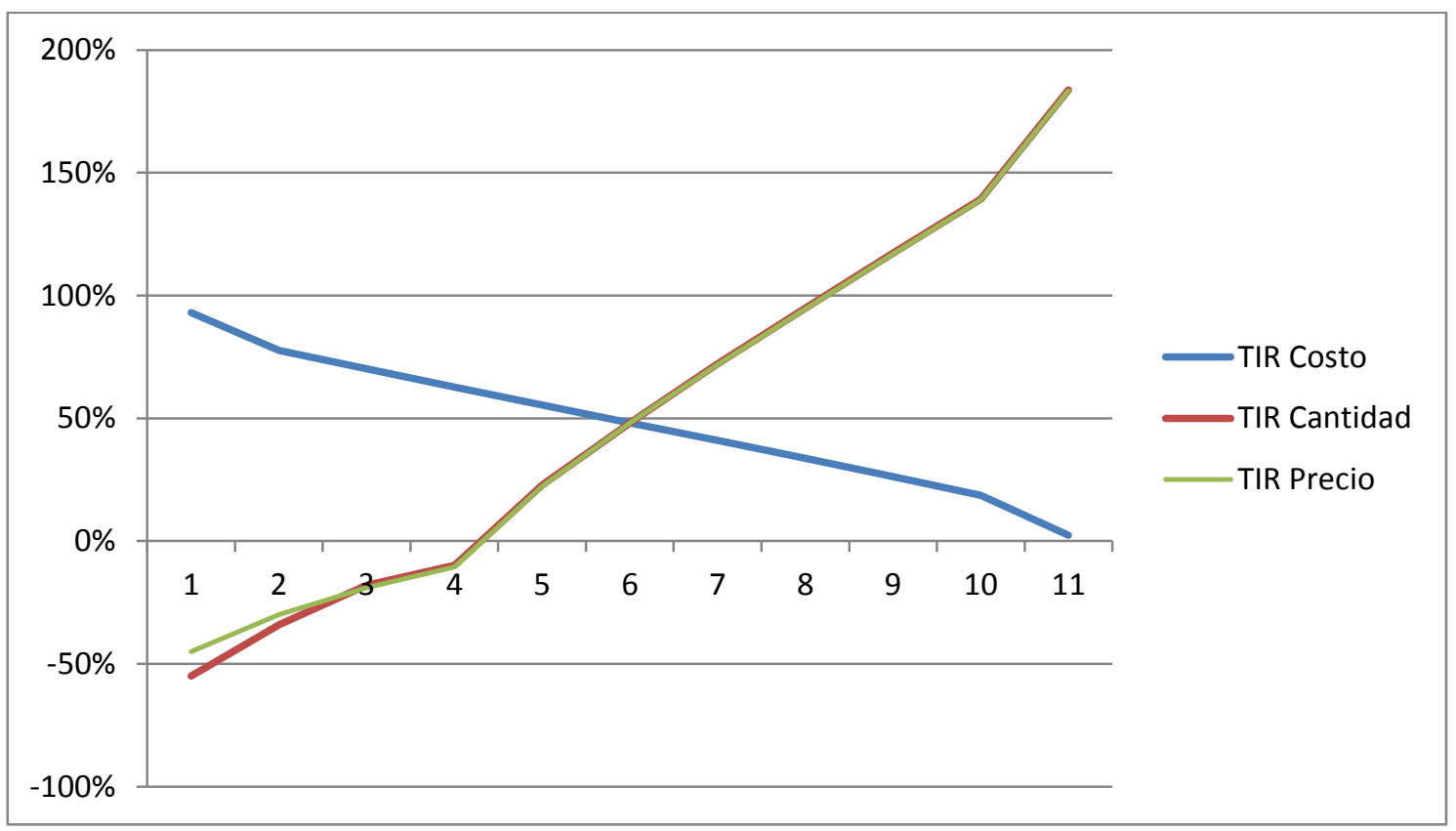

Elaboración: Propia 


\section{CONCLUSIONES}

-Para la implementación de una empresa de joyería de plata es muy importante tener como parte de la empresa a los artesanos pues son los que tienen la responsabilidad de la calidad del producto.

-Debe haber mucha comunicación y creatividad para desarrollar productos innovadores y a su vez la comunicación entre los artesanos con la empresa según las especificaciones del cliente porque son productos de alto valor.

-Hay una demanda creciente en el mercado chileno dado que cumplen con las características de poder adquisitivo y número de la demanda objetivo.

-Abarcar más regiones permitirá obtener mejores ingresos esperados a diferencia de estar en uno solo.

-Hacer inversiones en estrategias de comercialización, marketing y estudios de mercado para conocer los gustos en joyería de los clientes. 


\section{RECOMENDACIONES}

A continuación detallaremos las recomendaciones:

-Viajar a mercado de destino para averiguar sobre las tendencias de los diseños a través de ferias comerciales.

-Para tener mayor participación de mercado se debe requerir mayor inversión en el producto.

-Usar la tecnología para facilitar los procesos de operaciones de la empresa.

-Conocer los distintos tipos de piedras naturales que se producen en el Perú y conocer sus fortalezas y características para poder usarlo en las estrategias de ventas.

-La joyería es un negocio en el cual la primera impresión es importante; por lo tanto, se debe evitar vender productos que no estén trabajados al cien por ciento.

-Encontrar proveedores extranjeros de garantía para importar no solo piedras naturales sino piedras semipreciosas y cristales los cuales también se usan en la joyería y sería bueno para la estrategia de ventas porque diversificas tus productos y de costos por un menos precio. 


\section{REFERENCIAS}

24HorasChile. (25 de Junio de 2013). Recuperado el 2 de Diciembre de 2015, de http://www.24horas.cl/programas/lafabrica/los-chilenos-y-su-gusto-por-lasjoyas-de-lujo-713250

Acuerdos Comerciales. (2014). Acuerdos Comerciales. Recuperado el 2015, de http://www.acuerdoscomerciales.gob.pe/index.php?option=com_content\&view $=$ category $\&$ layout $=$ blog $\& \mathrm{id}=70 \&$ Itemid $=9$

ADEX. (3 de Junio de 2015). Perú21. Recuperado el 1 de Agosto de 2015, de http://peru21.pe/economia/adex-exportaciones-peruanas-registraron-caida-27abril-2220110

América Retail. (13 de Agosto de 2013). Recuperado el Setiembre de 2015, de http://www.america-retail.com/industria-y-mercado/brasil-y-china-los-paisescon-mas-potencial-en-e-commerce/

Arellano, R. (25 de Setiembre de 2014). Diario Gestión. Recuperado el 28 de Abril de 2015, de http://gestion.pe/economia/peru-pais-que-se-siente-clase-media-afirmarolando-arellano-2109567

ARINSA. (2013). Recuperado el 2015, de http://www.arinsa.com.pe/

Asociación de Exportadores. (23 de Octubre de 2014). Diario Gestión. Recuperado el 8 de Setiembre de 2015, de http://gestion.pe/mercados/menos-1-produccion-oroy-plata-peru-se-destina-joyeria-advierte-adex-2111923

ATKearney, The 2015 Global Retail E-Commerce Index. (2015). Recuperado el Enero de 2016, de https://www.atkearney.com/consumer-products-retail/e-commerceindex

Banco Cental de Chile. (5 de Febrero de 2016). Diario El Comercio. Recuperado el 10 de Febrero de 2016, de http://elcomercio.pe/economia/mundo/cuanto-crecioeconomia-chile-2015-noticia-1876572

Banco Central de Reserva del Perú. (Diciembre de 2011). Recuperado el Agosto de 2015, de http://www.bcrp.gob.pe/docs/Publicaciones/ReporteInflacion/2011/diciembre/Reporte-de-Inflacion-Diciembre-2011.pdf

Castilla, L. M. (13 de Junio de 2013). Youtube. Recuperado el 8 de Abril de 2015, de https://www.youtube.com/watch?v=GspEtZInoaU

ComexPerú. (17 de Mayo de 2015). Diario Gestión. Recuperado el 10 de Agosto de 2015, de http://gestion.pe/economia/tlc-peru-chile-seis-anos-exportacionesperuanas-crecen-111-2132040

Diario El Comercio. (20 de Marzo de 2015). Recuperado el 8 de Setiembre de 2015, de http://elcomercio.pe/economia/peru/pbi-asi-fue-su-crecimiento-mas-decadainteractivo-noticia-1798719 
El Mundo. (5 de Abril de 2013). Recuperado el 10 de Junio de 2015, de http://www.elmundo.es/elmundo/2013/04/06/espana/1365242520.html

Ferrero, A. (17 de Agosto de 2015). Recuperado el 20 de Octubre de 2015, de América Economía: http://www.americaeconomia.com/economiamercados/comercio/estabilidad-politica-y-economica-en-peru

INE Chile. (4 de Setiembre de 2014). Recuperado el 11 de Octubre de 2015, de http://www.ine.cl/canales/sala_prensa/noticias/noticia.php?opc=news\&id=615\& lang=esp

INEI. (2 de Enero de 2016). Perú21. Recuperado el 5 de Enero de 2016, de http://peru21.pe/economia/inei-inflacion-lima-fue-440-2015-2235645

La Tercera. (24 de Octubre de 2010). Recuperado el Agosto de 2015, de http://www.latercera.com/noticia/negocios/2010/10/655-301995-9-clase-mediaen-america-latina-equivale-al-65-de-la-poblacion-y-chile-lidera-con.shtml

Ministerio de Comercio Exterior y Turismo. (2015). Recuperado el 2015, de http://ww2.mincetur.gob.pe/

Ministerio de Energía y Mina. (2014). Recuperado el 5 de Setiembre de 2015, de http://www.minem.gob.pe/_detalle.php?idSector=1\&idTitular=159\&idMenu=su b149

Ministerio de Relaciones Exteriores de Chile. (Febrero de 2013). Foreign Trade Information System. Recuperado el Agosto de 2015, de http://www.sice.oas.org/ctyindex/CHL/DIRECON20124_s.pdf

Organismo de Evaluación y Fiscalización Ambiental. (2012). Recuperado el 2015, de http://www.oefa.gob.pe/wp-content/uploads/2012/10/Ley-del-SistemaNacional-de-Evaluaci\%C3\%B3n-y-Fiscalizaci\%C3\%B3n-Ambiental.pdf

Santander Trade. (2015). Recuperado el 2015, de https://es.portal.santandertrade.com/analizar-mercados/peru/economia

Seperack, S. (2012). Sistema Integrado de Información de Comercio Exterior. Recuperado el 2015, de http://www.siicex.gob.pe/siicex/resources\%5Cpromo\%5CCuzco-Chile-SilviaSeperack.pdf

Sociedad Nacional de Minería Petróleo y Energía. (16 de Mayo de 2014). Diario Gestión. Recuperado el 15 de Junio de 2015, de http://gestion.pe/economia/peru-segundo-pais-mundo-mayores-reservas-platasegun-snmpe-2097485

The Silver Institute. (2015). Recuperado el 2015, de https://www.silverinstitute.org/site/silver-essentials/

Transparency International. (2014). Transparency. Recuperado el 2015, de http://www.transparency.org/cpi2014/results 
World Economic Forum, The Global Information Technology Report. (2015).

Recuperado el 2015, de

http://www3.weforum.org/docs/WEF_Global_IT_Report_2015.pdf 
ANEXO 


\section{ANEXO 1: Producción de Plata En Perú (En toneladas)}

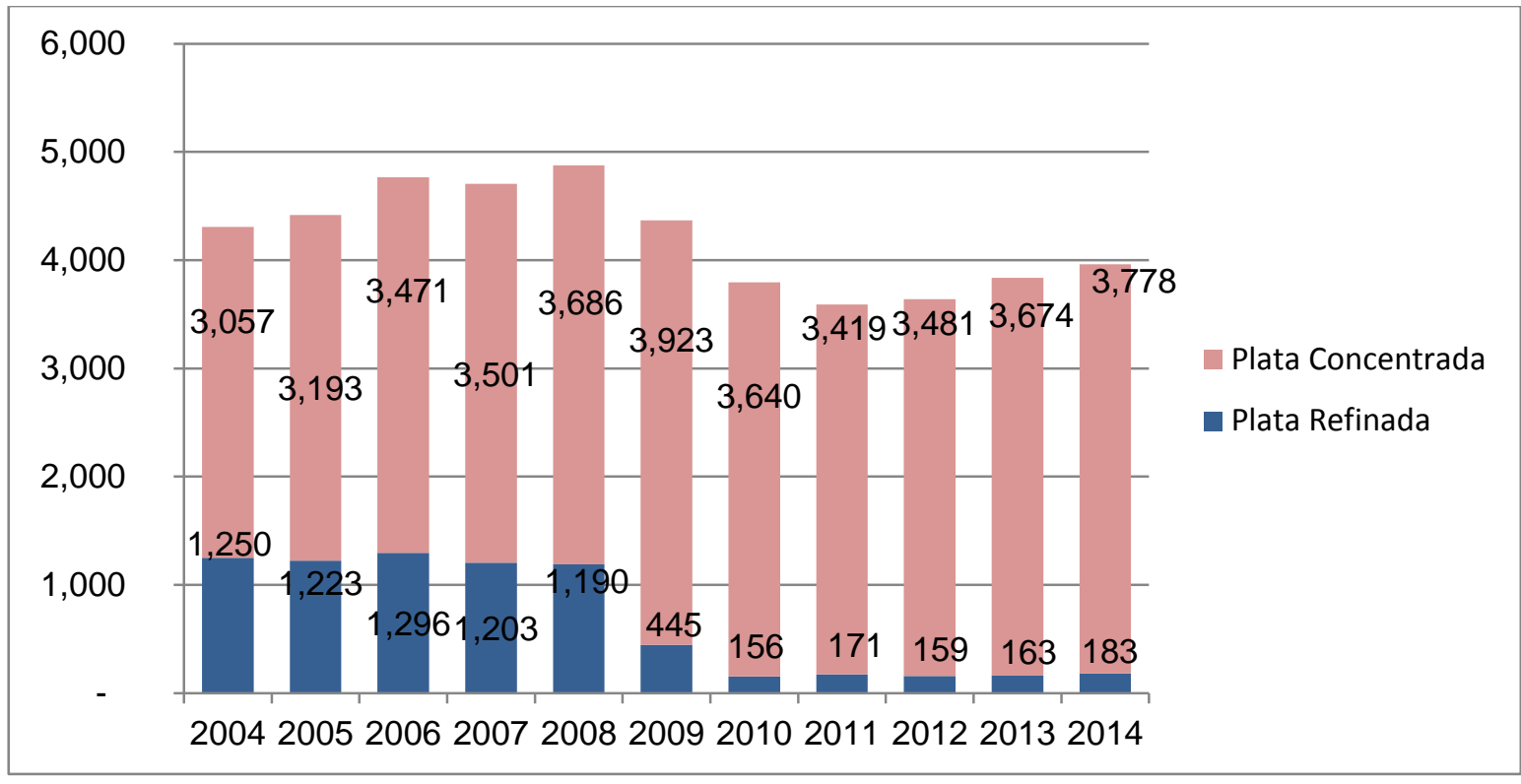

Fuente: Ministerio de Energía y Mina (Perú) 
ANEXO 2: Principales proveedores de Chile de todos los productos (millones de dólares).

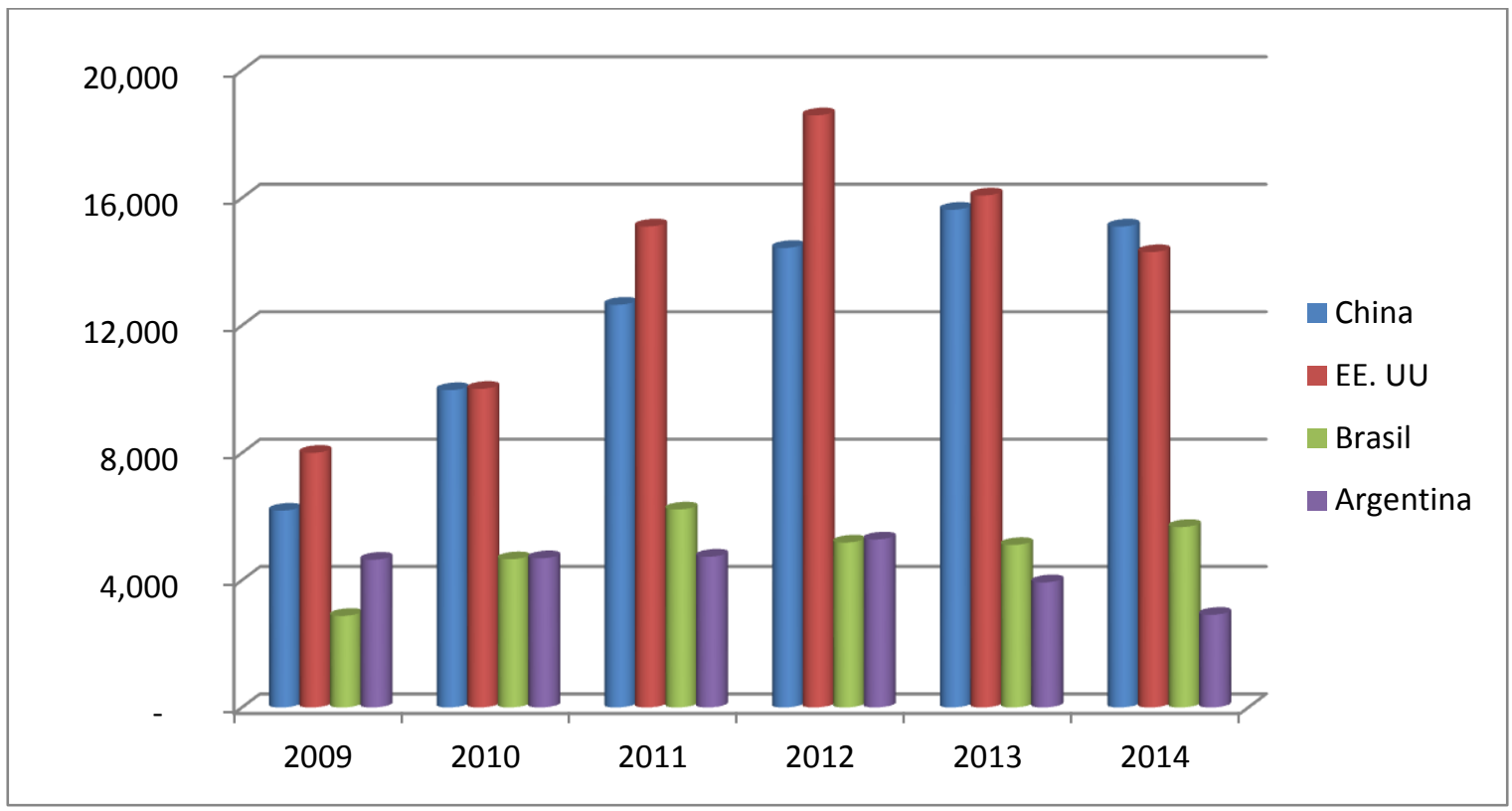

Fuente: TRADEMAP 
ANEXO 3: Participación de las exportaciones e importaciones de las Joyas de Plata en Chile

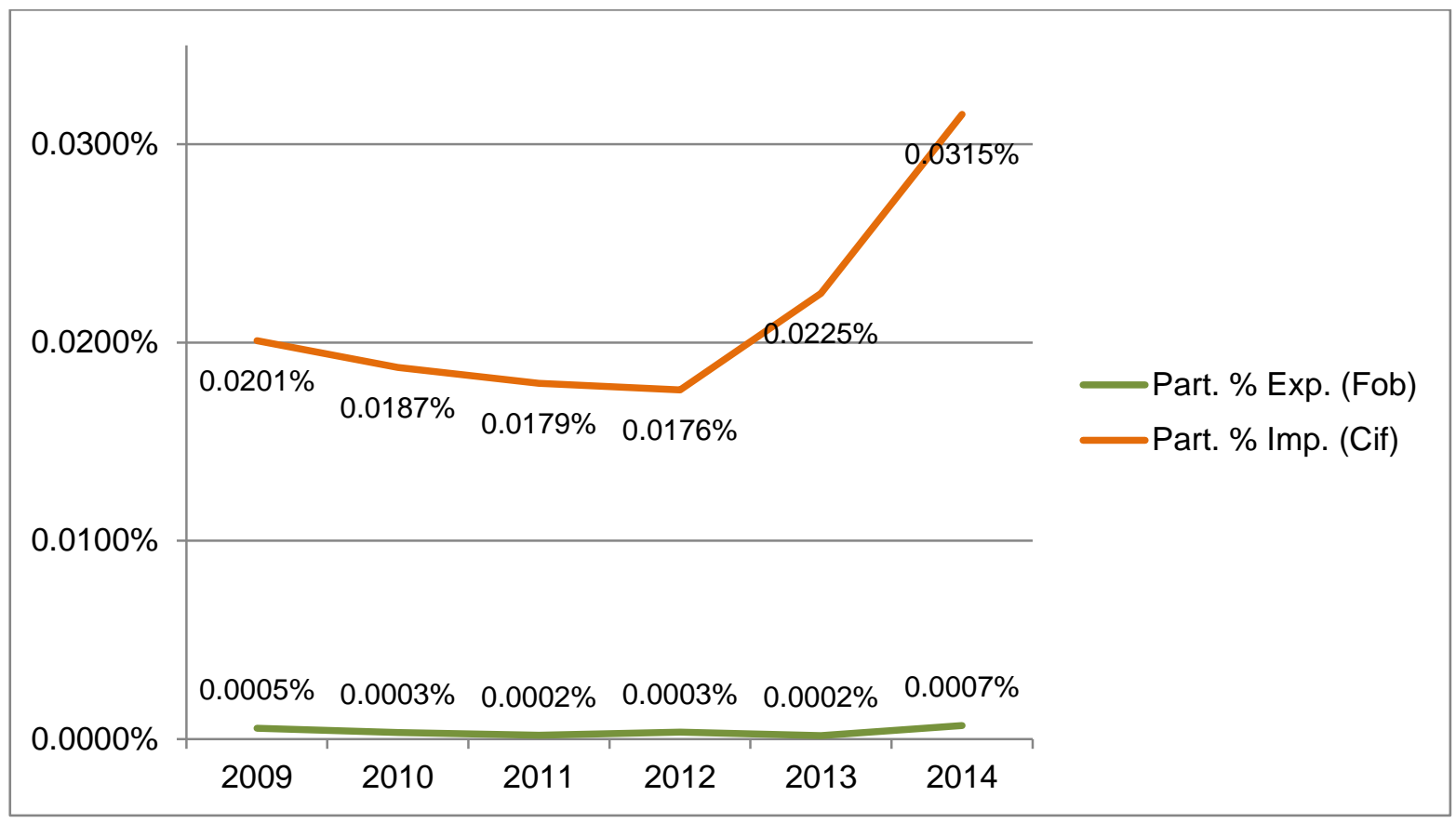

Fuente: TRADEMAP 


\section{ANEXO 4: Exportación de joyas de Perú a Chile y Estados Unidos (Año 2014)}

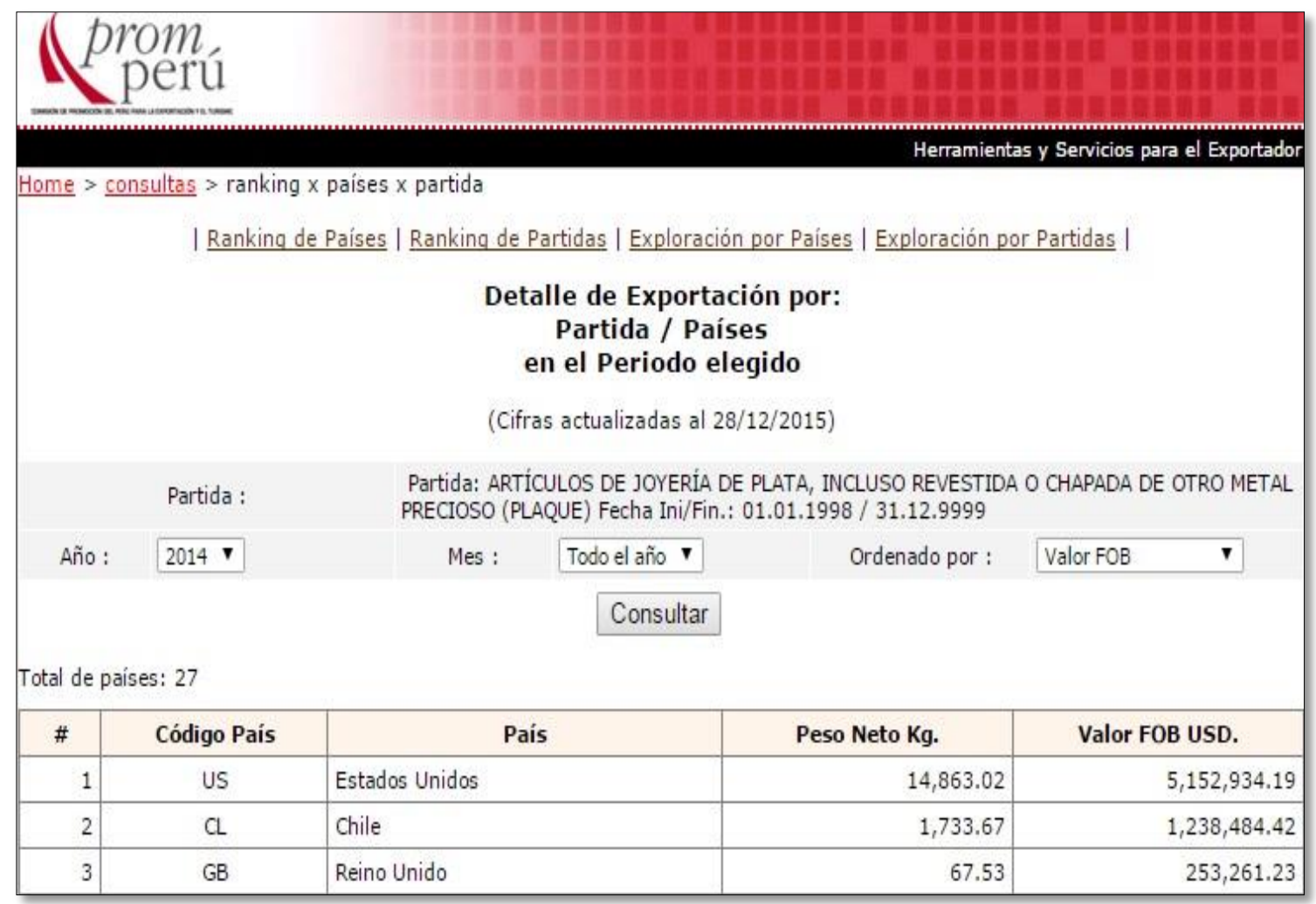

Fuente: PROMPERU 
ANEXO 5: Participación de los principales países exportadores de joyas de plata hacia Chile, 2014

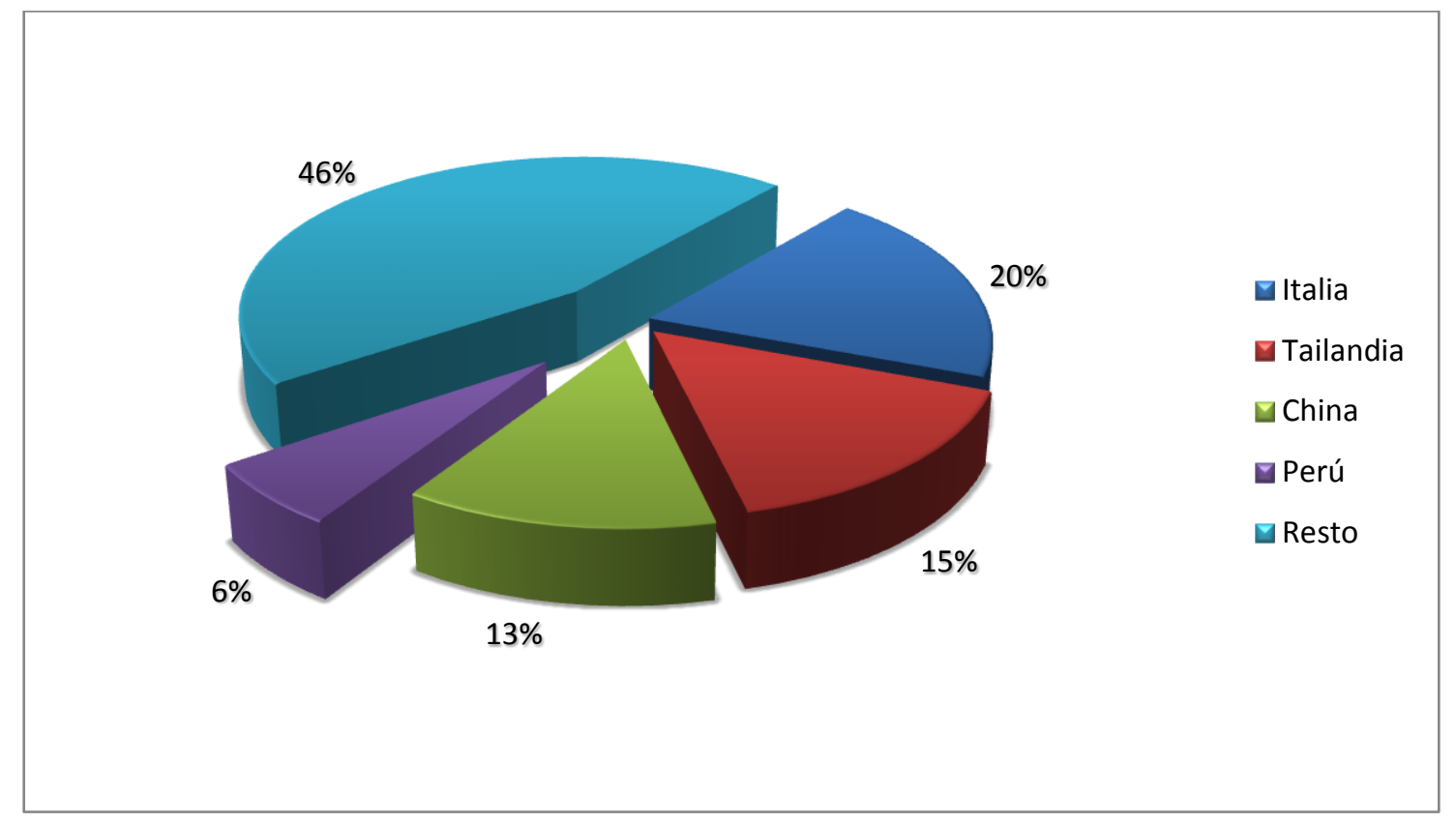

Fuente: TRADEMAP 


\section{ANEXO 6: Producción minera de Chile}

\begin{tabular}{|c|c|c|c|c|}
\cline { 2 - 5 } \multicolumn{1}{c|}{} & Minerales & $\begin{array}{c}\text { Participación } \\
\text { en las } \\
\text { reservas } \\
\text { mundiales }\end{array}$ & $\begin{array}{c}\text { Participación } \\
\text { en la } \\
\text { producción } \\
\text { mundial }\end{array}$ & $\begin{array}{c}\text { Ranking en } \\
\text { producción } \\
\text { mundial }\end{array}$ \\
\hline \multirow{4}{*}{ Metálicos } & COBRE (MT) & 28 & 32 & $1^{\circ}$ \\
\cline { 2 - 5 } & $\begin{array}{c}\text { MOLIBDENO } \\
(\mathrm{MT})\end{array}$ & 21 & 14 & $3^{\circ}$ \\
\cline { 2 - 5 } & RENIO (MT) & 52 & 52 & $1^{\circ}$ \\
\cline { 2 - 5 } & PLATA (MT) & 14 & 5 & $8^{\circ}$ \\
\cline { 2 - 5 } & ORO (MT) & 8 & 2 & $14^{\circ}$ \\
\hline \multirow{4}{*}{ No metálicos } & NITRATOS & 100 & 100 & $1^{\circ}$ \\
\cline { 2 - 5 } & YODO & 24 & 61 & $1^{\circ}$ \\
\cline { 2 - 5 } & LITIO [3] & 58 & 35 & \\
\hline
\end{tabular}

Fuente: Ministerio de Minería de Chile (COCHILCO) 


\section{ANEXO 7: Principal problema que enfrenta el Estado peruano}

\begin{tabular}{|c|c|c|c|}
\cline { 2 - 3 } \multicolumn{1}{c|}{} & $\mathbf{2 0 1 0}$ & $\mathbf{2 0 0 8}$ & $\mathbf{2 0 0 6}$ \\
\hline La corrupción de Funcionarios y autoridades & $56 \%$ & $55 \%$ & $49 \%$ \\
\hline Falta de eficiencia de los funcionarios y autoridades & $22 \%$ & $26 \%$ & $25 \%$ \\
\hline Falto de interés en los ciudadanos & $10 \%$ & $6 \%$ & $9 \%$ \\
\hline Falta de recurso económico & $7 \%$ & $8 \%$ & $12 \%$ \\
\hline Problema de coordinación entre las instituciones & $5 \%$ & $5 \%$ & $5 \%$ \\
\hline
\end{tabular}

Fuente: IPSOS APOYO

Encuesta realizada en Lima Metropolitana 


\section{ANEXO 8: Índice de percepción de corrupción}

\begin{tabular}{|c|c|c|c|c|}
\hline Puesto & País & $\begin{array}{c}\text { Puntaje } \\
\mathbf{2 0 1 4}\end{array}$ & $\begin{array}{c}\text { Puntaje } \\
\mathbf{2 0 1 3}\end{array}$ & $\begin{array}{c}\text { Puntaje } \\
\mathbf{2 0 1 2}\end{array}$ \\
\hline 1 & Dinamarca & 92 & 91 & 90 \\
\hline 2 & Nueva Zelanda & 91 & 91 & 90 \\
\hline 3 & Finlandia & 89 & 89 & 90 \\
\hline 4 & Suecia & 87 & 89 & 88 \\
\hline 5 & Noruega & 86 & 86 & 85 \\
\hline 5 & Suiza & 86 & 85 & 86 \\
\hline 7 & Singapur & 84 & 86 & 87 \\
\hline 8 & Holanda & 83 & 83 & 84 \\
\hline 9 & Luxemburgo & 82 & 80 & 80 \\
\hline 10 & Canadá & 81 & 81 & 84 \\
\hline$\ldots$ & $\ldots$ & $\ldots$ & $\ldots$ & $\ldots$ \\
\hline 85 & Perú & 38 & 38 & 38 \\
\hline
\end{tabular}

Fuente: TRANSPARENCY INTERNATIONAL 
ANEXO 9: Tipo de cambio en el Perú

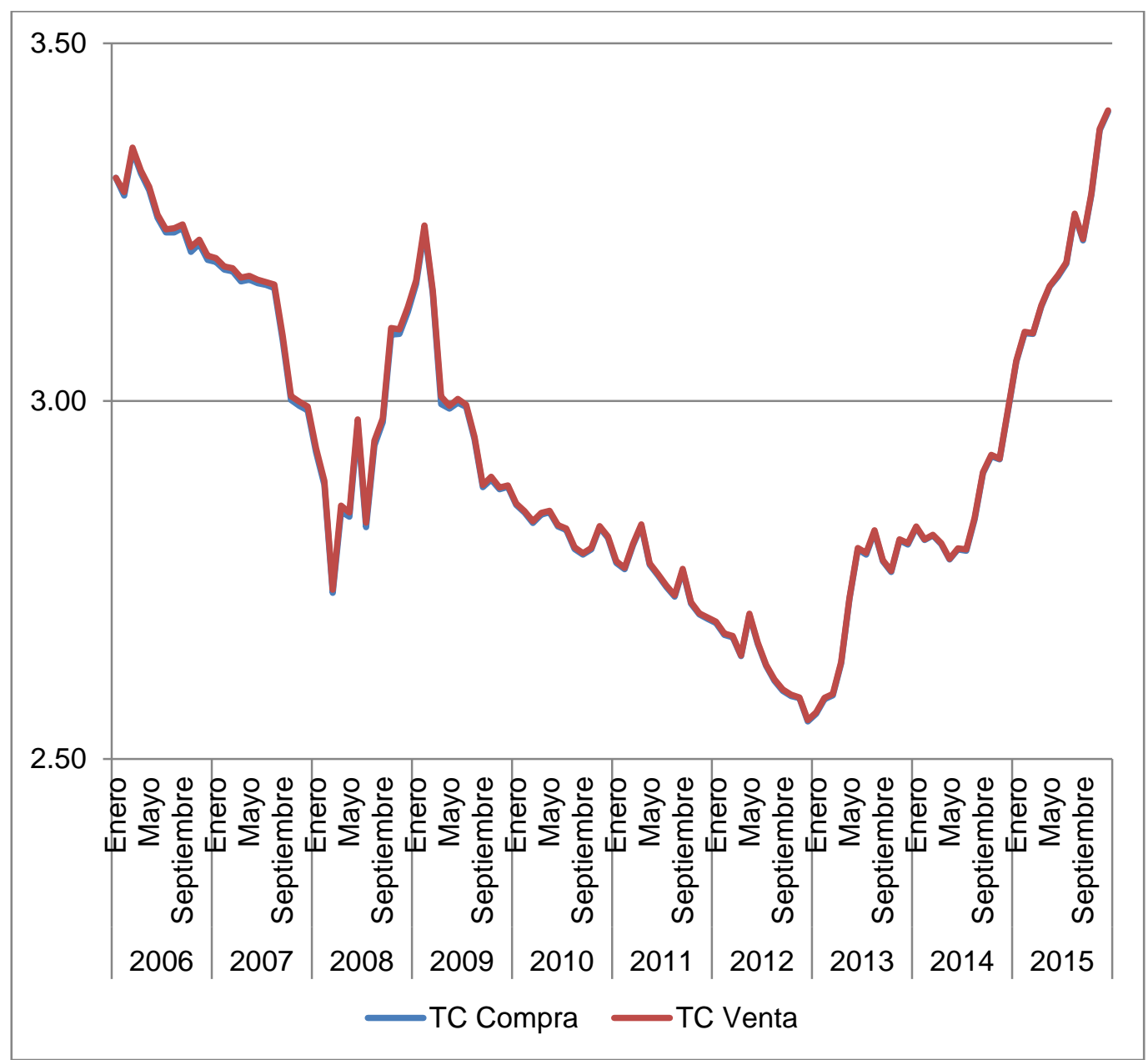

Fuente: BCRP 


\section{ANEXO 10: Medidas del BCRP contra la crisis internacional}

\begin{tabular}{|c|c|}
\hline AÑO 2008/2009 & MEDIDAS DEL BCRP PARA PROVEER LIQUIDEZ \\
\hline Setiembre / 2008 & $\begin{array}{l}\text { Encaje en moneda nacional y en moneda extranjera (libera recursos por S/.18 millones y US\$ } 102 \text { millones) } \\
\text { • Exonera encaje a adeudados externos de entidades financieras a plazos de } 2 \text { años o más. }\end{array}$ \\
\hline Octubre & $\begin{array}{l}\text { - Se extienden los plazos de las operaciones REPOS hasta } 1 \text { año y se amplía el número de participantes en las subastas (AFP's y } \\
\text { Fondos Mutuos) } \\
\text { - Se incorpora la opción de SWAP directo de dólares por soles. } \\
\text { - Se establecen REPOS en moneda extranjera. } \\
\text { Encaje en moneda nacional (libera recursos por } \mathbf{S} / \mathbf{9 6 7} \text { millones) } \\
\text { - Se establece un encaje único de } 9 \text { por ciento, que es igual al encaje mínimo legal, para las obligaciones sujetas al régimen } \\
\text { general. } \\
\text { - Se exonera de encaje al incremento de los créditos del exterior. } \\
\text { Encaje en moneda extranjera (libera recursos por US\$ } 279 \text { millones) } \\
\text { - Se reduce de } 49 \text { a } 35 \text { por ciento la tasa de encaje marginal aplicada sobre las obligaciones sujetas al régimen general. } \\
\text { Asimismo, se exonera de encaje al incremento de los créditos del exterior. } \\
\text { Encaje en moneda nacional (libera recursos por } \mathbf{S} / . \mathbf{1 5 4} \text { millones) } \\
\text { - Exoneración al } 33 \text { por ciento de obligaciones en soles hasta un máximo de S/. } 100 \text { millones. } \\
\text { - Reduce de } 120 \text { a } 35 \text { por ciento encaje a depósitos de no residentes. } \\
\text { - Reduce de } 120 \text { a } 9 \text { por ciento el encaje a fondos de no residentes destinados a financiar micro-finanzas. }\end{array}$ \\
\hline Noviembre & $\begin{array}{l}\text { Encaje en moneda extranjera (libera US\$ } \mathbf{2 7 , 2} \text { millones) } \\
\text { - Tope de } 35 \text { por ciento al encaje medio a créditos externos de corto plazo. } \\
\text { - Se reduce a } 35 \text { por ciento el encaje para las obligaciones del régimen especial. }\end{array}$ \\
\hline Diciembre & $\begin{array}{l}\text { Encaje en moneda nacional (libera S/. } 650 \text { millones) } \\
\text { - Se reduce la tasa del encaje mínimo legal de } 9,0 \text { a } 7,5 \text { por ciento. Encaje en moneda extranjera. } \\
\text { - Se reduce la tasa del encaje mínimo legal de } 9,0 \text { a } 7,5 \text { por ciento. } \\
\text { - Se reduce a } 35 \text { a } 30 \text { por ciento el encaje marginal para las obligaciones del régimen general. }\end{array}$ \\
\hline Enero / 2009 & $\begin{array}{l}\text { Encaje en moneda nacional (libera } \mathbf{S} / \mathbf{3 0 0} \text { millones) } \\
\text { - Se reduce la tasa del encaje mínimo legal de } 7,5 \text { a } 6,5 \text { por ciento. Además, se reduce el requerimiento mínimo de fondos de } \\
\text { encaje que los bancos deben mantener en su cuenta corriente del BCRP de } 2,0 \text { a } 1,5 \text { por ciento del TOSE. }\end{array}$ \\
\hline Febrero & $\begin{array}{l}\text { Se reduce la tasa de interés de referencia } \\
\text { - El Directorio del Banco Central de Reserva del Perú aprobó reducir la tasa de interés de referencia de la política monetaria de } \\
6,50 \text { a } 6,25 \text { por ciento. }\end{array}$ \\
\hline Marzo & $\begin{array}{l}\text { Se reduce la tasa de interés de referencia y la tasa de encaje en moneda nacional } \\
\text { - El Directorio del Banco Central de Reserva del Perú aprobó reducir la tasa de interés de referencia de la política monetaria de } \\
6,25 \text { a } 6,0 \text { por ciento. } \\
\text { - Se reduce la tasa del encaje mínimo legal de } 6,5 \text { a } 6,0 \text { por ciento, y el requerimiento de cuenta corriente de } 1,5 \text { por ciento a } 1,0 \\
\text { por ciento, a partir de abril (libera recursos por } S / .250 \text { Millones). }\end{array}$ \\
\hline AÑ̃ 2009 & MEDIDAS IMPLEMENTADAS PARA CONTROLAR EL FLUJO DE CAPITALES DE CORTO PLAZO \\
\hline Enero & $\begin{array}{l}\text { - Cambios del régimen de encaje en moneda nacional y en moneda extranjera y creación de una nueva facilidad de depósitos } \\
\text { para entidades financieras. } \\
\text { - Aumento del encaje mínimo legal de } 6 \text { a } 7 \text { por ciento; del encaje marginal en dólares de } 30 \text { a } 40 \text { por ciento y establecimiento de } \\
\text { marginal en soles de } 15 \text { por ciento. } \\
\text { - Incremento de } 1 \text { a } 2 \text { por ciento del encaje mínimo que debe mantenerse en la cuenta corriente de los bancos en el BCRP. } \\
\text { - Se aceptan depósitos a plazo de las entidades financieras en el BCRP. } \\
\text { - Se sustituye la emisión de CDBCRP por CDBCRP_NR (de negociación restringida a los participantes en la subasta primaria). } \\
\text { - Se establece el registro de transferencia de propiedad de los CDBCRP y CDR_BCRP. } \\
\text { - Se introduce una comisión a la transferencia de propiedad de los Certificados del BCRP. }\end{array}$ \\
\hline Marzo & $\begin{array}{l}\text { - Cambios del régimen de encaje en moneda nacional y en moneda extranjera } \\
\text { - Aumento del encaje mínimo legal de } 7 \text { a } 8 \text { por ciento; e incremento del encaje marginal en soles de } 15 \text { a } 20 \text { por ciento. } \\
\text { - Se establece una tasa de encaje en moneda nacional de } 40 \text { por ciento para las obligaciones con el exterior, excluyendo aquellas } \\
\text { con personas naturales o jurídicas no financieras. } \\
\text { - Se establece diciembre de } 2007 \text { como base para las obligaciones por créditos del exterior. } \\
\text { - Se establece un encaje único de } 9 \text { por ciento para las obligaciones sujetas al régimen general. Se exonera de encaje al } \\
\text { incremento de los créditos del exterior. }\end{array}$ \\
\hline Abril & $\begin{array}{l}\text { - Cambios del régimen de encaje en moneda nacional y en moneda extranjera } \\
\text { - Aumento del encaje mínimo legal de } 8 \text { a } 8,5 \text { por ciento y del encaje marginal en soles de } 20 \text { a } 25 \text { por ciento. Se eleva el encaje } \\
\text { marginal en dólares de } 40 \text { a } 45 \text { por ciento y se establece abril de } 2008 \text { como nueva base para el cálculo. } \\
\text { - Se establece una tasa de encaje en moneda nacional de } 120 \text { por ciento para las obligaciones provenientes de fuentes del } \\
\text { exterior, excluyendo aquellas con personas naturales o jurídicas no financieras. }\end{array}$ \\
\hline
\end{tabular}


- Cambios del régimen de encaje en moneda nacional y en moneda extranjera

- Aumento del encaje mínimo legal de 8,5 a 9,0 por ciento y de 45 a 49 por ciento la tasa de encaje marginal en moneda extranjera.

Julio

- Se establece una tasa de encaje de 9,0 por ciento para los créditos provenientes de fuentes del exterior con plazo promedio igual o mayor a 2 años hasta un límite en función de su patrimonio efectivo.

- Se establece una tasa de encaje en moneda nacional para el tramo del régimen especial que antes no estaba sujeto al encaje.

- Se eleva a 49 por ciento el encaje en moneda nacional aplicable a las operaciones sujetas a la variación del tipo de cambio. Fuente: BCRP 


\section{ANEXO 11: Población en edad de trabajar en el Perú según condición de actividad (Año 2014)}

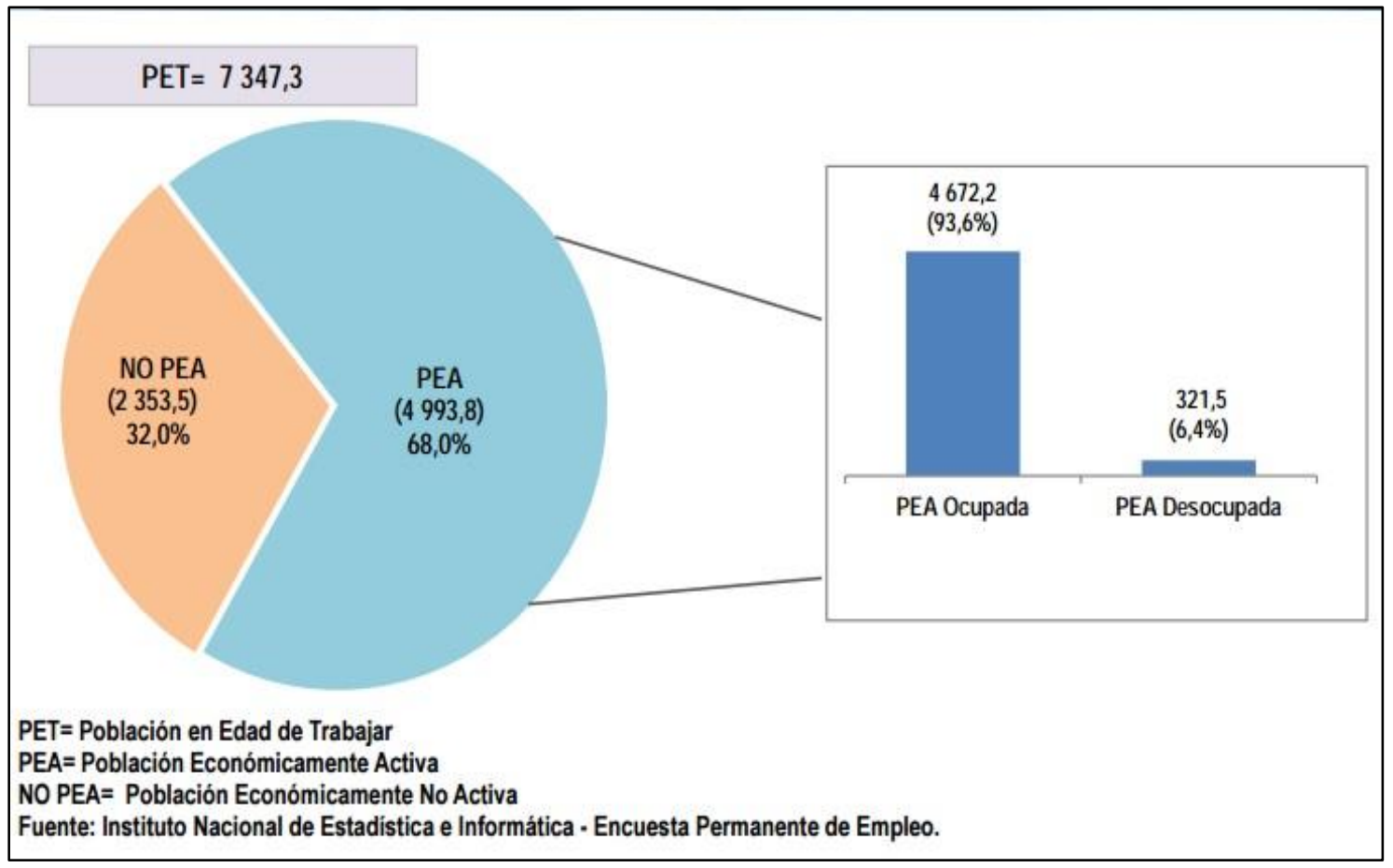

Fuente: INEI 


\section{ANEXO 12: Ranking de competitividad a nivel mundial}

\section{THE 2015 IMD WORLD COMPETITIVENESS SCOREBOARD}



(2014 anibisp win pretetwas)
COMPETITIVENESS SCOREBOARD (Ranks 31.61)

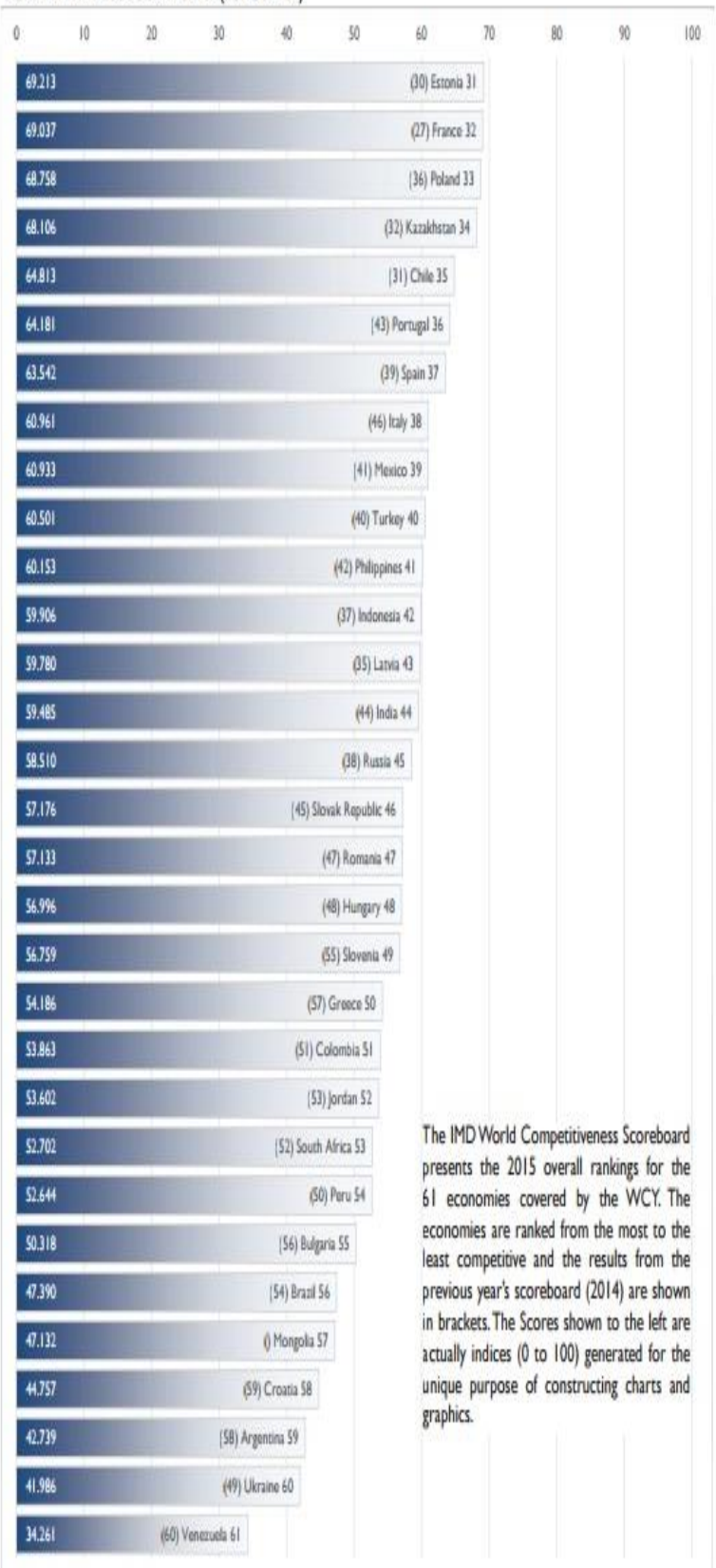

Fuente: IMD 


\section{ANEXO 13: Comparación de reporte de Competitividad entre Perú y Chile}

\begin{tabular}{|c|c|c|c|c|c|}
\hline \multirow{2}{*}{ Índice } & Eficiencia del Gobierno & \multicolumn{2}{|c|}{ Chile } & \multicolumn{2}{c|}{ Perú } \\
\cline { 3 - 6 } & Despilfarro del gasto público & Rank/144 & Puntaje & Rank/144 & Puntaje \\
\hline \multirow{5}{*}{ Variables } & Carga de la regulación gubernamental & 21 & 4.2 & 119 & 2.4 \\
\cline { 2 - 6 } & Eficiencia del marco legal en la resolución de litigios & 30 & 4.4 & 112 & 3.1 \\
\cline { 2 - 6 } & Eficiencia del marco legal en la normativa desafiantes & 33 & 4.1 & 109 & 2.8 \\
\cline { 2 - 6 } & Transparencia de las políticas del gobierno & 19 & 5.0 & 92 & 3.7 \\
\hline
\end{tabular}

Fuente: WORLD ECONOMIC FORUM.

PáginaWeb:http://reports.weforum.org/global-competitiveness-report-2014-

2015/economies/\#economy=CHL 


\section{ANEXO 14: Proyección del PBI per cápita de Chile hasta el 2020}

\section{PIB per cápita por paridad del poder adquisitivo [dólares]}

En 2015 los habitantes de Chile, Argentina o Libano tendrán un mayor poder de compra que los mexicanos.

\begin{tabular}{|c|c|c|c|c|c|c|c|}
\hline Sitio & Pais & 2015 & 2016 & 2017 & 2018 & 2019 & 2020 \\
\hline 1. & Qatar & 143,532 & 144,935 & 149,526 & 156,488 & 164,515 & 174,375 \\
\hline 2 & Luxemburgo & 93,174 & 94,689 & 96,757 & 98,901 & 100,909 & 102,940 \\
\hline 3 & Singapur & 85,198 & 88,485 & 92,577 & 96,978 & 101,373 & 106,049 \\
\hline 11 & Estados Unidos & 56,421 & 58,625 & 61,013 & 63,366 & 65,506 & 67,697 \\
\hline 17 & Australia & 47,608 & 49,257 & 51,194 & 53,186 & 55,124 & 57,089 \\
\hline 18 & Suecia & 47,229 & 48,876 & 50,820 & 52,787 & 54,690 & 56,584 \\
\hline 33 & España & 34,899 & 36,200 & 37,652 & 39,189 & 40,724 & 42,315 \\
\hline 44 & Guinea Ecuatorial & 26,810 & 27,480 & 26,031 & 24,110 & 21,730 & 20,562 \\
\hline 45 & Grecia & 26,773 & 28,204 & 29,744 & 31,385 & 33,009 & 34,595 \\
\hline 55 & Chile & 23,556 & 24,451 & 25,584 & 26,819 & 28,097 & 29,460 \\
\hline 56 & Antigua y Barbuda & 22,966 & 23,592 & 24,465 & 25,392 & 26,315 & 27,266 \\
\hline 57 & Argentina & 22,459 & 22,568 & 22,834 & 23,145 & 23,436 & 23,739 \\
\hline 59 & Uruguay & 21,247 & 22,116 & 23,171 & 24,371 & 25,595 & 26,962 \\
\hline 62 & Panamá & 20,418 & 21,618 & 23,081 & 24,757 & 26,315 & 27,888 \\
\hline 63 & Turquía & 20,188 & 21,007 & 21,983 & 23,022 & 24,067 & 25,161 \\
\hline 64 & Mauricio & 19,374 & 20,351 & 21,490 & 22,706 & 23,962 & 25,284 \\
\hline 65 & Libano & 18,422 & 18,984 & 19,766 & 20,598 & 21,641 & 22,733 \\
\hline 66 & México & 18,370 & 19,045 & 19,893 & 20,846 & 21,811 & २2,818 \\
\hline 67 & Bulgaria & 18,327 & 18,975 & 19,814 & 20,748 & 21,757 & 22,856 \\
\hline$\rho$ FMI & & & & & & & CNEXPANSIOI \\
\hline
\end{tabular}

Fuente: $\mathrm{CNN}$ 


\section{ANEXO 15: Máquinas para joyería: Laminadora y Diamantadora}
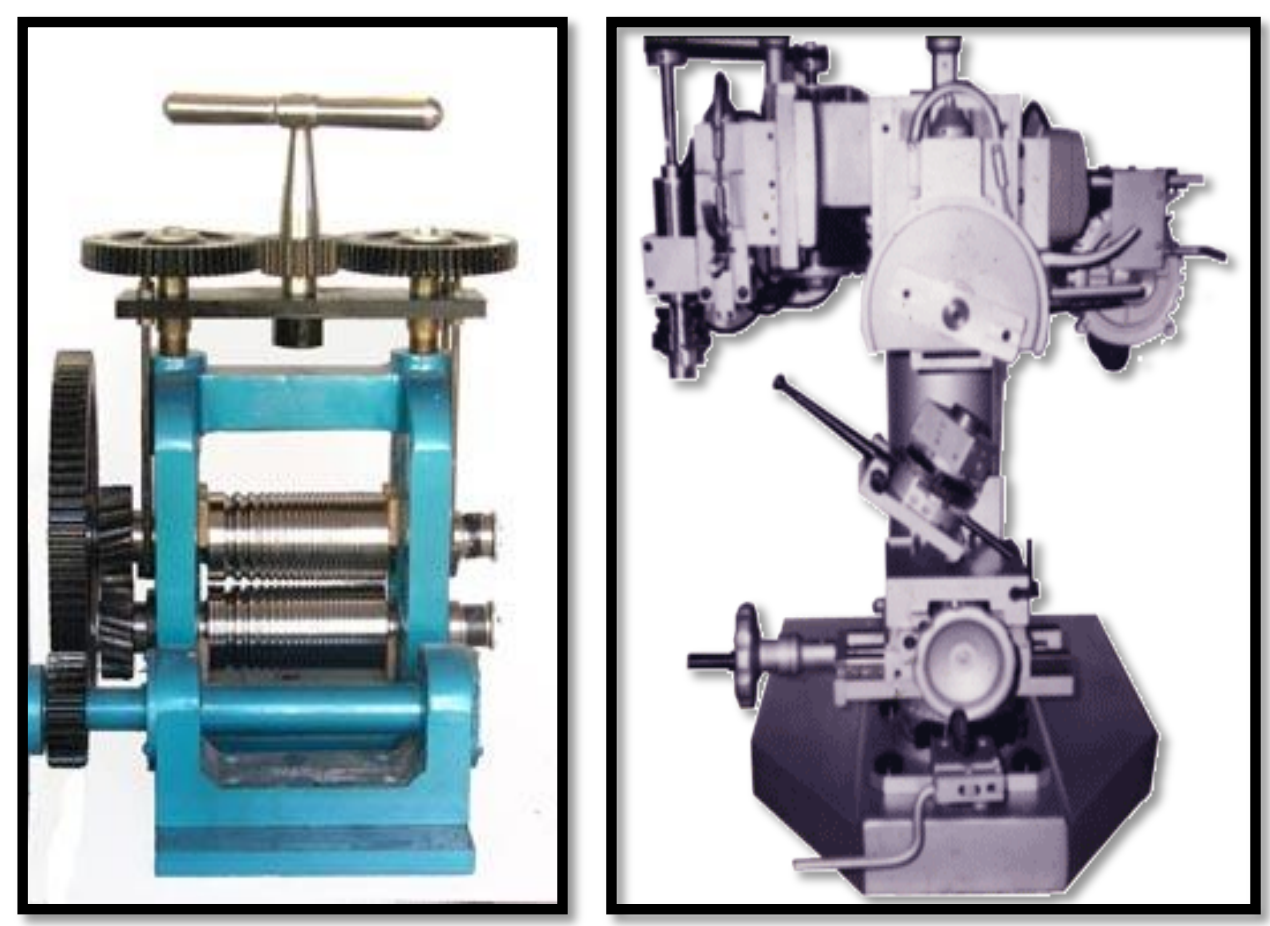

Fuente: Alibaba 
ANEXO 16: Participación de producción de plata a nivel mundial

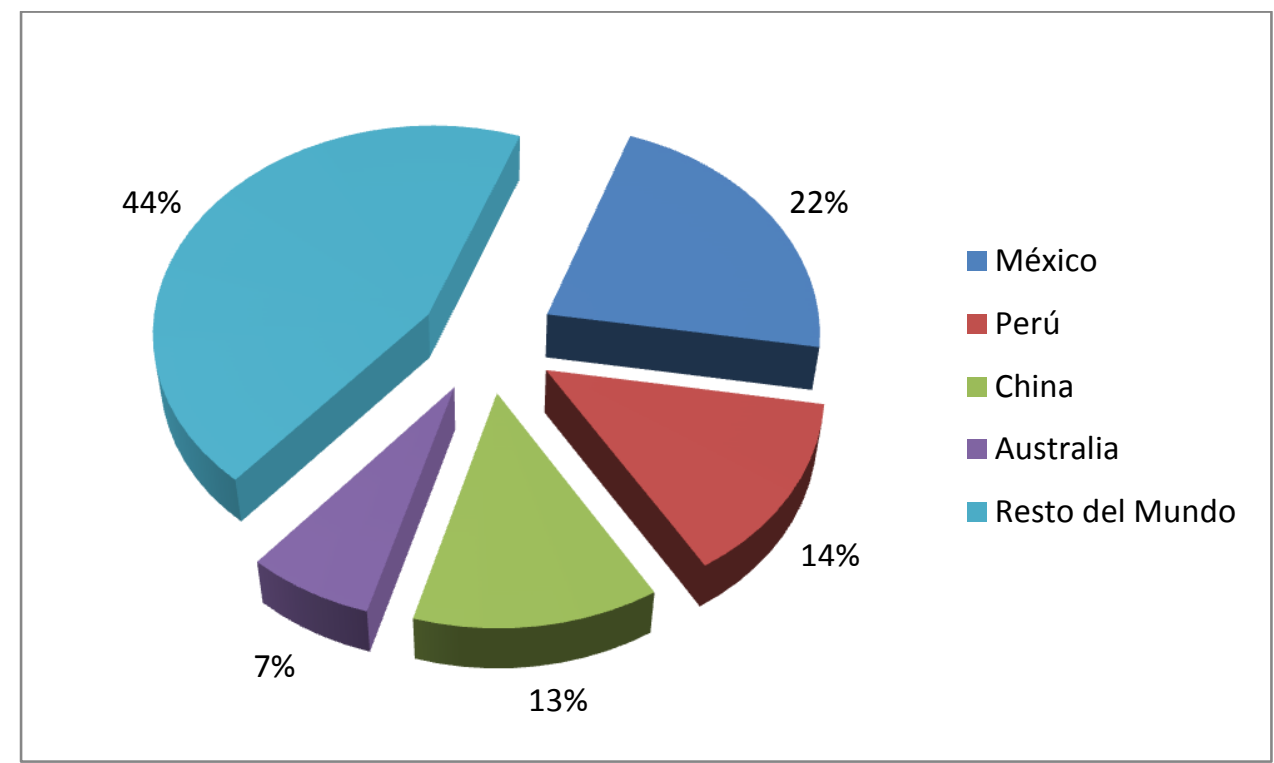

Fuente: SILVER INSTITUTE

(*)AÑO 2014 


\section{ANEXO 17: Número total de turistas internacionales anuales que ingresan a Perú}

\begin{tabular}{|c|c|c|c|c|c|c|}
\hline \multirow{2}{*}{ País de Residencia } & \multicolumn{6}{|c|}{ AÑ̃ } \\
\hline & 2009 & 2010 & 2011 & 2012 & $2013 \mathrm{P} /$ & $2014 \mathrm{P} /$ \\
\hline Total Turistas Internacionales 1/ & $2,139,961$ & $2,299,187$ & 2,597,803 & $2,845,623$ & $3,163,639$ & $3,214,934$ \\
\hline América del Sur & $1,034,279$ & $1,198,782$ & $1,433,730$ & $1,586,366$ & $1,816,415$ & $1,779,149$ \\
\hline Chile & 464,153 & 595,944 & 741,717 & 806,929 & 886,485 & 903,793 \\
\hline Ecuador & 136,054 & 152,445 & 160,841 & 176,071 & 208,358 & 223,995 \\
\hline Argentina & 121,172 & 127,062 & 147,403 & 158,950 & 155,145 & 155,931 \\
\hline Otros América del Sur & 312,900 & 323,331 & 383,769 & 444,416 & 566,427 & 495,430 \\
\hline América del Norte & 509,543 & 508,284 & 515,394 & 559,809 & 610,418 & 649,438 \\
\hline EE.UU. & 426,325 & 417,232 & 411,935 & 447,218 & 487,328 & 514,228 \\
\hline Canadá & 54,595 & 52,955 & 57,454 & 61,362 & 62,820 & 68,194 \\
\hline México & 28,623 & 38,097 & 46,005 & 51,229 & 60,270 & 67,016 \\
\hline Europa & 431,954 & 433,133 & 460,605 & 491,474 & 512,990 & 540,598 \\
\hline España & 90,714 & 96,666 & 105,231 & 111,041 & 122,567 & 131,174 \\
\hline Francia & 66,071 & 66,985 & 72,900 & 81,851 & 81,904 & 82,260 \\
\hline Alemania & 51,864 & 53,201 & 56,197 & 62,051 & 62,570 & 68,703 \\
\hline Otros Europa & 223,305 & 216,281 & 226,277 & 236,531 & 245,949 & 258,461 \\
\hline Asia & $\mathbf{8 5 , 8 3 4}$ & 79,218 & $\mathbf{9 9 , 5 1 7}$ & 116,192 & 129,920 & 135,207 \\
\hline Japón & 40,018 & 30,604 & 43,794 & 56,526 & 67,639 & 59,853 \\
\hline Corea del Sur & 7,824 & 10,157 & 12,059 & 13,318 & 14,000 & 17,265 \\
\hline China (R.P.) & 9,257 & 9,484 & 11,896 & 12,180 & 12,864 & 16,607 \\
\hline Otros Asia & 28,735 & 28,973 & 31,768 & 34,168 & 35,417 & 41,482 \\
\hline América Central & 37,393 & 39,895 & 47,635 & 44,640 & 46,618 & 50,116 \\
\hline Panamá & 8,956 & 10,718 & 10,960 & 12,908 & 15,121 & 16,367 \\
\hline Costa Rica & 7,842 & 8,765 & 9,302 & 9,319 & 9,489 & 11,452 \\
\hline Otros A.Central y El Caribe & 20,595 & 20,412 & 27,373 & 22,413 & 22,008 & 22,297 \\
\hline Oceanía & 36,281 & 35,087 & 35,624 & 41,456 & 41,876 & 48,564 \\
\hline Australia & 30,947 & 29,659 & 30,436 & 35,745 & 36,373 & 41,842 \\
\hline Nueva Zelandia & 5,263 & 5,363 & 5,134 & 5,616 & 5,406 & 6,578 \\
\hline Otros Oceanía & 71 & 65 & 54 & 95 & 97 & 144 \\
\hline África & 3,609 & 3,855 & 4,469 & 4,631 & 4,466 & 5,590 \\
\hline Sudáfrica & 2,444 & 2,689 & 2,994 & 2,943 & 2,672 & 2,604 \\
\hline Egipto & 131 & 141 & 222 & 225 & 209 & 326 \\
\hline Marruecos & 136 & 130 & 229 & 225 & 241 & 264 \\
\hline Otros África & 898 & 895 & 1,024 & 1,238 & 1,344 & 2,396 \\
\hline $\begin{array}{l}\text { No especificado por la } \\
\text { DIGEMIN (Los Inspectores } \\
\text { registran la Nacionalidad, pero no } \\
\text { la Residencia) }\end{array}$ & 1,068 & 933 & 829 & 1,055 & 936 & 6,272 \\
\hline
\end{tabular}

Fuente: MINCETUR 


\section{ANEXO 18: Índice Global del Comercio Electrónico}

\begin{tabular}{|c|c|c|c|c|c|c|c|}
\hline \multicolumn{8}{|c|}{ The 2015 Global Retail E-Commerce Index ${ }^{\text {TM }}$} \\
\hline Rank & $\begin{array}{l}\text { Change } \\
\text { in rank }\end{array}$ & Country & $\begin{array}{l}\text { Online } \\
\text { market size } \\
(40 \%)\end{array}$ & $\begin{array}{l}\text { Consumer } \\
\text { behavior } \\
(20 \%)\end{array}$ & $\begin{array}{l}\text { Growth } \\
\text { potential } \\
(20 \%)\end{array}$ & $\begin{array}{l}\text { Infra- } \\
\text { structure } \\
(20 \%)\end{array}$ & $\begin{array}{l}\text { Online market } \\
\text { attractiveness } \\
\text { score }\end{array}$ \\
\hline 1 & +2 & United States & 100.0 & 83.2 & 22.0 & 91.5 & 79.3 \\
\hline 2 & -1 & China & 100.0 & 59.4 & 86.1 & 43.6 & 77.8 \\
\hline 3 & +1 & United Kingdom & 87.9 & 98.6 & 11.3 & 86.4 & 74.4 \\
\hline 4 & -2 & Japan & 77.6 & 87.8 & 10.1 & 97.7 & 70.1 \\
\hline 5 & +1 & Germany & 63.9 & 92.6 & 29.5 & 83.1 & 66.6 \\
\hline 6 & +1 & France & 51.9 & 89.5 & 21.0 & 82.1 & 59.3 \\
\hline 7 & -2 & South Korea & 44.9 & 98.4 & 11.3 & 95.0 & 58.9 \\
\hline 8 & +5 & Russia & 29.6 & 66.4 & 51.8 & 66.2 & 48.7 \\
\hline 9 & +15 & Belgium & 8.3 & 82.0 & 48.3 & 81.1 & 45.6 \\
\hline 10 & -1 & Australia & 11.9 & 80.8 & 28.6 & 84.8 & 43.6 \\
\hline 11 & -1 & Canada & 10.6 & 81.4 & 23.6 & 88.9 & 43.1 \\
\hline 12 & +2 & Hong Kong & 2.3 & 93.6 & 13.0 & 100.0 & 42.2 \\
\hline 13 & +6 & Netherlands & 8.9 & 98.8 & 8.1 & 84.6 & 41.8 \\
\hline 14 & -3 & Singapore & 1.3 & 89.4 & 15.7 & 100.0 & 41.5 \\
\hline 15 & +13 & Denmark & 8.1 & 100.0 & 15.1 & 75.5 & 41.4 \\
\hline 16 & o & Sweden & 8.8 & 97.2 & 11.8 & 77.7 & 40.9 \\
\hline 17 & Not ranked & Mexico & 10.0 & 53.3 & 58.6 & 68.0 & 40.0 \\
\hline 18 & Not ranked & Spain & 13.2 & 73.1 & 20.2 & 80.1 & 39.9 \\
\hline 19 & +1 & Chile & 2.7 & 71.8 & 49.3 & 73.2 & 39.9 \\
\hline 20 & +6 & Norway & 8.2 & 99.4 & 5.6 & 76.3 & 39.5 \\
\hline 21 & -13 & Brazil & 19.6 & 57.4 & 28.0 & 72.4 & 39.4 \\
\hline 22 & -7 & Italy & 12.3 & 71.6 & 27.8 & 70.7 & 38.9 \\
\hline 23 & +6 & Switzerland & 7.1 & 89.6 & 7.4 & 82.5 & 38.8 \\
\hline 24 & -1 & Venezuela & 1.7 & 54.1 & 79.4 & 55.7 & 38.5 \\
\hline 25 & -4 & Finland & 6.4 & 98.3 & 3.8 & 77.3 & 38.4 \\
\hline 26 & -8 & New Zealand & 1.7 & 86.4 & 25.9 & 75.4 & 38.2 \\
\hline 27 & Not ranked & Austria & 5.9 & 85.3 & 19.0 & 74.8 & 38.1 \\
\hline 28 & Not ranked & Saudi Arabia & 1.1 & 46.6 & 67.3 & 74.6 & 38.1 \\
\hline 29 & -17 & Argentina & 5.7 & 70.3 & 43.9 & 64.3 & 38.0 \\
\hline 30 & -3 & Ireland & 4.9 & 74.4 & 27.6 & 74.1 & 37.2 \\
\hline \multicolumn{8}{|c|}{ Notes: Scores are rounded. 100 is the highest and o is the lowest for each dimension. } \\
\hline \multicolumn{8}{|c|}{$\begin{array}{l}\text { Sources: Euromonitor, International Telelcommunication Union, Planet Retail, World Bank, World Economic Forum, United Nations Department of Economic } \\
\text { and Social Affairs; A.T. Kearney analysis }\end{array}$} \\
\hline
\end{tabular}

Fuente: ATKEARNEY 


\section{ANEXO 19: Piedras Naturales de Perú}

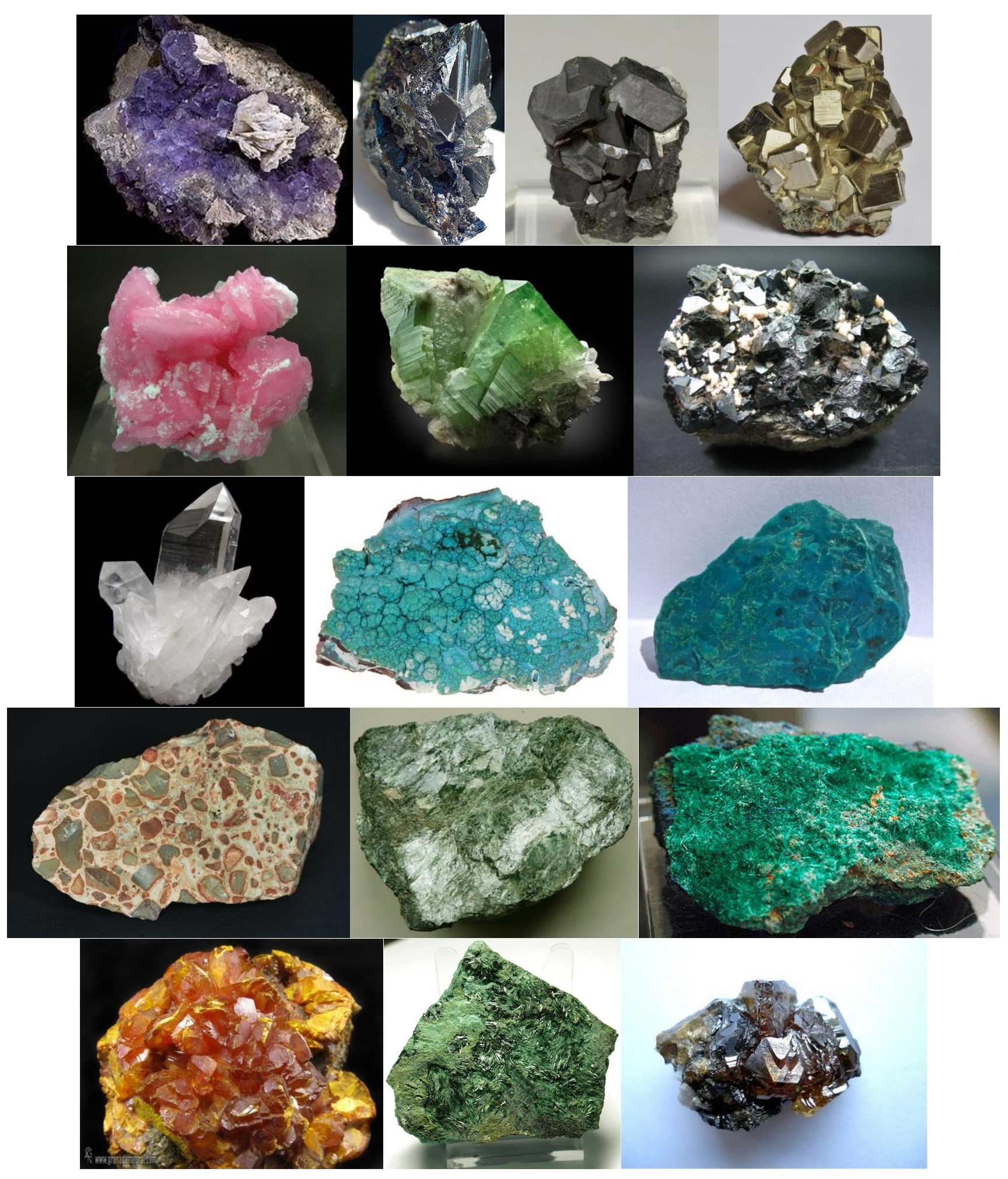




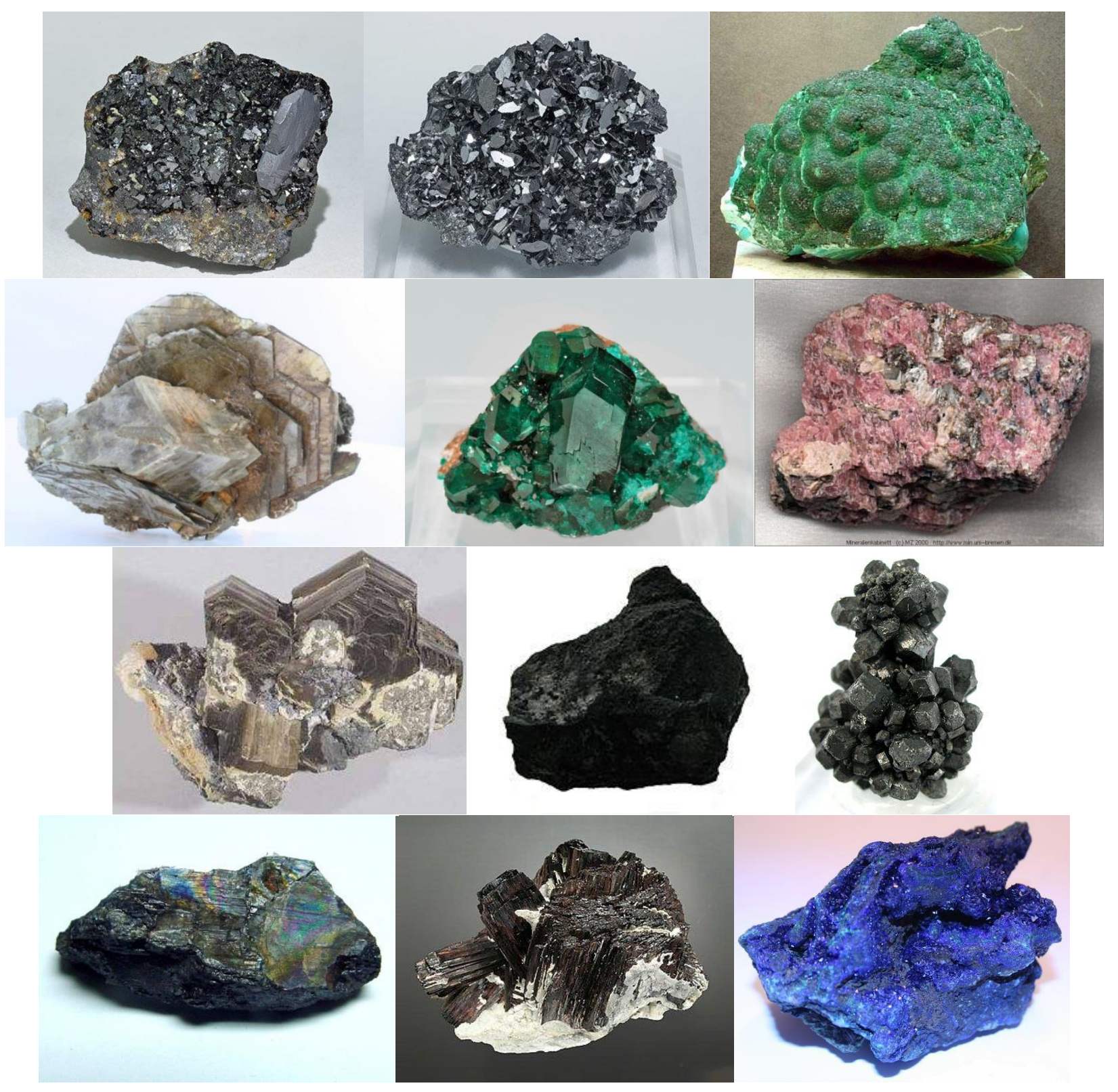

Fuente: Google Imagen 
ANEXO 20: Precio Histórico de la Plata (Año 2000-2015)

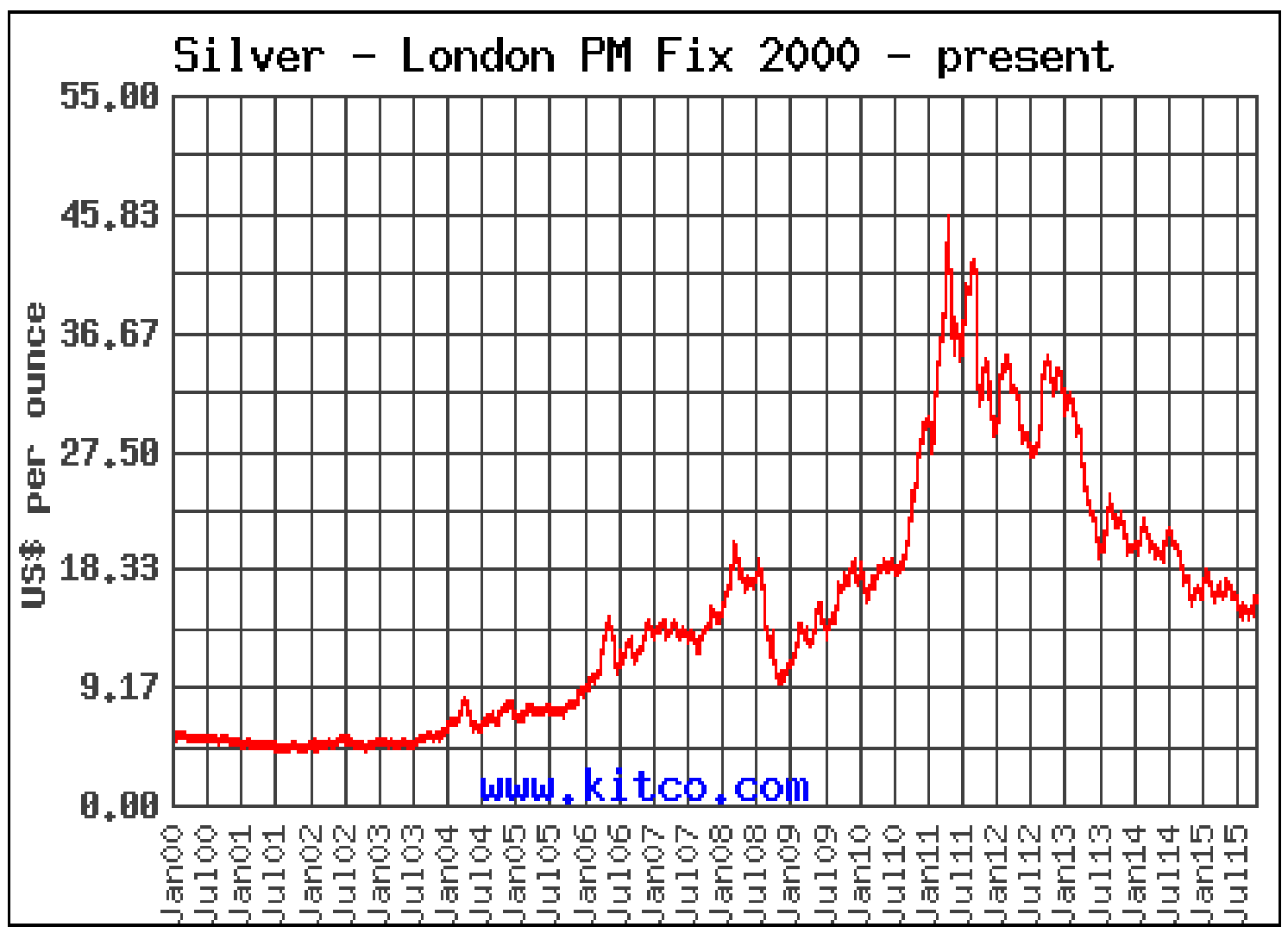

Fuente: KITCO 


\section{ANEXO 21: Precio Internacional del cobre}

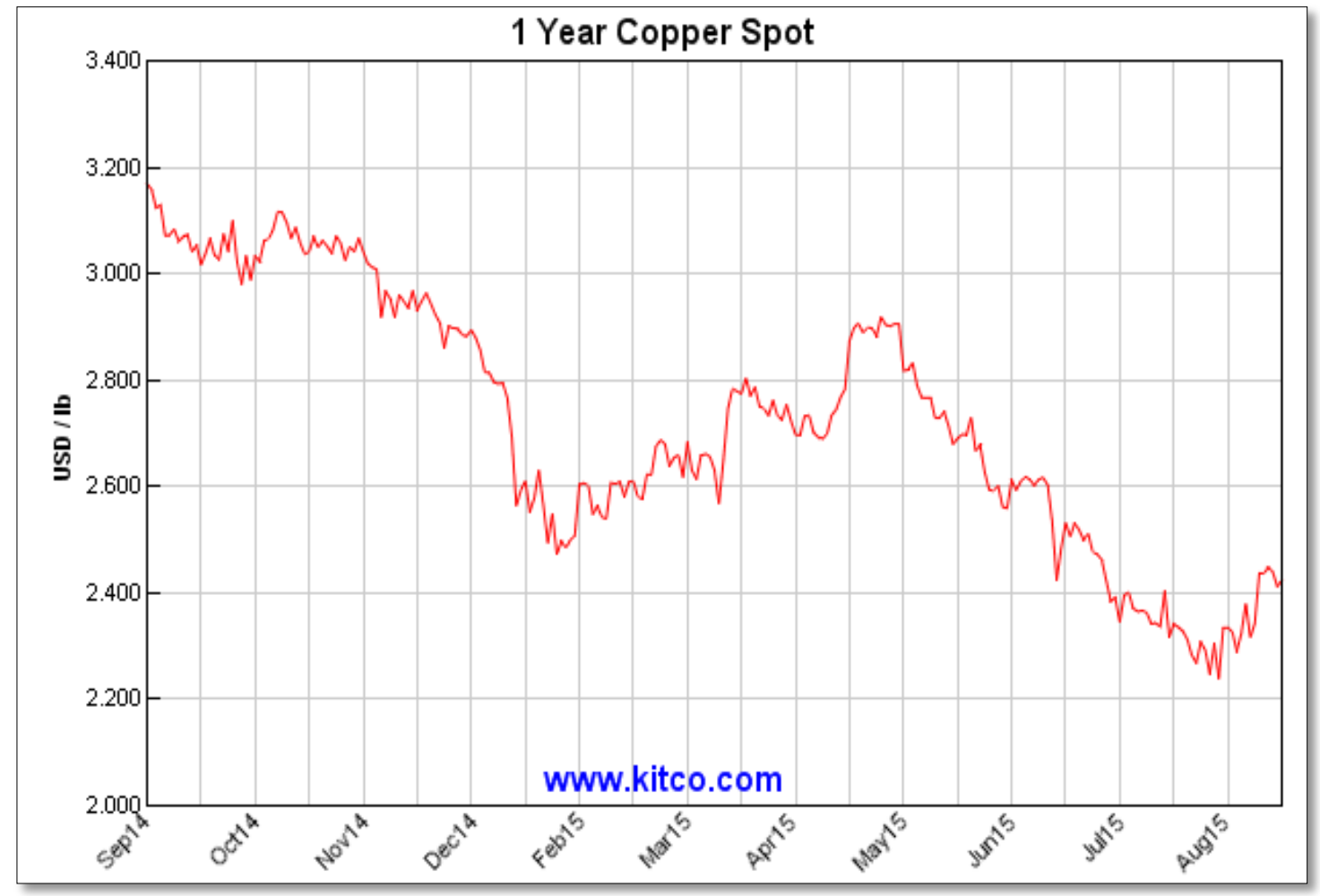

Fuente: KITCO 


\section{ANEXO 22: Exportación en US\$ de joyas de plata de Perú a Chile}

\begin{tabular}{|c|cc|rr|rr|rr|rr|rr|}
\hline MES & \multicolumn{2}{|c|}{$\mathbf{2 0 1 0}$} & \multicolumn{2}{|c|}{$\mathbf{2 0 1 1}$} & \multicolumn{2}{c|}{$\mathbf{2 0 1 2}$} & \multicolumn{2}{|c|}{$\mathbf{2 0 1 3}$} & \multicolumn{2}{|c|}{$\mathbf{2 0 1 4}$} & \multicolumn{2}{|c|}{$\mathbf{2 0 1 5}$} \\
\hline Enero & $\$$ & 26,119 & $\$$ & 9,002 & $\$$ & 39,840 & $\$$ & 15,670 & $\$$ & 68,276 & $\$$ & 476 \\
\hline Febrero & $\$$ & 19,843 & $\$$ & 13,770 & $\$$ & 18,671 & $\$$ & 39,560 & $\$$ & 49,639 & $\$$ & 40,028 \\
\hline Marzo & $\$$ & 35,967 & $\$$ & 16,399 & $\$$ & 122,020 & $\$$ & 49,723 & $\$$ & 16,430 & $\$$ & 119,914 \\
\hline Abril & $\$$ & 5,932 & $\$$ & 42,193 & $\$$ & 43,273 & $\$$ & 102,201 & $\$$ & 247,793 & $\$$ & 220,325 \\
\hline Mayo & $\$$ & 59,534 & $\$$ & 3,704 & $\$$ & 97,095 & $\$$ & 72,913 & $\$$ & 124,514 & $\$$ & 65,157 \\
\hline Junio & $\$$ & 51,564 & $\$$ & 72,333 & $\$$ & 45,482 & $\$$ & 197,963 & $\$$ & 80,582 & $\$$ & 163,385 \\
\hline Julio & $\$$ & 24,365 & $\$$ & 54,011 & $\$$ & 60,199 & $\$$ & 144,189 & $\$$ & 83,753 & $\$$ & 117,032 \\
\hline Agosto & $\$$ & 50,254 & $\$$ & 150,246 & $\$$ & 22,248 & $\$$ & 163,240 & $\$$ & 68,128 & $\$$ & 88,224 \\
\hline Septiembre & $\$$ & 12,060 & $\$$ & 13,193 & $\$$ & 1,221 & $\$$ & 85,503 & $\$$ & 112,885 & $\$$ & 239,262 \\
\hline Octubre & $\$$ & 11,154 & $\$$ & 84,750 & $\$$ & 123,207 & $\$$ & 181,963 & $\$$ & 111,823 & $\$$ & 81,700 \\
\hline Noviembre & $\$$ & 96,876 & $\$$ & 77,947 & $\$$ & 63,533 & $\$$ & 128,611 & $\$$ & 265,256 & $\$$ & 266,000 \\
\hline Diciembre & $\$$ & 75,378 & $\$$ & 27,336 & $\$$ & 84,313 & $\$$ & 100,370 & $\$$ & 9,406 & $\$$ & - \\
\hline
\end{tabular}

Fuente: PROMPERUSTAT 


\section{ANEXO 23: Exportación en Kilogramos de joyas de plata de Perú a Chile}

\begin{tabular}{|c|c|c|c|c|c|c|}
\hline MES & $\mathbf{2 0 1 0}$ & $\mathbf{2 0 1 1}$ & $\mathbf{2 0 1 2}$ & $\mathbf{2 0 1 3}$ & $\mathbf{2 0 1 4}$ & $\mathbf{2 0 1 5}$ \\
\hline Enero & 73.05 & 22.9 & 123.36 & 17.27 & 120.47 & 9.16 \\
\hline Febrero & 103.6 & 33.53 & 36.48 & 51.79 & 32.07 & 46.33 \\
\hline Marzo & 149.72 & 35.21 & 324.8 & 106.71 & 16.3 & 133.93 \\
\hline Abril & 40.64 & 196.28 & 61.97 & 276.24 & 502.71 & 311.2 \\
\hline Mayo & 233.03 & 9.6 & 209.87 & 107.76 & 245.02 & 76.3 \\
\hline Junio & 230.57 & 80.83 & 86.17 & 250.39 & 77 & 193.1 \\
\hline Julio & 95.32 & 138.32 & 185.53 & 149.08 & 104 & 235.85 \\
\hline Agosto & 101.49 & 82.01 & 56.23 & 313.48 & 58.6 & 151.09 \\
\hline Septiembre & 27.14 & 7.37 & 8.26 & 68.13 & 144.5 & 285.6 \\
\hline Octubre & 226.12 & 110.37 & 352.63 & 196.24 & 125.32 & 104.85 \\
\hline Noviembre & 387.93 & 418.42 & 114.09 & 135.29 & 248.86 & 493 \\
\hline Diciembre & 205.74 & 72.89 & 179.77 & 154.61 & 58.82 & - \\
\hline
\end{tabular}

Fuente: PROMPERUSTAT 


\section{ANEXO 24: Proyección de exportación de la empresa JOYERIA BARI EIRL (En Kilogramos)}

\begin{tabular}{|c|c|c|c|c|c|c|}
\hline Año & $\mathbf{K g}$ & Mes & Total Anual (Kg) & Participación & Participación en Kg & Total Empresa (Kg) \\
\hline \multirow{12}{*}{2016} & 189 & Enero & \multirow{12}{*}{1,850} & \multirow{12}{*}{$8 \%$} & 15 & \multirow{12}{*}{148} \\
\hline & 143 & Febrero & & & 11 & \\
\hline & 125 & Marzo & & & 10 & \\
\hline & 190 & Abril & & & 15 & \\
\hline & 144 & Mayo & & & 11 & \\
\hline & 126 & Junio & & & 10 & \\
\hline & 191 & Julio & & & 15 & \\
\hline & 144 & Agosto & & & 11 & \\
\hline & 127 & Septiembre & & & 10 & \\
\hline & 192 & Octubre & & & 15 & \\
\hline & 145 & Noviembre & & & 11 & \\
\hline & 127 & Diciembre & & & 10 & \\
\hline \multirow{12}{*}{2017} & 194 & Enero & \multirow{12}{*}{1,893} & \multirow{12}{*}{$10 \%$} & 19 & \multirow{12}{*}{189} \\
\hline & 146 & Febrero & & & 14 & \\
\hline & 128 & Marzo & & & 12 & \\
\hline & 195 & Abril & & & 19 & \\
\hline & 147 & Mayo & & & 14 & \\
\hline & 129 & Junio & & & 12 & \\
\hline & 196 & Julio & & & 19 & \\
\hline & 148 & Agosto & & & 14 & \\
\hline & 130 & Septiembre & & & 13 & \\
\hline & 197 & Octubre & & & 19 & \\
\hline & 149 & Noviembre & & & 14 & \\
\hline & 130 & Diciembre & & & 13 & \\
\hline \multirow{12}{*}{2018} & 198 & Enero & \multirow{12}{*}{1,935} & \multirow{12}{*}{$13 \%$} & 25 & \multirow{12}{*}{251} \\
\hline & 149 & Febrero & & & 19 & \\
\hline & 131 & Marzo & & & 17 & \\
\hline & 199 & Abril & & & 25 & \\
\hline & 150 & Mayo & & & 19 & \\
\hline & 132 & Junio & & & 17 & \\
\hline & 200 & Julio & & & 26 & \\
\hline & 151 & Agosto & & & 19 & \\
\hline & 132 & Septiembre & & & 17 & \\
\hline & 201 & Octubre & & & 26 & \\
\hline & 152 & Noviembre & & & 19 & \\
\hline & 133 & Diciembre & & & 17 & \\
\hline \multirow{12}{*}{2019} & 202 & Enero & \multirow{12}{*}{1,978} & \multirow{12}{*}{$15 \%$} & 30 & \\
\hline & 153 & Febrero & & & 22 & \\
\hline & 134 & Marzo & & & 20 & \\
\hline & 203 & Abril & & & 30 & \\
\hline & 154 & Mayo & & & 23 & \\
\hline & 135 & Junio & & & 20 & 296 \\
\hline & 205 & Julio & & & 30 & 296 \\
\hline & 154 & Agosto & & & 23 & \\
\hline & 135 & Septiembre & & & 20 & \\
\hline & 206 & Octubre & & & 30 & \\
\hline & 155 & Noviembre & & & 23 & \\
\hline & 136 & Diciembre & & & 20 & \\
\hline & 207 & Enero & & & 41 & \\
\hline & 156 & Febrero & & & 31 & \\
\hline & 137 & Marzo & & & 27 & \\
\hline & 208 & Abril & & & 41 & \\
\hline & 157 & Mayo & & & 31 & \\
\hline 2020 & 138 & Junio & & & 27 & 404 \\
\hline 2020 & 209 & Julio & 2,021 & $20 \%$ & 41 & 404 \\
\hline & 158 & Agosto & & & 31 & \\
\hline & 138 & Septiembre & & & 27 & \\
\hline & 210 & Octubre & & & 42 & \\
\hline & 159 & Noviembre & & & 31 & \\
\hline & 139 & Diciembre & & & 27 & \\
\hline
\end{tabular}

Elaboración: Propia 


\section{ANEXO 25: Importación mundial de joyas de plata en Chile (Kilogramos)}

\begin{tabular}{|c|c|c|c|c|c|c|}
\hline Mes & $\mathbf{2 0 1 0}$ & $\mathbf{2 0 1 1}$ & $\mathbf{2 0 1 2}$ & $\mathbf{2 0 1 3}$ & $\mathbf{2 0 1 4}$ & $\mathbf{2 0 1 5}$ \\
\hline Enero & 6,519 & 14,968 & 9,218 & 19,332 & 13,765 & 11,675 \\
\hline Febrero & 6,559 & 6,256 & 19,335 & 23,808 & 13,531 & 18,375 \\
\hline Marzo & 8,116 & 12,769 & 10,101 & 16,840 & 19,618 & 34,546 \\
\hline Abril & 6,706 & 18,464 & 17,459 & 17,924 & 21,797 & - \\
\hline Mayo & 12,056 & 17,233 & 19,962 & 15,540 & 23,227 & - \\
\hline Junio & 13,356 & 6,346 & 56,480 & 34,803 & 17,756 & - \\
\hline Julio & 11,267 & 8,594 & 15,497 & 16,529 & 23,181 & - \\
\hline Agosto & 16,601 & 7,134 & 16,275 & 36,990 & 12,001 & - \\
\hline Septiembre & 9,529 & 10,144 & 12,300 & 32,459 & 20,827 & - \\
\hline Octubre & 14,655 & 14,037 & 22,456 & 18,497 & 34,184 & - \\
\hline Noviembre & 15,113 & 11,428 & 30,427 & 15,209 & 30,623 & - \\
\hline Diciembre & 13,042 & 8,776 & 30,481 & 36,159 & 23,457 & - \\
\hline
\end{tabular}

Fuente: DATATRADE 
ANEXO 26: Máquinas de la joyería New Fashion Peru S.A.

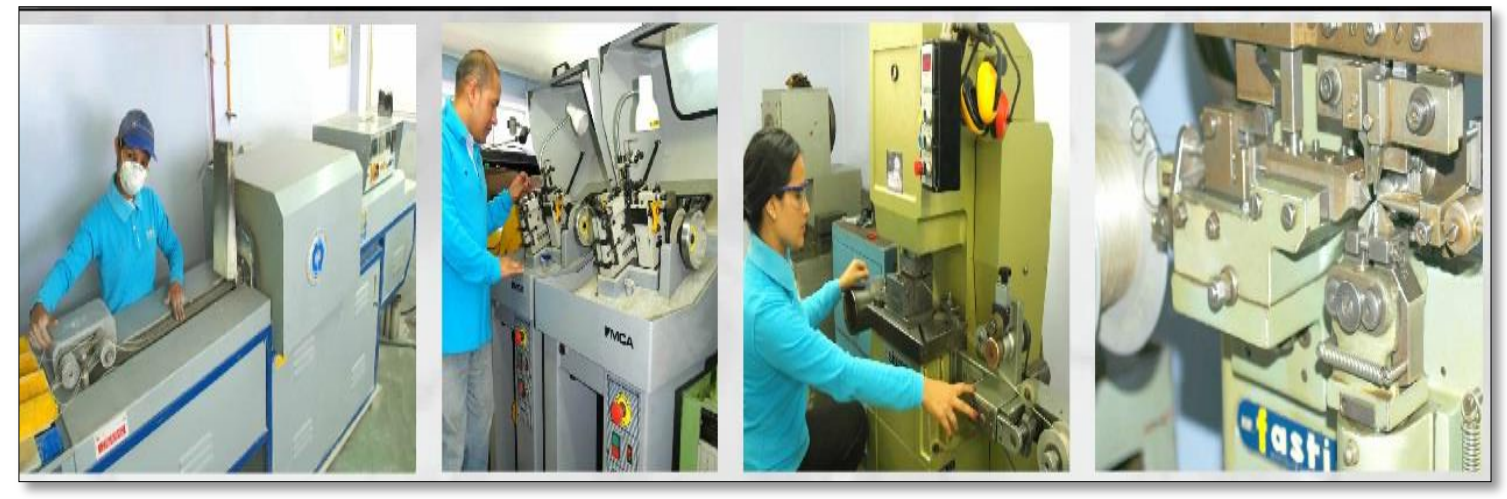

Fuente: New Fashion Perú (Página Web) 


\section{ANEXO 27: Canasta a la que pertenece la Partida NALADISA 7113110000 (Joyería de plata)}

\begin{tabular}{|c|c|c|c|}
\hline NALADISA & DESCRIPCION & PL & OBSERVACIONES \\
\hline 71069220 & Plata semilabrada en barras, hilos, alambres y perfiles de seccid & $\mathrm{D}-0$ & \\
\hline 71069230 & Tubos y perfiles huecos de plata & $\mathrm{D}-0$ & \\
\hline 71069290 & Las demás de plata semilabrada & D-0 & \\
\hline 71070010 & Chapados de plata en planchas, hojas, bandas y formas planas & D-0 & \\
\hline 71070020 & Chapados de plata en barras, hilos, alambres y perfiles de secc & D-0 & \\
\hline 71070030 & Tubos y perfiles huecos de chapados de plata & D-0 & \\
\hline 71070090 & Las demás chapados de plata sobre metales comunes & D-0 & \\
\hline 71081100 & Oro en polvo & D-0 & \\
\hline 71081210 & Oro en lingotes o en barras coladas & $\mathrm{D}-0$ & \\
\hline 71081290 & Las demás oros en bruto & $\mathrm{D}-0$ & \\
\hline 71081300 & Las demás formas semilabradas de oro & $\mathrm{D}-0$ & \\
\hline 71082000 & Oro para uso monetario & D-0 & \\
\hline 71090000 & CHAPADOS DE ORO SOBRE METALES COMUNES O SOBR & $\mathrm{D}-0$ & \\
\hline 71101100 & Platino en bruto o en polvo & $\mathrm{D}-0$ & \\
\hline 71101900 & Los demás platinos & $\mathrm{D}-0$ & \\
\hline 71102100 & Paladio en bruto o en polvo & $\mathrm{D}-0$ & \\
\hline 71102900 & Los demás paladios & D-0 & \\
\hline 71103100 & Rodio en bruto o en polvo & $\mathrm{D}-0$ & \\
\hline 71103900 & Los demás rodios & $\mathrm{D}-0$ & \\
\hline 71104100 & Iridio, osmio y rutenio en bruto o en polvo & $\mathrm{D}-0$ & \\
\hline 71104900 & Los demás inidio, osmio y rutenio & D-0 & \\
\hline 71110000 & CHAPADOS DE PLATINO SOBRE METALES COMUNES, SOE & D-0 & \\
\hline 71121000 & Desperdicios y residuos de oro o de chapados de oro, con excle & D-0 & \\
\hline 71122000 & Desperdicios y residuos de platino o de chapados de platino, co & $\mathrm{D}-0$ & \\
\hline 71129010 & Desperdicios y residuos de plata o de chapados de plata, con e: & $\mathrm{D}-0$ & \\
\hline 71129090 & Los demás desperdicios y residuos de metales preciosos o de 0 & $\mathrm{D}-0$ & \\
\hline 71131100 & Articulos de joyeria y sus partes, de plata, incluso revestidos of & D-5 & \\
\hline 71131910 & Articulos de joyeria y sus partes, de oro, incuso revestidos o ch & $\bar{U}=5$ & \\
\hline 71131920 & De platino, incluso revestidos o chapados de & D-5 & \\
\hline 71132000 & De chapados de metales preciosos sobre metales & D-5 & \\
\hline 71141100 & Articulos de orfebreria y sus partes, de plata, incluso revestidos & D-5 & \\
\hline 71141900 & De los demás metales preciosos, incluso & D-5 & \\
\hline 71142000 & De chapados de metales preciosos sobre metales & D-5 & \\
\hline
\end{tabular}

Fuente: Acuerdos Comerciales 


\section{ANEXO 28: Cronograma de Desgravación de la canasta D-5}

CRONOGRAMA DE CHILE:

Período de desgravación para mercancías cuyo gravamen vigente es de:

\begin{tabular}{|l|c|c}
\hline & $\begin{array}{c}\text { Margen de } \\
\text { preferencia } \\
\text { referencial }\end{array}$ & $\begin{array}{c}\text { Arancel residual } \\
\text { ad-valorem } \\
\mathbf{1 1 \%}\end{array}$ \\
\hline Del 1 julio 1998 al 30 junio 1999 & $0 \%$ & $11.0 \%$ \\
\hline Del 1 julio 1999 al 30 junio 2000 & $20 \%$ & $8.8 \%$ \\
\hline Del 1 julio 2000 al 30 junio 2001 & $40 \%$ & $6.6 \%$ \\
\hline Del 1 julio 2001 al 30 junio 2002 & $60 \%$ & $4.4 \%$ \\
\hline Del 1 julio 2002 al 30 junio 2003 & $80 \%$ & $2.2 \%$ \\
\hline A partir del 1 julio 2003 & $100 \%$ & $0.0 \%$ \\
\hline
\end{tabular}

CRONOGRAMA DEL PERU:

Período de desgravación para mercancías cuyo gravamen vigente es de:

\begin{tabular}{|l|c|c|c|c|c|}
\hline & $\begin{array}{l}\text { Margen de } \\
\text { preferencia } \\
\text { referencial }\end{array}$ & \multicolumn{4}{|c}{$\begin{array}{c}\text { Arancel residual } \\
\text { ad-valorem }\end{array}$} \\
\hline & & $\mathbf{1 2} \%$ & $\mathbf{1 2} \%+5 \%$ & $\mathbf{2 0 \%}$ & $\mathbf{2 0 \% + 5 \%}$ \\
\hline Del 1 julio 1998 al 30 junio 1999 & $0 \%$ & $12 \%$ & $17.0 \%$ & $20 \%$ & $25 \%$ \\
\hline Del 1 julio 1999 al 30 junio 2000 & $20 \%$ & $9.6 \%$ & $13.6 \%$ & $16 \%$ & $20 \%$ \\
\hline Del 1 julio 2000 al 30 junio 2001 & $40 \%$ & $7.2 \%$ & $10.2 \%$ & $12 \%$ & $15 \%$ \\
\hline Del 1 julio 2001 al 30 junio 2002 & $60 \%$ & $4.8 \%$ & $6.8 \%$ & $8 \%$ & $10 \%$ \\
\hline Del 1 julio 2002 al 30 junio 2003 & $80 \%$ & $2.4 \%$ & $3.4 \%$ & $4 \%$ & $5 \%$ \\
\hline A partir del 1 julio 2003 & $100 \%$ & $0.0 \%$ & $0.0 \%$ & $0 \%$ & $0 \%$ \\
\hline
\end{tabular}

Fuente: Acuerdos Comerciales 


\section{ANEXO 29: Ley de Comercio exterior de objetos fabricados con metales preciosos}

\section{BOE-A-1985-12768: Comercio exterior de objetos fabricados con metales preciosos}

\section{Artículo trece.}

1. Para la comercialización en el interior del país de objetos fabricados en el extranjero con metales preciosos se requiere:

a) Que se cumplan los requisitos que para el mercado interior se establecen en el Capítulo II de esta Ley.

b) Que con independencia de los contrastes con que los objetos vengan marcados por el país de origen, se marquen en destino con el punzón del importador y con el punzón de garantía.

2. No obstante lo anterior, si existiesen convenios suscritos y ratificados con otros países o entidades supranacionales, se estará a lo establecido en los mismos no exigiéndose, en su caso, ulteriores contrastes a la recepción de los objetos amparados por tales convenios.

Artículo catorce.

1. Los objetos de metales preciosos destinados a la exportación podrán fabricarse cualquiera que sea su «ley», cumpliéndose, exclusivamente, las prescripciones del país receptor.

2. No obstante lo anterior, si existiesen convenios suscritos y ratificados con otros países o entidades supranacionales, se estará a lo establecido en los mismos, procediéndose, en su caso, a marcar los objetos correspondientes, en concepto de contraste de garantía, con la marca que hubiera sido aceptada en dichos convenios.

Si eventualmente algún objeto destinado a la exportación retornase del país de destino, para su comercialización en el interior, deberá previamente cumplir los requisitos establecidos en el Capítulo II de la presente Ley.

\section{Artículo quince.}

Los objetos de metales preciosos podrán importarse con carácter temporal, precisándose en este caso el plazo máximo de tiempo que pueden permanecer en territorio nacional y quedando sometidos a la regulación comercial y aduanera vigente para cada modalidad.

Fuente: BOE (Boletín Oficial del Estado - España) 
ANEXO 30: Ejemplos de joyas para la colección "ULTRA"
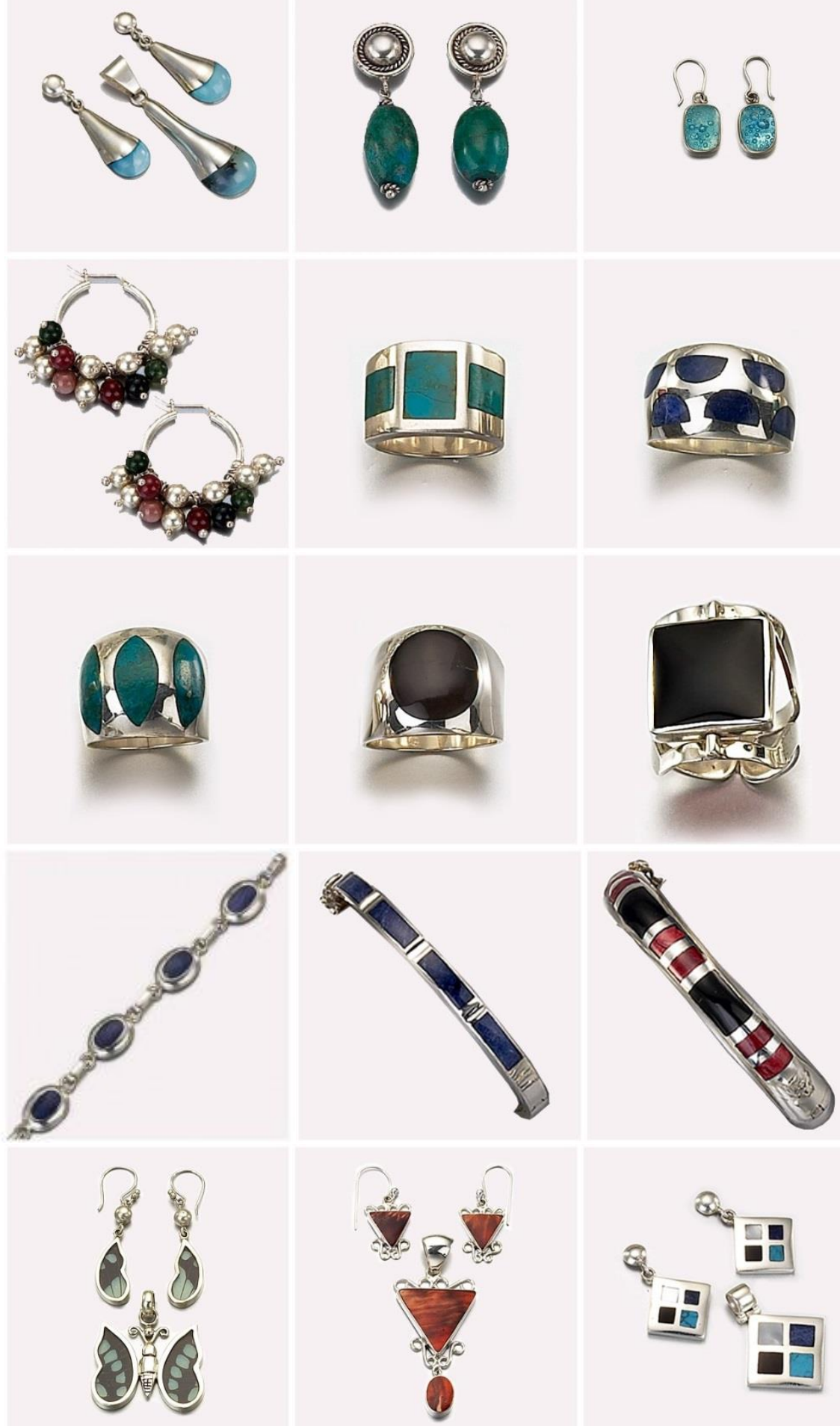

Elaboración: Propia 
ANEXO 31: Ejemplos de joyas para la colección "MYSTIC"

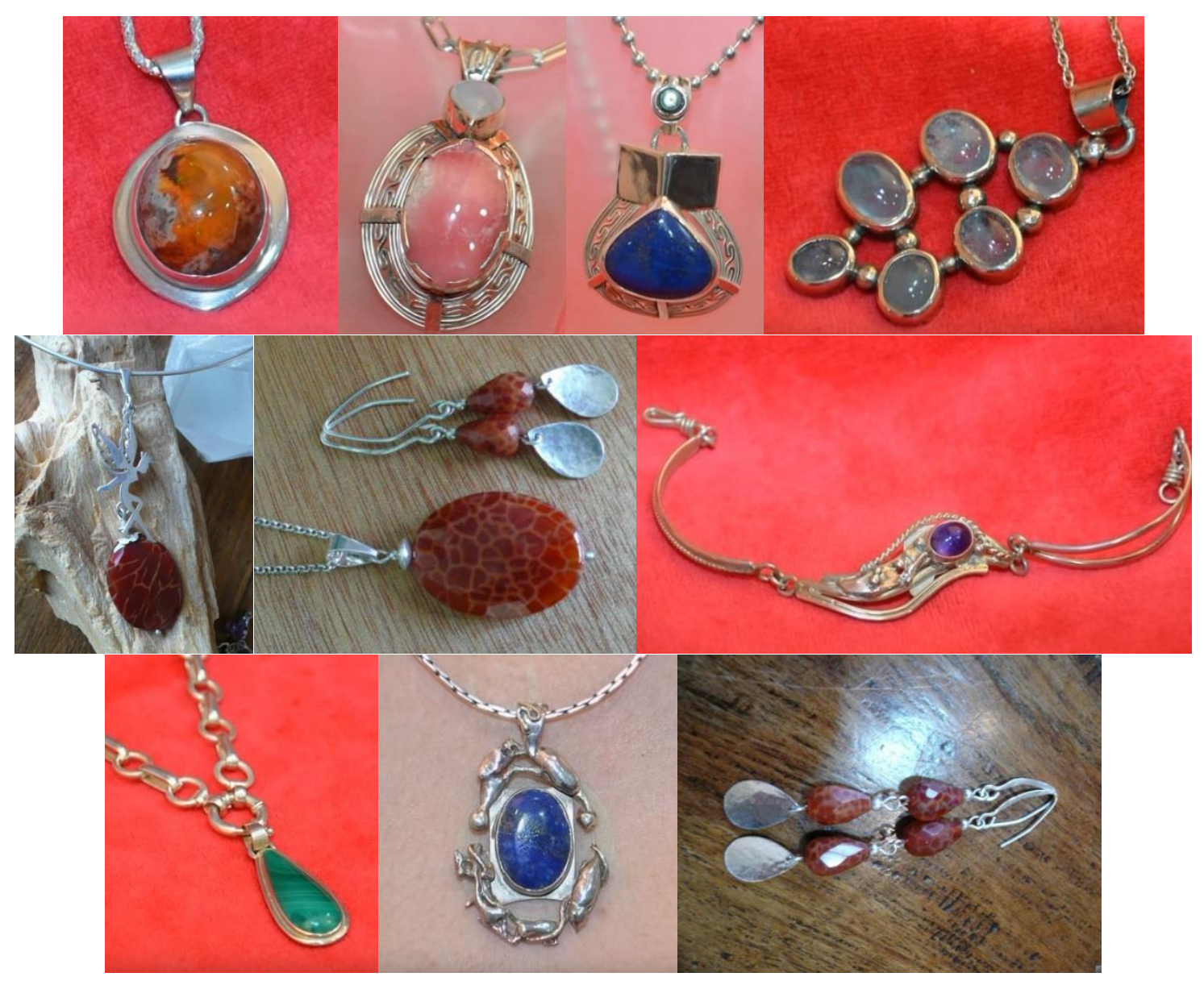

Elaboración: Propia 
ANEXO 32: Forma de empaque y materiales

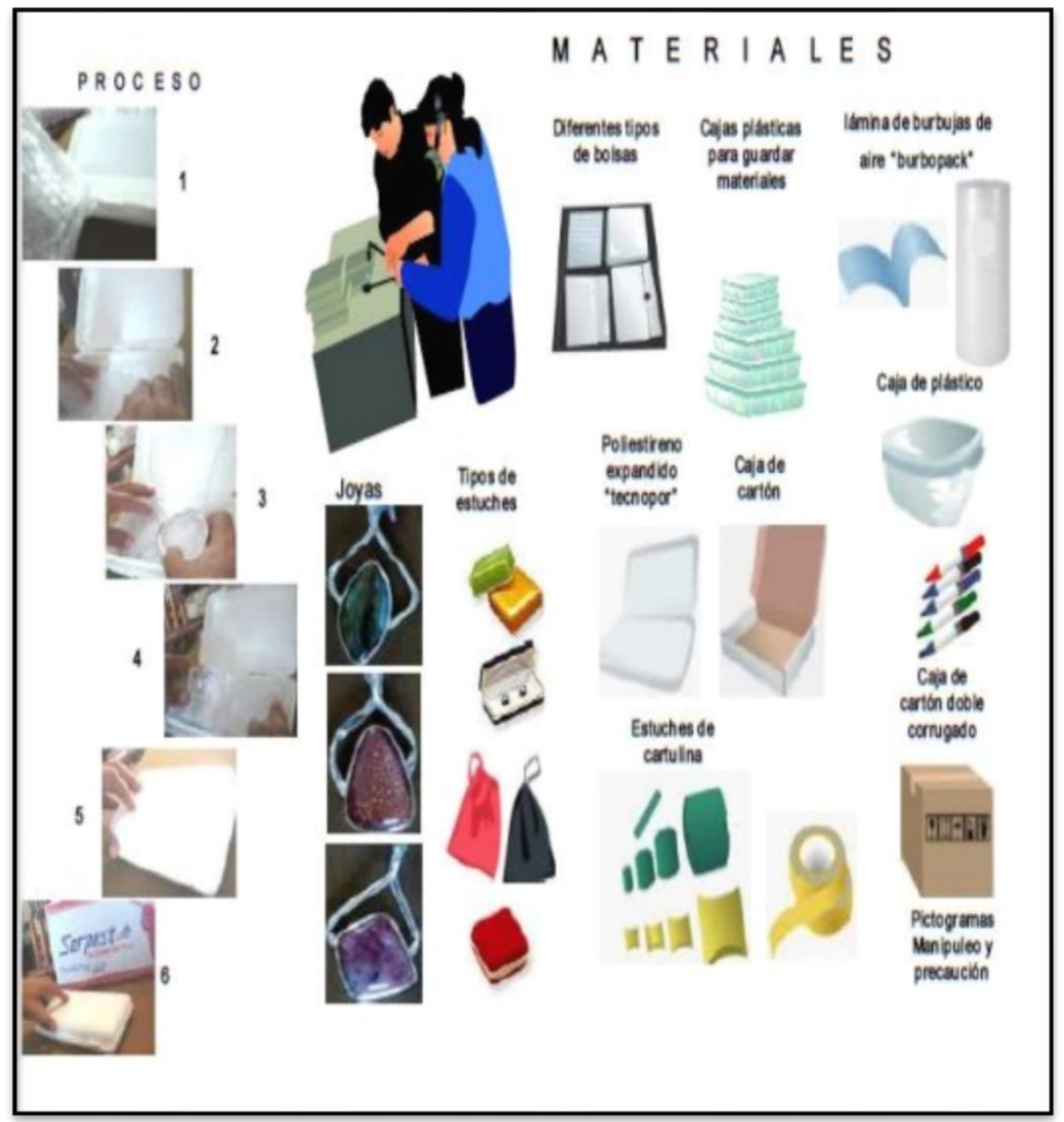

Fuente: PRODUCE 


\section{ANEXO 33: Búsqueda fonética para la marca JOLIBARI}
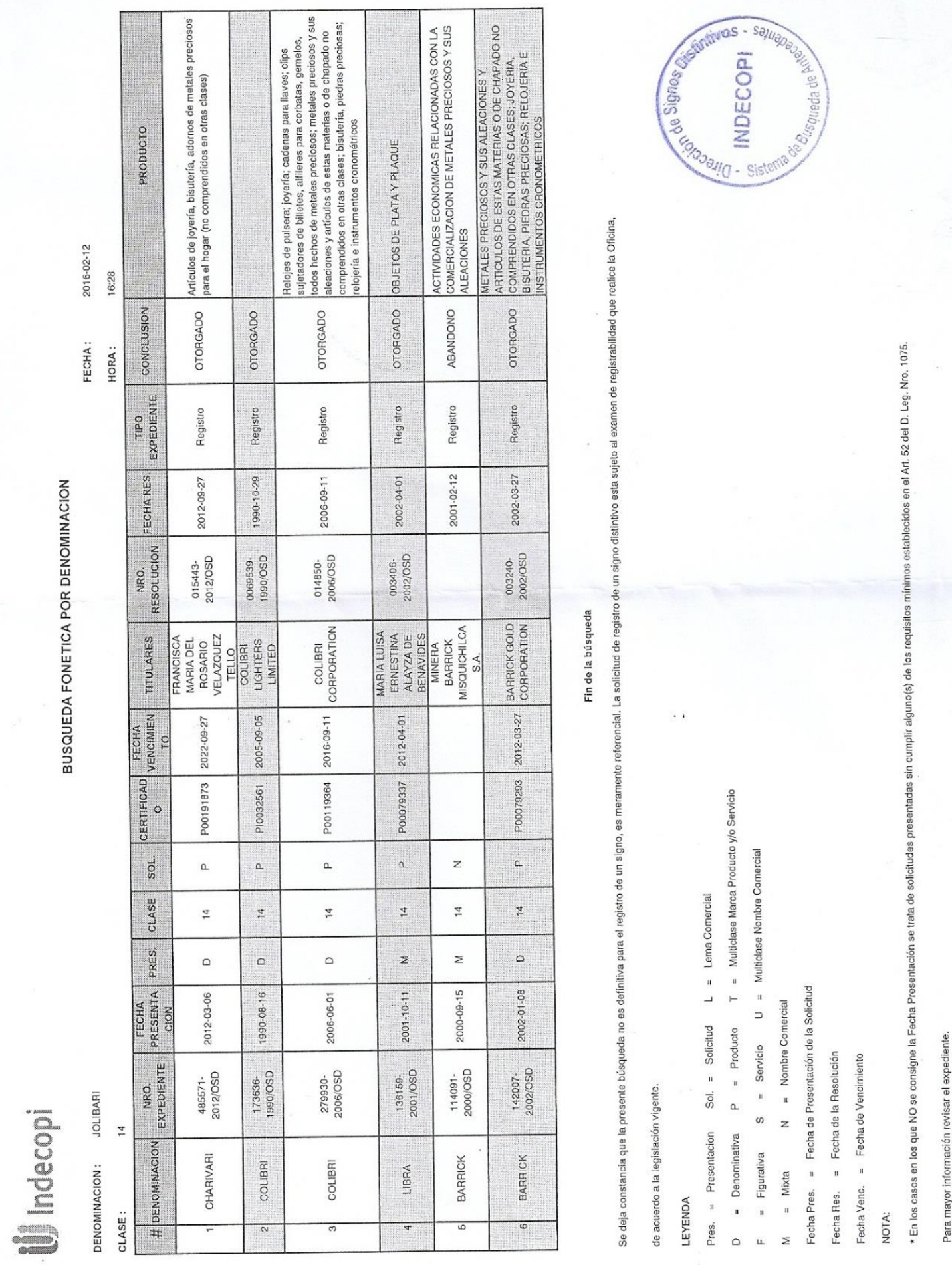

Elaboración: Propia 


\section{ANEXO 34: Ventajas y Costo de usar PayPal}

\section{Ventajas de usar PayPal}

- PAYPAL es una forma fácil y segura de pagar y recibir pagos sin necesidad de compartir tu información financiera.

- El registro es sin costo alguno

- Es un método de pago que utilizan miles de empresas y millones de personas en todo el mundo.

- Es rápido, es fácil y es seguro

- Las joyas serán pagadas a través de PayPal de tu tarjeta de crédito, débito o cuenta bancaria.

- PayPal es el único que conocerá el número de tu tarjeta o número de cuenta y él se encargará de pagar lo que compres a través de internet.

- Es la manera más rápida de pagar por internet ya que si eliges esta opción únicamente tendrás que ingresar con el correo electrónico y clave de tu cuenta de PayPal para realizar el pago.

- PayPal es el responsable de protegerte de los fraudes electrónicos y de todos tus datos personales, como números de tarjeta o de cuentas bancarias y de robo de identidad.

- No necesitas exponer tu información financiera o bancaria a todo el mundo para comprar online.

Descuentos

Descuentos por volumen

Le podemos ofrecer tasas a bajo costo cuando sus ventas excedan los $\$ 3,000$ y ha sido un miembro

PayPal por más de 90 dias. Luego de que haya creado su cuenta empresas PayPal, por favor complete el

formulario por única vez, sujeto a aprobación. Aplicar ahora

SUS VENTAS MENSUALES

$\$ 0,00$ USD - $\$ 3,000.00$ USD

$\$ 3,000.01$ USD - $\$ 10,000.00$

USD

$\$ 10,000.01$ USD - $\$ 100,000.00$

USD

$>\$ 100,000.00$ USD
SU COMISIÓN POR TRANSACCIÓN

$5.4 \%+\$ 0.30$ USD

$4.9 \%+\$ 0.30$ USD

$4.7 \%+\$ 0.30$ USD

$4.4 \%+\$ 0.30$ USD
EJEMPLOS

Comisión de 5.70 USD sobre una venta de 100 USD

Comisión de 5.20 USD sobre una venta de 100 USD

Comisión de 5.00 USD sobre una venta de 100 USD

Comisión de 4.70 USD sobre una venta de 100 USD

Fuente: PAYPAL 


\section{ANEXO 35: Plata Ley 999 del Proveedor Sudamericana}

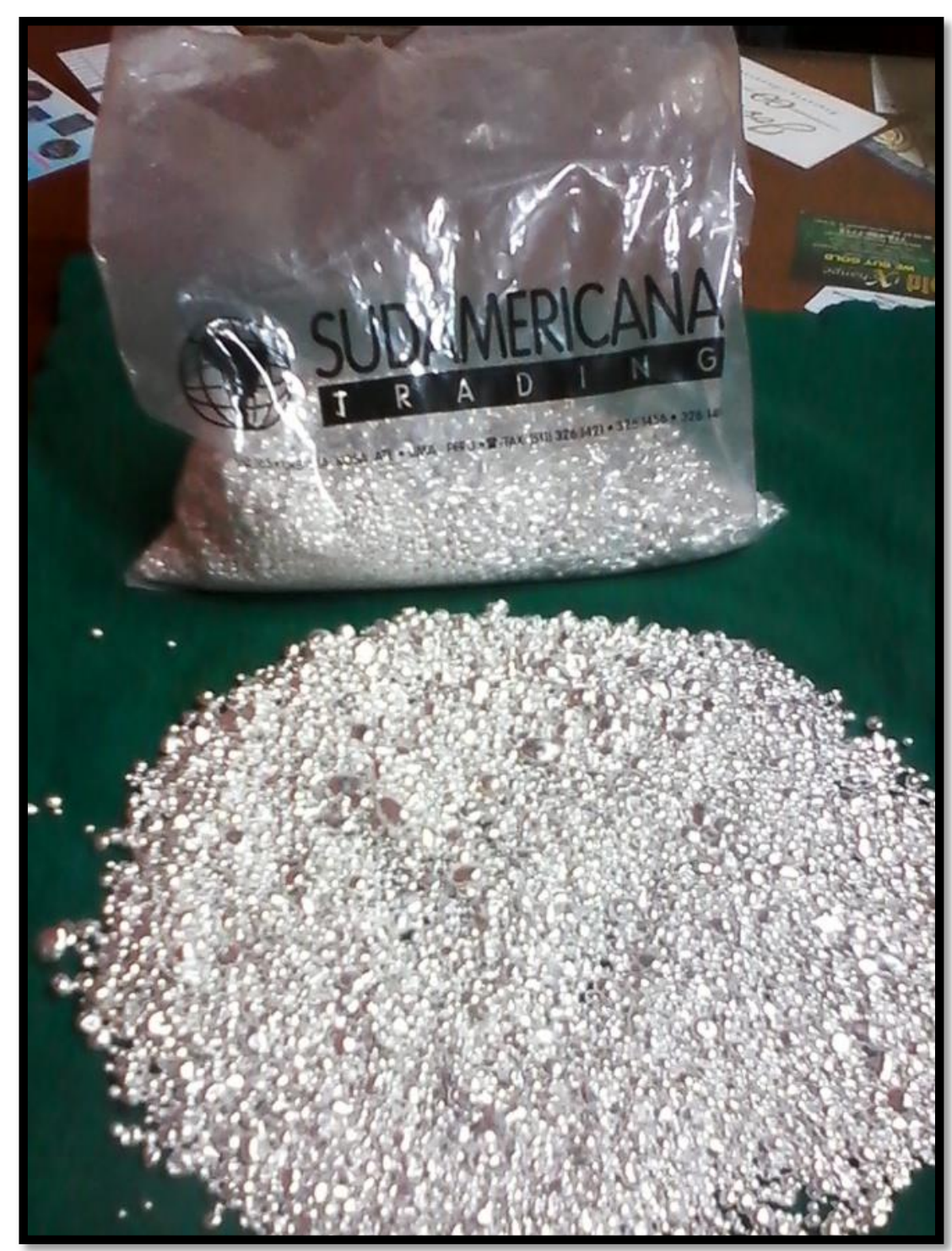

Fuente: Propia 


\section{ANEXO 36: Costos de Almacenaje en Talma}

\begin{tabular}{|c|c|c|c|}
\hline \multicolumn{4}{|l|}{ Servicio } \\
\hline Concepto & Unidad & Monto (USS) con I.G.V. & Descripción del servicio \\
\hline $\begin{array}{l}\text { Retiro de la carga no exportada / } \\
\text { Almacenaje }\end{array}$ & kg x día & 0.024 & $\begin{array}{l}\text { Almacenamiento de productos de exportación que } \\
\text { son retirados por el cliente del depósito temporal. }\end{array}$ \\
\hline $\begin{array}{l}\text { Retiro de la carga no exportada / } \\
\text { Manipuleo (Mínimo } \$ 29.50 \text { ) }\end{array}$ & kg x día & 0.048 & $\begin{array}{l}\text { Manipulación de productos de exportación que son } \\
\text { retirados por el cliente del depósito temporal. }\end{array}$ \\
\hline $\begin{array}{l}\text { Movilización de carga por cambio de } \\
\text { etiqueta (Mínimo } \$ 29.50 \text { ) }\end{array}$ & $\mathrm{kg}$ & 0.036 & $\begin{array}{l}\text { Movilización de la carga para el cambio de etiquetas } \\
\text { (agente de carga), reubicación de las parihuelas en } \\
\text { el almacen y emisión de un nuevo documento. }\end{array}$ \\
\hline $\begin{array}{l}\text { Movilización de carga por servicios } \\
\text { varios (Mínimo } \$ 29.50 \text { ) }\end{array}$ & $\mathrm{kg}$ & 0.036 & $\begin{array}{l}\text { Revisión de carga, toma de fotos, cambio de } \\
\text { embalaje, rotulado interno, toma de muestras, etc. }\end{array}$ \\
\hline $\begin{array}{l}\text { Charters } \\
\text { (Mínimo \$295) }\end{array}$ & $\mathrm{kg}$ & 0.118 & Atención de vuelos no regulares \\
\hline Servicio de fotografía & foto & 2.36 & $\begin{array}{l}\text { Movilización de la carga para realizar tomas } \\
\text { fotográficas a solicitud del cliente. }\end{array}$ \\
\hline \multicolumn{4}{|l|}{ Servicio } \\
\hline Concepto & Unidad & Monto (S/.) con I.G.V. & Descripción del servicio \\
\hline $\begin{array}{l}\text { Área de consolidación y } \\
\text { alistamiento de carga }\end{array}$ & S/. X hora & 177.00 & $\begin{array}{l}\text { Servicio de alquiler de diques para que el exportador } \\
\text { acondicione su mercadería para proceder con la } \\
\text { exportación. }\end{array}$ \\
\hline STEDEX & S/.xAWB & 38.94 & $\begin{array}{l}\text { Servicio de transmisión electrónica de datos y } \\
\text { desconsolidación a aduanas por guía hija }\end{array}$ \\
\hline
\end{tabular}

Fuente: TALMA 


\section{ANEXO 37: Presupuesto de pasaje Lima-Santiago de Chile}

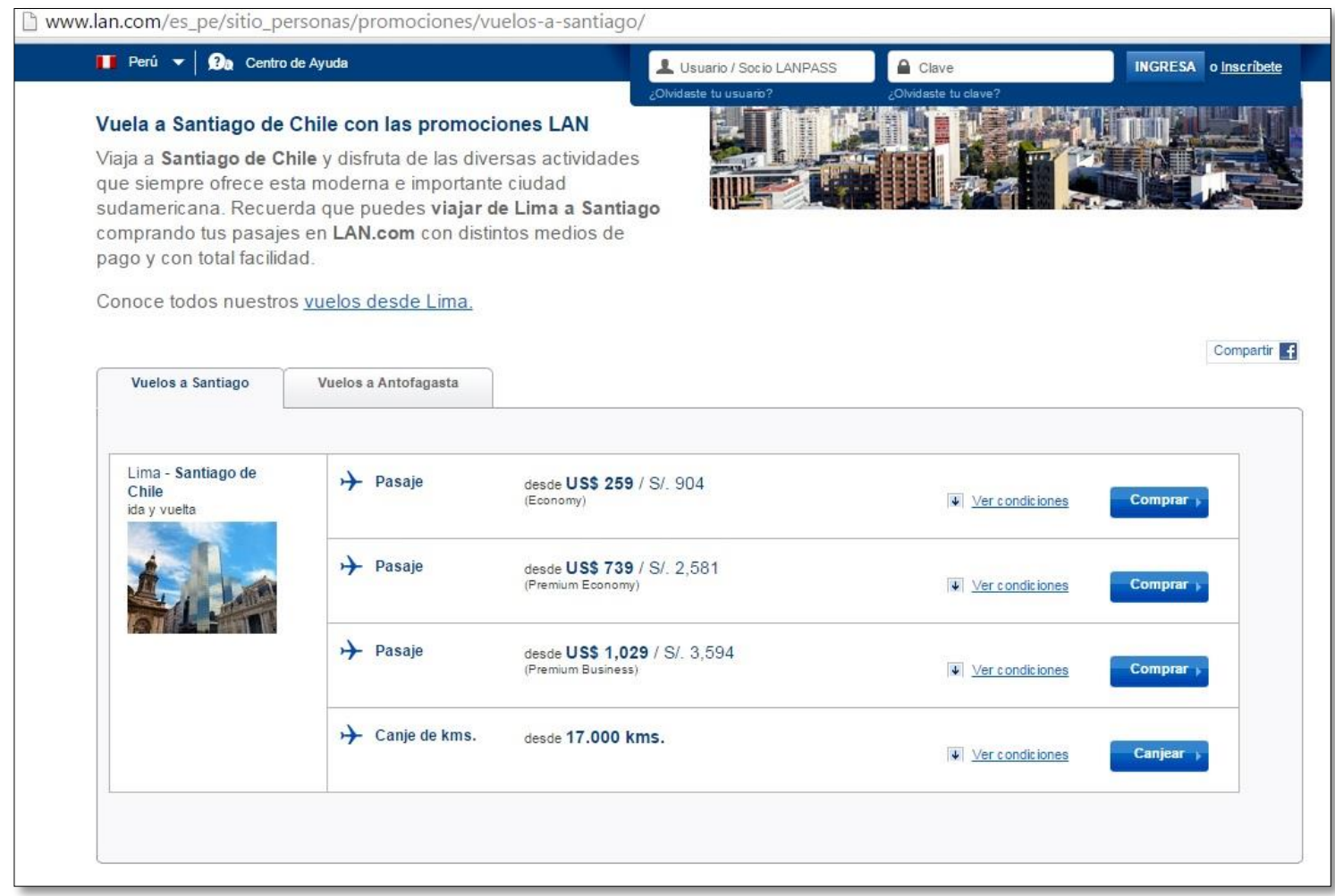

Fuente: LAN 


\section{ANEXO 38: Mapa de la sala del HOTEL MARRIOTT para las reuniones}

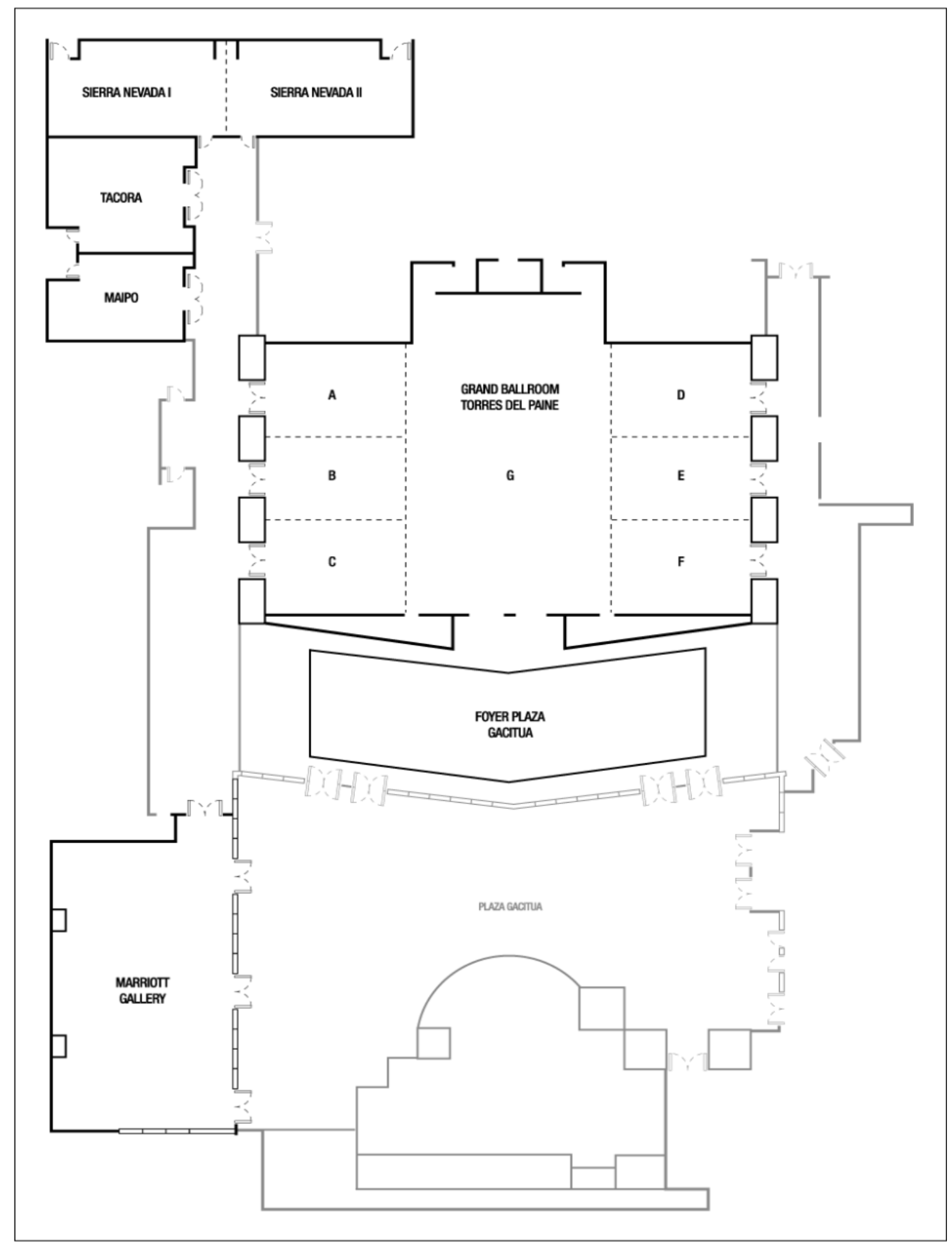

Fuente: Marriott Chile 


\section{ANEXO 39: Precio por habitación de un día en el HOTEL MARRIOTT en Chile}

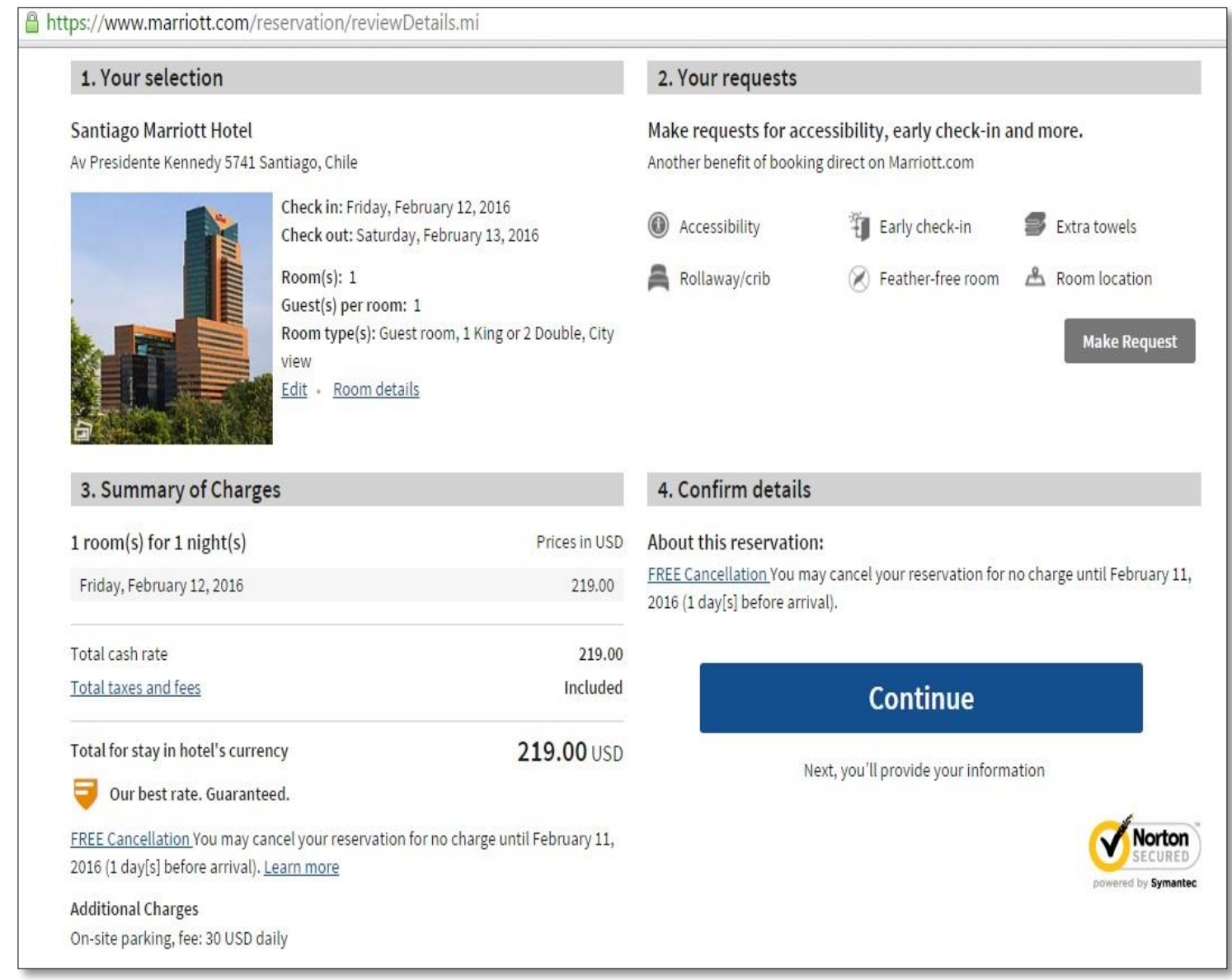

Fuente: Marriott 


\section{ANEXO 40: Cotización para los correos masivos}

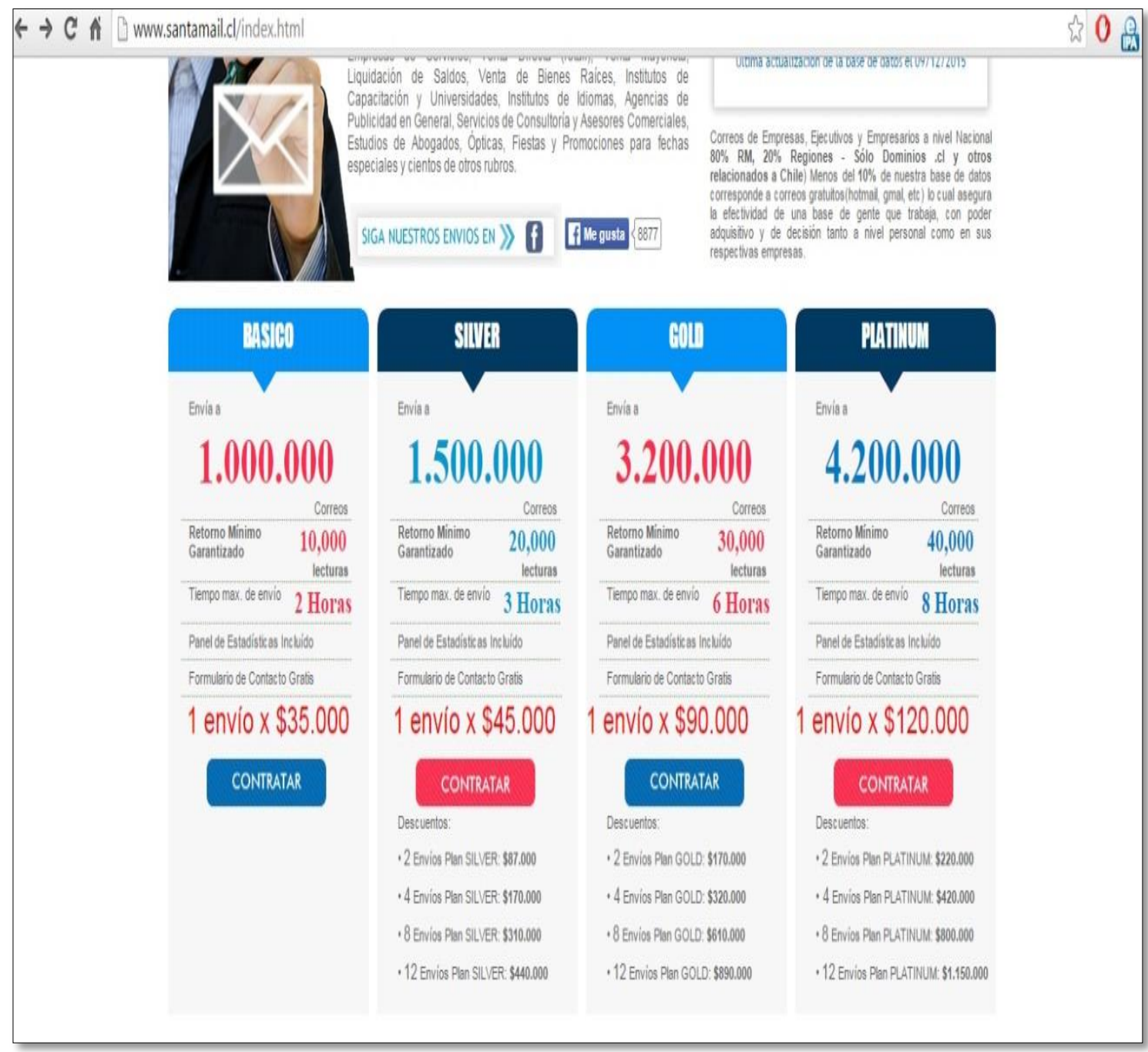

Fuente: Santamail 


\section{ANEXO 41: Principales máquinas para la producción de joyas}

\begin{tabular}{|c|c|}
\hline Máquina & Características \\
\hline & $\begin{array}{l}\text { Logra fundir } 12 \mathrm{Kg} \text { aunque a veces depende del tamaño del pírex, } \\
\text { durando } 10 \text { minutos en terminar de alear el metal }{ }^{14} \text {. }\end{array}$ \\
\hline & $\begin{array}{c}\text { Proceso para poder laminar el metal y obtener variedades de calibre o } \\
\text { grosor. Tiempo aproximado es de } 25 \text { minutos dependiendo de la } \\
\text { cantidad. }\end{array}$ \\
\hline & $\begin{array}{l}\text { Permite dar el acabado final a la joya para brindarle brillo al producto. El } \\
\text { tiempo depende de la habilidad del artesano, pero se considera un tiempo } \\
\text { aproximado de } 10 \text { minutos. }\end{array}$ \\
\hline & Herramienta que permite agrandar o reducir las tallas de los aros. \\
\hline
\end{tabular}

Elaboración: Propia 


\section{ANEXO 42: Búsqueda de Razón Social}

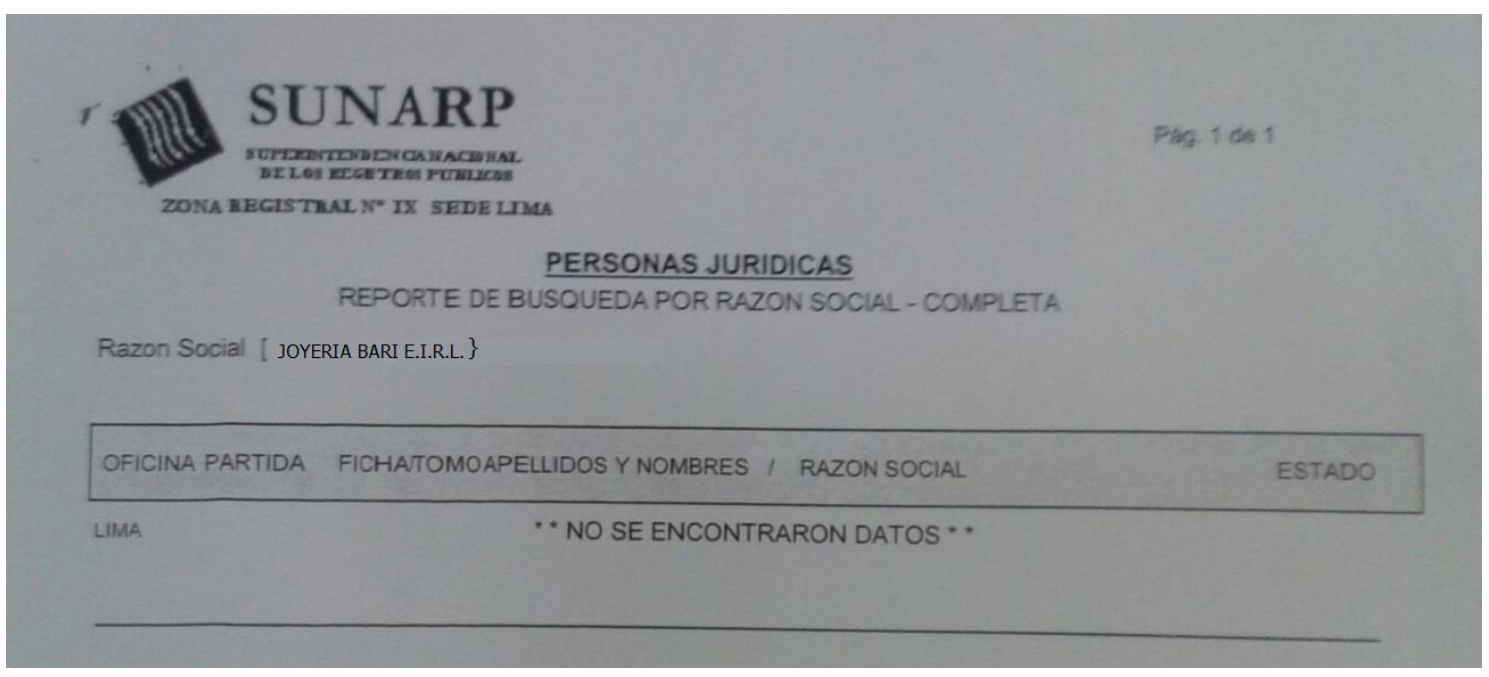

Elaboración: Propia 


\section{ANEXO 43: Minuta para una empresa EIRL}

SEÑOR NOTARIO DE ..VILLOTA.:

SÍRVASE EXTENDER EN SU REGISTRO DE ESCRITURAS PÚBLICAS UNA DE CONSTITUCIÓN DE EMPRESA INDIVIDUAL DE RESPONSABILIDAD LIMITADA QUE OTORGA DON:...GIANCARLO ANDRE BARRETO RIMAY.......

PRIMERA.- POR EL PRESENTE, DON:...GIANCARLO ANDRE BARRETO RIMAY.....

CONSTITUYE UNA EMPRESA INDIVIDUAL DE RESPONSABILIDAD LIMITADA BAJO LA DENOMINACIÓN DE: "JOYERIA BARI E.I.R.L." CON DOMICILIO EN LA CIUDAD DE ..LIMA..., QUE INICIA SUS OPERACIONES A PARTIR DE SU INSCRIPCIÓN EN EL REGISTRO MERCANTIL CON UNA DURACIÓN INDEFINIDA, PUDIENDO ESTABLECER SUCURSALES EN TODO EL TERRITORIO NACIONAL.

SEGUNDA.- EL OBJETO DE LA EMPRESA ES:...VENTA DE JOYAS...

SE ENTIENDEN INCLUIDOS EN EL OBJETO LOS ACTOS RELACIONADOS CON EL MISMO, QUE COADYUVEN A LA REALIZACION DE SUS FINES EMPRESARIALES. PARA CUMPLIR DICHO OBJETO, PODRÁ REALIZAR TODOS AQUELLOS ACTOS Y CONTRATOS QUE SEAN LÍCITOS, SIN RESTRICCIÓN ALGUNA.

TERCERA.- EL CAPITAL DE LA EMPRESA ES DE S/. 50,000.00

CUARTA.- SON ÓRGANOS DE LA EMPRESA, EL TITULAR Y LA GERENCIA. EL RÉGIMEN QUE LE CORRESPONDA ESTÁ SEÑALADO EN EL DECRETO LEY Nํ 21621, ARTÍCULOS 39 Y 50 RESPECTIVAMENTE Y DEMÁS NORMAS MODIFICATORIAS Y COMPLEMENTARIAS.

QUINTA.- GERENCIA ES EL ÓRGANO QUE TIENE A SU CARGO LA ADMINISTRACIÓN Y REPRESENTACIÓN DE LA EMPRESA. SERÁ DESEMPEÑADA POR UNA O MÁS PERSONAS NATURALES. EL CARGO DE GERENTE ES INDELEGABLE. EN CASO DE QUE EL CARGO DE GERENTE RECAIGA EN EL TITULAR, ÉSTE SE DENOMINARÁ TITULAR GERENTE.

SEXTA.- LA DESIGNACIÓN DEL GERENTE SERÁ EFECTUADA POR EL TITULAR, LA DURACIÓN DEL CARGO ES INDEFINIDA, AUNQUE PUEDE SER REVOCADO EN CUALQUIER MOMENTO.

SEPTIMA.- CORRESPONDE AL GERENTE:

1. ORGANIZAR EL RÉGIMEN INTERNO DE LA EMPRESA.

2. CELEBRAR CONTRATOS INHERENTES AL OBJETO DE LA EMPRESA, FIJANDO SUS CONDICIONES; SUPERVISAR Y FISCALIZAR EL DESARROLLO DE LAS ACTIVIDADES DE LA EMPRESA.

3. REPRESENTAR A LA EMPRESA ANTE LOS PODERES DEL ESTADO, INSTITUCIONES NACIONALES Y EXTRANJERAS, GOZANDO DE LAS FACULTADES GENERALES Y ESPECIALES A QUE SE REFIEREN LOS ARTÍCULOS 74, 75, 77 Y 436 DEL CÓDIGO PROCESAL CIVIL. TAMBIÉN GOZA DE LA FACULTAD A QUE SE REFIERE EL ARTÍCULO 10 DE LA LEY № 26636, PODRA CELEBRAR CONCILIACIÓN EXTRA JUDICIAL, ADEMAS PODRA CONSTITUIR Y REPRESENTAR A LA ASOCIACION QUE CREA CONVENIENTE Y DEMAS NORMAS COMPLEMENTARIAS.

4. CUIDAR LOS ACTIVOS DE LA EMPRESA. 
5. ABRIR Y CERRAR CUENTAS CORRIENTES, BANCARIAS, MERCANTILES Y GIRAR CONTRA LAS MISMAS, COBRAR Y ENDOSAR CHEQUES DE LA EMPRESA, ASI COMO ENDOSAR Y DESCONTAR DOCUMNETOS DE CREDITO. SOLICITAR SOBREGIROS, PRÉSTAMOS, CREDITOS O FINANCIACIONES PARA DESARROLLAR EL OBJETO SOCIAL CELEBRANDO LOS CONTRATOS RESPECTIVOS.

6. SOLICITAR TODA CLASE DE PRESTAMOS CON GARANTIAS HIPOTECARIA, PRENDARIA Y DE CUALQUIER FORMA, ADEMAS CONOCIMIENTO DE EMBARQUE, CARTA DE PODER, CARTA FIANZA, POLIZA, LETRAS DE CAMBIO, PAGARES, FACTURAS CONFORMADAS Y CUALQUIER OTRO TITULO VALOR.

7. SUSCRIBIR CONTRATOS DE ARRENDAMIENTO Y SUBARRENDAMIENTO.

8. COMPRAR Y VENDER LOS BIENES SEAN MUEBLES O INMUEBLES DE LA EMPRESA, SUSCRIBIENDO LOS RESPECTIVOS CONTRATOS.

9. CELEBRAR, SUSCRIBIR LEASING O ARRENDAMIENTO FINANCIERO, CONSORCIO, ASOCIACION EN PARTICIPACION Y CUALQUIER OTRO CONTRATO DE COLABORACION EMPRESARIAL, VINCULADOS AL OBJETO DE LA EMPRESA.

10. AUTORIZAR A SOLA FIRMA LA ADQUISICIÓN DE BIENES, CONTRATACIÓN DE OBRAS Y PRESTACIÓN DE SERVICIOS PERSONALES.

11. NOMBRAR, PROMOVER, SUSPENDER Y DESPEDIR A LOS EMPLEADOS Y SERVIDORES DE LA EMPRESA.

12. CONCEDER LICENCIA AL PERSONAL DE LA EMPRESA.

13. CUIDAR DE LA CONTABILIDAD Y FORMULAR EL ESTADO DE PÉRDIDAS Y GANANCIAS, EL BALANCE GENERAL DE LA EMPRESA Y LOS DEMÁS ESTADOS Y ANÁLISIS CONTABLES QUE SOLICITE EL TITULAR.

14. SOLICITAR, ADQUIRIR, TRANFERIR REGISTROS DE PATENTES, MARCAS, NOMBRES COMERCIALES CONFORME A LEY, SUSCRIBIENDO CUALQUIER CLASE DE DOCUMENTOS VINCULADOS, QUE CONLLEVE A LA REALIZACION DEL OBJETO SOCIAL.

15. PARTICIAPR EN LICITACIONES, CONCURSOS PUBLICOS Y/O ADJUDICACIONES, SUSCRIBIERON LOS RESPECTIVOS DOCUMENTOS, QUE CONLLEVE A LA REALIZACION DEL OBJETO SOCIAL.

OCTAVA.- PARA TODO LO NO PREVISTO RIGEN LAS DISPOSICIONES CONTENIDAS EN EL D.L. № $21621 \mathrm{Y}$ AQUELLAS QUE LAS MODIFIQUEN O COMPLEMENTEN.

DISPOSICION TRANSITORIA.- DON GIANCARLO ANDRÉ BARRETO RIMAY..,EJERCERA EL CARGO DE TITULAR GERENTE DE LA EMPRESA, PERUANO, CON DOMICILIO SEÑALADO EN LA INTRODUCCION DE LA PRESENTE.

AGREGUE USTED SEÑOR NOTARIO DE ...VILLOTA.....,LO QUE FUERE DE LEY, Y SÍRVASE CURSAR LOS PARTES NOTARIALES RESPECTIVOS AL REGISTRO MERCANTIL DE ..JOYERIA BARI EIRL..., PARA SU CORRESPONDIENTE INSCRIPCION.

..LIMA..., .FEBRERO DEL 2016. 
ANEXO 44: Costo del personal detallado (En US\$)

\begin{tabular}{|c|c|c|c|c|c|c|c|c|c|c|}
\cline { 5 - 11 } Trabajadores & $\begin{array}{c}\text { Sueldo } \\
\text { Mensual }\end{array}$ & CTS & $\begin{array}{c}\text { AFP Prima } \\
(\mathbf{1 3 \% )}\end{array}$ & ESSALUD (9\%) & $\begin{array}{c}\text { Neto } \\
\text { Mensual }\end{array}$ & $\mathbf{2 0 1 6}$ & $\mathbf{2 0 1 7}$ & $\mathbf{2 0 1 8}$ & $\mathbf{2 0 1 9}$ & $\mathbf{2 0 2 0}$ \\
\hline $\begin{array}{c}\text { Gerente } \\
\text { General }\end{array}$ & 573.1 & 23.9 & 74.5 & 51.6 & 723.0 & $7,026.7$ & $7,026.7$ & $7,026.7$ & $7,026.7$ & $7,026.7$ \\
\hline Jefe Comercial & 487.1 & 20.3 & 63.3 & 43.8 & 614.6 & $5,972.7$ & $5,972.7$ & $5,972.7$ & $5,972.7$ & $5,972.7$ \\
\hline $\begin{array}{c}\text { Asistente de } \\
\text { Operaciones }\end{array}$ & 257.9 & 10.7 & 33.5 & 23.2 & 325.4 & $3,162.0$ & $3,162.0$ & $3,162.0$ & $3,162.0$ & $3,162.0$ \\
\hline Contador & 71.6 & - & - & - & 71.6 & 859.6 & 859.6 & 859.6 & 859.6 & 859.6 \\
\hline
\end{tabular}

Elaboración: Propia 


\section{ANEXO 45: Total de Unidades producidas}

\begin{tabular}{|c|c|c|c|c|}
\hline Estructura & Pieza & Gr de Plata & Gr de Piedra Natural & Total Gramos \\
\hline $7 \%$ & Arete - Colgante & 4 & 3 & 7 \\
\hline $11 \%$ & Anillo - Sortija & 8 & 4 & 12 \\
\hline $23 \%$ & Collares & 15 & 10 & 25 \\
\hline $12 \%$ & Pulseras & 9 & 4 & 13 \\
\hline $47 \%$ & Set de joyas (Collar+Arete+Pulsera) & 30 & 20 & 50 \\
\hline $\mathbf{1 0 0 \%}$ & Total & $\mathbf{6 6}$ & $\mathbf{4 1}$ & $\mathbf{1 0 7}$ \\
\hline
\end{tabular}

\begin{tabular}{|c|c|c|c|c|c|c|c|c|}
\hline & Pieza & $\begin{array}{c}\text { Gramos de } \\
\text { Plata y } \\
\text { Piedra } \\
\text { Natural } \\
\end{array}$ & $\begin{array}{c}\text { Cantidad de } \\
\text { Unidades } \\
\text { producidas + } \\
\text { Merma } \\
\end{array}$ & $\begin{array}{c}\text { Merma(*) } \\
\text { Total en } \\
\text { Gramos }\end{array}$ & $\begin{array}{c}\text { Unidades } \\
\text { producidas en } \\
\text { Gramos }\end{array}$ & $\begin{array}{l}\text { Total Unidades } \\
\text { producidas }\end{array}$ & $\begin{array}{c}\text { Gramos de plata y } \\
\text { cobre usados }\end{array}$ & $\begin{array}{c}\text { Gramos de } \\
\text { piedra } \\
\text { natural } \\
\text { usados } \\
\end{array}$ \\
\hline \multirow{6}{*}{2016} & Arete & 9,697 & $1,385.3$ & 9 & 9,688 & 1,384 & 5,976 & 3,712 \\
\hline & Anillo & 16,624 & $1,385.3$ & 16 & 16,608 & 1,384 & 10,244 & 6,364 \\
\hline & Collares & 34,633 & $1,385.3$ & 33 & 34,600 & 1,384 & 21,342 & 13,258 \\
\hline & Pulseras & 18,009 & $1,385.3$ & 17 & 17,992 & 1,384 & 11,098 & 6,894 \\
\hline & Set de joyas & 69,266 & $1,385.3$ & 66 & 69,200 & 1,384 & 42,684 & 26,516 \\
\hline & Total & 148,230 & 6,927 & 142 & 148,088 & 6,920 & 91,344 & 56,744 \\
\hline \multirow{6}{*}{2017} & Arete & 12,403 & $1,771.9$ & 13 & 12,390 & 1,770 & 7,642 & 4,748 \\
\hline & Anillo & 21,262 & $1,771.9$ & 22 & 21,240 & 1,770 & 13,101 & 8,139 \\
\hline & Collares & 44,296 & $1,771.9$ & 46 & 44,250 & 1,770 & 27,294 & 16,956 \\
\hline & Pulseras & 23,034 & $1,771.9$ & 24 & 23,010 & 1,770 & 14,193 & 8,817 \\
\hline & Set de joyas & 88,593 & $1,771.9$ & 93 & 88,500 & 1,770 & 54,589 & 33,911 \\
\hline & Total & $\mathbf{1 8 9 , 5 8 8}$ & 8,859 & 198 & 189,390 & 8,850 & 116,820 & $\mathbf{7 2 , 5 7 0}$ \\
\hline \multirow{6}{*}{2018} & Arete & 16,473 & $2,353.3$ & 9 & 16,464 & 2,352 & 10,155 & 6,309 \\
\hline & Anillo & 28,240 & $2,353.3$ & 16 & 28,224 & 2,352 & 17,409 & 10,815 \\
\hline & Collares & 58,834 & $2,353.3$ & 34 & 58,800 & 2,352 & 36,269 & 22,531 \\
\hline & Pulseras & 30,593 & $2,353.3$ & 17 & 30,576 & 2,352 & 18,860 & 11,716 \\
\hline & Set de joyas & 117,667 & $2,353.3$ & 67 & 117,600 & 2,352 & 72,538 & 45,062 \\
\hline & Total & 251,808 & 11,767 & 144 & 251,664 & 11,760 & 155,232 & 96,432 \\
\hline \multirow{6}{*}{2019} & Arete & 19,419 & $2,774.1$ & 15 & 19,404 & 2,772 & 11,969 & 7,435 \\
\hline & Anillo & 33,289 & $2,774.1$ & 25 & 33,264 & 2,772 & 20,518 & 12,746 \\
\hline & Collares & 69,352 & $2,774.1$ & 52 & 69,300 & 2,772 & 42,746 & 26,554 \\
\hline & Pulseras & 36,063 & $2,774.1$ & 27 & 36,036 & 2,772 & 22,228 & 13,808 \\
\hline & Set de joyas & 138,704 & $2,774.1$ & 104 & 138,600 & 2,772 & 85,492 & 53,108 \\
\hline & Total & 296,826 & 13,870 & 222 & 296,604 & 13,860 & 182,952 & 113,652 \\
\hline \multirow{6}{*}{2020} & Arete & 26,458 & $3,779.7$ & 12 & 26,446 & 3,778 & 16,312 & 10,134 \\
\hline & Anillo & 45,357 & $3,779.7$ & 21 & 45,336 & 3,778 & 27,964 & 17,372 \\
\hline & Collares & 94,493 & $3,779.7$ & 43 & 94,450 & 3,778 & 58,259 & 36,191 \\
\hline & Pulseras & 49,136 & $3,779.7$ & 22 & 49,114 & 3,778 & 30,295 & 18,819 \\
\hline & Set de joyas & 188,986 & $3,779.7$ & 86 & 188,900 & 3,778 & 116,518 & 72,382 \\
\hline & Total & 404,430 & 18,899 & 184 & 404,246 & 18,890 & 249,348 & 154,898 \\
\hline
\end{tabular}

Elaboración: Propia

(*) Merma es la pérdida de plata 999 por la producción total de las joyas. 


\section{ANEXO 46: Obtención del Costo unitario para las joyas ley 950 y 925}

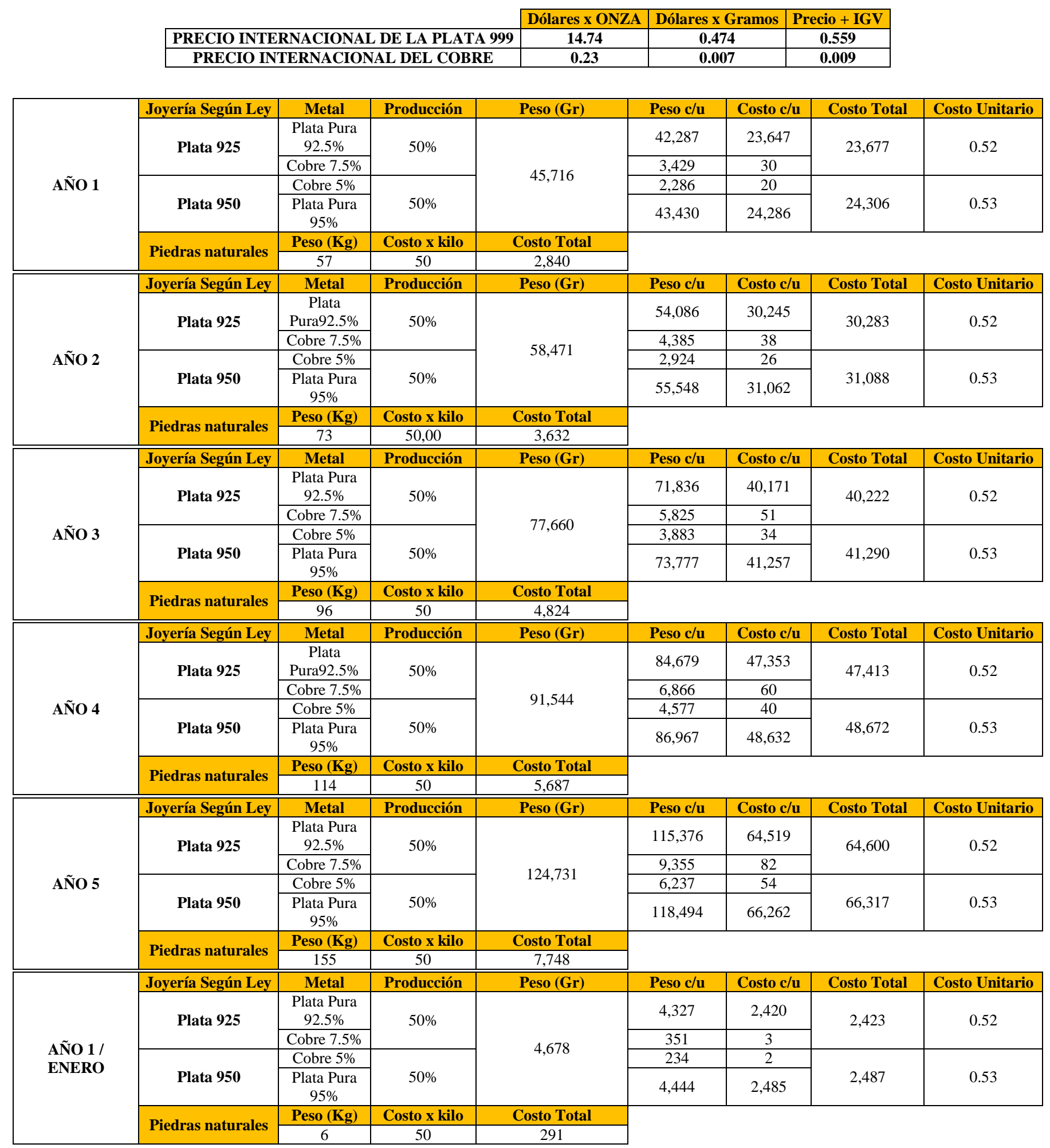

Elaboración: Propia 


\section{ANEXO 47: Unidades Producidas según colección de joyas MYSTIC - ULTRA}

\begin{tabular}{|c|c|}
\hline Porcentaje de piedra en la joya & $38 \%$ \\
\hline Porcentaje de plata en la joya & $62 \%$ \\
\hline Costo Plata 925 por Gramo & 0.52 \\
\hline Costo Plata 950 por Gramo & 0.53 \\
\hline Costo Piedra por Gramo & 0.05 \\
\hline Mano de Obra de Plata por Gramo & 0.57 \\
\hline Mano de Obra de Piedra Natural por Gramo & 0.57 \\
\hline Servicio de Fundición 1 y 2 Año por Gramo & 0.014 \\
\hline Servicio de Fundición 3,4 y 5 año por Gramo & 0.006 \\
\hline
\end{tabular}

A) Colección MYSTIC

\begin{tabular}{|c|c|c|c|c|c|c|c|c|c|}
\hline \multirow[b]{2}{*}{ Ã̃̃ } & \multicolumn{9}{|c|}{ MYSTIC - 950} \\
\hline & Producto & Unidades & $\begin{array}{l}\text { Peso en } \\
\text { Gramos }\end{array}$ & $\begin{array}{c}\text { Costo Total } \\
\text { Materia Prima }\end{array}$ & $\begin{array}{c}\text { Costo } \\
\text { Fundición } \\
\text { total }\end{array}$ & $\begin{array}{c}\text { Mano de Obra } \\
\text { de Plata }\end{array}$ & $\begin{array}{c}\text { Mano de Obra } \\
\text { de Piedra } \\
\text { Natural }\end{array}$ & $\begin{array}{l}\text { Costo Total } \\
\text { Producto }\end{array}$ & $\mathbf{C U}$ \\
\hline \multirow{6}{*}{2016} & Arete & 692 & 4,844 & 1,681 & 43 & 1,712 & 1,064 & 4,500 & 6.5 \\
\hline & Anillo & 692 & 8,304 & 2,882 & 73 & 2,935 & 1,823 & 7,715 & 11.1 \\
\hline & Collares & 692 & 17,300 & 6,005 & 153 & 6,115 & 3,799 & 16,072 & 23.2 \\
\hline & Pulseras & 692 & 8,996 & 3,123 & 79 & 3,180 & 1,975 & 8,357 & 12.1 \\
\hline & Set de joyas & 692 & 34,600 & 12,010 & 306 & 12,230 & 7,598 & 32,144 & 46.5 \\
\hline & TOTAL & 3,460 & 74,044 & 25,701 & 654 & 26,173 & 16,259 & 68,788 & 99.4 \\
\hline \multirow{6}{*}{2017} & Arete & 885 & 6,195 & 2,150 & 55 & 2,190 & 1,360 & 5,755 & 6.5 \\
\hline & Anillo & 885 & 10,620 & 3,686 & 94 & 3,754 & 2,332 & 9,866 & 11.1 \\
\hline & Collares & 885 & 22,125 & 7,680 & 196 & 7,821 & 4,858 & 20,554 & 23.2 \\
\hline & Pulseras & 885 & 11,505 & 3,994 & 102 & 4,067 & 2,526 & 10,688 & 12.1 \\
\hline & Set de joyas & 885 & 44,250 & 15,360 & 391 & 15,641 & 9,717 & 41,109 & 46.5 \\
\hline & TOTAL & 4,425 & 94,695 & 32,870 & 837 & 33,473 & 20,794 & 87,973 & 99.4 \\
\hline \multirow{6}{*}{2018} & Arete & 1,176 & 8,232 & 2,857 & 29 & 2,910 & 1,808 & 7,589 & 6.5 \\
\hline & Anillo & 1,176 & 14,112 & 4,898 & 50 & 4,988 & 3,099 & 13,010 & 11.1 \\
\hline & Collares & 1,176 & 29,400 & 10,205 & 104 & 10,392 & 6,456 & 27,105 & 23.0 \\
\hline & Pulseras & 1,176 & 15,288 & 5,307 & 54 & 5,404 & 3,357 & 14,095 & 12.0 \\
\hline & Set de joyas & 1,176 & 58,800 & 20,410 & 208 & 20,785 & 12,912 & 54,210 & 46.1 \\
\hline & TOTAL & 5,880 & $\mathbf{1 2 5 , 8 3 2}$ & 43,678 & 445 & 44,479 & 27,631 & 116,010 & 98.6 \\
\hline \multirow{6}{*}{2019} & Arete & 1,386 & 9,702 & 3,368 & 34 & 3,429 & 2,130 & 8,945 & 6.5 \\
\hline & Anillo & 1,386 & 16,632 & 5,773 & 59 & 5,879 & 3,652 & 15,334 & 11.1 \\
\hline & Collares & 1,386 & 34,650 & 12,027 & 122 & 12,248 & 7,609 & 31,945 & 23.0 \\
\hline & Pulseras & 1,386 & 18,018 & 6,254 & 64 & 6,369 & 3,957 & 16,612 & 12.0 \\
\hline & Set de joyas & 1,386 & 69,300 & 24,055 & 245 & 24,496 & 15,217 & 63,891 & 46.1 \\
\hline & TOTAL & 6,930 & 148,302 & 51,477 & 524 & 52,422 & 32,565 & 136,726 & 98.6 \\
\hline \multirow{6}{*}{2020} & Arete & 1,889 & 13,223 & 4,590 & 47 & 4,674 & 2,904 & 12,191 & 6.5 \\
\hline & Anillo & 1,889 & 22,668 & 7,868 & 80 & 8,013 & 4,978 & 20,899 & 11.1 \\
\hline & Collares & 1,889 & 47,225 & 16,392 & 167 & 16,693 & 10,370 & 43,539 & 23.0 \\
\hline & Pulseras & 1,889 & 24,557 & 8,524 & 87 & 8,680 & 5,392 & 22,640 & 12.0 \\
\hline & Set de joyas & 1,889 & 94,450 & 32,785 & 334 & 33,386 & 20,740 & 87,078 & 46.1 \\
\hline & TOTAL & 9,445 & 202,123 & 70,159 & 714 & 71,446 & 44,383 & 186,346 & 98.6 \\
\hline
\end{tabular}


B) Colección ULTRA

\begin{tabular}{|c|c|c|c|c|c|c|c|c|c|}
\hline \multirow[b]{2}{*}{ Ã̃̃O } & \multicolumn{9}{|c|}{ ULTRA - 925} \\
\hline & Producto & $\begin{array}{l}\text { Unidades } \\
\text { de venta }\end{array}$ & $\begin{array}{c}\text { Peso total en } \\
\text { gramos }\end{array}$ & $\begin{array}{c}\text { Costo total } \\
\text { Materia prima }\end{array}$ & $\begin{array}{l}\text { Costo de } \\
\text { Fundición }\end{array}$ & $\begin{array}{c}\text { Mano de Obre } \\
\text { de Plata }\end{array}$ & $\begin{array}{l}\text { Mano de Obra de } \\
\text { Piedra Natural }\end{array}$ & $\begin{array}{l}\text { Costo Total del } \\
\text { Producto }\end{array}$ & $\begin{array}{c}\text { Costo } \\
\text { unitario }\end{array}$ \\
\hline \multirow{6}{*}{2016} & Arete & 692 & 4,844 & 1,640 & 43 & 1,712 & 1,064 & 4,459 & 6.4 \\
\hline & Anillo & 692 & 8,304 & 2,812 & 73 & 2,935 & 1,823 & 7,644 & 11.0 \\
\hline & Collares & 692 & 17,300 & 5,858 & 153 & 6,115 & 3,799 & 15,925 & 23.0 \\
\hline & Pulseras & 692 & 8,996 & 3,046 & 79 & 3,180 & 1,975 & 8,281 & 12.0 \\
\hline & Set de joyas & 692 & 34,600 & 11,716 & 306 & 12,230 & 7,598 & 31,850 & 46.0 \\
\hline & TOTAL & 3,460 & 74,044 & 25,073 & 654 & 26,173 & 16,259 & 68,159 & 98.5 \\
\hline \multirow{6}{*}{2017} & Arete & 885 & 6,195 & 2,098 & 55 & 2,190 & 1,360 & 5,703 & 6.4 \\
\hline & Anillo & 885 & 10,620 & 3,596 & 94 & 3,754 & 2,332 & 9,776 & 11.0 \\
\hline & Collares & 885 & 22,125 & 7,492 & 196 & 7,821 & 4,858 & 20,367 & 23.0 \\
\hline & Pulseras & 885 & 11,505 & 3,896 & 102 & 4,067 & 2,526 & 10,591 & 12.0 \\
\hline & Set de joyas & 885 & 44,250 & 14,984 & 391 & 15,641 & 9,717 & 40,733 & 46.0 \\
\hline & TOTAL & 4,425 & 94,695 & 32,066 & 837 & 33,473 & 20,794 & 87,169 & 98.5 \\
\hline \multirow{6}{*}{2018} & Arete & 1,176 & 8,232 & 2,788 & 29 & 2,910 & 1,808 & 7,520 & 6.4 \\
\hline & Anillo & 1,176 & 14,112 & 4,779 & 50 & 4,988 & 3,099 & 12,891 & 11.0 \\
\hline & Collares & 1,176 & 29,400 & 9,955 & 104 & 10,392 & 6,456 & 26,856 & 22.8 \\
\hline & Pulseras & 1,176 & 15,288 & 5,177 & 54 & 5,404 & 3,357 & 13,965 & 11.9 \\
\hline & Set de joyas & 1,176 & 58,800 & 19,911 & 208 & 20,785 & 12,912 & 53,711 & 45.7 \\
\hline & TOTAL & 5,880 & $\mathbf{1 2 5 , 8 3 2}$ & 42,610 & 445 & 44,479 & 27,631 & 114,942 & 97.7 \\
\hline \multirow{6}{*}{2019} & Arete & 1,386 & 9,702 & 3,285 & 34 & 3,429 & 2,130 & 8,862 & 6.4 \\
\hline & Anillo & 1,386 & 16,632 & 5,632 & 59 & 5,879 & 3,652 & 15,193 & 11.0 \\
\hline & Collares & 1,386 & 34,650 & 11,733 & 122 & 12,248 & 7,609 & 31,651 & 22.8 \\
\hline & Pulseras & 1,386 & 18,018 & 6,101 & 64 & 6,369 & 3,957 & 16,459 & 11.9 \\
\hline & Set de joyas & 1,386 & 69,300 & 23,467 & 245 & 24,496 & 15,217 & 63,302 & 45.7 \\
\hline & TOTAL & 6,930 & 148,302 & 50,218 & 524 & 52,422 & 32,565 & 135,467 & 97.7 \\
\hline \multirow{6}{*}{2020} & Arete & 1,889 & 13,223 & 4,478 & 47 & 4,674 & 2,904 & 12,079 & 6.4 \\
\hline & Anillo & 1,889 & 22,668 & 7,676 & 80 & 8,013 & 4,978 & 20,706 & 11.0 \\
\hline & Collares & 1,889 & 47,225 & 15,991 & 167 & 16,693 & 10,370 & 43,138 & 22.8 \\
\hline & Pulseras & 1,889 & 24,557 & 8,316 & 87 & 8,680 & 5,392 & 22,432 & 11.9 \\
\hline & Set de joyas & 1,889 & 94,450 & 31,983 & 334 & 33,386 & 20,740 & 86,276 & 45.7 \\
\hline & TOTAL & 9,445 & 202,123 & 68,443 & 714 & 71,446 & 44,383 & 184,630 & 97.7 \\
\hline
\end{tabular}

Elaboración: Propia 